\title{
Endotoxemia : effects on the circulation and the brain : studies in fetal sheep and neonatal rats
}

Citation for published version (APA):

Coumans, A. B. C. (2003). Endotoxemia : effects on the circulation and the brain : studies in fetal sheep and neonatal rats. [Doctoral Thesis, Maastricht University]. Universiteit Maastricht. https://doi.org/10.26481/dis.20030626ac

Document status and date:

Published: 01/01/2003

DOI:

10.26481/dis.20030626ac

Document Version:

Publisher's PDF, also known as Version of record

\section{Please check the document version of this publication:}

- A submitted manuscript is the version of the article upon submission and before peer-review. There can be important differences between the submitted version and the official published version of record.

People interested in the research are advised to contact the author for the final version of the publication, or visit the DOI to the publisher's website.

- The final author version and the galley proof are versions of the publication after peer review.

- The final published version features the final layout of the paper including the volume, issue and page numbers.

Link to publication

\footnotetext{
General rights rights.

- You may freely distribute the URL identifying the publication in the public portal. please follow below link for the End User Agreement:

www.umlib.nl/taverne-license

Take down policy

If you believe that this document breaches copyright please contact us at:

repository@maastrichtuniversity.nl

providing details and we will investigate your claim.
}

Copyright and moral rights for the publications made accessible in the public portal are retained by the authors and/or other copyright owners and it is a condition of accessing publications that users recognise and abide by the legal requirements associated with these

- Users may download and print one copy of any publication from the public portal for the purpose of private study or research.

- You may not further distribute the material or use it for any profit-making activity or commercial gain

If the publication is distributed under the terms of Article $25 \mathrm{fa}$ of the Dutch Copyright Act, indicated by the "Taverne" license above, 


\section{Endotoxemia:}

effects on the circulation and the brain

Studies in fetal sheep and neonatal rats

Audrey Barbara Catharina Coumans 



\title{
Endotoxemia:
}

\section{effects on the circulation and the brain}

\section{Studies in fetal sheep and neonatal rats}

\author{
PROEFSCHRIFT
}

Ter verkrijging van de graad van doctor

aan de Universiteit Maastricht,

op gezag van de Rector Magnificus,

Prof. Dr. A.C. Nieuwenhuijzen Kruseman,

volgens het besluit van het College van Decanen,

in het openbaar te verdedigen op

donderdag 26 juni 2003 om 12.00

door

Audrey Barbara Catharina Coumans

geboren op 24 juni 1972, te Heerlen 
Promotores

Prof. dr J. de Haan

Prof. dr R. Berger, Ruhr Universität Bochum, Germany

Co-promotor

dr T.H.M. Hasaart

Beoordelingscommissie

Prof. dr H.A.J. Struijcker Boudier (voorzitter)

Prof. dr C.E. Blanco

Prof. dr D. Giussani (University of Cambridge, Verenigd Koninkrijk)

Prof. dr G. Ramsay

Prof. dr J.S.H. Vles

ISBN 90-5681-164-9 


\section{Contents}

Chapter 1. Perinatal brain damage and its relationship with preterm birth, asphyxia and intrauterine infection, a review of the literature.

Chapter 2. General introduction.

Chapter 3. Endotoxemia severely affects circulation during normoxia and asphyxia in immature fetal sheep.

Chapter 4. The role of nitric oxide on fetal cardiovascular control during normoxia and acute hypoxia in 0.75 gestation sheep.

Chapter 5. The role of nitric oxide in fetal organ blood flow distribution during normoxia and acute hypoxia in endotoxin treated preterm sheep.

Chapter 6. Endotoxin mediated changes in cardiac output distribution to the fetal sheep lung.

Chapter 7. Intracisternal application of endotoxin enhances the susceptibility to subsequent hypoxic-ischemic brain damage in neonatal rats.

Chapter 8. The effects of low dose endotoxin (LPS) on the umbilicoplacental circulation in preterm sheep.

Chapter 9. Summary and discussion.

Chapter 10. Samenvatting en discussie.

Dankwoord.

Curriculum Vitae. 


\section{List of abbreviations}

\begin{tabular}{ll|ll}
\hline & & \\
ACH & Acetyl Choline & $\mathrm{mmHg}^{+}$ & millimetres mercury \\
$\mathrm{ATP}$ & adenosine triphosphate & $\mathrm{Na}^{+}$ & Natrium ion \\
bpm & beats per minute & $\mathrm{NMDA}-\mathrm{R}$ & N-methyl-d-aspartate receptor \\
$\mathrm{BE}$ & Base Excess & $\mathrm{NO}$ & Nitric Oxide \\
$\mathrm{BPD}$ & BronchoPulmonary Dysplasia & $\mathrm{NOS}$ & Nitric Oxide Synthase \\
$\mathrm{Ca}{ }^{2+}$ & Calcium ion & $\mathrm{O}_{2}$ & superoxide radical \\
cGMP & cyclic Guanyl Mono Phosphate & $\mathrm{PCO}_{2}$ & Partial Bicarbondioxide Pressure \\
$\mathrm{CP}$ & Cerebral Palsy & $\mathrm{PKC}$ & protein kinase C \\
$\mathrm{CRH}$ & Corticotropin Releasing Hormone & $\mathrm{PL}$ & phospholipids \\
$\mathrm{CVO}$ & Combined Ventricular Output & $\mathrm{PLA} 2$ & phospholipase A2 \\
DAG & diacylglycerol & $\mathrm{PLC}$ & phospholipase C \\
E. coli & Escherichia Coli & $\mathrm{PO} 2$ & Partial Oxygen Pressure \\
eNOS & endothelial nitric oxide synthase & $\mathrm{PPROM}$ & Preterm Premature Rupture Of the \\
FHR & Fetal Heart Rate & & Membranes \\
$\mathrm{H} \mathrm{O}_{2}$ & hydrogen peroxide & $\mathrm{PVL}$ & Peri Ventricular Leukomalacia \\
$\mathrm{IL}$ & Inter Leukin & $\mathrm{RDS}$ & Respiratory Distress Syndrome \\
iNOS & inducible nitric oxide synthase & RR & Relative Risk \\
IU & International Units & s.c. & subcutaneous \\
IUI & intrauterine infection & $\mathrm{SEM}$ & Standard Error of the Mean \\
i.c. & intracisternally & sO 2 & Oxygen Saturation \\
i.p. & intraperitoneally & TLR & toll-like receptor \\
IP3 & inositol 1,4,5-trisphosphate & TNF- $\alpha$ & Tumor Necrosis Factor alpha \\
i.v. & intravenous & TORCH & Toxoplasmosis, Rubella, Cytomegaly, \\
LAL & Limulus amoebocyte lysate & & Herpes \\
L-NAME & L-Nitro Arginine Methyl Ester & Qumb & Umbilical Blood Flow \\
LPS & Lipopolysaccharide & VSCC & voltage-sensitive calcium channel \\
MAP & Mean Arterial Pressure & & \\
mGluR & metabotropic glutamate receptor & & \\
& & & \\
\hline & & \\
\hline
\end{tabular}


We shall not cease from exploration And the end of all our exploring Will be to arrive where we started And know the place for the first time T.S. Elliott, “Little Gidding” 



\section{Chapter 1}

\section{Perinatal brain damage and its relationship with preterm birth,}

\section{asphyxia and intrauterine infection, a review of the literature}

1. Clinical background

1.1. Epidemiology of brain damage

1.2. Asphyxia and hypoxia in relation to brain damage

- Fetal cardiovascular response to hypoxia

- Fetal cerebral response to hypoxia

- Cerebral response in the immature fetus

- Energy metabolism

1.3. Neuropathological features of hypoxic-ischemic encephalopathy

1.4. Preterm birth

1.5. Preterm birth and intrauterine infection

1.6. Endotoxins

1.7. Intrauterine infection and brain damage

2. The effects of endotoxins on cardiovascular control

2.1. Adult cardiovascular control

2.2. Fetal cardiovascular control

3 The effects of endotoxins on the brain

3.1. Nitric Oxide (NO)

3.2. Endothelin 



\section{Clinical background}

\subsection{Epidemiology of brain damage}

Despite the improvements in obstetric care, the number of children suffering from perinatal brain damage has not decreased over the past two decades. On the contrary, epidemiological data show an increase in the number of children affected by cerebral palsy, likely associated with the improvements in survival of very premature infants due to achievements of neonatal care (Hagberg et al, 1993). The prevalence for moderate or severe encephalopathy was 3.8/1000 live births in a large Australian study with various causes of newborn encephalopathy. Major risk factors were maternal thyroid disease, prolapse of the umbilical cord, moderate or severe antepartum bleeding, and a birth weight below the third percentile (Badawi et al, 1998). Depending on the localisation of the brain damage these children can develop spastic paresis, choreo-athetosis, ataxia, and disorders of sensomotor coordination (Berger and Garnier, 1999). Later in life, they are at risk for developing disorders of visual and auditory systems and impairment in intellectual ability, which are associated with cerebral palsy (CP) (Volpe, 1995). Cerebral palsy is a complex of symptoms characterized by the aberrant control of movement or posture that appears in early life and can lead to costly life-long disability (Grether and Nelson, 1997). These features are not the result of recognized progressive disease. Subtypes of spastic $\mathrm{CP}$ are categorized depending on the different types of motor disability, hemiplegia, quadriplegia or diplegia. The risk of $\mathrm{CP}$ is strongly associated with gestational age. The risk among very preterm neonates is one in 20 survivors whereas the risk is less than one per 1000 survivors in children weighing more than 2500 gram at birth (Nelson and Grether, 1999). An important type of brain lesion associated with $\mathrm{CP}$ is periventricular leukomalacia (PVL), a cerebral lesion characterized by foci of necrosis in the white matter in the adjacent area of the lateral ventricles which occurs in $7 \%$ to $26 \%$ of neonates with birthweights under $1500 \mathrm{~g}$ (Levene et al, 1983; Trounce et al, 1988). Forty-seven to $80 \%$ of these infants develop aberrant 
neuromuscular tone and posture and often cognitive impairment. (Fawer et al, 1985; Stewart et al, 1987).

White matter damage in preterm infants is named periventricular leukomalacia, but in the majority of cases, other parts of the brain are also affected including subcortical and callosal white matter as well as the internal capsule (Leech and Alvord, 1974; Golden et al, 1997; Gilles et al,1998). Gray matter areas like the cerebral cortex, thalamus and basal ganglia can also be damaged (Golden et al, 1997; Inder et al, 1999, Hagberg et al, 2002).

Even though perinatal care has improved, the morbidity of children with perinatal brain damage has not changed. The impact on both children and family is considerable and the ensuing care demands a high level of commitment and co-operation between various therapists. Until now, no effective strategy has been developed to cure this disease or to prevent it.

For years it was believed that adverse circulatory events during child birth were the main origin of CP (Volpe, 1998). This hypothesis is supported by the fact that most white matter damage occurs in the so-called watershed areas, which are areas between the main cerebral arteries (Takashima and Tanaka, 1978; Nakamura et al, 1994). Furthermore, in the cortex, sulci are more damaged than gyri because of the hairpin bend the penetrating blood vessels are forced into as they cross the border from grey to white matter (De Reuck et al, 1984). Likewise, the susceptibility of oligodendroglial progenitors to oxidative stress, excitotoxicity and in vitro ischemia (Oka et al, 1993; Fern et al, 2000; Hagberg et al, 2002) underlines this hypothesis. 


\subsection{Asphyxia and hypoxia in relation to brain damage}

When discussing the pathophysiology of fetal-neonatal brain damage, the imprecise term asphyxia, meaning "pulseless" is often used as a synonym for hypoxia-ischemia of the brain. The American College of Obstetricians and Gynecologists advised that asphyxia should be regarded severe enough to cause hypoxic ischemic encephalopathy in case of: 1) umbilical artery or metabolic acidosis $\mathrm{pH}<7.00,2$ ) an Apgar Score of 0 to 3 for more than 5 minutes, 3 ) neonatal neurological sequelae, such as seizures, coma or hypotonia and, 4) multiple organ failure (ACOG 1995).

Asphyxia is usually caused by an acute reduction in the uterine or umbilical circulation which in turn can be caused by abruptio placentae, uterine hypertonia, placenta praevia, vena cava occlusion syndrome, hypotension or compression of the umbilical cord (Jensen and Berger, 1991). Estimates suggest that between 2 and 4 /1000 full term newborn infants suffer asphyxia at or shortly before birth. Approximately 15 to $20 \%$ of such asphyxiated infants that suffer from hypoxic-ischemic encephalopathy, will die during the newborn period, and of the survivors 25 $\%$ will exhibit permanent neuropsychologic deficits (Vannuci and Perlman, 1997).

\section{Fetal cardiovascular response to hypoxia}

Between 80 and 100 days of gestation, the immature sheep fetus reacts with either no change (between 80 and 90 days gestation) or an increase (between 90 and 100 days gestation) in fetal heart rate, and fetal blood pressure usually remains unaltered from baseline in response to a 1 hour episode of acute hypoxaemia (Boddy et al, 1974; Iwamoto et al, 1989; Iwamoto, 1989). The absence of a hypertensive response in the immature sheep fetus may be related to a fall in the combined ventricular output. Although heart rate can sometimes increase, the reduced stroke volume usually favours a fall in ventricular output (Iwamoto et al, 1989). In contrast, the same hypoxemic episode in fetuses older than 120 days of gestation induces invariably a transient fall in fetal heart rate and a gradual increase in fetal arterial blood pressure (Boddy et al, 1974; Iwamoto et al, 1989; Iwamoto, 1989; Cohn et al, 1974; Giussani et al, 1994). 
14 Chapter 1

Hypoxia also leads to an activation of the sympathetic-adrenergic nervous system and thus increased production of catecholamines. Catecholamines are released from the adrenal medulla because of increased sympathetic activity and the direct effect of hypoxia on the gland. During hypoxemia other factors such as renin and angiotensin II are also increased, inducing increased peripheral resistance (Dawson, 1994). Due to this, and the stimulation of the baroreceptors, increased peripheral vasoconstriction occurs, leading to redistribution of cardiac output in favour of the central organs (brain, heart and adrenals) away from the periphery such as the gastrointestinal tract, renal, pulmonary, cutaneuous and skeletal muscle beds (Cohn et al, 1974; Peeters et al, 1979; Reuss et al, 1982; Yaffe et al, 1987). If the asphyxic insult persists, the fetus is unable to maintain this circulatory centralisation, and both cardiac output and extent of cerebral perfusion fall (Hanson, 1997).

Prior to 110 days of gestational age, there are no changes in vascular resistance or blood flow in the fetal carcass (taken to mean muscle and skin of the limbs and trunk), but reduced vascular resistance allowing blood flow to increase in the cerebral, myocardial and adrenal circulations (Boddy et al, 1974; Iwamoto et al, 1989; Iwamoto et al, 1989). In contrast, at gestational ages over 110 days, a similar degree of fetal hypoxaemia leads to pronounced vasoconstriction in the carcass, the gastrointestinal tract, the spleen, the kidney, and the lungs, shunting blood flow away from the peripheral circulations towards the cerebral, myocardial and adrenal vascular beds (Cohn et al, 1974; Sheldon, 1979; Jensen and Berger, 1993).

The fetus reacts to a severe lack of oxygen with several reflexes, which are rapid in onset and via endocrine responses, which develop more slowly. Receptors leading to this response are the baroreceptor and chemoreceptor.

Both baroreceptors and chemoreceptors are located in the carotid and aortic arch. Stimulation of baroreceptors results in bradycardia via vagal efferent pathways. Denervation of the aortic and carotid bodies in fetal sheep does not only abolish fetal bradycardia and hypertension upon hypoxia, but also attenuates peripheral vasoconstriction (Itskovitz et al, 1991), although the 
increase in carotid blood flow, observed in intact fetuses at the onset of acute hypoxaemia (Giussani et al, 1993) is not changed. These effects are attributed to interruption of carotid chemoreflex, rather than baroreflex, signals due to the relative timings of the fetal bradycardia and hypertensive responses to acute hypoxaemia: in the intact fetuses the initial episode of bradycardia finished before any significant elevation in fetal arterial blood pressure was detected (Giussani et al, 1993).

Data from several studies demonstrate the importance of the fetal carotid chemoreceptors in initiating fetal heart rate and peripheral vasoconstrictor responses to acute hypoxaemia. Before 120 days gestation, fetal tachycardia in response to acute hypoxaemia may result not only from immaturity of the chemoreflex pathways but also from differential rates of maturation of sympathetic and parasympathetic nervous system chronotropic control, with sympathetic innervation dominating (Nuwayhid et al, 1975; Assali et al, 1977). Establishment of sympathetic innervation of the fetal heart is known to occur between 85-100 days in the sheep (Rawashdeh et al, 1988). Therefore, prior to ca. 120 days, the relative influence of cholinergic mechanisms is less than later in gestation, and the balance of cholinergic and adrenergic inputs is such that there is no fetal bradycardic response during hypoxaemia (Walker et al, 1979; Iwamoto et al, 1989, Iwamoto, 1989). However, in fetuses older than 120 days, fetal bradycardia at the onset of acute hypoxaemia is produced by carotid chemoreflex-mediated increases in efferent vagal activity (Giussani et al, 1994; Giussani et al, 1993), resulting in relative dominance of cholinergic over adrenergic stimulation of the pacemaker centres of the heart (Walker et al, 1979). 


\section{Fetal cerebral response to hypoxia}

When hypoxia occurs, cerebral oxygen delivery decreases and partial pressure of carbon dioxide increases, causing vasodilatation of the cerebral vascular bed and cerebral hyperperfusion. With lower oxygen delivery, cerebral oxygen consumption is maintained by an increase in cerebral extraction of oxygen delivered to the brain (Rudolph, 1984). Also, brain blood flow to phylogenetically older structures such as the brainstem, pons, medulla oblongata is increased compared to cortical flow (Peeters et al, 1979; Lou et al, 1985; Jensen and Berger, 1991; de Haan et al, 1997; Johnson et al, 1997). Depending on the extent of the oxygen deficit and the maturity of the fetus, cerebral perfusion can reach two to three times the original rate of blood flow.

Complete arrest of uterine perfusion is found to cause an initial reduction of blood flow to the brain (Jensen et al, 1987). If the lack of oxygen continues, the anaerobic energy reserves of the heart become exhausted. Cardiac output and mean arterial blood pressure fall (Rudolph and Heymann, 1976) and if blood pressure reaches values below $25 \mathrm{~mm} \mathrm{Hg}$, cerebral autoregulation is lost and a further reduction of cerebral blood flow ensues (Lou et al, 1979), which affects the parasagittal region of the cerebrum and the white matter most of all (Berger and Garnier, 1999). Brief umbilical occlusions, mimicking uterine contractions during labour, resulted in acidosis with hypotension and severe asphyxia combined with selective neuronal damage in the fetal sheep brain after a maximum of 4 hours (de Haan et al, 1997). Fetal asphyxia, induced by reduction of uterine blood flow, is associated with increases in cerebrospinal fluid levels of hypoxanthine and xanthine, both substrates in the formation of oxygen free radicals, in the recovery phase with microscopically detectable brain damage (de Haan et al, 1993).

\section{Cerebral response in the immature fetus}

It has been suggested that immature fetuses are more susceptible to asphyxia since they have a limited ability to increase blood flow to the white matter through vasodilatation (Szymonowicz et al, 1990) due to immaturity of cardiovascular development. Cardiovascular changes in 
response to hypoxemia show a specific development during fetal maturation. Before 110 days gestation in fetal sheep, hypoxemia for one hour, induced by giving the ewe a hypoxic gas mixture, leads to an increase in fetal heart rate and a small fall in arterial blood pressure (Boddy et al, 1974; Dawes, 1984; Iwamoto et al, 1989). After 110 days gestation there is still a rise in heart rate for an hour but with a transient increase in arterial blood pressure (Boddy et al, 1974; Cohn et al, 1974) and an increase in fetal heart rate variability (Dalton et al, 1977; Parer et al, 1980, Giussani et al, 1994). The immature fetus can survive a prolonged period of asphyxia, but this capacity to survive exposes the fetus to profound hypotension and hypoperfusion. A secondary period of significant cerebral hypoperfusion and reduced oxygen delivery that occurs post-asphyxia, might contribute to the patterns of cerebral injury seen in the human preterm fetus (Bennet et al, 1999). Keunen and co-workers investigated whether neuronal damage results after total umbilical cord occlusion of increasing duration in midgestation fetal sheep. In immature sheep of midgestational age ( 85 to 90 days), a prolongation of the duration of total umbilical cord occlusion up to 20 minutes resulted in a progressive increase in the severity of asphyxia but not in neuronal damage (Keunen et al, 1997). Brief umbilical occlusions in immature fetuses at 90 days gestation lead to bradycardia and fetal demise with ongoing occlusions (Keunen and Hasaart, 1999).

\section{Energy metabolism}

When the brain is deprived of oxygen, aerobic metabolism will be replaced by anaerobic metabolism. This will result in lower levels of adenosine triphosphate (ATP) leading to a lower membrane potential (Palmer et al, 1990). Excitotoxicity, toxic glutamate receptor activation, is a key mediator of central neuronal loss consequent to hypoxic-ischemic insults (Choi and Rothman, 1990). During hypoxia-ischemia, as cellular energy reserves and Na+ gradients fall, increased release and impaired uptake of glutamate mediate a toxic buildup of extracellular glutamate, leading to overstimulation of glutamate receptors and consequent neuronal cell death. Excitotoxicity can be exacerbated by decreased cellular energy stores since normal brain 
functioning is not only oxygen dependent but also relying on glucose because neuronal interactions require a source of energy. Excitotoxicity leads to increased $\mathrm{Ca}^{2+}$ influx, which can activate cytotoxic intracellular pathways.

The prolonged availability of extracellular glutamate during hypoxia-ischemia is transduced by neuronal membrane receptors into potentially lethal intracellular ionic derangements, in particular, intracellular $\mathrm{Na}^{+}$and $\mathrm{Ca}^{2+}$ overload. Excitotoxic neuronal cell death, which tends to occur by necrosis, correlates well with measures of total $\mathrm{Ca}^{2+}$ influx, and removal of extracellular $\mathrm{Ca}^{2+}$ attenuates glutamate-induced neuronal death.

Sustained elevations in intracellular $\mathrm{Ca}^{2+}$ can initiate "toxic cascades," which are capable of ultimately killing the cell (Figure 1). These cascades include activation of catabolic enzymes, such as proteases, phospholipases and endonucleases. Endonuclease activation can be triggered by influx of large amounts of $\mathrm{Ca}^{2+}$, which may lead to DNA breakdown during hypoxiaischemia. Increased intracellular $\mathrm{Ca}^{2+}$ also activates a variety of protein kinases. In particular, $\mathrm{Ca}^{2+} /$ calmodulin kinase $(\mathrm{CaMK})$ and the classical $\mathrm{Ca}^{2+}$-dependent isoforms of protein kinase $\mathrm{C}$ (PKC) can modify the function of many ion channels, including NMDA and AMPA/KA receptor-gated channels and voltage-gated $\mathrm{Ca}^{2+}$ channels. An especially important deleterious consequence of $\mathrm{Ca}^{2+}$ overload following excitotoxic glutamate receptor activation is formation of free radical production, which is linked to elevated $\mathrm{Ca}^{2+}$ in several ways: (1) $\mathrm{Ca}^{2+}$-dependent activation of phospholipase A2, with liberation of arachidonic acid and further metabolism, leading to "by-product" free radical production and lipid peroxidation; (2) stimulation of NMDA receptors, leading to activation of NO synthase and the release of NO, which can then generate highly reactive peroxynitrite; and (3) uncoupling of mitochondrial electron transport, enhancing mitochondrial production of free radicals. 
It is likely that excitotoxicity may be an important trigger for mitochondrial free radical production in ischemia-reperfusion injury. Supporting the idea that free radicals are important downstream mediators of excitotoxicity, treatment with free radical scavengers can attenuate NMDA or AMPA receptor-mediated neuronal death (Siegel et al, 1999).

Once the hypoxic period is over, a phase of reperfusion starts 6 to 12 hours after the hypoxic event, leading to another wave of neuronal cell damage, probably due to the release of oxygen radicals and synthesis of NO. Also apoptosis is thought to play a role in this secondary neuronal cell damage (Berger and Garnier, 1999). 


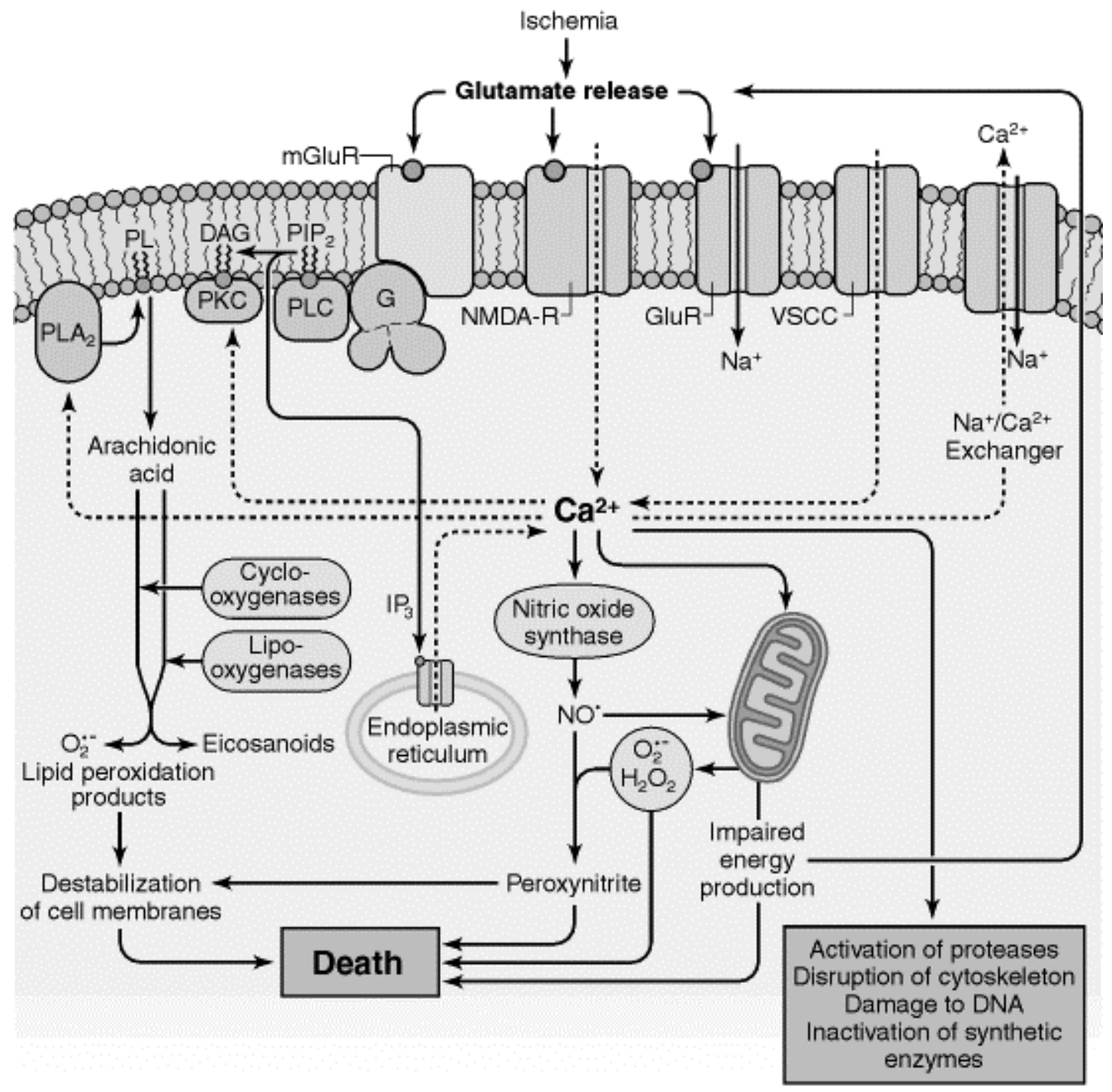

Figure 1. Mechanisms contributing to neuronal injury during ischemia-reperfusion (published with permission from Siegel et al, 1999).

Several pathways believed to contribute to excitotoxic neuronal injury in ischemia. mGluR, metabotropic glutamate receptor; NMDA-R, $N$-methyl-d-aspartate receptor; GluR, AMPA/Kainate type of glutamate receptors; PL, phospholipids; PLA2, phospholipase A2; DAG, diacylglycerol; PLC, phospholipase C; PKC, protein kinase C; G, G protein; PIP2, phosphatidylinositol 4,5-bisphosphate; IP3, inositol 1,4,5-trisphosphate; NO, NO; O2, superoxide radical; H2O2, hydrogen peroxide; VSCC, voltage-sensitive Ca2+ channel. 


\subsection{Neuropathological features of hypoxic-ischemic encephalopathy}

Some basic varieties can be recognized in the features of brain lesions. Maturity of the fetus and the nature of the insult are major factors that determine if and what degree of brain lesions will arise.

There are essentially six forms of hypoxic-ischemic brain lesion (after Berger and Garnier, 1999): selective neuronal cell damage, status marmoratus, parasagittal brain damage, periventricular leucomalacia, intraventricular or periventricular haemorrhage and focal or multifocal ischemic brain lesions (Volpe, 1995, Gilles et al, 1983). Selective neuronal necrosis is the most common variety of hypoxic-ischemic encephalopathy and may coexist with other features of brain damage as well (Keunen and Hasaart, 1999). With increasing immaturity, oligodendrocytes may become more vulnerable than neurons (Volpe, 1992). The predilection sites of selective neuronal loss are the cerebral cortex, hippocampus and the cerebellum. The neuronal loss is predominantly localized in the areas of vascular border zones in the depth of the sulci. Neuronal loss in the basal ganglia and thalamus is frequently observed after repeated episodes of hypoxia-ischemia.

In mature fetuses, selective neuronal cell damage is most frequently found in the cerebral cortex, hippocampus, cerebellum and the anterior horn cells of the spinal cord (Streicher et al, 1968; Larroche, 1977; Norman, 1978; Rorke, 1982; Friede, 1989; Volpe, 1995). This cell damage usually starts after 10 minutes of ischemia in the mature fetus (Williams, 1992). However, immature lambs tolerate severe asphyxia extremely well with respect to neuronal damage (Keunen et al, 1997, Keunen et al, 2000). Within the cortex, the border zones between the major cerebral arteries are the worst affected. Neuronal damage is often more marked than damage to oligodendrocytes, astroglia and microglia, which are mostly more resistant to hypoxia (Volpe, 1995). Status marmoratus only affects $5 \%$ of children with hypoxic-ischemic lesions since hypoxia mainly affects basal ganglia and the hypothalamus. In the perinatal period these 
children often have seizures but the extent of the disease is not fully developed before 8 months after birth. Microscopically there is loss of neurons and hypermyelination. The increased amount of myelinated astrocytes give the affected structures, especially the putamen a marble appearance (Friede, 1989; Rorke, 1982; Rorke, 1992).

Since several years, the assumption that asphyxia during the perinatal period is the major cause of non-progressive impairment such as $\mathrm{CP}$ has been challenged by epidemiological studies which reveal only approximately $8-20 \%$ of all CP can be attributed to perinatal events (Blair and Stanley, 1993). The past years, more and more attention is drawn to the association between an increased risk of perinatal brain damage and preterm birth.

\subsection{Preterm birth}

Preterm birth, defined as birth before 37 weeks of gestation, is a leading cause of perinatal mortality and morbidity worldwide, affecting $5 \%$ to $10 \%$ of all births (van den Berg and Oeshsli, 1984). Preterm neonates have a significantly higher risk of death than term neonates (Rush et al, 1976; Kessel et al, 1984; Main and Main, 1986) and survivors are at risk for shortterm and long-term morbidity including necrotising enterocolitis, bronchopulmonary dysplasia, retinopathy, intracerebral hemorrhages, periventricular leukomalacia and neurological developmental disorders. Among those infants born before 30 weeks who survive, approximately $25 \%$ will have a major disability. Another $10 \%$ will have some disability and an additional $30 \%$ will have cognitive, perceptual and behavioural problems that could interfere with school performance (Hall et al, 1995; Schothorst and van Engeland, 1996; McCarton et al, 1997).

Prevention of preterm birth is the single most important challenge to modern obstetrics today. Progress in this area has been hampered by lack of understanding of the basic mechanisms responsible for premature labour and delivery (Gomez et al, 1995). 
Preterm premature rupture of the membranes (PPROM) is associated with about one third of low birth weight deliveries. PPROM has been reported to be the third most important factor leading to perinatal death after amniotic fluid infection and abruptio placentae. Factors associated with PPROM include PPROM in a prior pregnancy, histologic chorioamnionitis, abnormal bleeding, polyhydramnion, incompetent cervix, smoking, and selected vaginal microorganisms in the current pregnancy (Harger et al, 1990; Gibbs et al, 1992).

Several clinical and laboratory studies have shown that many preterm deliveries result from premature activation of cells in the cervix, decidua, and fetal membranes in response to local mediators of maternal or fetal stress, ascending genital tract infection, and/or decidual hemorrhage. Supposed mediators include peptide hormones (e.g. corticotropin releasing hormone (CRH) and/or inflammatory-cytokines (e.g. interleukin-1, -6, and -8 (IL-1, IL-6 and IL-8)) which induce the production of oxytotic factors (e.g. prostanoids and endothelin) capable of instigating cervical change and/or membrane rupture (Fidel et al, 1994; Lockwood, 1995). IL13 has been shown to exist in abundance in uterine decidua and seems to be a potent stimulus for prostaglandin E2 biosynthesis in human amnion (Romero et al, 1992; Romero et al, 1994). Recently, evidence was gathered that interruption of the oxygen supply during birth only accounts for $6 \%$ of spastic $\mathrm{CP}$ and that other factors, more specifically ante partum etiologies are probably more relevant (Nelson and Grether, 1998). Maternal fever and /or a clinical diagnosis of chorioamnionitis without a recognized infection in the neonate often lead to lower Apgar scores and other signs of neurologic depression, sometimes with seizures and a need for resuscitation and respiratory support. Apparently, exposure to an infection can mimic birth asphyxia (Nelson and Willoughby, 2002; Damman and Leviton, 1997). 
$24 \mid$ Chapter 1

\subsection{Preterm birth and intrauterine infection}

Intrauterine infection (IUI) is recognized as an important initiator of preterm labour and PPROM (Gomez et al, 1997). Intrauterine infection with associated maternal and fetal inflammatory responses may account for up to $30 \%$ of preterm birth (Gibbs et al, 1992). Three lines of evidence support a role for infection in the onset of preterm labour: (1) the administration of bacteria or bacterial products to animals results in either abortion or labour (2) systemic maternal infections such as pyelonephritis, pneumonia, malaria and typhoid fever are associated with the onset of labour and (3) localized intrauterine infection is associated with preterm labour and delivery (Gomez et al, 1997).

Chorioamnionitis is often defined according to the presence of fever, maternal or fetal tachycardia, uterine tenderness, malodorous amniotic fluid, and maternal leukocytosis (Nelson and Willoughby, 2000). These signs often have a relationship with maternal sepsis but are not sensitive indicators for infections with non-purulent agents common in the genital tract such as mycoplasma and ureaplasma. Also, epidural analgesia may cause maternal fever, (Lieberman et al, 1997) however, whether epidurals produce fever in the absence of chorioamnionitis has been questioned (Dashe et al, 1999).

Intrauterine infection can be classified into two broad categories according to the location of the microorganisms: intra-amniotic and extra-amniotic infections (Gomez et al, 1997). The gold standard for the diagnosis of intrauterine infection is a positive microbiologic culture for microorganisms. The two techniques that have been used for microbiologic studies are transabdominal amniocentesis and transcervical retrieval, either by needle puncturing of the membranes or by aspiration through an intrauterine catheter. The transcervical retrieval is associated with an unacceptable risk of contamination with vaginal flora.

There are several pathways for bacterias to spread to the amniotic cavity and fetus: (1) ascending from vagina or cervix (2) hematogenous dissemination through the placenta (3) 
retrograde seeding from the peritoneal cavity due to invasive procedures. The most common route is the ascending route.

One of the processes leading to intrauterine infection is the following (after Gomez et al, 1997):

1. An overgrowth of facultative organisms or the presence of pathologic organisms in the vagina or cervix. Bacterial vaginosis may be an early manifestation of this overgrowth.

2. After bacteria gain access to the intrauterine cavity they reside in the decidua. This localized inflammatory reaction leads to deciduitis and further extension to chorionitis.

3. This infection may invade the fetal vessels (choriovasculitis) or advance through the amnion (amnionitis) into the amniotic cavity leading to intra-amniotic infection.

4. Once in the amniotic cavity, the bacteria can gain access to the fetus by different ports of entry. Aspiration of the amnion fluid may lead to congenital pneumonia. Otitis, conjunctivitis and omphalitis are infections caused by bacteria spreading from infected amniotic fluid. Seeding from these sites to the fetal circulation may lead to bacteremia and sepsis.

Vaginal pathogens including Neisseria gonorrhea, Chlamydia trachomatis, Trichomonas vaginalis and bacteroides species, as well as bacterial vaginosis and asymptomatic bacteriuria are found in greater frequency in women destined to deliver preterm with or without antecedent PPROM (Gibbs et al, 1992).

Several cytokines have been studied such as IL-1, IL-6, IL-8, IL-15 in response to infection with various results. The presence of IL-15 mRNA and peptide in the amniochorion and decidua and its increased presence in the amnion fluid during preterm labour suggests a possible role for IL15 in preterm labour.

Some of the intra-amniotic cytokines that link intrauterine infection with preterm delivery (Romero et al, 1989; Mazor et al, 1995) now seem to be of fetal origin (Eschenbach, 1997). Indeed, fetal umbilical vein pro-inflammatory cytokine levels, but not maternal serum values, 
seem to correlate with the presence and severity of amnion inflammation and umbilical vasculitis (Salafia et al, 1997).

In 41 pregnancies complicated by PPROM, fetal plasma interleukin-6 (IL-6) levels obtained via cordocentesis were significantly higher in the 24 infants who had a positive amniotic fluid culture than in the 17 infants whose amniotic fluid was sterile (Romero et al, 1998). In pregnancies that resulted in preterm labour, IL-6 levels were significantly higher in those that led to spontaneous delivery within 48 hours than in those that ended later. Maternal plasma IL-6 concentrations did not correlate with either the procedure-to-delivery interval or fetal or amniotic IL-6 levels.

These observations support the hypothesis that a fetal inflammatory response precedes imminent preterm delivery. Cytokines in the amniotic fluid and fetal or neonatal circulation, as a humoral characteristic of the fetal inflammatory response, seem to increase the risk for neonatal brain injury and long-term disability. Recent observations support the hypothesis that morphologic characteristics (fetal vasculitis) are also associated with an increased risk for perinatal brain damage (Damman and Leviton, 1997).

Rupture of the membranes is not a prerequisite for intra-amniotic infection, since bacteria are capable of crossing intact membranes (Galask et al, 1984). Bacteria can be present in the amniotic fluid (Romero et al, 1993) in combination with endotoxins in the neonatal blood without previous rupture of the membranes (Okumura et al, 1999). Children with lower Apgar scores and neurologic signs of depression have an increased incidence of bacteria in the amniotic fluid in the absence of prolonged rupture of the membranes (Nelson and Willoughby, 2002).

It seems logical that bacterial infection would initiate preterm birth by causing an inflammatory reaction within the uterus and effectively switching on labour at an earlier stage. Bacteria do not directly synthesise prostaglandins (Bennet et al, 1992) but they do release phospholipases which may liberate arachidonic acid from intracellular lipid pools thus increasing the amount of 
prostaglandins. An important mechanism by which bacteria might activate inflammatory mediators within the uterus is endotoxin.

\subsection{Endotoxins}

The term endotoxin was used for the first time in 1894 by Richard Pfeiffer who observed that a heat stable toxic material bound to the membrane of Vibrio Cholerae was released only after the cells disintegrated. He called the material endotoxin, to distinguish it from filterable material released by bacteria (Pfeiffer, 1894).

Few, if any, other microbial products have been as extensively studied as bacterial endotoxins. Endotoxin is a molecular complex of lipid and polysaccharide; therefore a frequently used term is also lipopolysaccharide (LPS).

Gram-negative bacteria are coated by highly toxic and chemically stable endotoxins which are partially shed when bacteria are destroyed by antibiotics in the bloodstream of the patient (Goto and Nakamura, 1980). The function of the outer membrane of Gram-negative bacteria is to act as permeability barrier. The outer membrane is impermeable to large molecules and hydrophobic compounds from the environment. Endotoxin is located on the outer face of the membrane, where it mediates contact with the environment. It is essential to the function of the outer membrane, and as a structural component of the cell, it may play several roles in the pathogenesis of Gram-negative bacterial infections. First, it is a permeability barrier that is permeable only to low molecular weight, hydrophilic molecules. This prevents penetration of the bacteria by bile salts and other toxic molecules from the gastrointestinal tract. It is also a barrier to lysozyme and many antimicrobial agents. Second, it impedes destruction of the bacterial cells by serum components and phagocytic cells. Third, LPS plays an important role as a surface structure in the interaction of the pathogen with its host. For example, LPS may be involved in adherence (colonization), or resistance to phagocytosis that determine the course and outcome of an infection. Since antibiotics have no effect on LPS (Spink et al, 1948), this toxic 
mediator persists in the circulation of an affected patient and is associated with a high mortality and morbidity.

Romero and co-workers showed that early spontaneous birth with PPROM was more likely when endotoxin was detected. Endotoxin also stimulates the synthesis of inflammatory cytokines including IL $-1 \beta$ and TNF- $\alpha$ in amnion cells and in intact fetal membranes (Romero et al, 1987). Upon release from the bacterial outer membrane, LPS activates monocytes and macrophages to produce inflammatory cytokines such as TNF- $\alpha$, Il-1 and IL- 6 , which serve as endogenous mediators of inflammation. Endotoxins have different effects on macrophages, they can either result in activation of monocytes and macrophages and thus cause septic shock or they can lead to refractoriness to subsequent challenge with high concentrations of this toxic product, which is also known as endotoxin tolerance (Dobrovolskaia and Vogel, 2002). The incidence of sepsis has increased as a result of improvement in the survival of patients with multiple trauma, cancer and AIDS. As a result, much time and effort has been put in the detection of LPS. The assays have been greatly improved and simplified over the past years thus making the determination of endotoxin rapid and easy. Until recently, suspected samples were tested on rabbits. Rabbits are sensitive to endotoxin and if a suspect sample of saline injected into a rabbit caused a fever, then it was contaminated. Unfortunately this method was expensive and slow, taking up to 48 hours to obtain a result. A Limulus amoebocyte lysate (LAL) assay, produced by extracting blood from a crab, can take as little as 45 minutes. A suspect sample is mixed with reconstituted LAL and allowed to rest in a small tube. After 45 minutes the tube is inverted and if a clot has formed it will stick to the top of the inverted tube, thus rendering the sample positive.

However, the absence of measurable amounts of circulating endotoxin (at specific timepoints) is not absolute proof of the absence of bacterial participation in sepsis. Detection might be impossible due to the endotoxin release kinetics (short peaks), insensitive measurement techniques or very high (local) potency of the endotoxins even at extremely low non-detectable 
concentrations. (Redl et al, 1993). In addition, the sepsis may be caused by fungi or Gram positive organisms. Figure 2 (after Baron et al, 1996) illustrates the basic structure of endotoxin.

\section{Figure 2. Structure of LPS}

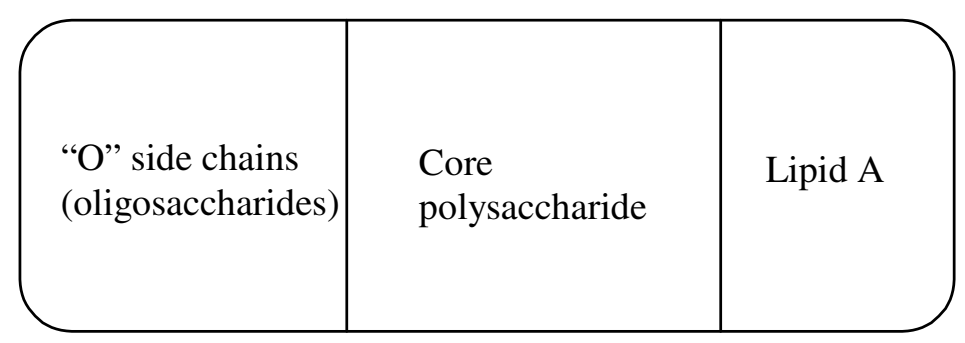

The structure of endotoxin molecules from Salmonella and E. coli is known in detail. Although all endotoxin molecules are similar in chemical structure and biologic activity, some diversity has evolved with differences in potency and toxicity.

The molecular complex can be divided into three regions (Fig. 1): (1) the O-specific chains, which consist of a variety of oligosaccharide residues, (2) the core polysaccharide which is the basic structure of the macromolecule, and (3) lipid A, composed usually of a glucosamine disaccharide with attached long-chain fatty acids and phosphate (Baron et al, 1996). The polysaccharide portions are responsible for antigenic diversity, whereas the lipid A part represents toxicity. Dissociation of the complex has revealed that the polysaccharide is important in solubilizing the toxic lipid A component, and in the laboratory it can be replaced by carrier proteins (e.g., bovine serum albumin) (Baron et al, 1996).

The more pertinent toxic effects include pyrogenicity, leukopenia followed by leukocytosis, complement activation, depression in blood pressure, mitogenicity, induction of prostaglandin synthesis, and hyperthermia followed by hypothermia. These events can culminate in sepsis and lethal shock. However, not all effects of endotoxin are necessarily detrimental; several induce responses potentially beneficial to the host, assuming the stimulation is not excessive. These include:

1. mitogenic effects on B lymphocytes that increase resistance to viral and bacterial infections 
2. induction of gamma interferon production by $\mathrm{T}$ lymphocytes, which may enhance the antiviral state, promote rejection of tumor cells, and activate macrophages and natural killer cells

3. activation of the complement cascade with the formation of $\mathrm{C} 3 \mathrm{a}$ and $\mathrm{C} 5 \mathrm{a}$

4. induction of the formation of interleukin-1 by macrophages and interleukin-2 and other mediators by T lymphocytes.

These potential beneficial effects of "nontoxic" endotoxin derivatives might create treatments for diseases caused by a deficiency in the immune response. For example, the toxicity of endotoxin is largely attributed to lipid A. The toxicity of lipid A is markedly reduced after hydrolysis of a phosphate group or deacylation of one or more fatty acids from the lipid A molecule. These relatively nontoxic lipid A derivatives may be useful in reducing the severity of bacterial sepsis in which bacterial endotoxin produces a life-threatening clinical course as was demonstrated in a double blind randomized clinical trial (Astiz et al, 1995). Recently, it was shown that alkaline phosphatase (AP) was able to dephosphorylate LPS. To test whether LPSdephosphorylation can be used for intervention during sepsis, the effects of Salmonella LPS and its dephosphorylated counterpart monophosphoryl lipid A on macrophage activation were studied. When mice received AP immediately after the LPS challenge, the survival rate was $100 \%$, over $57 \%$ in the control group. Thus the enzymatic removal of phosphate groups from LPS by AP represents a crucial detoxification reaction, which may provide a new strategy to treat LPS-induced diseases like sepsis (Bentala et al, 2002).

Endotoxin, which has first been identified in the intestinal tract, accumulates mainly in the liver, and can affect a range of cell and host proteins.

Two major theories exist with respect to the way LPS is recognized by the host. One theory assumes that cell-associated structures bind LPS and transduce signals for gene expression. The 
other theory suggests that LPS binding proteins facilitate insertion into the membrane which leads to intracellular signalling.

Toll like receptors which are innate immune receptors have been first identified in Drosophila. Ten homologs have recently been identified and are named Toll-like receptors (TLR). The first human TLR, which is known as TLR4 (Lemaitre et al, 1996), was cloned several years ago. Kupffer cells, granulocytes, macrophages, platelets, and lymphocytes all have a cell receptor on their surface called CD14, which binds endotoxin. Endotoxin binding to the CD14 receptor on macrophages is enhanced by interaction with a host protein made in the liver (i.e., LPS-binding protein). Targeted gene deletion studies show that knock-out mice lacking CD 14 (Haziot et al, 1995) or have a defective gene that encodes for TLR-4 (Poltorak et al, 1998) fail to respond to LPS. Eklind and co-workers found an upregulation of the mRNA expression of CD14 in the immature brain following LPS stimulation which has been described before (Eklind et al, 2001; Lacroix et al, 1998). The extent of involvement of each cell type probably depends on the level of endotoxin exposure. It does seem clear that the host cellular response to endotoxin, rather than a direct toxic effect of endotoxin, plays the major role in causing tissue damage (Baron et al, 1996).

\subsection{Intrauterine infection and brain damage}

It is a recurring motif of modern medicine that more chronic diseases than was previously suspected, has probably infection or inflammation as an important part of its pathogenesis. Striking examples are multiple sclerosis, atherosclerosis, stroke (Ross; 1999; Becker, 1998) and in children tics and obsessive compulsive disorder (Shulman, 1999; Perlmutter et al, 1999). Several studies since 1955 have suggested that prenatal exposure to infection or associated factors can adversely influence brain development. Outcomes that may be associated with these risk factors according to early findings are CP (Eastman and DeLeon, 1955; Nelson and 
Ellenberg, 1985), diminished intelligence (Broman et al, 1975), and morphological brain lesions in human infants and in experimental animals (Gilles et al, 1976; Leviton and Gilles, 1984).

Recent studies have investigated the role of intrauterine infection (IUI) in causing cerebral palsy and some demonstrated a relationship (Murphy et al, 1995; O’Shea et al, 1998).

Clinical chorioamnionitis is an infection of the uterus and its contents during pregnancy. Its diagnosis is based on the presence of fever $\left(\mathrm{T}>38^{\circ} \mathrm{C}\right)$ plus two or more of the following conditions: maternal tachycardia, fetal tachycardia, uterine tenderness, foul smelling of the amniotic fluid, or maternal leukocytosis (Gibbs, 1989). The incidence varies between $10 \%$ and $20 \%$ (Newton, 1993).

Neonates who were born from mothers with an IUI are more prone to brain damage than their healthy peers (Yoon et al, 1997; Yoon et al, 2000). Antenatal exposure to intra-amniotic inflammation and evidence of a systemic fetal inflammatory response (funisitis, defined by neutrophil infiltration into the umbilical vessel walls or Wharton jelly) are strong and independent risk factors for the subsequent development of $\mathrm{CP}$ at the age of three years (Yoon et al,2000). Maternal endotoxaemia induced with LPS resulted in an increased expression of IL-1 $\beta$ and TNF- $\alpha$ mRNA in the fetal rat brain (Cai et al, 2000). A meta-analysis by Wu showed that chorioamnionitis is a risk factor for both $\mathrm{CP}$ and cystic PVL, for both term as well as preterm infants (Wu, 2002).

Although very low birth weight neonates are more prone for $\mathrm{CP}$, the outcome depends on the reason for preterm delivery. Neonates born to preeclamptic mothers have a lower risk than neonates born early for other reasons (Murphy et al, 1995; Kitchen et al, 1987; Nelson and Grether, 1995).

At least half of the incidence of CP occur in infants born weighing more than 2500 gram, but only one study has examined markers of infection as risk factors for $\mathrm{CP}$ in such infants (Grether 
and Nelson, 1997). In this study, maternal fever in labour $\left(>38^{\mathrm{O}} \mathrm{C}\right)$ or clinical or histological evidence of chorioamnionitis or more than one of these were observed in $2.9 \%$ of control infants, $14.4 \%$ of children with moderate or severe spastic CP and $21.7 \%$ of children with severe $\mathrm{CP}$. The cerebral palsy in this study was not explained by prenatal factors such as cerebral malformations of Toxoplasmosis, Rubella, Cytomegaly virus or Herpes (TORCH) infections. The estimated proportion of CP that might be attributed to IUI not including TORCH infections was $12 \%$, which is at least comparable with the potentially birth-asphyxiating conditions for which the attributable risk was estimated to be $6 \%$ (Nelson and Grether, 1998). A number of potential confounders did not alter the association of IUI and CP, most children with $\mathrm{CP}$ born of pregnancies complicated by IUI did not have sepsis or other recognized neonatal infections. In most cases there was no prolonged rupture of the membranes raising the question of chronic or reactivated infection with organisms of relatively low virulence which has been postulated as a common cause of preterm birth (Goldenberg and Rouse, 1998), rather than fulminating acute ascending infection at the time of delivery.

Maternal infection was also linked with low Apgar scores (Grether and Nelson, 1997; Badawi et al, 1998; Perlman, 1999; Alexander and McIntyre, 1999; Bahn et al, 1998) and was also associated with hypotension, the need for intubation, neonatal seizures, meconium aspiration syndrome and a clinical diagnosis of hypoxic-ischemic or neonatal encephalopathy (Grether and Nelson, 1997; Badawi et al, 1998; Keogh et al, 1999).

IUI may interact with other factors in causing brain damage: children born to women with not only an infection, but also potentially asphyxiating obstetric complications, were at much higher risk than those with any one of these risk factors or neither (Nelson and Grether, 1998). This observation is based on small numbers but mechanisms that could explain this are known. IL-1 beta injection aggravates ischemic damage in the striatum in the neonatal rat when subjected to middle cerebral artery occlusion (Stroemer and Rothwell, 1998). 
Furthermore, exposure to fetoplacental inflammation is associated with perinatal brain damage especially in the very preterm fetuses, i.e. those born before 30 weeks of gestation, and/or those born with a very low birth weight (<1500 gr) (Damman and Leviton, 1997; Goldenberg and Rouse, 1998; Mazor et al, 1998).

The combination of premature birth and chorioamnionitis increases the risk of peri-and intraventricular haemorrhage up to $80 \%$ (Berger et al, 1997).

Yoon and co-workers observed an increased expression of TNF- $\alpha$, IL-1 $\beta$, and IL- 6 being much higher in brains with periventricular lesions than in those without PVL (Yoon et al, 1997). The mothers of newborns with brain white matter lesions had higher concentrations of these cytokines in their amniotic fluid than did mothers delivered of newborns without brain damage (Yoon et al, 1997; Yoon et al, 2000) although this difference disappeared after adjustment for birthweight and gestational age. Nelson and co-workers did not find an association between cytokine concentration and CP risk in infants of less than 32 weeks gestational age born to nonpreeclamptic mothers. Cytokines are produced as a response to infection but they play many roles at many points in brain development (Mehler and Kessler, 1998) and can be either neurotoxic or neuroprotective depending upon the timing and other factors (Morganti-Kossman et al, 1997; Carlson et al, 1999). It seems the fetal environment itself influences the susceptibility to detrimental perinatal effects. IUI cause an increase in cytokines and surfactant proteins. This effect was more profound than that induced by glucocorticoids (Jobe et al, 2000). 


\section{The effects of endotoxins on cardiovascular control}

\subsection{Adult cardiovascular control}

In 1914, Schottmüller wrote, "Septicaemia is a state of microbial invasion from a portal of entry into the blood stream which causes sign of illness." This definition remained unchanged since the terms sepsis and septicaemia were ill-defined and referred to several clinical conditions, present in a patient with bacteraemia (Schotmüller, 1914). However, less than fifty percent of patients with signs and symptoms of sepsis have positive results on blood culture, and not all patients with bacteraemia have signs of sepsis. Thus, sepsis and septicaemia are two very different definitions. In the last few decades, discovery of endogenous mediators of the host response have led to the recognition that the clinical syndrome of sepsis is the result of excessive activation of host defence mechanisms rather than the direct effect of microorganisms.

Serious bacterial infections, either with or without bacteraemia, are associated with important changes in the function of every organ system in the body. These changes are mediated by elements of the host immune system against infection. Shock is deemed present when volume replacement fails to treat hypotension and associated clinical evidence indicates inadequate perfusion of major organ systems, leading to multi organ failure.

The American College of Chest Physicians / Society of Critical Care Medicine consensus conference created definitions of sepsis (after Bone et al, 1992).

The clinical features of sepsis include 2 or more of the following conditions as a result of a documented infection:

1) Rectal temperature greater than $38^{\circ} \mathrm{C}$ or less than $36^{\circ} \mathrm{C}$

2) Tachycardia (>90 bpm)

3) Tachypnea ( $>20$ breaths per min)

With sepsis, at least 1 of the following manifestations of inadequate organ function/perfusion also must be included: 
1) alteration in mental state

2) hypoxemia $\left(\mathrm{PaO}_{2}<72 \mathrm{~mm} \mathrm{Hg}\right.$ with pulmonary disease not as the direct cause of hypoxemia),

3) elevated plasma lactate level and

4) oliguria (urine output $<30 \mathrm{~mL}$ or $0.5 \mathrm{~mL} / \mathrm{kg}$ for at least $1 \mathrm{~h}$ )

Thus, septic shock is defined as a condition in a subset of people with severe sepsis who develop hypotension despite adequate fluid resuscitation, along with the presence of perfusion abnormalities that may include lactic acidosis, oliguria, or an acute alteration in mental status (Holzheimer and Mannick, 2001). Patients receiving inotropic or vasopressor agents may not be hypotensive by the time that they manifest hypoperfusion abnormalities or organ dysfunction. Multiple organ dysfunction syndrome is the presence of altered organ function in a patient who is acutely ill and in whom homeostasis cannot be maintained without intervention.

The manifestations of septicaemia depend on the age of the patient, the illness being more lethal at extremes of age. Signs are non specific but there are signs in the skin suggestive of the diagnosis such as purpuric lesions associated with meningococcaemia and pustular lesions in staphylococcal septicaemia. Usually there is a rapid deterioration in the patient's conditions and also mental state. Often patients have fever with tachycardia and bounding pulse but as the illness progresses there can be hypothermia with a rapid pulse and peripheral vasoconstriction. The diagnosis can be made by clinical assessment but blood and urine cultures, wound swabs and aspirate from an infected site should always be obtained so antibiotic treatment can start without undue delay (Souhami and Moxham, 1990). The largest problem in the treatment of endotoxic shock is multi organ failure. Over the past years the incidence of septic shock in humans still increased, with a mortality of 30\%-50\%. 


\subsection{Fetal cardiovascular control}

Regarding the effects of LPS on fetal cardiovascular control it seems likely that the main problems in adult circulation such as profound hypotension caused by peripheral vasodilatation will also occur in the fetal situation. The first study regarding LPS in the pregnant ewe was performed in 1972, when LPS was administered to the ewe. It showed a rapid decrease in mean arterial pressure and uteroplacental blood flow, which is followed by a decrease in uteroplacental oxygen delivery to about $30 \%$ of control value. However, the same authors found no change in cardiac output and umbilical blood flow in the acutely prepared fetal sheep even when given a large dose endotoxin (Bech-Jansen et al, 1972). Few data have been published on the cardiovascular effects of LPS since this publication.

In respect to the defence mechanism of the fetus when encountering hypoxia, the presence of endotoxin might lead to a disturbance in this defence, leading to hypoperfusion of vital organs such as the brain and perfusion of non-vital organs such as the lungs, skin, muscles and other peripheral organs in analogy with the adult situation during endotoxaemia. A fall in oxygen delivery to the brain and/or cerebral hypoperfusion might then lead to brain damage. Furthermore, it is stipulated that LPS can also have a direct neurotoxic effect on the brain thus leading to brain damage. Intrathecal LPS in piglets causes an inflammatory reaction with an increased blood-brain barrier permeability and cerebral oedema (Gardenfors et al, 2002).

One might suggest that due to this increased permeability, LPS can gain access to the brain and thus cause damage.

\section{The effects of endotoxins on the brain}

As stated before, the monocyte receptor CD14 is an important mediator of the inflammatory response. When stimulated by LPS through this receptor, monocytes are activated and produce a large variety of inflammatory cytokines such as IL- 1 and TNF $\alpha$ that can activate arterial endothelium. When monocytes are activated they also release platelet-derived growth factor that 
leads to proliferation of smooth muscle cells. Monocytes also lead to an increased expression of tissue factor in the clotting pathway and thus can cause an increased coaguloability.

This increased coaguloability was recently established when a polymorphism in the promotor of the CD14 gene, C (-260) T, was detected as a risk factor for coronary heart disease in two separate studies (Unkelbach et al, 1999; Hubacek et al, 1999). A different group of investigators studied the associated risk of the TT genotype and found that the TT-genotype is not associated with an increased risk of cerebral ischemia in general but is associated with a risk of atherosclerotic or microangiopathic stroke (Lichy et al, 2002).

The influence of endotoxin on global cerebral blood flow, metabolism, net flux of cytokines and catecholamines, was investigated in eight healthy young volunteers. Although TNF-alpha peaked at 90 minutes, coinciding with a peak in subjective symptoms, there was no direct reduction in cerebral oxidative metabolism (Moller et al, 2002).

A hallmark of endotoxemia and sepsis is the heterogeneous pattern of vasoconstriction and vasodilation in different organs, culminating in a fall in total peripheral vascular resistance concomitant with regional maldistribution of blood flow. These changes in the distribution of cardiac output are most likely caused by vasoactive substances, i.e. such as $\mathrm{NO}, \mathrm{PGI}_{2}$, angiotensin converting enzyme (ACE) activity, endothelin and adrenomedullin, released from the endothelium under experimental septic conditions. In this context, the role of two very important vasoregulators, $\mathrm{NO}$ and endothelin, in the endotoxin mediated alterations of fetal cardiovascular control is discussed.

\subsection{Nitric Oxide (NO)}

$\mathrm{NO}$ is a free radical and is synthesized from the amino acide L-arginine and oxygen through a reaction which is catalysed by NO synthase (NOS) (Nathan, 1992; Bolanos et al, 1998). NO relaxes vascular smooth muscle through intracellular processes some dependent (Moncada, 1992) and some independent of cGMP (Bolanos et al, 1998). Several isoforms have been 
purified and cloned. These include the calcium-dependent isoforms (isolated from nerve and endothelial cells), nNOS and eNOS, and the inducible calcium-independent isoform (iNOS) (Bredt et al, 1990; Marletta et al, 1988). All three isoforms of NOS can be expressed in large blood vessels (Beasley, 1990, Bredt et al, 1990; Nozaki et al, 1993, Wood et al, 1990).

Biological effects of cytokines that could influence the progression of injury in the brain include stimulation of the synthesis of other cytokines and neuronal injury mediators such as NO synthase (Saliba and Henrot, 2001). Overproduction of the vasodilator nitric oxide contributes to hypotension and vascular hyporeactivity to vasoconstrictor agents.

LPS stimulates astrocytes and microglia to produce various cytokines such as TNF- $\alpha$, IL-1 $\beta$ and IL-6. Recent clinical studies have demonstrated that expression of TNF- $\alpha$, IL-1 $\beta$, and IL-6 is much higher in brains with periventricular lesions (PVL) than in those without PVL (Yoon et al, 1997).

Hypoxia/ischemia also induces an inflammatory response in the immature rodent central nervous system, characterized by the very early expression of IL-1 $\beta$ and TNF- $\alpha$ (Szaflarski et al, 1995). The latter induces NO production in astrocytes (Cerami, 1992).

Regardless of the involvement of NO on normal physiological brain development and function, an increasing body of evidence suggests that excessive biosynthesis of NO is involved in brain damage due to perinatal asphyxia (Dorrepaal et al, 1997).

$\mathrm{NO}$ is known to be a potent mediator in the regulation of resting tone in cerebral, renal, mesenteric and hindquarter vascular beds and hence in blood pressure homeostasis in adults (Gardiner et al, 1990; Garnier et al, 2002). There is also some suggestion that NO contributes to cardiovascular control during hypoxia in adults and fetal sheep (Gardiner et al, 1990; Green et al, 1996; Harris et al, 2001; Iadecola et al, 1994). NO might mediate the fetal circulatory centralization that occurs during partial cord occlusion (Santos et al, 1997). As posed before, the ability of the fetus to mount an appropriate cardiovascular response to episodes of reduced oxygen supply is a crucial mechanism that protects the fetal brain from neuronal injury by 
40 Chapter 1

increasing cerebral perfusion during hypoxia. There is experimental evidence that NO is an important vasodilator in the cerebral circulation and that developmental changes in NOS may contribute to developmental changes in hypoxic cerebral vasodilation (Harris et al, 2001). Green and co-workers (Green et al, 1996) demonstrated the central role of NO in maintaining fetal cardiovascular function during both normoxia and hypoxia. In term fetal sheep intravenous application of the NO-synthase inhibitor L-NAME resulted in bradycardia and lowered carotid blood flow. This was accompanied by transient hypertension and an increase of both the carotid and femoral vascular resistance. During intra-uterine exposure to hypoxia, the magnitude of the subsequent chemoreflex bradycardia was reduced after L-NAME treatment and the well known rebound tachycardia during recovery was absent with NOS inhibition (Green et al, 1996). Moreover, NOS inhibition blunted the rise in carotid blood flow and fall in carotid vascular resistance during hypoxia. Since there were no significant differences in mean arterial pressure in vehicle- and L-NAME infused groups during hypoxia, it is thought that NO mediates the vasodilation of the carotid bed during hypoxia in the fetus.

\subsection{Endothelin}

In addition to the relaxing factors prostacyclin and NO, the vascular endothelium synthesizes the 21-amino acid peptide, endothelin-1 (ET-1). ET-1 is released in response to several stimuli, including hypoxia (Elton et al, 1992; Li et al, 1994), endotoxemia (Morel et al, 1989; Nakamura et al, 1991), increased pressure (Hishikawa et al, 1995) and shear stress (Kuchan and Frangos, 1993). In response to these stimuli, ET-1 causes both acute responses, such as vasodilation and vasoconstriction, as well as chronic changes, such as smooth muscle proliferation. Interestingly, the vascular responses to ET-1 vary with developmental age in fetal and neonatal sheep and these effects are vascular bed specific, i.e. ET-1 induced vasoconstriction increases with gestational age in femoral, middle cerebral, and renal arteries but not adrenal arteries (Docherty et al, 2001). These hemodynamic effects are mediated through two receptor subtypes: $\mathrm{ET}_{\mathrm{A}}$ 
receptors and $\mathrm{ET}_{\mathrm{B}}$ receptors. $\mathrm{ET}_{\mathrm{A}}$ receptors and a very small subpopulation of $\mathrm{ET}_{\mathrm{B}}$ receptors are located on vascular smooth muscle cells and are responsible for the vasoconstricting effects of ET-1. A second very large subpopulation of $\mathrm{ET}_{\mathrm{B}}$ receptors are located on vascular endothelial cells and are responsible for the vasodilating effects of ET-1, that are mediated by NOproduction (Lusher et al, 1990).

The possible involvement of the endothelin system in human septic shock is further supported by a clear correlation between endothelin plasma levels and morbidity and mortality in septic patients (Pittet et al, 1991). Increased plasma ET-1 levels are seen in various species during endotoxemia (Kaszaki et al, 1997; Pernow et al, 1989). Infusion of ET-1 to humans causes cardiovascular changes resembling in part those seen during sepsis, i.e. decreased cardiac output and vasoconstriction in the pulmonary, splanchnic and renal circulation (Weitzberg et al, 1991; Weitzberg et al, 1993). In fetal sheep ET-1 is able to constrict fetoplacental microcirculation and decrease fetal oxygen consumption (Adamson et al, 1996). Bacterial endotoxin or sepsis was shown to increase ET-1 concentrations in fetal umbilical arterial plasma more than fivefold in both pigs and humans reaching levels close to threshold vasoconstriction (Lundberg et al, 1991). Other pro-inflammatory agents such as IL-1, TNF- $\alpha$, and TGF- $\beta$, also increase the production of ET-1 from endothelial cells.

Endothelin-induced pulmonary hypertension is a reproducible phenomenon seen in several animal models (Volk and Cox, 2000). The pathophysiology includes a characteristic biphasic increase in mean pulmonary artery pressure and pulmonary vascular resistance and is thought to involve different mediators, including cytokines, which lead to increased expression of adhesion molecules, leukocyte activation and endothelial damage resulting in endothelial edema, vascular obliteration and vasoconstriction (Bigatello and Zapol, 1996). Although ET-1 produces systemic vasoconstriction, its effects on the pulmonary circulation vary with age and vascular tone (Black et al, 1988; Wong et al, 1993; Wong et al, 1994). In the lung of the fetal lamb the $\mathrm{ET}_{\mathrm{B}}$ receptor is highly expressed. ET-1 activates the $\mathrm{ET}_{\mathrm{B}}$ receptor, which stimulates endothelial NO-synthase 
42 Chapter 1

(eNOS) activity and NO production, mediating vascular smooth muscle relaxation and pulmonary vasodilation (Filep, 1993). In fact, pulmonary vasodilation has been described after exposure to NO, a substance, which is produced in large amounts after LPS application. 


\section{Literature}

Adamson SL, Whiteley KJ, Langille BL. Endothelin-1 constricts fetoplacental microcirculation and decreases fetal $\mathrm{O}_{2}$ consumption in sheep. Am J Physiol 1996;270:H16-H23.

Alexander JM, McIntire DM, Leveno KJ. Chorioamnionitis and the prognosis for term infants. Obstet Gynecol 1999;94:274-278.

Ashwal S, Dale PS, Longo LD. Regional cerebral blood flow: studies in the fetal lamb during hypoxia, hypercapnia, acidosis, and hypotension. Pediatr Res 1984;18:1309-1316.

Assali NS, Brinkman CR III, Woods JR Jr, Dandavino A, Nuwayhid B. Development of neurohumoral control of fetal, neonatal, and adult cardiovascular functions. Am J Obstet Gynecol 1977;129: 748-759.

Astiz ME, Rackow EC, Still JG, Howell ST, Cato A, Von Eschen KB, Ulrich JT, Rudbach JA, McMahon G, Vargas R. Pretreatment of normal humans with monophosphoryl lipid A induces tolerance to endotoxin: a prospective, double-blind, randomized, controlled trial. Crit Care Med 1995;23:9-17.

Badawi N, Kurinczuk JJ, Keogh JM, Alessandri LM, O'Sullivan F, Burton PR, Pemberton PJ, Stanley FJ. Antepartum risk factors for newborn encephalopathy: the Western Australian casecontrol study. BMJ 1998;317:1549-53

Bahn SA, Jacobson J, Petersen F. Maternal and neonatal outcome following prolonged labour induction. Obstet Gynecol 1998;92:403-407.

Baron S, Peake RC, James DA, Susman M, Kennedy CA, Durson Singleton MJ, Schuenke S. Medical Microbiology. Churchill Livingstone Inc. 1996.

Beasley D. Interleukin 1 and endotoxin activate soluble guanylate cyclase in vascular smooth muscle. Am J Physiol 1990;259: R38-R44.

Bech-Jansen P, Brinkman CR III, Johnson GH, Assali NS. Circulatory shock in pregnant sheep I. Effects of endotoxin on uteroplacental and fetal umbilical circulation. Am J Obstet Gynecol 1972;112:1084-1094.

Bech-Jansen P, Brinkman CR III, Johnson GH, Assali NS. Circulatory shock in pregnant sheep II. Effects of endotoxin on fetal and neonatal circulation. Am J Obstet Gynecol 1972;133:37-43.

Becker KJ. Inflammation and acute stroke. Curr Opin Neurol. 1998;11:45-49.

Bennet PR, Elder MG, Myatt L. Secretion of phospholipases by bacterial pathogens may initiate preterm labour. Am J Obstet Gynecol 1992;163:241-242.

Bennet L, Rossenrode S, Gunning MI, Gluckman PD, Gunn AJ. The cardiovascular and cerebrovascular responses of the immature fetal sheep to acute umbilical cord occlusion. J Physiol 1999;517:247-257. 
Bentala H, Verweij WR, Huizinga-Van der Vlag A, van Loenen-Weemaes AM, Meijer DK, Poelstra K. Removal of phosphate from lipid a as a strategy to detoxify lipopolysaccharide. Shock 2002;18:561-6.

Berg BJ Van den, Oeshsli FW. Perinatal Epidemiology. Oxford University Press, Oxford. 1984.

Berger R, Bender S, Sefkow S, Klingmüller V, Künzel W, Jensen A. Peri/intraventricular haemorrhage: a cranial ultrasound study on 5286 neonates. Eur J Obstet Gynecol Peprod Biol 1997;75:191-203.

Berger R and Garnier Y. Pathophysiology of perinatal brain damage. Brain Res Rev 1999; 30:10734.

Bigatello LM and Zapol WM. New approaches to acute lung injury. Br J Anaesth 1996;77:99-109.

Black SM, Johengen MJ, Soiffer SJ. Coordinated regulation of genes of the nitric oxide and endothelin pathways during the development of pulmonary hypertension in fetal lambs. Pediatr Res 1988;44:821-30.

Blair E and Stanley F. When can cerebral palsy be prevented? The generation of causal hypotheses by multivariate analysis of a case-control study. Pediatr Perinat Epidemiol 1993;7:272-301.

Boddy K, Dawes GS, Fisher R, Pinter S, Robinson JS. Foetal respiratory movements, electrocortical and cardiovascular responses to hypoxemia and hypercapnia in sheep. J Physiol 1974;243:599618.

Bolaños JP, Almeida A, Medina JM. Nitric oxide mediates brain mitochondrial damage during perinatal anoxia. Brain Res 1998;787:117-122.

Bone RC, Balk RA, Cerra FB, Dellinger RP, Fein AM, Knaus WA, Schein RM, Sibbald WJ. Definitions for sepsis and organ failure and guidelines for the use of innovative therapies in sepsis. The ACCP/SCCM Consensus Conference Committee. American College of Chest Physicians/Society of Critical Care Medicine. Chest 1992; 101:1644-1655.

Bredt DS, Hwang PM, Snyder SH. Localisation of nitric oxide synthase indicating a neural role for nitric oxide. Nature 1990;347:768-770.

Broman SH, Nichols PL, Kennedy WA. Preschool IQ: prenatal and early developmental correlates. Hillsdale. 1975.

Cai Z, Pan Z, Pang Y, Evans OB, Rhodes PG. Cytokine induction in fetal rat brains and brain injury in neonatal rats after maternal lipopolysaccharide administration. Pediatr Res 2000; 47: 64-72.

Carlson NG, Wieggel WA, Chen J, Bacchi BA, Rogers SW, Gahring LC. Inflammatory cytokines IK-1 alpha, IL-1 beta, IL-6 and TNF-alpha impart neuroprotection to an excitotoxin though distinct pathways. J Immunol 1999;163:3963-3968.

Cerami A. Inflammatory cytokines. Clin Immunol Immunopathol 1992;62:3-10.

Choi DW and Rothman SM. The role of glutamate neurotoxicity in hypoxic-ischemic neuronal death. Annu Rev Neurosci 1990;13:171-182. 
Cohn EH, Sacks EJ, Heymann MA, Rudolph AM. Cardiovascular responses to hypoxemia and acidemia in fetal lambs. Am J Obstet Gynecol 1974;120:817-824.

Dalton KJ, Dawes GS, Patrick JE. Diurnal, respiratory and other rhythms of fetal lambs. Am J Obstet Gynecol 1977;127:414-424.

Dammann $\mathrm{O}$ and Leviton A. Role of the fetus in perinatal infection and neonatal brain damage. Curr Opin Pediatr 2000; 12:99-104.

Damman O and Leviton A. Maternal intrauterine infection, cytokines and brain damage in the preterm newborn. Pediatr Res 1997; 42:1-8.

Dashe JS, Rogers, BB, McIntire DD, Leveno KJ. Epidural analgesia and intrapartum fever: placental findings. Obstet Gynecol 1999;93:341-345.

Dawes GS. The central control of fetal breathing and skeletal muscle movements. J Physiol 1984;134:1-18.

Dawson DA. Nitric oxide and focal ischemia: multiplicity of action and diverse outcome. Cerebrovasc Brain Metab Rev 1994;6:299-324.

De Reuck JL. Cerebral angioarchitecture and perinatal brain lesions in premature and full-term infacnts. Acta Neurol Scand 1984;70:391-395.

Docherty CC, Kalmar-Nagy J, Engelen M, Nathanielsz PW. Development of fetal vascular responses to endothelin-1 and acetylcholine in the sheep. Am J Physiol Regulatory Integrative Comp Physiol 2001;280:R554-R62.

Dobrovolskaia MA and Vogel SN. Toll receptors, CD 14 and macrophage activation and deactivation by LPS. Microbes and Infection 2002;4:903-914.

Dorrepaal CA, van Bel F, Moison RM, Shadid M, van de Bor M, Steendijk P, Berger HM. Oxidative stress during post-hypoxic-ischemic reperfusion in the newborn lamb: the effect of nitric oxide synthesis inhibition. Pediatr Res 1997;41:321-326.

Eastman NJ and DeLeon M. The etiology of cerebral palsy. Am J Obstet Gynecol 1955;69:950-961.

Eklind S, Mallard C, Leverin A, Gilland E, Blomgren K, Mattsby-Baltzer I, Hagberg H. Bacterial endotoxin sensitizes the immature brain to hypoxic-ischaemic injury. Eur J Neuroscience 2001;13:1101-1106.

Elton TS, Oparil S, Taylor GR, Hicks PH, Yang RH, Jin H, Chen YF. Normobaric hypoxia stimulates endothelin-1 gene expression in the rat. Am J Physiol 1992;263: R1260-R1264.

Eschenbach DA. Amniotic fluid infection and cerebral palsy. Focus on the fetus. JAMA 1997;278:247-248.

Fawer C-L, Calame A, Furrer M-T. Neurodevelopmental outcome at 12 months of age related to cerebral ultrasound appearance of high-risk preterm neonates. Early Hum Dev 1985; 11:123.

Fern R and Moller T. Rapid ischemic cell death in immature oligodendrocytes: a fatal glutamate release feedback loop. J Neurosci 2000;20:34-42. 
Fidel PL Jr, Romero R, Wolf N, Cutright J, Ramirez M, Araneda H, Cotton DB. Systemic and local cytokine profiles in endotoxin-induced preterm parturition in mice. Am J Obstet Gynecol 1994;170:1467-1475.

Filep J. Endothelin peptides: biological actions and pathophysiological significance in the lung. Life Sci 1993;52:119-33.

Friede RL, Developmental Neuropathology. Springer-Verlag, Heidelberg. 1989.

Galask RP, Varner MW, Petzold CR, Wilbur SL. Bacterial attachment to the chorioamniotic membranes. Am J Obstet Gynecol 1984; 148:915.

Gardenfors A, Nilsson F, Skagerberg G, Ungerstedt U, Nordstrom CH. Cerebral physiological and biochemical changes during vasogenic brain oedema induced by intrathecal injection of bacterial lipopolysaccharides in piglets. Acta Neurochir 2002;144:601-8.

Gardiner SM, Compton AM, Bennet T, Palmer RMJ, Moncada S. Control of regional blood flow by endothelium derived nitric oxide. Hypertension 1990;15:486-92.

Garnier Y, Coumans ABC, Jensen A, Hasaart THM, Berger R. Infection related perinatal brain injury: the pathogenetic role of an impaired fetal cardiovascular control. J Soc Gyn Invest 2002, submitted.

Gibbs RS, Blanco JD, St Clair PJ, Castaneda YS. Quantitative bacteriology of amniotic fluid from women with clinical intraamniotic infection at term. J Infect Dis 1982;145:1-8.

Gibbs RS. Severe infections in pregnancy. Med Clin North Am. 1989;73:713-21.

Gibbs RS, Romero R, Hillier SL, Eschenbach DA, Sweet RL. A review of premature birth and subclinical infection. Am J Obstet Gynecol 1992; 166:1515-1528.

Gilles FH, Leviton A, Karr CS. Endotoxin leucoencephalopathy in the telencephalon of the newborn kitten. J Neurol Sci 1976;27:189-191.

Gilles FH, Leviton A, Dooling EC. The Developing Human Brain: Growth and Epidemiologic Neuropathology. John Wright PSG. Boston. 1983.

Gilles FH, Leviton A, Golden JA, Paneth N, Rudelli RD. Groups of histopathologic abnormalities in brains of very low birthweight infants. J Neuropathol Exp Neurol 1998;57:1026-1034.

Giussani DA, Spencer JA, Moore PJ, Bennet L, Hanson MA. Afferent and efferent components of the cardiovascular reflex responses to acute hypoxia in term fetal sheep. J Physiol 1993;461: 431-449.

Giussani DA, Spencer JAD, Hanson MA. Fetal cardiovascular reflex responses to hypoxaemia. Fet Matern Med Rev 1994;6:17-37.

Golden JA, Gilles FH, Rudelli R, Leviton A. Frequency of neuropathological abnormalities in very low birth weight infants. J Neuropathol Exp Neurol 1997;56:472-478.

Goldenberg RL and Andrews WW. Intrauterine infection and why preterm prevention programs have failed. Am J Public Health 1996;86:781-783. 
Goldenberg RL and Rouse DJ. Prevention of premature birth. N Engl J Med 1998;339:313-320.

Gomez R, Ghezzi F, Romero R, Muñoz H, Tolosa JE, Rojas I. Premature labour and intra-amniotic infection. Clinical aspects and role of the cytokines in diagnosis and pathophysiology. Clin Perinatol 1995; 22:281-342.

Gomez R, Romero R, Edwin SS, David C. Pathogenesis of preterm labour and preterm premature rupture of membranes associated with intraamniotic infection. Infect Dis Clin North Am 1997; 11:135-176.

Goto H and Nakamura S. Liberation of endotoxin from E. Coli by addition of antibiotics. Jpn J Exp Med 1980; 50:35-38.

Green LR, Bennet L, Hanson MA. The role of nitric oxide synthesis in cardiovascular responses to acute hypoxia in the late gestation sheep fetus. J Physiol 1996;497:271-277.

Grether JK and Nelson KB. Maternal infection and cerebral palsy in infants of normal birth weight. JAMA 1997; 278:207-211.

Grether JK, Nelson KB, Emery ES, Cummins SK. Prenatal and perinatal factors and cerebral palsy in very low birth weight infants. J Pediatr 1996;128:407-414.

Haan de HH, Reempts van JLH, Vles JSH, Haan de J, Hasaart THM. Effects of asphyxia on the fetal lamb brain. Am J Obstet Gynecol 1993;169:1493-1501.

Haan HH and Hasaart THM. Neuronal death after perinatal asphyxia. Eur J Obstet Gynecol Reprod Biol 1995;61:123-127.

Haan de HH, Gunn AJ, Williams CE, Gluckman PD. Brief repeated umbilical cord occlusions cause sustained cytotoxic cerebral edema and focal infacts in near-term fetal lambs. Pediatr Res 1997;41:96-104.

Haan de HH, Ijzermans AC, de Haan J, Van Belle H, Hasaart TH. Effects of surgery and asphyxia on levels of nucleosides, purine bases, and lactate in cerebrospinal fluid of fetal lambs. Pediatr Res 1994;36:595-600.

Hagberg B, Hagberg G, Olow I. The changing panorama of cerebral palsy in Sweden. VI. Prevalence and origin during the birth year period 1983-1986. Acta Paediatr 1993; 82:387-393.

Hagberg H, Peebles D, Mallard C. Models of white matter injury: comparison of infectious, hypoxic-ischemic and excitotoxic insults. Ment Ret Dev Dis Res Rev 2002;8:30-38.

Hall A, McLeod A, Counsell C, Thomson L, Mutch L. School attainment, cognitive ability and motor function in a total Scottish very-low-birthweight population at eight years: A controlled study. Dev Med Child Neurol 1995;37:1037-1050.

Hanson MA. Do we now understand the control of the fetal circulation? Eur J Obst Gynecol and Reprod Biol 1997;75:55-61. 
Harger JH, Hsing AW, Tuomala RE, Gibbs RS, Mead PB, Eschenbach DA, Knox GE, Polk BF. Risk factors for preterm premature rupture of fetal membranes: a multicenter case-control study. Am J Obstet Gynecol 1990;163:130-7.

Harris AP, Helou S, Gleason CA, Traystman RJ, Koehler RC. Fetal cerebral and peripheral circulatory responses to hypoxia after nitric oxide synthase inhibition. Am J Physiol Regul Integr Comp Physiol 2001;281:R381-90.

Haziot A, Ferrero E, Lin XY, Stewart CL, Goyert SM. CD14- deficient mice are exquisitely insensitive to the effects of LPS. Prog Clin Biol Res 1995;392:349-351.

Hishikawa K, Nakaki T, Marumo T, Suzuki H, Kato R, Saruta T. Pressure enhances endothelin-1 release from cultured human endothelial cells. Hypertension 1995;25:449-52.

Holzheimer RG, Mannick JA. Surgical Treatment. Evidence-Based and Problem-Oriented. Zuckschwerdt Verlag. München. 2001.

Hubacek JA, Pit'ha J, Skodova Z, Stanek V, Poledne R. C(-260)sT polymorphism in the promotor of the CD 14 monocyte receptor gene as a risk factor for myocardial infarction. Circulation 1999;99:3218-3220.

Inder TE, Huppi PS, Warfield S, Kikinis R, Zientara GP, Barnes PD, Jolesz F, Volpe JJ. Periventricular white matter injury in the premature infant is followed by reduced cerebral cortical gray matter volume at term. Ann Neurol 1999;46:755-760.

Iadecola C, Pelligrino DA, Moscowitz MA, Lassen NA. Nitric oxide synthase inhibition and cerebrovascular regulation. J Cereb Blood Flow Metab 1994;14:175-92.

Itskovitz J, LaGamma EF, Bristow J, Rudolph AM. Cardiovascular responses to hypoxaemia in sino-aortic denervated fetal sheep. Ped Res 1991;30:381-385.

Iwamoto HS, Kaufman T, Keil LC, Rudolph AM. Responses to acute hypoxemia in fetal sheep at 0.6-0.7 gestation. Am J Physiol 1989;256:H613-H620.

Iwamoto HS. Cardiovascular responses to reduced oxygen delivery: studies in fetal sheep at 055-07 gestation. In: Advances in Fetal Physiology: Reviews in Honor of GC Liggins, eds., Gluckman PD, Johnston BM, \& Nathanielsz PW, pp. 43-54 Perinatology Press, Ithaca, New York. 1989

Jensen A, Berger R. Fetal circulatory responses to oxygen lack. J Dev Physiol 1991; 16:181-207.

Jensen A, Berger R. Regional distribution of cardiac output. In : Fetus and neonate- Physiology and Clinical Applications: Volume 1-The Circulation, eds., Hanson MA, Spencer JAD, Rodeck CH, pp 23-74. Cambridge University Press, Cambridge. 1993.

Jensen A, Hohmann M, Kunzel W. Dynamic changes in organ blood flow and oxygen consumption during acute asphyxia in fetal sheep. J Dev Physiol 1987; 9:41-55.

Jobe AH, Newnham JP, Willet KE, Sly P, Ervin MG, Bachurski C, Possmayer F, Hallman M, Ikegami M. Effects of antenatal endotoxin and glucocorticoids on the lungs of preterm lambs. Am J Obstet Gynecol 2000;182:401-8. 
Johnson GN, Palahniuk RJ, Tweed WA. Regional cerebral blood flow changes during severe fetal asphyxia produced by slow partial umbilical cord compression. Am J Obstet Gynecol 1997; $135: 48-52$.

Kaszaki J, Wolfard A, Boros M, Baranyi L, Okada H, Nagy S. Effects of antiendothelin treatment on the early hemodynamic changes in hyperdynamic endotoxemia. Acta Chir Hung 1997;36:152-3.

Keogh JM, Badawi N, Kurinczuk JJ, Pemberton PJ, Stanley JF. Group B streptococcus infection, not birth asphyxia. Aust NZ J Obstet Gynaecol 1999;39:108-110.

Kessel SS, Villar J, Berendes HW, Nugent RP. The changing pattern of low birth weight in the United States (1970 to 1980). JAMA 1984; 251:1978-82.

Keunen H, Blanco CE, van Reempts JLH, Hasaart THM. Absence of neuronal damage after umbilical cord occlusion of 10, 15 and 20 minutes in midgestation fetal sheep. Am J Obstet Gynecol 1997; 176:515-520.

Keunen H, Deutz NEP, van Reempts JLH, Hasaart THM. Transient umbilical cord occlusion results in hippocampal damage but not in cerebral arterio-venous difference for nitrite, a stable end product of NO. J Soc Gynecol Invest 1999; 6:120-126.

Keunen $\mathrm{H}$ and Hasaart THM. Fetal arterial pressure and heart rate changes in surviving and nonsurviving immature fetal sheep following brief repeated total umbilical cord occlusions. Eur J Obstet Gynecol Reprod Biol 1999;87:121-157.

Keunen H, Vles JSH, Gavilanes D, van Reempts JLH, Hasaart THM. Effect of repetitive umbilical cord occlusions on neuronal brain activity measured by the cerebral function analyzing monitor and histologic outcome in immature fetal sheep. J Soc Gynecol Invest 2000; 7:218-223.

Kitchen WH, Doyle LW, Ford GW, Rickards AL, Lissenden JV, Ryah MM. Cerebral palsy in very low birthweight infants surviving to 2 years with modern perinatal intensive care. Am J Perinatol 1987;4:29-35.

Kuchan MJ and Frangos JA. Shear stress regulates endothelin-1 release via protein kinase C and cGMP in cultured endothelial cells. Am J Physiol 1993;264:H150-H6.

Lacroix S, Feinstein D, Rivest S. The bacterial endotoxin lipopolysaccharide has the ability to target the brain in upregulating its membrane CD14 receptor within specific cellular populations. Brain Pathol 1998;8:6225-640.

Lark DB and Anderson GW. Correlations of complications of labour with lesions in the brains of infants. J Neuropathol Exp Neurol 1961;20:275-278.

Larroche JC. Developmental Pathology of the Neonate. Excerpta Medica. Almere. 1977.

Leech RW and Alvord EC, Jr. Morphologic variations in periventricular leukomakacia. Am J Pathol 1974; 74:591-602. 
Lemaitre B, Nicolas E, Michaut L, Reichhart JM, Hoffman JA. The dorsoventral regulatory gene cassette spatzle/Toll/cactus controls the potent antifungal response in Drosophila adults. Cell 1996;86:973-983.

Levene MI, Minglesworth JS, Dubowitz V. Hemorrhagic periventricular leukomalacia in the neonate: A real-time ultrasound study. Pediatrics 1983; 71:794-797.

Leviton A, Gilles FH. Acquired perinatal leukoencephalopathy. Ann Neurol 1984;6:1-8.

Leviton A, Paneth N, Reuss ML, Susser M, Allred EN, Dammann O, Kuban K, Van Marter LJ, Pagano M, Hegyi T, Hiatt M, Sanocka U, Shahrivar F, Abiri M, Disalvo D, Doubilet P, Kairam R, Kazam E, Kirpekar M, Rosenfeld D, Schonfeld S, Share J, Collins M, Genest D, ShenSchwarz S. Maternal infection, fetal inflammatory response, and brain damage in very low birth weight infants. Developmental Epidemiology Network Investigators. Pediatr Res 1999; 46:56675.

Li H, Chen SJ, Chen YF, Meng QC, Durand J, Oparil S, Elton TS. Enhanced endothelin-1 and endothelin receptor gene expression in chronic hypoxia. J Appl Physiol 1994;77:1451-9.

Lichy C, Meiser H, Grond-Ginsbach C, Buggle F, Dorfer C, Grau A. Lipopolysaccharide receptor CD14 polymorphism and risk of stroke in a South-German population. J Neurol 2002;249:8213.

Lieberman E, Lang JM, Frigoletto Jr F, Richardson DK, Ringer SA, Cohon A. Epidural analgesia, intrapartum fever and neonatal sepsis evaluation. Pediatrics 1997;99:415-419.

Lockwood CJ. Recent advances in elucidating the pathogenesis of preterm delivery, the detection of patients at risk, and preventative therapies. Curr Opinion Obstet Gynecol 1994; 6:7-18.

Lou, HC, Lassen NA, Tweed WA, Johnson G, Jones M, Palahniuk RJ. Pressure passive cerebral blood flow and breakdown of the blood-brain barrier in experimental fetal asphyxia. Acta Paediatr Scand 1979; 68:57-63.

Lou HC, Tweed WA, Davies JM. Preferential blood flow increase to the brain stem in moderate neonatal hypoxia: reversal by naloxone. Eur J Pediatr 1985; 144: 225-227.

Lundberg JM, Ahlborg G, Hemsen A, Nisell H, Lunell NO, Pernow J, Rudehill A, Weitzberg E. Evidence for release of endothelin-1 in pigs and humans. J Cardiovasc Pharmacol 1991;17:3503.

Luscher TF, Yang Z, Tschudi M, Von Segesser L, Stulz P, Boulanger C, Siebermann R, Turnia M, Buhler FM. Interaction between endothelin-1 and endothelium derived relaxing factor in human arteries and veins. Circ Res 1990;66:1088-94.

Main DM and Main EK: Management of preterm labour and delivery. In Gabbe SG, Niebyl J, Simpson JL (eds): Obstetrics: Normal and problem pregnancies. Churchill Livingstone. New York. 1986. 
Marletta MA, Yoon PS, Iyengar R, Leaf CD, Wishnok JS. Macrophage oxidation of L-arginine to nitrite and nitrate: nitric oxide is an intermediate. Biochem 1988;27:8706-8711.

Mazor M, Cohen J, Romero R, Ghezzi F, Tolosa JE, Gomez R. Cytokines and preterm labour. Fetal Matern Med Rev 1995; 7:207-233.

Mazor M, Chaim W, Maymon E, Hershkowitz R, Romero R. The role of antibiotic therapy in the prevention of prematurity. Clin Perinatol 1998;25:659-685.

McCarton CM, Brooks-Gunn J, Wallace IF, Bauer CR, Bennett FC, Bernbaum JC, Broyles RS, Casey PH, McCormick MC, Scott DT, Tyson J, Tonascia J, Meinert CL. Results at age 8 years of early intervention for low-birth -weight premature infants. The Infant Health and Development Program. JAMA 1997;277:126-132.

Mehler MF and Kessler JA. Cytokines in brain development and function. Adv Protein Chem 1998;52:223-251.

Moller K, Strauss GI, Qvist J, Fonsmark L, Knudsen GM, Larsen FS, Krabbe KS, Skinhoj P, Pedersen BK. Cerebral blood flow and oxidative metabolism during human endotoxemia. J Cereb Blood Flow Metab 2002;22:1262-1270.

Moncada S. The L-arginine-nitric oxide pathway. Act Physiol Scand 1992;145: 201-227

Morel DR, Lacroix JS, Hemsen A, Steinig DA, Pittet JF, Lundberg JM. Increased plasma and pulmonary lymph levels of endothelin during endotoxin shock. Eur J Pharmacol 1989;167:4278.

Morganti-Kossman MC, Lenzlinger PM, Hans V, Stahel P, Csuka E, Ammann E, Stocker R, Trentz $\mathrm{O}$, Kossmann T. Production of cytokine following brain injury: beneficial and deleterious for the damaged tissue. Mol Psychiatry 1997;2:133-136.

Murphy DJ, Sellers S, MacKenzie IZ, Yudkin PL, Johnson AM. Case-control study of antenatal risk factors for cerebral palsy in very preterm singleton babies. Lancet 1995;346:1449-1454.

Nakamura T, Kasai K, Sekiguchi Y, Banba N, Takahashi K, Emoto T, Hattori Y, Shimoda S. Elevation of plasma endothelin concentrations during endotoxin shock in dogs. Eur J Pharmacol 1991;205:277-82.

Nakamura Y, Okudera T, Hashimoto T. Vascular architecture in white matter of neonates; its relationship to periventricular leukomalacia. J Neuropathol Exp Neurol 1994;53:582-589.

Nathan C. Nitric oxide as a secretory product of mammalian cells. FASEB J 1992;6:3051-3064.

Nelson KB and Grether JK. Can magnesium sulfate reduce the risk of cerebral palsy in very low birthweight infants? Pediatrics 1995;263-269.

Nelson KB and Willoughby RE. Infection, inflammation and the risk of cerebral palsy. Curr Opin Neurol 2000;13:133-139.

Nelson KB and Willoughby RE. Overview: infection during pregnancy and neurologic outcome in the child. Ment Ret Dev Dis Res Rev 2002;8:1-2. 
Nelson KB, Grether JK, Dambrosia JM, Dickens B, Phillips, TM. Cytokine concentrations in neonatal blood of preterm children with cerebral palsy. Am J Obstet Gynecol 2000;182:S47.

Nelson KB and Ellenberg JH. Predictors of low and very low birth weight and the relation of these to cerebral palsy. JAMA 1985;254:1473-1479.

Nelson KB and Grether JK. Potentially asphyxiating conditions and spastic cerebral palsy in infants of normal birth weight. Am J Obstet Gynecol 1998;179:507-513.

Nelson KB and Grether JK. Causes of cerebral palsy. Curr Opin Pediatr 1999;11:487-491.

Newton ER. Chorioamnionitis and intraamniotic infection. Clinical Ob Gyn 1993;36:795-808.

Norman MG. Perinatal brain damage. Perspect Pediatr Pathol 1978;4:41-92.

Nozaki K, Moskowitz MA, Maynard KI, Koketsu N, Dawson TM, Bredt DS, Snyder SH. Possible origins and distribution of immunoreactive nitric oxide synthase-containing nerve fibers in cerebral arteries. J Cerebr Blood Flow Metab 1993;13:70-79.

Nuwayhid B, Brinkman CR III, Su C, Bevan JA, Assali NS. Development of autonomic control of fetal circulation. Am J Physiol 1975a ;228: 337-344.

O'Shea TM, Klinepeter KL, Meis PJ, Dillard RG. Intrauterine infection and the risk of cerebral palsy in very low-birthweight infants. Paediatr Perinat Epidemiol 1998;12:72-83.

Oka A, Belliveau MJ, Rosenberg PA, Volpe JJ. Vulnerability of oligodendroglia to glutamate: pharmacology, mechanisms, and prevention. J Neurosci 1993;13:1441-1453.

Okumura A, Hayakawa F, Kato T, Kuno K, Watanabe K. Correlation between the serum level of endotoxin and periventricular leukomalacia in preterm infants. Brain Dev 1999;21:378-381.

Palmer C, Brucklacher RM, Christensen MA, Vannucci RC. Carbohydrate and energy metabolism during the evolution of hypoxic-ischemic brain damage in the immature rat. J Cereb Blood Flow Metab 1990;10:664-666.

Parer JT, Dijkstra HR, Vredebregt PPM, Harris JL, Krueger TR, Reuss ML. Increased fetal heart rate variability with acute hypoxia in chronically instrumented sheep. Eur J Obstet Gynecol Reprod Biol 1980;10:393.

Peeters LLH, Sheldon RE, Jones Jr MD, Makowski EL, Meschia G. Blood flow to fetal organs as a function of arterial oxygen content. Am J Obstet Gynecol 1979; 135:637-646.

Perlman JM. Maternal fever and neonatal depression: preliminary observations. Clin Pediatr 1999;38:287-291.

Perlmutter SJ, Leitman SF, Garvey MA, Hamburger S, Feldman E, Leonard HL, Swedo SE. Therapeutic plasma exchange and intravenous immunoglobulin for obsessive-compulsive disorder and tic disorders in childhood. Lancet 1999;354:1153-1158.

Pernow J, Hemsen A, Lundberg JM. Increased plasma levels of endothelin-like immunoreactivity during endotoxin administration in the pig. Acta Physiol Scand 1989;137:317-8. 
Pfeiffer R and Fränkel C. Mikrophotographischer Atlas der Bakterienkunde. Berlin, Verlag von August Hirschwald. 1892.

Pfeiffer, R. Weitere Untersuchungen über das Wesen der Choleraimmunität und über specifisch baktericide Prozesse. Ztschr f Hyg u Infektionskrankh 1894; 18: 1-16.

Pittet JF, Morel DR, Hemsen A, Gunning K, Lacroix JS, Suter PM, Lundberg JM. Elevated plasma endothelin-1 concentrations are associated with the severity of illness in patients with sepsis. Ann Surg 1991;213:261-4.

Poltorak A, He X, Smirnova I, Liu MY, Huffel CV, Du X, Birdwell D, Alejos E, Silva M, Galanos C, Freudenberg M, Ricciardi P, Castagnoli P, Layton B, Beutler B. Defective LPS signalling in $\mathrm{C} 3 \mathrm{H} / \mathrm{HeJ}$ and C57BL/10ScCr mice: mutations in Tlr4 gene. Science 1998; 282:2085-2088.

Rawashdeh NM, Rose JC, Ray ND. Differential maturation of beta-adrenoceptor-mediated responses in the lamb fetus. Am J Physiol 1988;255: R794-R798.

Redl H, Bahrami S, Schlag G, Traber DL. Clinical decterction of LPS and animal models of endotoxemia. Immunobiol 1993;187:330-345.

Reuss ML, Parer JT, Harris JL, Krueger TR. Hemodynamic effects of alpha-adrenergic blockade during hypoxia in fetal sheep. Am J Obstet Gynecol 1982;142:410-415.

Romero R, Kadar N, Hobbins JC, Duff GW. Infection and labor: the detection of endotoxin in amniotic fluid. Am J Obstet Gynecol 1987;157:815-819.

Romero R, Brody DT, Oyarzun E, Mazor M, Wu YK, Hobbins JC, Durum SK. Infection and labour. III. Interleukin-1: a signal for the onset of parturition. Am J Obstet Gynecol 1989; 160:11171123.

Romero R, Mazor M, Brandt F, Sepulveda W, Avila C, Cotton DB, Dinarello CA. Interleukin-1 alpha and interleukin-1 beta in preterm and term human parturition. Am J Reprod Immunol 1992;27:117-123.

Romero R, Yoon BH, Mazor M, Gomez R, Diamond MP, Kenney JS, Ramirez M, Fidel PL, Sorokin Y, Cotton D. The diagnostic and prognostic value of amniotic fluid white blood cell count, glucose, interleukin-6, and Gram stain in patients with preterm labour and intact membranes. Am J Obstet Gynecol 1993;169:805-816.

Romero R, Baumann P, Gonzalez R, Gomea R, Rittenhouse L, Behnke E, Mitchell MD. Amniotic fluid prostanoid concentrations increase early during the course of spontaneous labour at term. Am J Obstet Gynecol 1994;171:16313-1620.

Romero R, Gomez R, Ghezzi F, Yoon BH, Mazor M, Edwin SS, Berry SM. A fetal systemic inflammatory response is followed by the spontaneous onset of preterm parturition. Am J Obstet Gynecol 1998; 179:186-193.

Rorke LB. Pathology of Perinatal Brain Injury. Raven Press. New York. 1982. 
Rorke LB. Anatomical features of the developing brain implicated in pathogenesis of hypoxicischemic injury. Brain Pathol 1992;2:211-221.

Ross R. Atherosclerosis-an inflammatory disease. N Engl J Med. 1999;340:115-126.

Rudolph AM. The fetal circulation and its response to stress. J Dev Physiol 1984; 6:11-19.

Rudolph AM. Distribution and regulation of blood flow in the fetal and neonatal lamb. Circ Res $1985 ; 57: 811-821$.

Rudolph AM and Heymann MA. Cardiac output in the fetal lamb. The effects of spontaneous and induced changes of heart rate on right and left ventricular output. Am J Obstet Gynecol 1976; 124:183-192.

Rush RW, Keirse MJ, Howat P, Baum JD, Anderson AB, Turnbull AC. Contribution of preterm delivery to perinatal mortality. Br Med J 1976; 2:965-968.

Salafia CM, Sherer DM, Spong CY, Lencki S, Eglinton GS, Parkash V, Marley E, Lage JM. Fetal but not maternal serum cytokine levels correlate with histologic acute placental inflammation. Am J Perinatol 1997; 14:419-422.

Saliba E, Henrot A. Inflammatory mediators and neonatal brain damage. Biol Neonate 2001;79:224227.

Santos AC, Yun EM, Bobby PD, Noble G, Arthur GR, Finster M. The effects of bupivacaine, Lnitro-L-arginine-methyl ester, and phenylephrine on cardiovascular adaptations to asphyxia in the preterm fetal lamb. Anesth Analg 1997;85:1299-1306.

Schothorst PF and van Engeland H. Long-term behavioral sequelae of prematurity. J AM Acad Child Adolesc Psychiatry 1996;35:175-183.

Schottmüller H. Wesen und Behandlung der Sepsis. Verh Dtsch Ges Inn Med 1914; 31: 257-280.

Sheldon RE, Peeters LL, Jones MD Jr, Makowski EL, Meschia G. Redistribution of cardiac output and oxygen delivery in the hypoxemic fetal lamb. Am J Obstet Gyecol 1979;135:1071-1078.

Shulman ST. Pedatric autoimmune neuropsychiatric disorders associated with streptococci (PANDAS). Pediatr Infect Dis J 1999;18:281-282.

Siegel GJ, Agranoff BW, Fisher SK, Albers RW, Uhler MD. Basic Neurochemistry, Molecular, Cellular and Medical Aspects. LippincottRaven. Philadelphia. 1999.

Wansbrough-Jnes MH, Wright SG, McManus TJ. Infectious, tropical and parasitic diseases. In Souhami RL and Moxham J (eds). Textbook of medicine. Churchill Livingstone, London. 1990.

Spink W, Braude AI, Castaneda MR, Goytia R. Aureomycin therapy in human brucellosis due to Brucella militensis. JAMA 1948;138:1145-1147.

Stewart AL, Reynolds EO, Hope PL, Hamilton PA, Baudin J, Costello AM, Bradford BC, Wyatt JS. Probability of neurodevelopmental disorders estimated for US appearance of brains of very preterm infants. Dev Med Child Neurol 1987; 29:3. 
Streicher E, Wiesniewski H, Klatzo I. Resistance of immature brain to experimental cerebral edema. Neurology 1965;15:833.

Stroemer RP and Rothwell NJ. Exacerbation of ischemic brain damage by localized striatal injection of interleukin-1 beta in the rat. J Cereb Blood Flow Metab 1998;18:833-839.

Szaflarski J, Burtrum D, Silverstein FS. Cerebral hypoxia-ischemia stimulates cytokine gene expression in perinatal rats. Stroke 1995;26:1093-100.

Szymonowicz W, Walker AM, Yu VY, Stewart ML, Cannata J, Cussen L. Regional cerebral blood flow after hemmorrhagic hypotension in the preterm, near-term and newborn lamb. Pediatr Res $1990 ; 28: 361-366$.

Takashima S, Tanaka K. Development of cerebrovascular architecture and its relationship to periventricular leukomalacia. Arch Neurol 1978;35:11-16.

Trounce JQ, Shaw DE, Levene MI, Rutter N. Clinical risk factors and periventricular leukomalacia. Arch Dis Child 1988, 63:17-22.

Unkelbach K, Gardemann A, Kostrzewa M, Philipp M, Tilmanns H, Haberbosch W. A new promotor polymorphism in the gen of lipopolysaccharide receptor CD 14 is associated with expired myocardial infarction in patients with low atherosclerotic risk profile. Arterioscler Thromb Vasc Biol 1999;19:932-938.

Vannuci RC and Perlman JM. Interventions for perinatal hypoxic-ischemic encephalopathy. Pediatrics 1997; 100:1004-1014.

Volk T, Kox WJ. Endothelium function in sepsis. Inflamm Res 2000;49:185-98.

Volpe JJ. Brain injury in the premature infant-current concepts of pathogenesis and prevention. Biol Neonate 1992; 62:231-242.

Volpe JJ. Neurology of the newborn. Saunders. Philadelphia. 1995.

Volpe JJ. Brain injury in the premature infant: overview of clinical aspects, neuropathology, and pathogenesis. Semin Pediatr Neurol 1998;5:135-151.

Walker AM, Cannatta JP, Dowling MH, Ritchie BC, Maloney JE. Age-dependent pattern of autonomic heart rate control during hypoxia in fetal and newborn lambs. Biol Neonate 1979;35: 198-208.

Weitzberg E, Ahlborg G, Lundberg JM. Long-lasting vasoconstriction and efficient regional extraction of endothelin-1 in human splanchnic and renal tissues. Biochem Biophys Res Commun 1991;180:1298-303.

Weitzberg E, Ahlborg G, Lundberg JM. Differences in vascular effects and removal of endothelin-1 in human lung, brain, and skeletal muscle. Clin Physiol 1993;13:653-62.

Williams CE, Gunn AJ, Mallard C, Gluckman, PD. Outcome after ischemia in the developing sheep brain: an electroencephalographic and histological study. Ann Neurol 1992;31:14-21. 
Williams MA, Mittendorf R, Stubblefiel PG, Liebermann E, Schoenbaum SC, Monson RR. Cigarettes, coffee and preterm premature rupture of the membranes. Am J Epidemiol 1992;135:895-903.

Wood KS, Buga GM, Byrns RE, Ignarro LJ. Vascular smooth muscle-derived relaxing factor (MDRF) and its close similarity to nitric oxide. Biochem Biophys Res Comm 1990;170: 80-88.

Wong J, Vanderford PA, Fineman JR, Chang R, Soiffer SJ. Endothelin-1 produces pulmonary vasodilation in the intact newborn lamb. Am J Physiol 1993;265:H1318-H25.

Wong J, Vanderford PA, Fineman JR, Soiffer SJ. Developmental effects of endothelin-1 on the pulmonary circulation in the intact newborn lamb. Pediatr Res 1994;36:394-401.

Wu YW. Systematic review of chorioamnionitis and cerebral palsy. Ment Ret Dev Dis Res Rev 2002;8:25-29.

Yaffe H, Parer JT, Block BS, Llanos AJ. Cardiorespiratory response to graded reductions of uterine blood flow in the sheep. J Dev Physiol 1987;9:325-336.

Yoon BH, Jun JK, Romero R, Park KH, Gomez R, Choi JH, Kim IO. Amniotic fluid inflammatory cytokines (interleukin-6, interleukin- $1 \beta$ and tumor necrosis factor- $\alpha$, neonatal brain white matter lesions and cerebral palsy. Am J Obstet Gynecol 1997;177:19-26.

Yoon BH, Romero R, Kim CJ, Koo JN, Choe G, Syn HC, Chi JG. High expression of tumor necrosis factor- $\alpha$ and interleukin-6 in periventricular leukomalacia. Am J Obstet Gynecol 1997;177:406-11.

Yoon BH, Romero R, Park JS, Kim CJ, Kim SH, Choi J-H, Han TR. Fetal exposure to an intraamniotic inflammation and the development of cerebral palsy at the age of three years. Am $\mathbf{J}$ Obstet Gynecol 2000; 182:675-681. 


\section{Chapter 2}

Introduction to the experiments 
From clinical studies it is known that fetuses whose mothers have an intrauterine infection, are more susceptible to perinatal brain damage. The relation between intrauterine infection and fetal brain damage is however incompletely understood. Two pathways appear to be likely. First, brain damage might result from a direct cytotoxic effect of lipopolysaccharides (LPS) on cerebral tissue or second, brain injury might be caused by alterations of the fetal cardiovascular system leading to cerebral hypoperfusion and hypoxic-ischemic brain injury.

We used fetal endotoxemia with LPS as a paradigm for fetal infection.

In chapter 3 we studied the effects of LPS on the fetal circulation to answer the following questions:

1. What happens with the distribution of fetal organ blood flow, when a fetus is subjected to LPS, during a period of normoxia?

2. What are the effects of LPS on the fetal circulation, and the distribution of organ blood flow when this endotoxemic fetus is rendered asphyctic for a short period?

3. Does the fetal circulation recover after a short period of asphyxia when the state of endotoxemia continues?

Endotoxin also stimulates the synthesis of inflammatory cytokines including IL $-1 \beta$ and TNF- $\alpha$ in amnion cells even in intact fetal membranes. Since TNF- $\alpha$ induces NO production, we wanted to further examine the role of NO in the process of fetal organ blood flow distribution. Therefore, we first studied the contribution of NO per se in fetal organ blood flow distribution during normoxia and hypoxia and addressed the following questions in chapter 4:

1. Does NO regulate cardiovascular control in the fetal sheep during normoxia and hypoxia?

2. Does NO alter the fetal response mechanism of redistribution to acute hypoxia? 
Secondly, in chapter 5, we maintained the same experimental set-up and pretreated the fetuses with the NOS inhibitor L-NAME, shortly before administration of LPS. Therefore, in chapter 5, we studied the role of NO in fetal blood flow distribution and addressed the following questions: 1. Is the redistribution of fetal organ blood flow, during endotoxemia, NO dependent?

2. Will the increase in peripheral blood flow be attenuated by pretreating the animals with L-NAME?

In the course of analyzing the data on the lungs we observed remarkable changes in the cardiac output distribution to the lung after LPS. Changes in cardiac output distribution to the fetal lung after LPS application were not studied before.

The following questions were addressed in chapter 6:

1. Is the mechanism of increased percentage cardiac output to the fetal lung after LPS administration mediated by NO?

2. Is the mechanism of increased percentage cardiac output to the fetal lung after LPS administration mediated by endothelin?

After studying the distribution of fetal organ blood flow during normoxia and hypoxia in the endotoxemic fetal sheep and the role of NO in this process, an important issue was left unanswered. In the immediate recovery period, oxygen delivery to the fetal brain was nearly arrested. It is therefore quite conceivable that such disturbances of the cardiovascular system might cause fetal brain injury.

On the other hand, endotoxins may also damage the brain directly. Animal studies provide evidence that endotoxin induces increased cytokine expression in adult rat brains. 
60 Chapter 2

In chapter 7 we wanted to answer the following questions:

1. Does LPS without cerebral hypoxia-ischemia lead to brain injury in neonatal rats?

2. Does LPS aggravate hypoxic-ischemic cerebral injury in neonatal rats?

In order to avoid effects of LPS on the cardiovascular system, we chose a direct route by application of LPS into the intrathecal space in the brain.

In chapter 8, we studied the long-term effects of LPS on umbilical blood flow and brain histology.

The following questions had our interest:

1. What is the time course of the fall in umbilical blood flow after LPS administration?

2. Is there a relationship between fetal endotoxemia and histological brain injury? 


\section{Chapter 3}

Endotoxemia severely affects circulation during normoxia and asphyxia in immature fetal sheep

Y. Garnier, A.B.C. Coumans, R. Berger, A. Jensen and T. H. M. Hasaart

J Soc Gynecol Investig 2001;8(3):134-143 


\section{Introduction}

Hypoxic-ischemic cerebral damage is an important contributor to perinatal mortality and morbidity, including long-term neurologic sequalae in term and preterm fetuses. Furthermore, there is increasing evidence that perinatal brain damage is caused not only by hypoxic-ischemic insults, but also by ascending intrauterine infection before or during birth (1). It is well known that gram-negative anaerobic bacteria are involved in colonization and infection of the genitourinary tract in pregnant women and could be associated with preterm labor and birth. Because pregnant women with fever and bacteriuria give birth to a higher incidence of infants with neurologic defects at 1 year of age than do mothers free of urinary tract infection (2), it appears that human maternal endotoxemia is associated with fetal central nervous system damage. Furthermore, there is evidence from epidemiologic studies that exposure to placental infection before or during birth is associated with cerebral white matter damage especially in very preterm fetuses (ie, those born before 32 weeks' gestation) and those born with very low birth weight $(<1500 \mathrm{~g})(1)$. In addition, the incidence of periventricular or intraventricular hemorrhage is significantly higher in premature babies exposed to intrauterine infection $(3,4)$. However, the relation between intrauterine infection and fetal brain damage is incompletely understood. Two pathways seem to be likely. First, brain injury might result from a direct neurotoxic effect of lipopolysaccharides (LPS) released from gram-negative bacteria during chorioamnionitis. Second, cerebral damage might be caused by endotoxemic alterations of the fetal cardiovascular system resulting in placental and cerebral hypoperfusion. In addition, endotoxemia can also affect fetal circulatory centralization during acute asphyxia, a vital mechanism that enables the fetus to maintain cerebral blood flow during asphyxia and thus to protect its brain from hypoxic-ischemic injury. The purpose of the present study was to examine whether endotoxemia induced by intravenous infusion of LPS would affect the fetal cardiovascular system during normoxia and asphyxia. 


\section{Methods}

\section{$\underline{\text { Animal preparation }}$}

Thirteen fetal sheep were chronically instrumented at a mean gestational age of $107 \pm 1$ days (term $=147$ days). All ewes had surgery with use of sterile techniques while they were under general anesthesia (thiopental sodium $1 \mathrm{~g} / 70 \mathrm{~kg}$ intravenously for induction and $0.5-1.0 \%$ halothane in a 1:1 nitrous oxide and oxygen mixture for maintenance). The ewe received $1 \mathrm{~g}$ ampicillin (Pentrexyl; Bristol-Myers, Woerden, The Netherlands) subcutaneously and $10 \mu \mathrm{g}$ buprenorphin (Temgesic; Schering, The Netherlands) per kilogram of body weight twice a day for three consecutive postoperative days. The ewe's abdominal wall was opened in the midline, and a snare was placed around the descending aorta below the renal artery, which was then used to arrest uterine and ovarian blood flow during the experiment, as described previously (5). Polyvinyl catheters ( $1.25 \mathrm{~mm}$ outer and $0.75 \mathrm{~mm}$ inner diameter) were inserted into a tibial fetal vein and artery of each hindleg and advanced into the caudal vena cava and abdominal aorta, respectively. Furthermore, catheters were placed into both brachial arteries. An additional catheter was placed into the amniotic cavity. All catheters were filled with heparin $(100 \mathrm{IU} / \mathrm{mL}$; Heparin-Natrium, Braun, Melsungen, Germany) and exteriorized through the ewe's flank and protected by a pouch sewn to the skin. Ewes were housed in individual cages with free access to food and water.

\section{$\underline{\text { Experimental protocol }}$}

The experiments were performed 3 days after the surgical procedure, ie, at $110 \pm 1$ days. After control measurements of the physiologic variables were made, seven of 13 fetuses were treated randomly by an intravenous infusion (at -60 minutes) of LPS derived from Escherichia coli (O127:B8, Sigma-Aldrich, Deisenhoten, Germany) at a dose of $53 \pm 3 \mu \mathrm{g} / \mathrm{kg}$ fetal body weight for 10 minutes, while the remaining fetuses received saline solution. Although the most common infection in newborns is gram-positive group B streptococcus, E coli also has been reported to be an important placental pathogen involved in chorioamnionitis at preterm birth. 
The dosage of LPS used in the present study was taken from similar studies on term fetal sheep previously performed in our laboratory (6). Furthermore, we did a pilot experiment on a preterm sheep fetus in which we applied LPS at a dosage of $50 \mu \mathrm{g} / \mathrm{kg}$ fetal body weight. In the 2 hours after injection we could not detect any significant changes in fetal heart rate (control 192; 1 hour 207; 2 hours 175 bpm) or mean arterial blood pressure (control 55.8; 1 hour 51.9; 2 hours 48.7 $\mathrm{mmHg}$ ). Up to this time point the LPS dose was therefore unlikely to have been excessive. We used endotoxin instead of live organisms because of its easy handling, simple quantification for controlled experiments, and the convenient standardization of endotoxin, whereas live organisms are difficult to standardize and prepare (7).

To determine the effects of endotoxemia on the time course of circulatory centralization before, during, and after asphyxia, blood flow to the fetal organs and the distribution of combined ventricular output were measured using a modified microsphere technique (4). The isotopelabeled microspheres $\left({ }^{141} \mathrm{Ce},{ }^{114} \mathrm{In},{ }^{113} \mathrm{Sn},{ }^{103} \mathrm{Ru},{ }^{95} \mathrm{Nb}\right.$, and ${ }^{46} \mathrm{Sc}, 16-\mu \mathrm{m}$ diameter, New England Nuclear, Boston, MA), suspended in $10 \%$ dextran containing $0.01 \%$ Tween 80 , were sonicated and checked for size, shape, and aggregation. Depending on the specific activity, $0.7-1.8$ million microspheres per batch were injected into the inferior vena cava at baseline (-60 minutes), shortly before the onset of maternal aortic occlusion (-1 minute), at the peak of asphyxia (+2 minutes), and after the release of the snare $(+4,+30$, and +60 minutes, recovery period $)(8,9)$. Reference blood samples were withdrawn from both a carotid and a femoral artery at a rate of $1.75 \mathrm{~mL} / \mathrm{min}$. Sampling was continuous for 390 seconds from -1 to +5.5 minutes. Separate samples were taken for 90 seconds at baseline (-60 minutes) and during recovery (+30 minutes and +60 minutes). The volume of blood withdrawn was about $38.5 \mathrm{~mL}$ and was simultaneously replaced by maternal blood maintained at 39C in a water bath. Asphyxia was induced by arrest of uterine blood flow by a single occlusion of the descending maternal aorta for 2 minutes. The experimental protocols were approved by the Animal Medical Ethics Committee of Maastricht University and met the guidelines of the responsible governmental agency. 


\section{$\underline{\text { Measurements }}$}

Fetal heart rate and mean arterial blood pressure were recorded continuously during the experiment on a personal computer, using a customized hemodynamic data acquisition system. Before each blood flow measurement, and also at -30 minutes (control period), blood samples were taken from the fetal descending aorta and analyzed for blood gases, acid-base balance (AVL 993; AVL Medical Instruments AG, Schaffhausen, Switzerland), hemoglobin concentration, and arterial oxygen saturation of hemoglobin ([SO 2$]$; OSM 2 Hemoximeter, Radiometer, Copenhagen, Denmark). After the experiment, a lethal dose of sodium pentobarbitone (Euthasate; Apharmo, Duiven, The Netherlands) was given to the ewe, and the fetuses were perfused with $200 \mathrm{~mL}$ of formalin $(10 \%$, w/v, saline). This procedure made the dissection of the fetuses much easier. No effect of formalin on organ wet weight was observed. Fetal organs were weighed and placed in vials, which were filled to the same height to reduce variations in geometry. The intestines were separated from the mesentery, opened, and cleared of contents. Paired organs (lungs, kidneys, and adrenals) were counted separately, as were the right and left sides of the cerebrum. Significant preferential streaming of microspheres could not be detected. Specimens of skin and muscle were taken from the hips and shoulders. Cotyledons and upper and lower body were homogenized by a meat chopper and the samples filled into vials.

The applied solid-state semiconductor gamma counter (thallium activated, sodium iodine crystal) had a high energy resolution of about $2 \mathrm{keV}$ and was connected to a multichannel (1024) pulse height analyzer (LKB 1282; Compugamma, Wallac, Turku, Finland). The results were normalized with respect to time and sample weight.

\section{$\underline{\text { Calculations }}$}

Fetal combined ventricular output and blood flow to the various organs were calculated from counts of the injected nuclide recovered in fetal organs or placenta, from counts in the appropriate reference sample, and from the withdrawal rate of the reference sample $(8,9)$. The 
percentage of combined ventricular output distributed to a given organ was calculated from the absolute blood flow to that organ and the combined ventricular output. The vascular resistance was calculated by dividing arterial blood pressure (corrected for amniotic fluid pressure) by blood flow and was expressed in $\mathrm{mmHg} / \mathrm{mL}$ per minute per $100 \mathrm{~g}$ of tissue. Blood flow below 1 $\mathrm{mL} / \mathrm{minute}$ per $100 \mathrm{~g}$ was treated as 1 . Umbilical vascular resistance $(\mathrm{mmHg} / \mathrm{mL}$ per minute per kilogram of fetal weight) was calculated by dividing the perfusion pressure of the umbilical circulation (arterial blood pressure minus the estimated umbilical venous blood pressure before [11 $\mathrm{mmHg}]$ and during [17 $\mathrm{mmHg}]$ reduction in uterine blood flow) by umbilical blood flow (10). However, one has to take into account that during severe vasoconstriction of the umbilical arteries umbilical venous pressure could be underestimated. Oxygen delivery to the various organs ([DO $\left.\mathrm{DO}_{2}\right] ; \mathrm{mL} \mathrm{O}_{2} /$ minute per $100 \mathrm{~g}$ ) was calculated according to the following formula: organ blood flow $(\mathrm{mL} /$ minute per $100 \mathrm{~g}) \times \mathrm{SO}_{2} \times$ hemoglobin $(\mathrm{g} / \mathrm{mL}) \times 1.34\left(\mathrm{~mL} \mathrm{O}_{2} / \mathrm{g}\right.$ hemoglobin).

\section{$\underline{\text { Statistics }}$}

Results are given as mean \pm standard error of the mean. The data were analyzed for intragroup and intergroup differences by two-way multivariate analysis of variance for repeated measures. Games-Howell test was used as a post-hoc testing procedure. Statistical analysis was performed using Super Anova Statistical Package (Abacus Inc., Berkeley, CA).

\section{Results}

\section{Control group}

During the control period, combined ventricular output, fetal heart rate, mean arterial blood pressure, blood gases, $\mathrm{pH}$, and plasma concentrations of glucose and lactate were in the normal range for chronically prepared immature fetal sheep (11). During the control period there were no significant changes in fetal heart rate and mean arterial blood pressure, blood gases, acid- 
base balance, and organ blood flow. The small but insignificant decrease in cardiac output might be attributable to slight fetal stress from flushing vascular catheters.

Arrest of uterine blood flow for 2 minutes significantly decreased $\mathrm{SO}_{2}, \mathrm{pO}_{2}, \mathrm{pH}$, and $\mathrm{BE}$, and increased partial pressure of carbon dioxide $\left(\mathrm{pCO}_{2}\right)$ and plasma concentrations of lactate (Table 1). At the end of occlusion, fetal heart rate decreased by $40 \%$ but blood pressure did not change (Figure 1). At this time point, combined ventricular output decreased by $72 \%$, whereas the portion distributed to the placenta did not change and blood flows to central organs, ie, heart, brain, and adrenals increased by 474\%,248\%, and 464\%, respectively (Table 2, Table 3 and Table 4). There was uneven distribution of combined ventricular output to the various regions of the brain during asphyxia. The portion distributed to the cerebrum and brainstem progressively increased after 2 minutes of asphyxia, whereas that to the cerebellum, choroid plexus, and hippocampus did not change (data not shown). During asphyxia the distribution of combined ventricular output and regional blood flow to most of the peripheral organs of the upper and lower body segments, ie, the intestines, liver, kidney, skin, scalp, and carcass, decreased to very low values and recovered gradually thereafter (Table 2, Table 3 and Table 4).
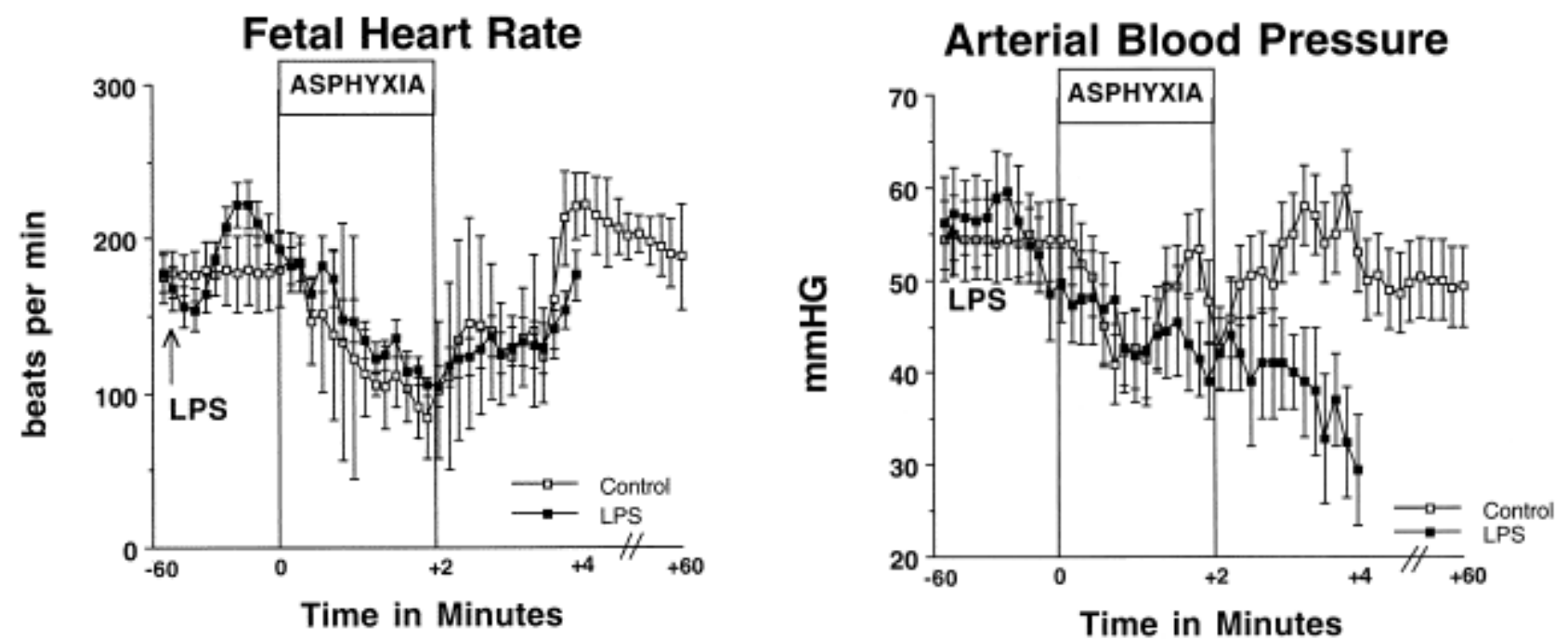

Figure 1. Changes in fetal heart rate and mean arterial blood pressure in control $(n=6)$ and lipopolysaccharide (LPS)-treated $(n=7)$ immature fetal sheep before, during, and after arrest of uterine blood flow for 2 minutes. 
Fetal heart rate tended to decrease, and mean arterial blood pressure tended to increase immediately after LPS infusion with a reversed response later on, but those changes were not significant. Compared with control fetuses, LPS-treated fetuses developed sustained hypotension during the immediate recovery period $(\mathrm{P}<0.01)$. Unlike the control fetuses, five of seven LPS-treated fetuses died within 30 minutes after arrest of uterine blood flow. Values are given as mean \pm standard error of the mean. The data were analyzed within and between groups using a two-way analysis of variance followed by Games-Howell post-hoc test $(* \mathrm{P}<0.05, * * \mathrm{P}<0.01)$.

In the immediate recovery period, ie, at +4 minutes, fetal heart rate decreased significantly but mean arterial blood pressure did not change (Figure 1). At this time point blood flow to the heart, adrenals, and all parts of the brain significantly increased whereas blood flow to the choroid plexus decreased (Table 4). Blood flow to the body was still poor while placental flow returned to baseline values (Table 2 and Table 4). At +30 and +60 minutes those values were not different from baseline.
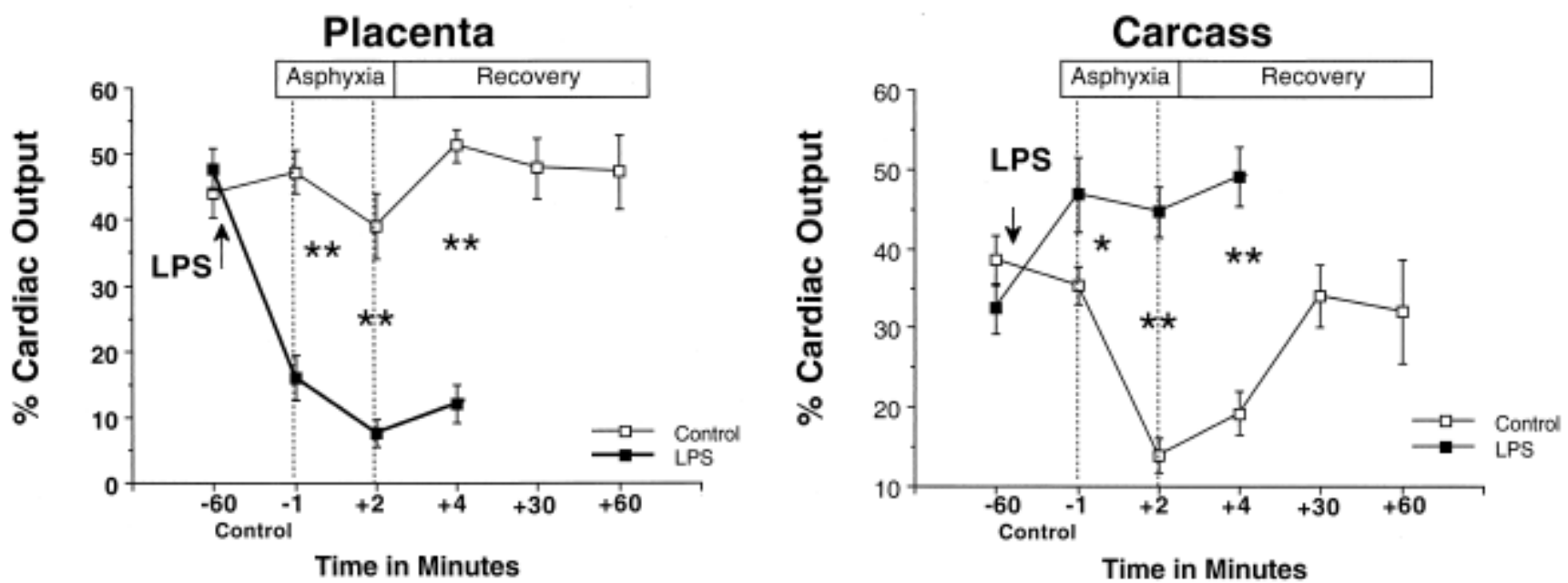

Figure 2. Combined ventricular output directed to the placenta and carcass in control $(n=6)$ and lipopolysaccharide (LPS)-treated $(n=7)$ immature fetal sheep before, during, and after arrest of uterine blood flow for 2 minutes. 
Unlike in control fetuses, in LPS-treated fetuses there was a significant decrease in the percentage of combined ventricular output directed to the placenta, whereas that directed to the carcass significantly increased. During arrest of uterine blood flow the portion distributed to the carcass remained elevated in fetuses of the study group $(\mathrm{P}<0.001)$. Values are given as mean \pm standard error of the mean. The data were analyzed within and between groups using a two-way analysis of variance followed by Games-Howell post-hoc test $(* \mathrm{P}<0.05$, **P $<0.01)$.

\section{Study group}

Before application of LPS (control -60 minutes) there were no significant differences in physiologic variables, blood gases, and blood flows between control and study groups (Table 1, Table 2, Table 3 and Table 4). However, after LPS infusion was started, $\mathrm{SO}_{2}$ and $\mathrm{pH}$ significantly decreased, whereas plasma concentrations of lactate increased indicating mixed acidemia. Fetal heart rate tended to decrease, and mean arterial blood pressure tended to increase immediately after LPS infusion with a reversed response later on, but these changes were not significant (Figure 1).

After application of LPS fetal cardiovascular control was severely affected. During the control period there was an inverse response in the distribution of combined ventricular output directed to the placenta and that directed to the fetal body. The percentage of cardiovascular output directed to the placenta decreased from $48 \%$ to $16 \%(\mathrm{P}<0.001)$, whereas that to the carcass increased from $32 \%$ (control -60 minutes) to $47 \%$ (control -1 minute; $\mathrm{P}<.01$; Figure 2). Blood flow to the adrenals doubled during this period, and the portions of combined ventricular output directed to the heart $(\mathrm{P}<0.05)$ and peripheral organs, including the intestines $(P<0.05)$, liver $(P$ $<0.05)$, and carcass $(P<0.05)$, were significantly higher in LPS-treated fetuses compared with controls (Table 3 and Table 4). Regarding blood flow to the parts of the brain, there were no significant changes between groups despite a significant decrease in $\mathrm{O}_{2}$ saturation in LPStreated fetuses during the control period, which resulted in significantly decreased cerebral oxygen delivery in LPS-treated fetuses ( $\mathrm{P}<0$.05; Figure 3). 


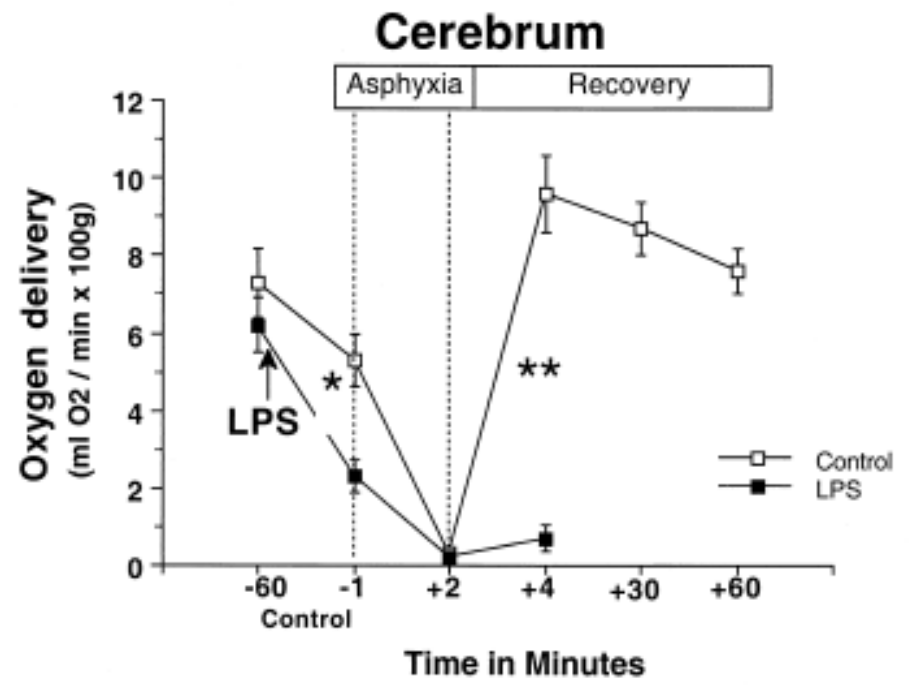

Figure 3. Oxygen delivery to the cerebrum $\left(\mathrm{mL} \mathrm{O}_{2}\right.$ /minute $\left.\times 100 \mathrm{~g}\right)$ in control $(n=6)$ and lipopolysaccharide (LPS)-treated $(n=7)$ immature fetal sheep before, during, and after arrest of uterine blood flow for 2 minutes.

During the immediate recovery period there was still a severe cut back in delivery of oxygen in fetuses of the study group. Values are given as mean \pm standard error of the mean. The data were analyzed within and between groups using a two-way analysis of variance followed by Games-Howell post-hoc test $(* \mathrm{P}<0.05, * * \mathrm{P}<0.01)$.

Arrest of uterine blood flow for 2 minutes caused severe acidosis and metabolic changes in LPStreated fetuses (Table 1). Thus, the decrease in $\mathrm{pH}$ and the increase in plasma concentrations of lactate were more pronounced in the study group than those in the control group. However, there were only minor changes in fetal heart rate and mean arterial blood pressure (Figure 1). There was a progressive decrease in the portion of combined ventricular output distributed to the placenta at the peak of asphyxia ( +2 minutes), whereas the percentage distributed to the carcass remained elevated $(P<0.001$; Figure 2$)$. Furthermore, adrenal blood flow was still high. 
During the immediate recovery, ie, 2 minutes after arrest of uterine blood flow had been released, arterial oxygen saturation and $\mathrm{PO}_{2}$ were still poor and severe mixed acidemia persisted ( $\mathrm{pH}$ below 7.0). Combined ventricular output remained low, and placental blood flow did not recover. Compared with control fetuses, blood flow to the parts of the brain were $50 \%$ lower, and cerebral oxygen delivery remained at very low values $(P<.01$; Figure 3$)$. In addition, sustained hypotension developed in LPS-treated fetuses $(P<.01$; Figure 1$)$, and unlike the control fetuses, five of seven LPS-treated fetuses died within 30 minutes after arrest of uterine blood flow. 


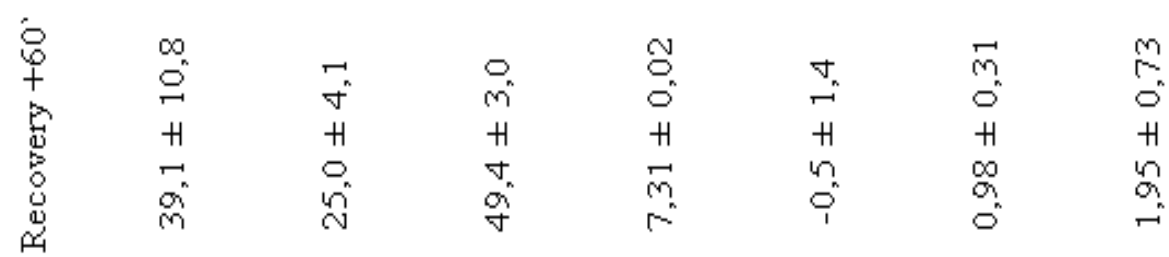

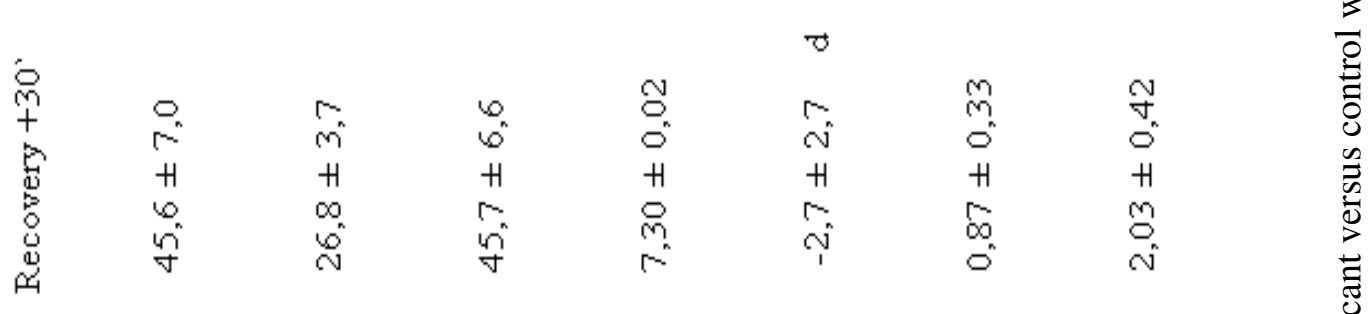

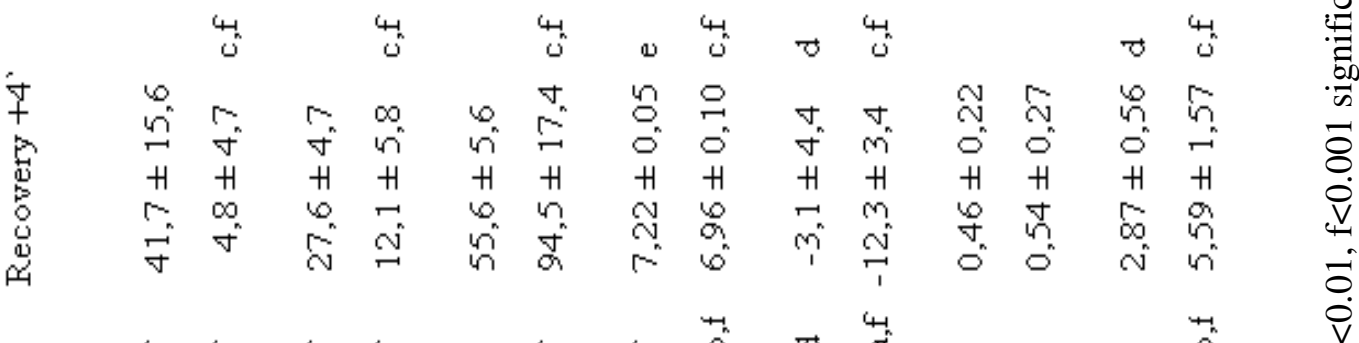

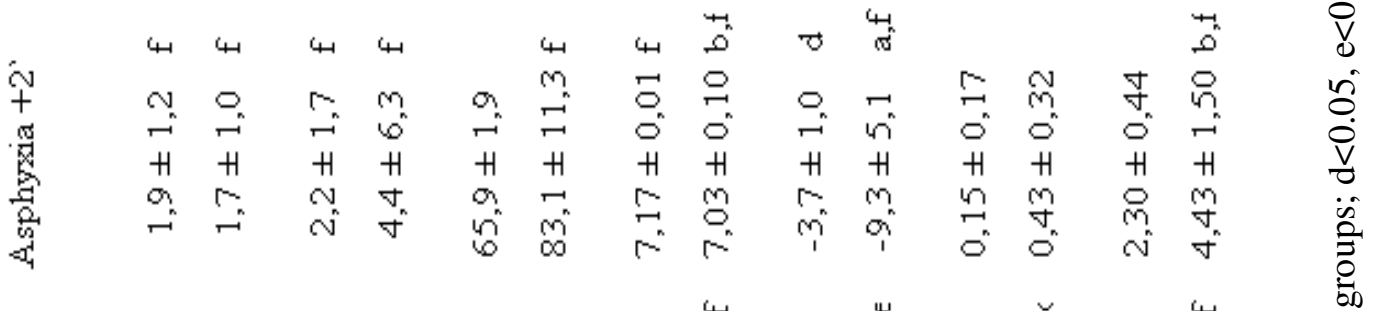

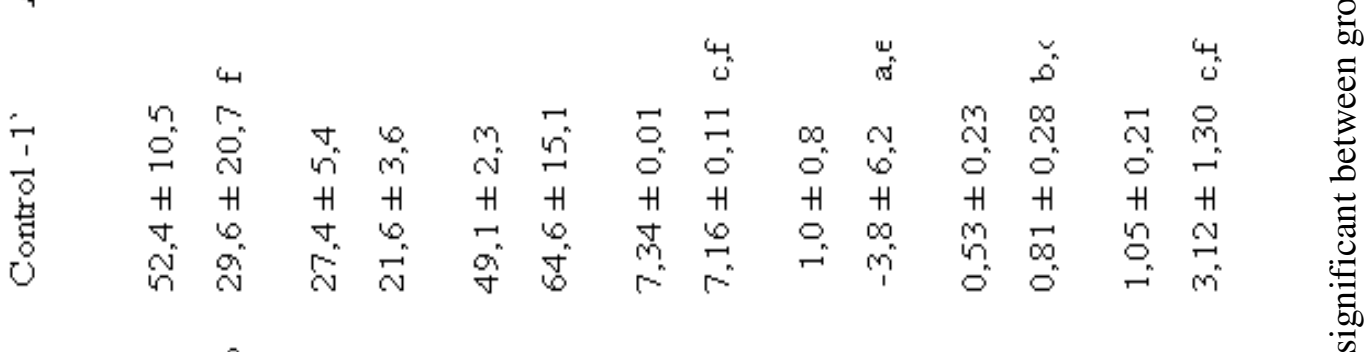

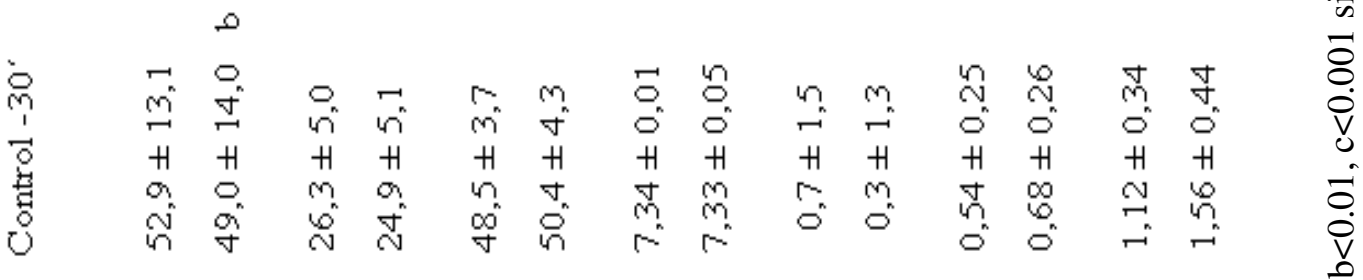

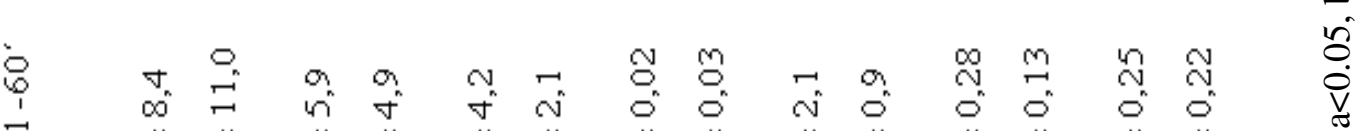

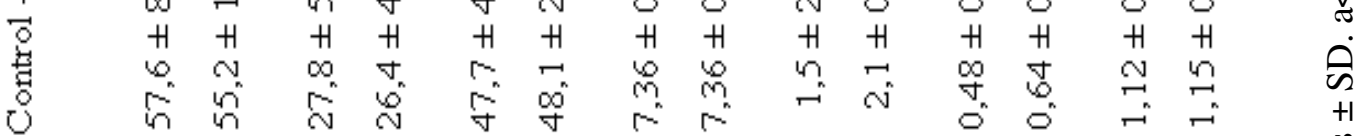

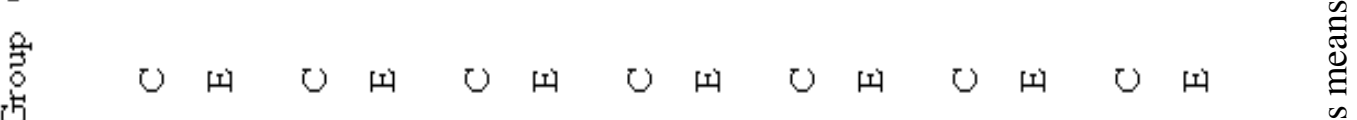

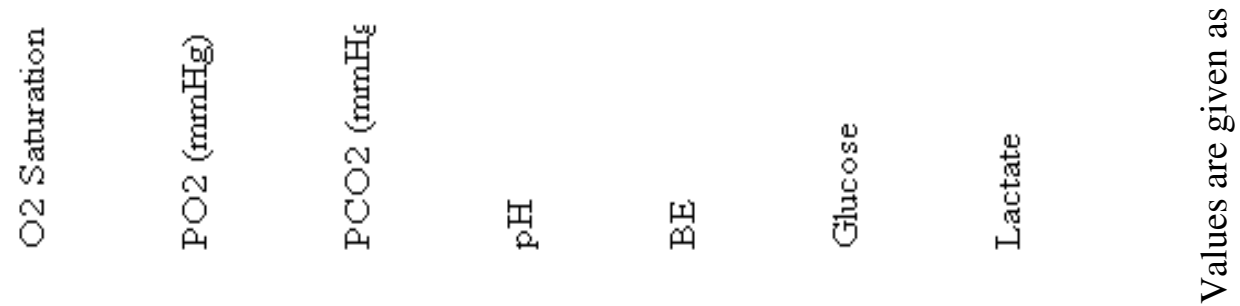




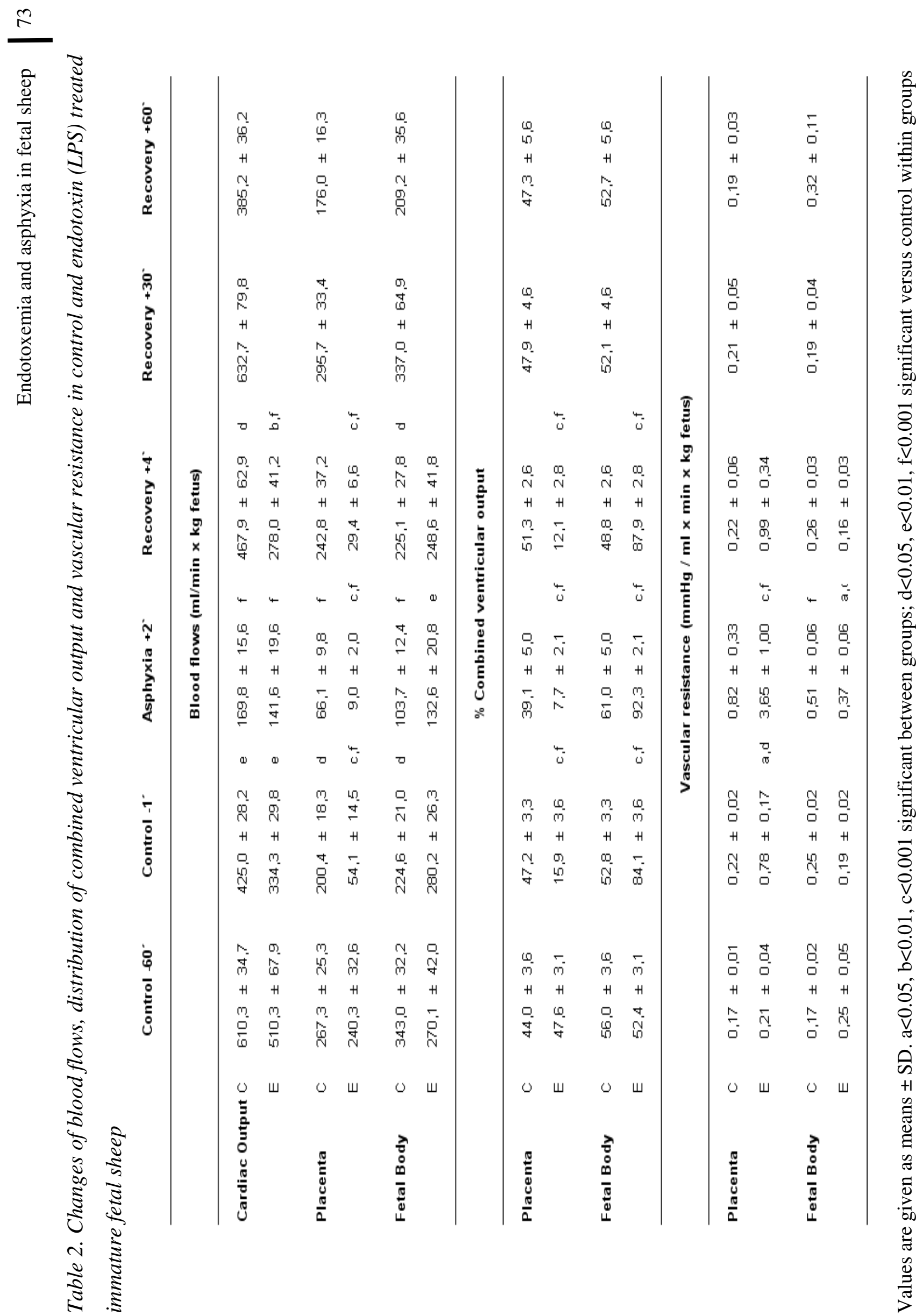




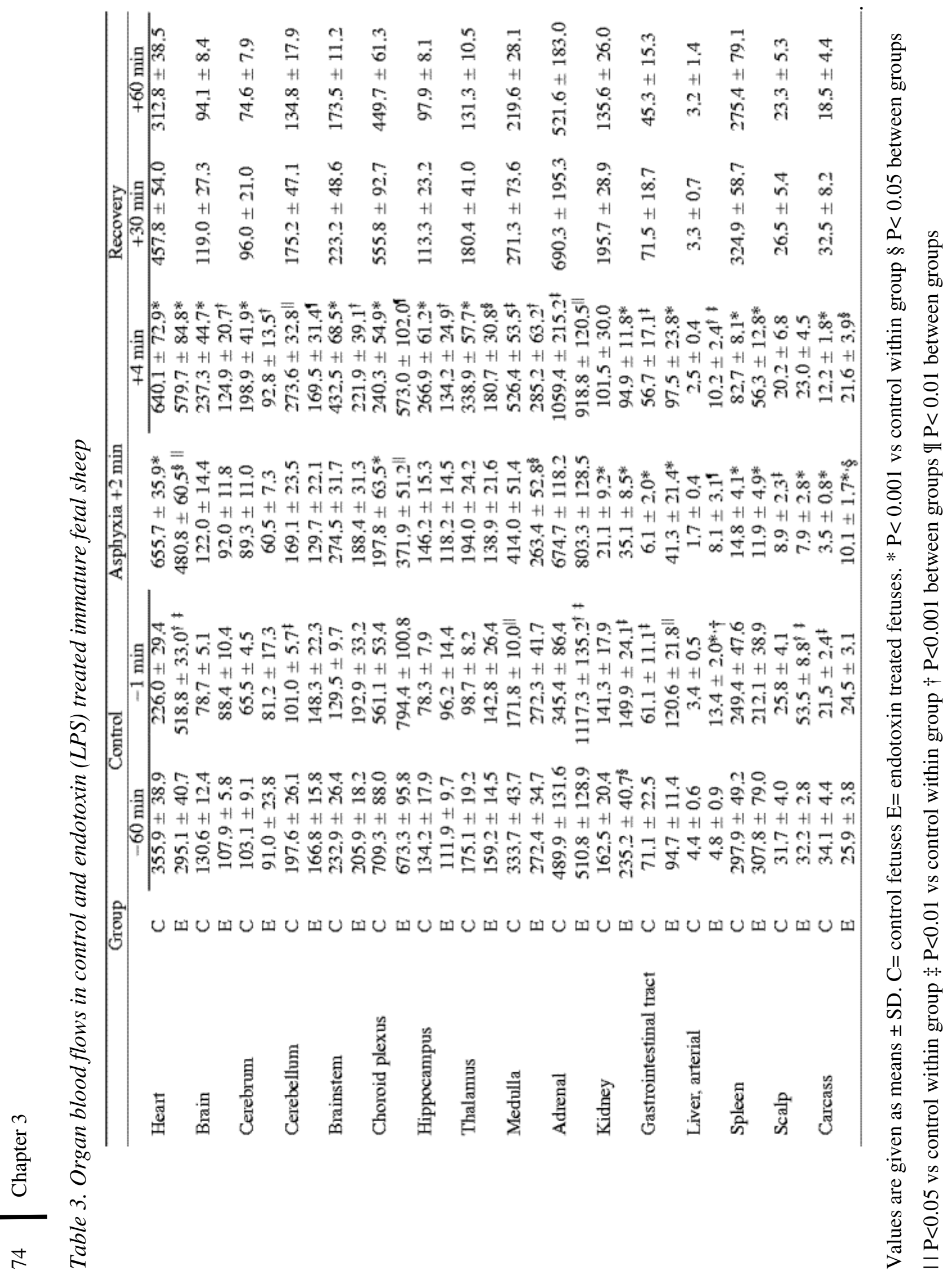




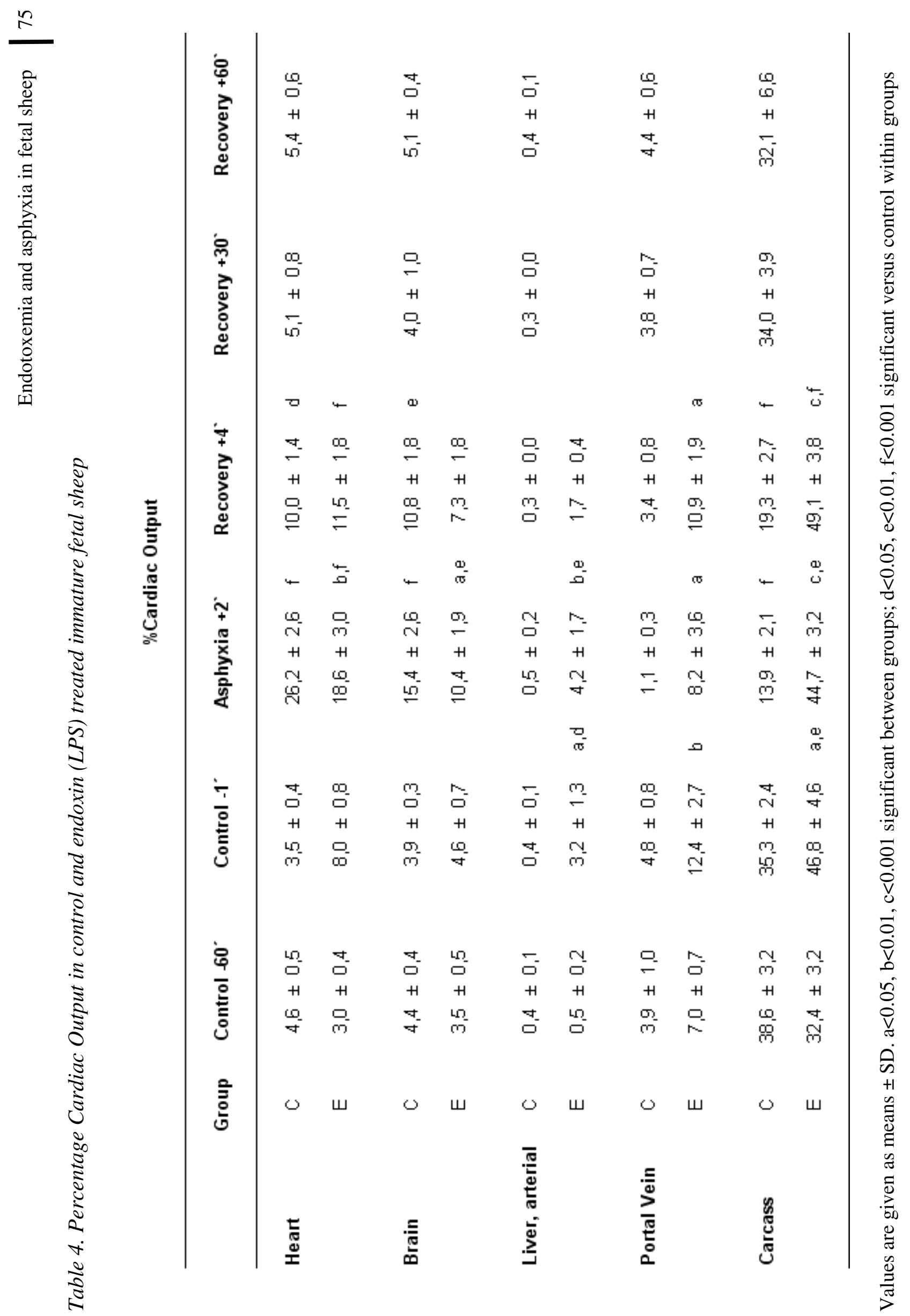




\section{Discussion}

There is evidence from recent epidemiologic and clinical studies that exposure to intrauterine infection and chorioamnionitis is associated with white matter brain damage especially in very low birth weight infants $(1,12)$. Lipopolysaccharides derived from the cell walls of gramnegative bacteria seem to be the link between intrauterine infection and brain damage. Lipopolysaccharides stimulate astrocytes and microglia to produce large amounts of various cytokines, such as tumor necrosis factor $\alpha$ (TNF- $\alpha$ ), interleukin (IL)-1, and IL-6. Tumor necrosis factor $\alpha$ is known to induce nitric oxide (NO) production in astrocytes (13). Nitric oxide combines with superoxide anion to peroxynitrate, a very reactive agent that destroys cell membranes and leads to cell death. In a recent in vitro study LPS caused a significant increase in TNF- $\alpha$ concentration in hippocampal slices of fetal guinea pigs. Interestingly, NO production was not modulated after oxygen-glucose deprivation in that experimental model (14). In addition, after oxygen-glucose deprivation, LPS did not affect the prolonged inhibition of protein synthesis, which is known to be a sensitive marker of neuronal cell death. The question therefore remains open whether fetal brain damage is brought about by a direct toxic effect of LPS on neuronal tissue or is caused by reduced cerebral oxygen delivery resulting from cardiovascular deterioration during endotoxemia.

We therefore studied cardiovascular responses to LPS in preterm fetal sheep before, during, and after intrauterine asphyxia of 2 minutes duration. Infusion of LPS severely affected the fetal cardiovascular system. Within 30 minutes after asphyxia five of seven LPS-treated fetuses died of sustained circulatory decentralization. The most pronounced changes in organ blood flow were observed in the placenta and the fetal carcass. After injection of LPS the percentage of cardiovascular output distributed to the placenta decreased from $48 \%$ to $16 \%$, whereas that to the carcass increased from $32 \%$ to $47 \%$. These changes were accompanied by both hypoxemia and combined respiratory and metabolic acidosis. 


\section{Placenta}

Because the umbilical and placental vessels lack autonomic innervation (15), the regulation of umbilical and placental blood flow must depend on circulating or locally released vasoactive substances $(16,17)$. In the fetal sheep the microcirculation of the placenta is remarkably inert to many vasoconstrictors, including norepinephrine and angiotensin II, whereas the umbilical artery and vein are more vasoactive $(18,19)$. When endotoxin is administered to the pregnant ewe, there is a precipitous decrease in mean arterial blood pressure and uteroplacental blood flow, which is followed by a decrease in uteroplacental oxygen transfer to about one third of the control value (20). Interestingly, the same authors found no significant changes in cardiac output and umbilical blood flow in the acutely prepared fetal sheep even when they administered very large doses of endotoxin to the fetus (21). In the present study we found a highly significant decrease in placental blood flow and an increase in placental vascular resistance within 60 minutes after LPS treatment. Because we did not measure umbilical venous blood pressure in the present study, it remains unknown whether the observed increase in placental vascular resistance was caused by vasoconstriction of the large umbilical arteries or the microcirculation. The increase in placental vascular resistance might be the result of endothelin-mediated vasoconstriction. Endothelin (ET-1) is a potent endothelium-derived vasoconstrictive peptide that is able to constrict fetoplacental microcirculation and decrease fetal oxygen consumption in sheep (22). Bacterial endotoxin or sepsis was shown to increase ET-1 concentrations in fetal umbilical arterial plasma more than fivefold in both pigs and humans, reaching levels close to threshold vasoconstriction (23). Therefore, the significant increase in placental vascular resistance in our model resulting in prolonged placental hypoperfusion and hypoxia seems to be mediated by LPS-induced production of ET-1 in the umbilical circulation. 


\section{Carcass}

The severe reduction in placental blood flow during the control period in the study group was accompanied by an inverse response in the fetal carcass. At that time moderate hypoxemia $\left(\mathrm{SO}_{2}\right.$ $29.6 \pm 20.7 \%)$ and acidosis $(\mathrm{pH} 7.16 \pm 0.11)$ were present. Blood flow to the carcass decreased during severe maternal hypoxemia or reduction in uterine blood flow $(10,24)$. It increased, however, during graded reduction in umbilical blood flow (25). Interestingly, oxygen consumption of the carcass decreased twice as much during uterine blood flow reduction (10) than during umbilical blood flow reduction (25), although in both studies total fetal oxygen delivery was reduced by a similar amount $(50 \%)$. In the present study oxygen delivery to the carcass was not significantly different between control and study groups. However, arterial liver blood flow significantly increased during endotoxemia, which reflects the hyperdynamic early stage of sepsis, with subsequent local and systemic liberation of proinflammatory mediators. Fetuses treated with LPS did not have lower blood flow to the carcass despite moderate hypoxemia and acidosis during the control period, which reflects a lack of control of vascular resistance resulting in circulatory decentralization during and after asphyxia.

\section{Brain}

During the control period significant differences in blood flow to the brain were not observed in LPS-treated fetuses, although oxygen saturation decreased by $50 \%$. This finding is surprising, because an inverse relationship between cerebral blood flow and arterial $\mathrm{O}_{2}$ content has been described in term and preterm fetal sheep $(11,26,27)$. One possible explanation for this phenomenon might be that the physiologic mechanisms mediating the response of cerebral blood flow to hypoxia are altered by LPS. After 2 minutes of asphyxia, blood flow to the brain remained unchanged and did not differ between groups. During the immediate recovery period cerebral blood flow increased significantly in control fetuses, probably because of lower oxygen and higher carbon dioxide partial pressures. In addition, the increase in mean arterial blood 
pressure also might have led to cerebral hyperperfusion, because autoregulation of cerebral blood flow is usually lost during hypoxemia (10). In contrast, LPS-treated fetuses had severe hypotension that was accompanied by a 50\% reduction in brain blood flow compared with control fetuses. At mean arterial blood pressures of below $25-30 \mathrm{mmHg}$ there is increased loss of cerebral autoregulation and hence reduced cerebral blood flow, which particularly affects the parasagittal region of the cerebrum and the white matter. Immature fetuses seem to be at risk by their limited ability to increase the cerebral circulation through vasodilation (27). This inability caused a prolonged and severe decrease in cerebral oxygen delivery below $3 \mathrm{~mL} \mathrm{O} / 100 \mathrm{~g}$ tissue per minute. In a previous study in preterm fetal sheep, oxygen delivery below that threshold caused neuronal cell death (28).

By analyzing the raw data on radionuclide counting in the lungs, we made some interesting observations. During and after asphyxia the percentage of injected microspheres trapped in the lungs of LPS-treated fetuses increased significantly compared with other organs (-60 minutes $4.5 \pm 0.8 \% ;-1$ minute $9.5 \pm 3.5 \%[\mathrm{P}<0.05$ versus -60 minutes $]+2$ minutes $24.9 \pm 6.8 \%[\mathrm{P}<$ 0.01 versus -60 minutes]). Although we were not able to measure pulmonary blood flow exactly because we did not draw a reference sample from the pulmonary artery, the most obvious reason for this phenomenon would seem to be vasodilation of the pulmonary vascular bed. In fact, pulmonary vasodilation has been described after exposure to NO, a substance that is produced in large amounts after LPS application. These observations warrant further experiments to study the effects of LPS on pulmonary vascular control. It could be said that in the present study the LPS dose was excessive and that the failure of the LPS group to recover from asphyxia resulted from excessive application of endotoxin rather than from a combined effect of LPS and asphyxia. However, we believe that this is not very likely. Shortly before asphyxia (-1 minute) the cardiovascular system of the LPS-treated group was altered but not severely compromised, as shown in Table 1. Additional effects of asphyxia were observed at +2 minutes and +4 minutes. Thus, up to that time point the LPS dose was not 
excessive. Furthermore, as mentioned in the Methods section, we studied fetal heart rate and mean arterial blood pressure in a pilot experiment after injection of LPS over 2 hours. Within this time interval we did not observe any significant changes in fetal heart rate (control 192; 1 hour 207; 2 hours 175 bpm) or mean arterial blood pressure (control 55.8; 1 hour 51.9; 2 hours $48.7 \mathrm{mmHg}$ ). We therefore think that the high rate of fetal demise in the present study was brought about by the combined effect of asphyxia and LPS and would not have been observed by the injection of LPS alone. However, that will have to be investigated in further studies. Experiments using smaller amounts of LPS to study longer recovery periods after asphyxia and endotoxemia are in progress.

It is difficult to speculate whether the dose of LPS used in the present study would cause similar effects under clinical conditions. As we know from the literature, LPS has been used in a wide range of doses under various experimental conditions. One reason might be that the endotoxic effect of LPS varies widely with the bacterial strain from which it has been isolated as well as with the animal species into which it is injected. Experimental findings can therefore hardly be applied to the human situation. However, because severe endotoxemic shock has been described in preterm human neonates after ascending intrauterine infection, LPS-induced alterations of fetal cardiovascular control are likely to occur under clinical conditions as well.

\section{Acknowledgements}

The excellent technical assistance of May Bost, Joyce Suyk, Monique de Groot is gratefully acknowledged. 


\section{References}

1. Dammann $\mathrm{O}$ and Leviton A. Maternal intrauterine infection, cytokines, and brain damage in the preterm infant. Pediatr Res 1997;42:1-8.

2. Niswander KR and Gordon M. In: The women and their pregnancies. The Collaborative Perinatal Study of the National Institute of Neurological Diseases and Stroke, WB Saunders, 1972;252-256. Philadelphia.

3. Paneth N, Pinto-Martin J, Gardiner J et al. Incidence and timing of germinal matrix/intraventricular hemorrhage in low birth weight infants. Am J Epidemiol 1993;137:11671176.

4. Berger R, Bender S, Sefkow S, Klingmüller V, Künzel W and Jensen A. Peri/intraventricular haemorrhage: A cranial ultrasound study on 5286 neonates. Eur J Obstet Gynecol Reprod Biol 1997;75:191-203.

5. Jensen A, Hohmann M and Künzel W. Dynamic changes in organ blood flow and oxygen consumption during acute asphyxia in fetal sheep. J Dev Physiol 1987;9:543-559.

6. Jensen A, Lang U and Braems G. Cardiovascular effects of endotoxin and asphyxia in fetal sheep near term. In: W. Künzel and M. Kirschbaum (Eds). Oxygen: Basis of the regulation of vital functions in the fetus. 1992;156-157. Springer Verlag, Berlin.

7. Redl H, Bahrami S, Schlag G and Traber DL. Clinical detection of LPS and animal models of endotoxemia. Immunobiology 1993;187:330-345.

8. Heymann MA, Payne BD, Hoffman JIE and Rudolph AM. Blood flow measurements with radionuclide-labeled particles. Prog Cardiovasc Dis 1977;20:55-79.

9. Rudolph AM and Heymann MA. Circulation of the fetus in utero: Methods for studying distribution of blood flow, cardiac output and organ blood flow. Circ Res 1967;21:163-184.

10. Jensen A, Roman C and Rudolph AM. Effects of reducing uterine blood flow on fetal blood flow distribution and oxygen delivery. J Dev Physiol 1991;15:309-323.

11. Jensen A and Berger R. Fetal circulatory responses to oxygen lack. J Dev Physiol 1991;16:181207.

12. Zupan V, Gonzalez P, Lacaze-Masmonteil T et al. Periventricular leukomalacia: Risk factors revisited. Dev Med Child Neurol 1996;38:1061-1067.

13. Cerami A. Inflammatory cytokines. Clin Immunol Immunopathol 1992;62:3-10.

14. Berger R, Garnier Y, Pfeiffer D and Jensen A. Lipopolysaccharides do not alter metabolic disturbances in hippocampal slices of fetal guinea pigs after oxygen-glucose deprivation. Pediatr Res 2000;48:351-355.

15. Reilly FD and Russel PT. Neurohistochemical evidence supporting an absence of adrenergic and cholinergic innervation in the human placenta and umbilical cord. Anat Rec 1977;188:277-286.

16. Hemsen A. Biochemical functional characterization of endothelin peptides with special 
reference to vascular resistance. Acta Physiol Scand 1991;602:1-61.

17. Hemsen A, Gillis C, Larsson O, Haegerstrand A and Lundberg JM. Characterization, localization and actions of endothelins in umbilical vessels and placenta of man. Acta Physiol Scand 1991;43:395-404.

18. van Huisseling H, Muijers GJJM, de Haan J and Hasaart THM. Fetal hypertension induced by norepinephrine infusion and umbilical artery flow velocity waveforms in fetal sheep. Am J Obstet Gynecol 1991;165:450-455.

19. Paulick RP, Meyers RL, Rudolph CD and Rudolph AM. Umbilical and hepatic venous responses to circulating vasoconstrictive hormones in fetal lamb. Am J Physiol 1991;260:H1205-H1213.

20. Bech-Jansen P, Brinkman CR, III, Johnson GH and Assali NS. Circulatory shock in pregnant sheep. I. Effects of endotoxin on uteroplacental and fetal umbilical circulation. Am J Obstet Gynecol 1972;112:1084-1094.

21. Bech-Jansen P, Brinkman CR, III, Johnson GH and Assali NS. Circulatory shock in pregnant sheep. II. Effects of endotoxin on fetal and neonatal circulation. Am J Obstet Gynecol 1972;113:37-43.

22. Adamson SL, Whiteley KJ and Langille BL. Endothelin-1 constricts fetoplacental microcirculation and decreases fetal $\mathrm{O}_{2}$ consumption in sheep. Am J Physiol 1996;270:H16$\mathrm{H} 23$.

23. Lundberg JM, Ahlborg G, Hemsen A et al. Evidence for release of endothelin-1 in pigs and humans. J Cardiovasc Pharmacol 17;1991:350-353.

24. Cohn HE, Sacks EJ, Heymann MA and Rudolph AM. Cardiovascular responses to hypoxemia and acidemia in fetal lambs. Am J Obstet Gynecol 1974;120:817-824.

25. Itskovitz J, LaGamma EF and Rudolph AM. Effects of cord compression on fetal blood flow distribution and $\mathrm{O}_{2}$ delivery. Am J Physiol 1987;252:H100-H109.

26. Ashwal S, Dale PS and Longo LD. Regional cerebral blood flow: Studies in the fetal lamb during hypoxia, hypercapnia, acidosis, and hypotension. Pediatr Res 1984;18:1309-1316.

27. Berger R and Garnier Y. Pathophysiology of perinatal brain damage. Brain Res Rev 1999;32:107-134.

28. Berger R, Lehmann T, Karcher J, Schachenmayr W and Jensen A. Relation between cerebral oxygen delivery and neuronal cell damage in fetal sheep near term. Reprod Fertil Dev 1996;8:317-321. 


\section{Chapter 4}

The role of nitric oxide on fetal cardiovascular control during normoxia and acute hypoxia in 0.75 gestation sheep.

A.B.C. Coumans, Y. Garnier, S. Supçun, A. Jensen, T.H.M. Hasaart, R. Berger 


\section{Introduction:}

Fetal asphyxia is an important contributor to perinatal mortality and morbidity. The incidence of asphyxia has been reported to be between $0.29 \%$ and $0.9 \%$ depending on the inclusion criteria and the population studied (1). The ability of the fetus to mount an appropriate cardiovascular response to episodes of reduced oxygen supply is of great importance for its survival and development. When a fetus is exposed to asphyxia, several responses have been observed. First, there is a rapid fall in heart rate and a rise in peripheral vascular resistance. This is predominantly mediated by carotid chemoreflexes (2). After these changes, a maintained peripheral vasoconstriction and vasodilatation of cerebral, myocardial and adrenal beds occur. This mechanism, redistribution, results in blood flow being directed from peripheral tissues towards vital, centrally localized organs like the brain, heart and adrenals $(3,4,5)$. The vasoconstriction is attributed to a rise in plasma catecholamines. In addition, hypoxia has a direct effect at a local tissue level, where the vascular endothelium may act as a hypoxic sensor and effector system. This has also been proven in fetal sheep where in late-gestation fetal lambs (132-140 days) fetal pulmonary vasoconstriction after acute constriction of the ductus arteriosus was mediated by NO-ET-1 interactions (6). This includes the release of a variety of vasoactive substances such as nitric oxide (NO), endothelin-1 and prostacyclin.

NO is a free radical and is synthesized from the amino acide L-arginine and oxygen through a reaction which is catalysed by nitric oxide synthase (NOS) $(7,8)$. NO relaxes vascular smooth muscle through intracellular processes some dependent (1) and some independent of cGMP (8). Several isoforms have been purified and cloned. These include the calcium-dependent isoforms (isolated from nerve and endothelial cells), nNOS and eNOS, and the inducible calciumindependent isoform (iNOS) $(9,10)$. All three isoforms of NOS can be expressed in large blood vessels $(11,9,12,13)$. After the infusion of NOS-inhibitors fetal heart rate falls, whereas arterial blood pressure progressively rises (14). In addition, cardiac output is severely reduced (15) and an increase in carotid, femoral, and placental vascular resistance can be observed $(14,15,16)$. 
However, after prolonged inhibition of NOS, this system is replaced by alternative mechanisms regulating fetal cardiovascular control (10). During hypoxia, arterial blood pressure does not rise and rebound tachycardia is absent, if NOS is inhibited by L-NAME. Furthermore, the increase in carotid blood flow and fall in vascular resistance is blunted (14). Thus, NO seems to alter fetal cardiovascular control during basal and hypoxic conditions.

Nevertheless, the impact of NO on fetal cardiovascular control is only partially understood and as yet no studies have been performed on the effects of NO on fetal blood flow distribution after acute hypoxia. In particular, there is a significant lack of data on NO-mediated blood flow regulation in 0.75 gestation fetuses. Hence, the role of NO in redistributing cardiac output towards the central organs, i.e. brain, heart, adrenals, during asphyxia in immature fetuses remains unexplored. We therefore studied the distribution of cardiac output in 0.75 gestation sheep during normoxia and acute hypoxia. NOS was inhibited using nitro-L-arginine methyl ester (L-NAME). 


\section{Methods:}

\section{$\underline{\text { Animal preparation }}$}

Thirteen fetal sheep were chronically instrumented at a mean gestational age of $107 \pm 1$ days (term is 147 days). All ewes underwent surgery with use of sterile techniques while they were under general anesthesia (thiopental sodium $1 \mathrm{gm} / 70 \mathrm{~kg}$ intravenously for induction, $0.5-1.0 \%$ halothane in a 1:1 nitrous oxide and oxygen mixture for maintenance). The ewes received $1 \mathrm{gm}$ ampicilline (Pentrexyl®; Bristol-Myers, Woerden, The Netherlands) s.c. and $10 \mu \mathrm{g}$ buprenorphin (Temgesic $®$; Schering, The Netherlands) per kg body weight twice a day for three consecutive postoperative days. A midline abdominal incision was performed. A snare was placed around the maternal distal aorta below the renal artery to induce fetal hypoxia (24). The fetal limbs were identified and exteriorised through an incision in the uterus. Polyvinyl catheters (Maxxim Medical BV, Den Bosch, The Netherlands) with $0.75 \mathrm{~mm}$ inner diameter and $1.25 \mathrm{~mm}$ outer diameter were inserted via a tibial fetal vein and artery of each hindleg and advanced into the caudal vena cava and abdominal aorta, respectively. Catheters were also placed into both brachial arteries. The fetal skin was closed with cyanoacrylate glue (Cyanolit, Japan). An intrauterine pressure catheter was inserted, and the uterus was sutured after replacing the amniotic fluid with a $0.9 \%$ saline solution at $39^{\circ} \mathrm{C}$. Catheters were filled with heparin (500 IU/ml; Heparin-Natrium ${ }^{\circledR}$, Braun, Melsungen, Germany) and exteriorised through a small incision in the flank of the ewe. Catheters were protected by a pouch sewn to the skin of the ewe. A recovery period of 72 hours followed the operation before experiments were started. Ewes were housed in individual cages and had free access to food and water.

Guidelines for care and use of animals, as approved by the local Animal Medical Ethics Committee at Maastricht University, were followed. 


\section{$\underline{\text { Experimental protocol }}$}

The experiments were performed 3 days after the surgical procedure at $110 \pm 1$ days. This recovery period is generally accepted as an adequate recovery period from surgical stress in the model at hand. Seven fetuses were treated with a $30 \mathrm{mg}$ bolus i.v. L-NAME (at -70 min) followed by a continuous L-NAME i.v. infusion of $6 \mathrm{mg} / \mathrm{min}$ until the end of the experiments (+30 min) (Sigma Aldrich, Zwijndrecht, The Netherlands), while the remaining six fetuses received vehicle solution $(\mathrm{NaCl} 0.9 \%)$. The applied dosage of L-NAME was within the therapeutic range as described in the literature (16). To determine the effects of L-NAME on circulatory centralization before, during and after hypoxia, blood flow to fetal organs and the distribution of combined ventricular output were measured by injecting five batches of differently labeled isotope microspheres $\left({ }^{141} \mathrm{Ce},{ }^{114} \mathrm{In},{ }^{113} \mathrm{Sn},{ }^{103} \mathrm{Ru}\right.$ and ${ }^{46} \mathrm{Sc}, 16 \mu \mathrm{m}$ diameter, New England Nuclear, Boston, MA, USA) into the inferior vena cava $(17,18)$. Depending on the specific activity, 0.7-1.8 million microspheres were injected over a period of 20 seconds, before infusion of L-NAME (at $-75 \mathrm{~min}$ ), before the onset of maternal aorta occlusion ( $-1 \mathrm{~min}$ ), at the bottom of hypoxia (+2 $\mathrm{min})$, and after the release of the snare ( $+4 \mathrm{~min}$ and $+30 \mathrm{~min})$ with $\mathrm{t}$ 0 being the start of the full occlusion of the maternal aorta. Reference blood samples were withdrawn from both a carotid and a femoral artery at a rate of $1.75 \mathrm{ml} / \mathrm{min}$. Sampling was continuous for $390 \mathrm{~s}$ from -1 to $+5.5 \mathrm{~min}$. Separate samples were taken for $90 \mathrm{~s}$ at control $(-75$ min) and during recovery (+30 min). The volume of blood withdrawn was simultaneously replaced by maternal blood maintained at $39^{\circ} \mathrm{C}$ in a waterbath. The experimental protocols were approved by the Animal Medical Ethics Committee of Maastricht University and met the guidelines of the responsible governmental agencies. 


\section{Measurements}

Fetal heart rate and mean blood pressure were continuously recorded during the experiment on a personal computer, using a customized hemodynamic data acquisition system.

Before each blood flow measurement, and additionally at $-30 \mathrm{~min}$, blood samples were taken from the fetal descending aorta and analysed for blood gases, acid base balance (AVL 993, Radiometer, Copenhagen, Denmark), hemoglobin concentration and arterial oxygen saturation of hemoglobin (OSM 2 Hemoximeter, Radiometer, Copenhagen, Denmark). The hemoximeter was calibrated to fetal sheep hemoglobin. $\mathrm{HCO}_{3}{ }^{-}$concentration was calculated by the blood gas analyzer according to the following formula: $\mathrm{HCO}_{3}{ }^{-}=0.0307 \times \mathrm{PCO}_{2} \times 10(\mathrm{pH}-6.105)$. At the same time points, glucose and lactate were measured (YSI, 2300 Statplus Analyzer/2, Yellow Springs Instruments, Ohio, United States).

After the experiment animals were humanely killed using a lethal intravenous dose of sodium pentobarbitone (Euthesate ${ }^{\circledR}$; Apharmo, Duiven, The Netherlands) which was administered to the ewe. The fetuses were perfused in utero with $200 \mathrm{ml}$ formalin $(10 \%$, w/v, saline). Fetal organs were weighed and placed in vials, which were filled to the same height to reduce variations in geometry. The intestines were separated from the mesentery, opened and cleared from contents. Paired organs (lungs, kidneys, and adrenals) were counted separately, as were the right and left sides of the cerebrum. Significant preferential streaming of microspheres could not be detected. Specimens of skin and muscle were taken from the hips and shoulders. Cotyledons, upper and lower carcass were homogenized with a meat chopper and the samples placed in vials. The applied solid-state semi-conductor gamma counter (thallium activated, sodium iodine crystal) had a high energy resolution of about $2 \mathrm{keV}$ and was connected to a multichannel (1024) pulse height analyzer (LKB 1282, Compugamma, Wallac, Turku, Finland). The results were normalized with respect to time and sample weight. 


\section{$\underline{\text { Calculations }}$}

Fetal combined ventricular output (CVO) and blood flow to the various organs were calculated from counts of the injected nuclide recovered in fetal organs or placenta, from counts in the appropriate reference samples, and from the withdrawal rate of the reference samples $(17,18)$. Blood flows below $1 \mathrm{ml} / \mathrm{min} / 100$ gram were treated as 1 .

The percentage of combined ventricular output distributed to a given organ was calculated from the absolute blood flow to that organ and the combined ventricular output. Oxygen delivery to the various organs ([DO2]; $\mathrm{ml} \mathrm{O} 2 / \mathrm{min} / 100 \mathrm{~g}$ ) was calculated according to the following formula: organ blood flow (ml/min/100g) x SO2 x hemoglobin (g/ml) x $1.34(\mathrm{ml} \mathrm{O} 2 / \mathrm{g} \mathrm{Hb})$.

\section{$\underline{\text { Statistics }}$}

Results are given as means \pm SEM. The data were analysed for intra- and intergroup differences by two-way multivariate analysis of variance for repeated measures. Games-Howell-test was used as post-hoc testing procedure. Statistical analysis was performed by Super Anova Statistical Package (Abacus, Inc. Ca. USA). 


\section{Results:}

\section{Blood gases, MAP and FHR}

At the beginning of the experiments (- $75 \mathrm{~min}$ ), blood gases (Table 1), MAP and FHR (Fig 1 and 2) were within the normal range for chronically prepared fetal sheep $(19,5)$. Acute hypoxia caused a severe fall in oxygen saturation, $\mathrm{pH}$ and $\mathrm{BE}$ as well as a rise in $\mathrm{PCO} 2$ and plasma lactate concentration. Except for a significant decrease in $\mathrm{pH}$ and $\mathrm{BE}$ at the end of the recovery period ( $+30 \mathrm{~min})$ and a transient rise in hemoglobin, differences between the two treatments could not be detected in these variables (Table 1).

Table 1. Acid-base balance and blood gases in control $(n=6)$ and L-NAME treated $(n=7)$ premature sheep, given as means $\pm S E$

\begin{tabular}{|c|c|c|c|c|c|c|c|}
\hline \multirow[b]{2}{*}{ Time } & & \multicolumn{3}{|l|}{ normoxia } & \multirow{2}{*}{$\begin{array}{l}\text { occlusion } \\
2\end{array}$} & \multicolumn{2}{|l|}{ recovery } \\
\hline & & -75 & -30 & -1 & & 4 & 30 \\
\hline \multirow[t]{2}{*}{$\mathrm{SO}_{2}(\%)$} & Control & $49.9 \pm 4.3$ & $43.9 \pm 6.2$ & $44.5 \pm 3.8$ & $2.5 \pm 0.8 \#$ & $34.6 \pm 6.7$ & $37.0 \pm 5.5$ \\
\hline & L-Name & $40.1 \pm 6.6$ & $35.0 \pm 7.6$ & $35.6 \pm 9.1$ & $2.0 \pm 1.2 \#$ & $30.5 \pm 3.4$ & $26.1 \pm 7.9$ \\
\hline \multirow[t]{2}{*}{$\mathrm{PCO}_{2}(\mathrm{mmHg})$} & Control & $47.7 \pm 1.6$ & $48.8 \pm 1.8$ & $51.3 \pm 1.0$ & $69.0 \pm 3.0$ & $58.7 \pm 1.8$ & $47.8 \pm 4.3$ \\
\hline & L-Name & $50.6 \pm 1.7$ & $48.4 \pm 4.1$ & $52.0 \pm 2.5$ & $72.6 \pm 3.2 \#$ & $61.9 \pm 2.8$ & $51.0 \pm 12.0$ \\
\hline \multirow[t]{2}{*}{$\mathrm{PO}_{2}(\mathrm{mmHg})$} & Control & $26.5 \pm 3.1$ & $24.0 \pm 2.2$ & $25.6 \pm 2.8$ & $4.7 \pm 1.7 \#$ & $26.9 \pm 2.2$ & $25.3 \pm 1.7$ \\
\hline & L-Name & $25.9 \pm 1.8$ & $24.3 \pm 1.9$ & $25.4 \pm 1.7$ & $14.4 \pm 3.7^{*}, \#$ & $24.6 \pm 2.1$ & $22.7 \pm 1.9$ \\
\hline \multirow[t]{2}{*}{$\mathrm{pH}$} & Control & $7.35 \pm 0.01$ & $7.34 \pm 0.01$ & $7.33 \pm 0.01$ & $7.15 \pm 0.01 \#$ & $7.21 \pm 0.02 \#$ & $7.27 \pm 0.02$ \\
\hline & L-Name & $7.33 \pm 0.02$ & $7.29 \pm 0.01$ & $7.27 \pm 0.01$ & $7.12 \pm 0.01 \#$ & $7.15 \pm 0.01 \#$ & $7.14 \pm 0.04^{*}, \#$ \\
\hline \multirow[t]{2}{*}{$\mathrm{BE}(\mathrm{mmol} / \mathrm{L})$} & Control & $1.3 \pm 1.0$ & $0.9 \pm 0.7$ & $1.4 \pm 0.4$ & $-4.3 \pm 0.3 \#$ & $-4.5 \pm 1.4 \#$ & $-3.7 \pm 1.1 \#$ \\
\hline & L-Name & $0.3 \pm 0.5$ & $-3.4 \pm 1.6$ & $-2.6 \pm 0.7$ & $-6.3 \pm 1.1 \#$ & $-7.8 \pm 0.6 \#$ & $-9.0 \pm 1.2 * \#$ \\
\hline \multirow[t]{2}{*}{ Glucose } & Control & $0.58 \pm 0.1$ & $0.61 \pm 0.1$ & $0.60 \pm 0.1$ & $0.16 \pm 0.1$ & $0.51 \pm 0.1$ & $1.00 \pm 0.2$ \\
\hline & L-Name & $0.68 \pm 0.1$ & $0.61 \pm 0.1$ & $0.62 \pm 0.1$ & $0.14 \pm 0.0 \#$ & $0.49 \pm 0.1$ & $1.30 \pm 0.2 \#$ \\
\hline \multirow[t]{2}{*}{ Lactate } & Control & $1.4 \pm 0.2$ & $1.4 \pm 0.3$ & $1.4 \pm 0.3$ & $3.0 \pm 0.5 \#$ & $3.5 \pm 0.4 \#$ & $3.0 \pm 0.7 \#$ \\
\hline & L-Name & $1.3 \pm 0.2$ & $1.4 \pm 0.3$ & $1.4 \pm 0.3$ & $2.7 \pm 0.4 \#$ & $3.4 \pm 0.3 \#$ & $3.9 \pm 0.4 \#$ \\
\hline \multirow[t]{2}{*}{$\mathrm{Hb}(\mathrm{g} / \mathrm{dl})$} & Control & $9.2 \pm 0.3$ & $9.3 \pm 0.7$ & $9.3 \pm 0.6$ & $10.7 \pm 0.4$ & $10.3 \pm 0.5$ & $9.4 \pm 0.9$ \\
\hline & L-Name & $9.3 \pm 0.5$ & $10.8 \pm 0.5 \#$ & $10.5 \pm 0.8$ & $11.8 \pm 0.6 \#$ & $11.1 \pm 0.4 \#$ & $10.4 \pm 0.2$ \\
\hline
\end{tabular}

Values are given as means \pm standard error.

$* P<0.05$, significant between groups at the same timepoint.

\# $P<0.05$, significant versus control at timepoint $t-75$ within group. 
After injection of L-NAME, fetal MAP increased significantly by $16 \%(\mathrm{p}<0.05)$ while FHR fell significantly by $17 \%(\mathrm{p}<0.05)$ in contrast to the control group where FHR and MAP did not change during normoxia. During acute hypoxia $(+2 \mathrm{~min})$ MAP rose significantly $(\mathrm{p}<0.05)$ and FHR was maintained in the L-NAME group in contrast to controls where MAP initially decreased and then returned to control values while FHR fell significantly $(\mathrm{p}<0.05)$. In the immediate recovery period, MAP was still higher and FHR lower after L-NAME infusion compared to control values $(\mathrm{p}<0.05)$ (Figures 1 and 2$)$. Thus, there was a significant higher MAP and lower FHR in the L-NAME group compared to the control group during normoxia. During the hypoxia period FHR was not different between the two groups, although MAP was significantly higher in the L-NAME group $(\mathrm{p}<0.05)$. During the recovery period MAP was still significantly higher and FHR was significantly lower $(\mathrm{p}<0.05)$ in the L-NAME group $(\mathrm{p}<0.05)$.

Table 2. Blood flows in control $(n=6)$ and L-NAME treated $(n=7)$ premature sheep.

\begin{tabular}{|ccccccc|}
\hline & \multicolumn{2}{c}{ normoxia } & occlusion & \multicolumn{2}{c|}{ recovery } \\
\hline & & -75 & -1 & 2 & 4 & 30 \\
\hline CVO & Control & $591.5 \pm 30.3$ & $400.9 \pm 16.9 \#$ & $206.1 \pm 42.3 \#$ & $460.1 \pm 73.6$ & $521.6 \pm 61.8$ \\
& L-Name & $602.1 \pm 63.4$ & $218.9 \pm 18.7 *, \#$ & $78.4 \pm 12.3 *$,\# & $109.2 \pm 9.7$ & $211.3 \pm 34.5 *, \#$ \\
\hline placenta & Control & $269.6 \pm 30.2$ & $189.6 \pm 19.9 \#$ & $92.2 \pm 34.2 \#$ & $251.0 \pm 45.7$ & $253.2 \pm 33.7$ \\
& L-Name & $267.7 \pm 36.2$ & $92.2 \pm 10.3 *, \#$ & $32.6 \pm 8.7 \#$ & $44.6 \pm 7.6 *, \#$ & $92.9 \pm 15.7 *, \#$ \\
\hline fetal body & Control & $321.9 \pm 38.4$ & $211.3 \pm 32.5 \#$ & $113.9 \pm 14.6 \#$ & $209.1 \pm 35.7$ & $268.4 \pm 46.7$ \\
& L-Name & $334.4 \pm 33.2$ & $126.7 \pm 13.4 \#$ & $45.8 \pm 6.7 \#$ & $64.6 \pm 5.6 *, \#$ & $118.4 \pm 20.9 *, \#$ \\
\hline \multirow{2}{*}{ placenta } & Control & $45.6 \pm 4.0$ & $47.3 \pm 3.6$ & $44.7 \pm 7.4$ & $54.6 \pm 4.6$ & $48.5 \pm 4.5$ \\
& L-Name & $44.5 \pm 2.8$ & $42.1 \pm 3.4$ & $41.6 \pm 6.6$ & $40.8 \pm 4.6 *$ & $44.0 \pm 3.6$ \\
\hline fetal body & Control & $54.4 \pm 4.1$ & $52.7 \pm 3.6$ & $55.3 \pm 7.4$ & $45.4 \pm 4.6$ & $51.5 \pm 4.5$ \\
& L-Name & $55.5 \pm 2.8$ & $57.9 \pm 3.4$ & $58.4 \pm 6.6$ & $59.2 \pm 4.6 *$ & $56.0 \pm 3.6$ \\
\hline
\end{tabular}

CVO Combined Ventricular Output

Values are given as means \pm standard error.

$* P<0.05$, significant between groups at the same timepoint.

$\# P<0.05$, significant versus control at timepoint $t-75$ within group. 
Table 3. Organ blood flows in control $(n=6)$ and L-NAME treated $(n=7)$ premature sheep

\begin{tabular}{|c|c|c|c|c|c|c|}
\hline \multicolumn{7}{|c|}{ blood flow (ml/min/100 gr) } \\
\hline & & \multicolumn{2}{|c|}{ control } & \multirow{2}{*}{$\frac{\text { occlusion }}{2}$} & \multicolumn{2}{|c|}{ recovery } \\
\hline & & -75 & -1 & & 4 & 30 \\
\hline \multirow[t]{2}{*}{ heart } & Control & $418.2 \pm 75.0$ & $293.8 \pm 70.1$ & $632.1 \pm 16.8 \#$ & $672.2 \pm 72.4 \#$ & $530.2 \pm 53.2$ \\
\hline & L-Name & $438.0 \pm 45.0$ & $245.6 \pm 22.7 \#$ & $528.2 \pm 33.3$ & $268.3 \pm 23.4 *$ & $316.2 \pm 25.0 *$ \\
\hline \multirow[t]{2}{*}{ brain } & Control & $167.3 \pm 50.5$ & $93.7 \pm 21.1$ & $145.9 \pm 30.1$ & $237.6 \pm 37.4$ & $152.4 \pm 31.9$ \\
\hline & L-Name & $223.1 \pm 26.9$ & $101.6 \pm 19.4 \#$ & $123.6 \pm 21.3 \#$ & $158.4 \pm 23.6 \#$ & $154.3 \pm 14.5 \#$ \\
\hline \multirow[t]{2}{*}{ cerebrum } & Control & $118.6 \pm 25.8$ & $61.8 \pm 3.6 \#$ & $97.6 \pm 15.8$ & $178.1 \pm 31.1 \#$ & $110.2 \pm 21.6$ \\
\hline & L-Name & $132.5 \pm 18.3$ & $00.0 \pm 11.0 \pi$ & $54.7 \pm 12.5 \#$ & $85.4 \pm 15.4 *$ *\# & $83.8 \pm 11.7 \#$ \\
\hline \multirow[t]{2}{*}{ brainstem } & Control & $260.6 \pm 58.7$ & $157.8 \pm 36.7$ & $288.3 \pm 41.0$ & $386.5 \pm 30.3 \#$ & $244.0 \pm 51.7$ \\
\hline & L-Name & $311.4 \pm 37.0$ & $147.1 \pm 27.6 \#$ & $211.0 \pm 30.5$ & $212.6 \pm 37.6 *$ & $193.3 \pm 38.9 \#$ \\
\hline \multirow[t]{2}{*}{ nucl caudatus } & Control & $152.5 \pm 40.0$ & $81.1 \pm 12.2 \#$ & $109.0 \pm 16.9$ & $166.5 \pm 18.3$ & $139.9 \pm 28.7$ \\
\hline & L-Name & $163.5 \pm 19.4$ & $72.8 \pm 14.5 \#$ & $77.2 \pm 18.0 \#$ & $86.2 \pm 14.7 *$ *\# & $112.6 \pm 16.6$ \\
\hline \multirow[t]{2}{*}{ cerebellum } & Control & $228.1 \pm 52.6$ & $118.3 \pm 18.6 \#$ & $169.9 \pm 28.0$ & $279.5 \pm 39.0$ & $213.0 \pm 47.0$ \\
\hline & L-Name & $220.0 \pm 27.1$ & $92.6 \pm 18.3 \#$ & $102.2 \pm 23.1$ \# & $142.5 \pm 24.0$ & $134.5 \pm 21.2 \#$ \\
\hline \multirow[t]{2}{*}{ hippocampus } & Control & $143.1 \pm 31.3$ & $78.1 \pm 8.8 \#$ & $141.4 \pm 16.8$ & $220.2 \pm 33.0 \#$ & $154.0 \pm 32.4$ \\
\hline & L-Name & $189.0 \pm 22.9$ & $91.3 \pm 18.5 \#$ & $119.0 \pm 24.3 \#$ & $133.3 \pm 25.7 *$ & $122.6 \pm 18.5 \#$ \\
\hline \multirow[t]{2}{*}{ (hypo)thalamus } & Control & $195.8 \pm 44.7$ & $100.8 \pm 10.8$ \# & $192.5 \pm 28.4$ & $343.8 \pm 65.6 \#$ & $233.3 \pm 50.6$ \\
\hline & L-Name & $237.8 \pm 27.9$ & $112.9 \pm 21.0$ \# & $145.9 \pm 24.1$ \# & $173.1 \pm 30.0 *$ & $180.8 \pm 14.3$ \\
\hline \multirow[t]{2}{*}{ pons } & Control & $322.7 \pm 76.0$ & $160.1 \pm 17.8 \#$ & $380.3 \pm 52.7$ & $527.0 \pm 66.9 \#$ & $344.9 \pm 78.9$ \\
\hline & L-Name & $388.2 \pm 48.0$ & $178.7 \pm 33.4$ \# & $296.8 \pm 41.3$ & $277.4 \pm 52.5 *$ & $249.9 \pm 41.9 \#$ \\
\hline
\end{tabular}


Table 3 continued

\begin{tabular}{|ccccccc|}
\hline & & \multicolumn{2}{c}{ normoxia } & occlusion & \multicolumn{2}{c|}{ recovery } \\
\hline & & -75 & -1 & 2 & 4 & 30 \\
\hline adrenal & Control & $477.6 \pm 100.8$ & $347.5 \pm 84.5$ & $605.6 \pm 145.9$ & $1016.6 \pm 255.3$ & $597.3 \pm 142.8$ \\
& L-Name & $441.3 \pm 96.0$ & $192.0 \pm 28.0$ & $198.4 \pm 54.2$ & $215.9 \pm 29.5 *$ & $451.2 \pm 52.2$ \\
\hline kidney & Control & $162.5 \pm 20.4$ & $141.3 \pm 17.9$ & $21.1 \pm 9.2 \#$ & $101.5 \pm 30.0 \#$ & $195.7 \pm 28.9$ \\
& L-Name & $215.3 \pm 23.2$ & $115.7 \pm 9.7 \#$ & $18.7 \pm 7.1 \#$ & $50.3 \pm 5.9 \#$ & $146.7 \pm 21.8$ \\
\hline gastro-intestinal & Control & $71.1 \pm 22.5$ & $61.1 \pm 11.1$ & $6.1 \pm 2.0 \#$ & $56.7 \pm 17.1$ & $71.5 \pm 18.7$ \\
& L-Name & $60.1 \pm 5.6$ & $21.3 \pm 1.9 *$,\# & $6.5 \pm 1.0 \#$ & $10.0 \pm 8.0 *$,\# & $19.9 \pm 3.4$ \\
\hline liver & Control & $4.4 \pm 0.6$ & $3.4 \pm 0.5$ & $1.7 \pm 0.4$ & $2.5 \pm 0.4$ & $3.3 \pm 0.7$ \\
& L-Name & $5.5 \pm 0.7$ & $2.5 \pm 0.3$ & $1.4 \pm 0.6$ & $0.5 \pm 0.2$ & $2.3 \pm 1.0$ \\
\hline muscle & Control & $29.5 \pm 6.6$ & $14.5 \pm 1.9 \#$ & $5.5 \pm 4.0 \#$ & $10.0 \pm 4.2 \#$ & $18.5 \pm 2.6 *, \#$ \\
& L-Name & $32.7 \pm 6.1$ & $11.6 \pm 1.6 \#$ & $1.1 \pm 0.4 \#$ & $1.5 \pm 0.3 \#$ & $7.3 \pm 2.2 \#$ \\
\hline spleen & Control & $332.3 \pm 62.0$ & $218.1 \pm 58.0$ & $11.1 \pm 5.0 \#$ & $74.3 \pm 14.2 \#$ & $240.9 \pm 65.8$ \\
& L-Name & $385.3 \pm 62.0$ & $230.7 \pm 38.8 \#$ & $2.9 \pm 0.8 \#$ & $18.0 \pm 4.3 \#$ & $147.5 \pm 48.8$ \\
\hline carcass & Control & $37.2 \pm 5.9$ & $17.0 \pm 3.5 \#$ & $6.2 \pm 2.5 \#$ & $10.9 \pm 1.0 \#$ & $23.9 \pm 3.9 \#$ \\
& L-Name & $38.5 \pm 3.8$ & $13.9 \pm 1.5 \#$ & $1.9 \pm 0.6 \#$ & $4.9 \pm 0.6 \#$ & $12.0 \pm 2.5 *$ \# \\
& & & & & & \\
\hline
\end{tabular}

Values are given as means \pm standard error.

$\# P<0.05$, significant versus control at timepoint $t-75$ within group.

$P<0.05$, significant between groups at the same timepoint. 
Figure 1. Mean Arterial Pressure

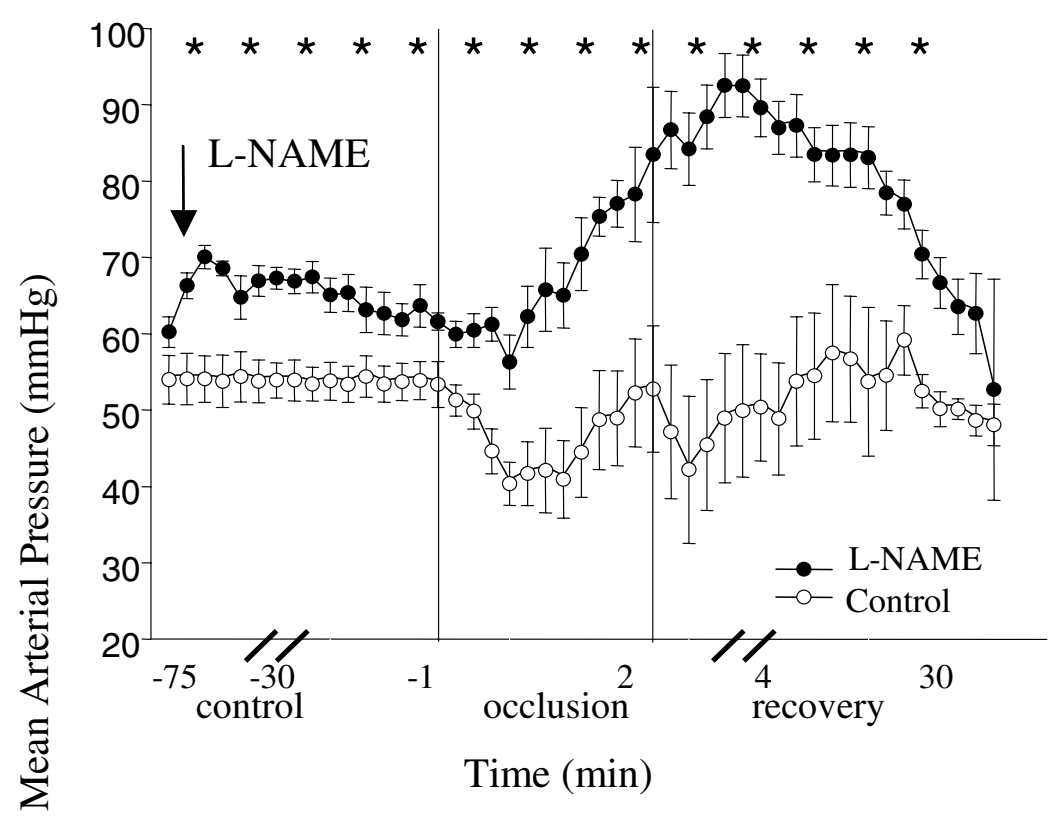

Figure 2. Fetal Heart Rate

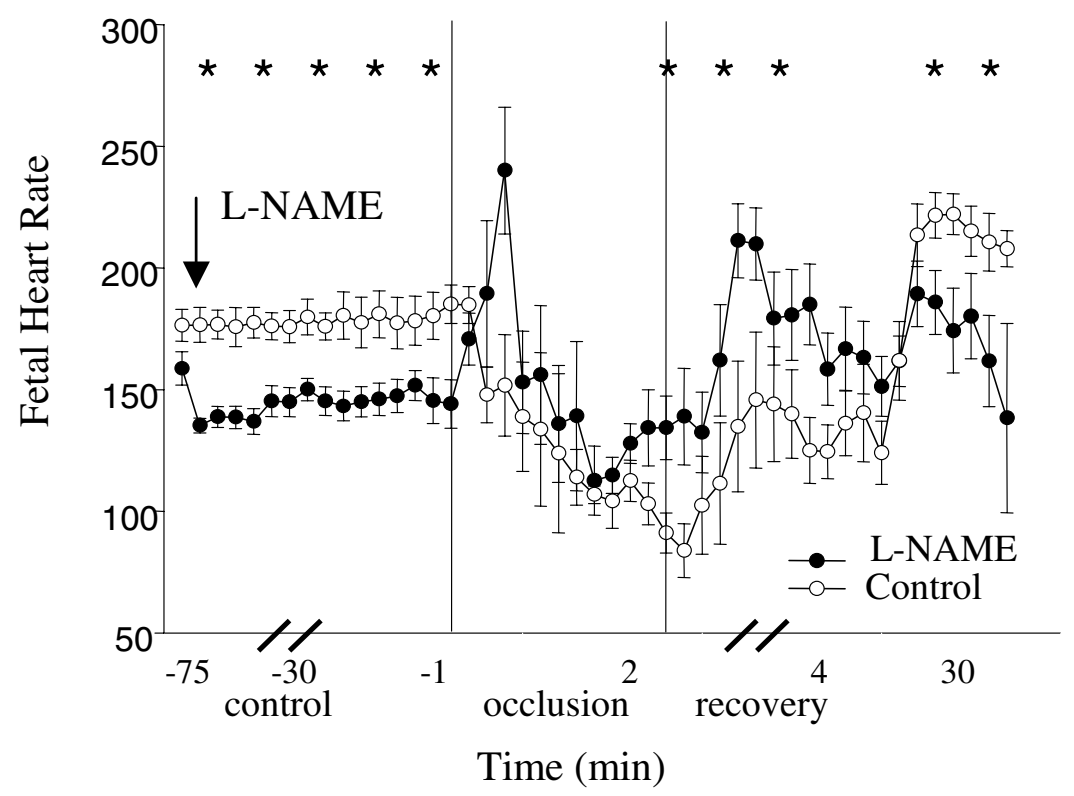

Figure 1: Mean Arterial Pressure

Figure 2: Fetal Heart Rate

Changes in mean arterial pressure and fetal heart rate in control $(n=6)$ and $L-N A M E$ treated $(n=7) 0.75$ gestation sheep before, during and after acute hypoxia.

* $P<0.05$ between the groups at the various timepoints

Changes within groups are not depicted. 


\section{Blood flow}

\section{Cardiac Output}

A decrease in cardiac output by $32 \%$ occurred in the control group during the control period, which was as a consequence reflected in organ blood flows (table 2 and 3). In the control group, hypoxia caused a severe fall in cardiac output followed by a full recovery thereafter. In the LNAME group, L-NAME injection reduced cardiac output by $64 \%$ during normoxia. In contrast to controls cardiac output remained low in fetuses of the L-NAME group throughout the entire recovery period (Table 2).

\section{Placenta}

As with cardiac output, placental blood flow declined by $66 \%$ after L-NAME injection (-1 min) and dropped to $12 \%$ of the control value at the nadir of hypoxia (+ $2 \mathrm{~min}$ ) (Table 2$)$. In the LNAME group, blood flow increased only partially after occlusion and was significantly lower during the recovery period ( $+4 \mathrm{~min}$ and $+30 \mathrm{~min})$. As compared to untreated fetuses, the resistance in the placental circulation at the maximum of hypoxia (+2 $\mathrm{min}$ ) was significantly higher while the percentage of cardiac output distributed to the placenta during the immediate recovery period (+4 min) was lower (Table 2$)$.

\section{Fetal body}

Blood flow to the fetal body decreased in both groups and although this decrease was more pronounced in the L-NAME group this was not significantly different from the decrease in the control group (+2 min), but the rise in blood flow thereafter was much lower in the L-NAME group ( $+4 \mathrm{~min}$ and $+30 \mathrm{~min}$ ) (Table 2 ). Shortly after hypoxia the percentage of cardiac output distributed to the fetal body was higher after L-NAME infusion (Table 2). 


\section{Blood flow to various organs}

\section{Heart}

In both groups, cardiac blood flow rose during aorta occlusion. However, shortly thereafter, blood flow to the heart fell again in the L-NAME treated fetuses and remained low until the end of the experiments $(+30 \mathrm{~min})$ (Table 3$)$.

\section{Brain}

Blood flow to the brain decreased by $55 \%$ after L-NAME administration. Shortly after hypoxia (+4 $\mathrm{min})$, the rise in cerebral blood flow was more pronounced in the control group (Table 3 ). As with blood flow to the brain oxygen delivery fell to very low levels during aortic occlusion and did not recover completely (Figure 3). In deeper parts of the brain the changes in blood flow resembled those seen in the cerebrum, with almost only a minor increase in blood flow after occlusion in the L-NAME group in comparison to controls (Table 3). 
Figure 3. Oxygen delivery to the brain

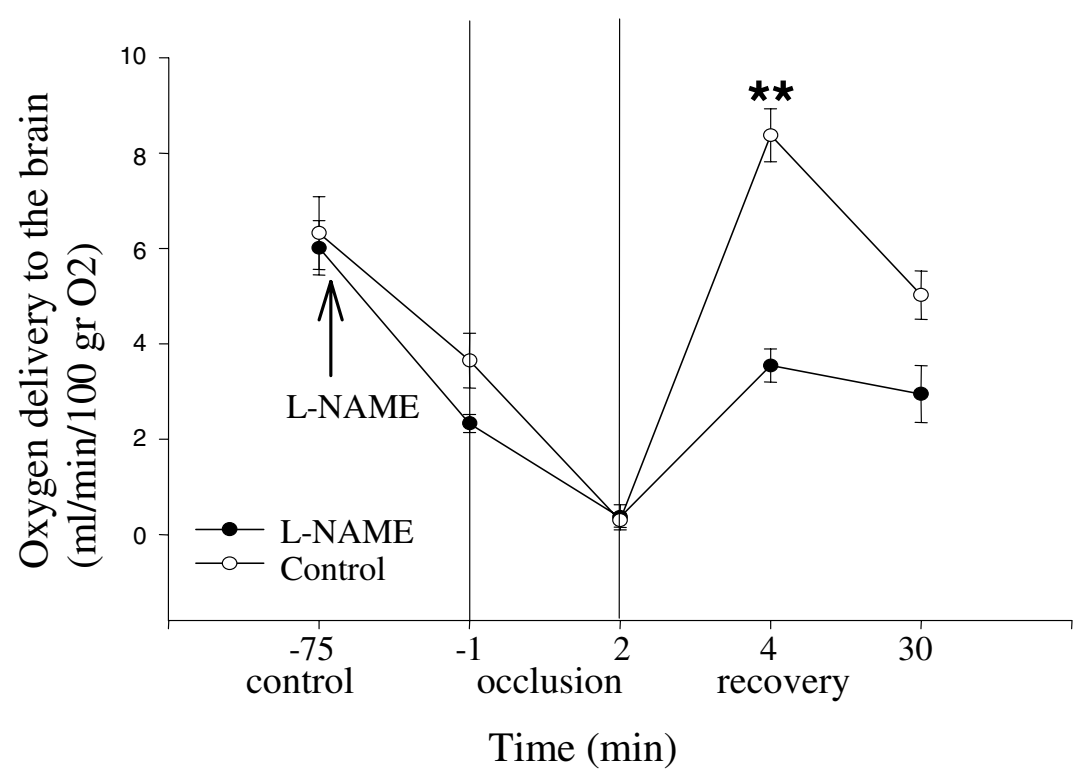

Figure 3. Oxygen delivery to the brain

Oxygen delivery to the brain $\left(\mathrm{ml} \mathrm{O}_{2}\right.$ /minute $\left.\times 100 \mathrm{~g}\right)$ in control $(n=6)$ and L-NAME treated $(n=7)$ immature fetal sheep before, during and after acute hypoxia.

** $P<0.001$ between the groups at timepoint $t+4$. 
Table 4. \% Cardiac output in control $(n=6)$ and L-NAME $(n=7)$ treated premature fetal sheep.

\begin{tabular}{|ccccccc|}
\hline & & \multicolumn{2}{c}{ normoxia } & occlusion & \multicolumn{2}{c|}{ recovery } \\
\hline & & -75 & -1 & 2 & 4 & 30 \\
\hline heart & Control & $4.3 \pm 0.6$ & $7.2 \pm 3.2$ & $23.7 \pm 5.0 \#$ & $10.6 \pm 1.5 \#$ & $6.5 \pm 0.4$ \\
& L-Name & $2.9 \pm 0.4$ & $4.4 \pm 0.4$ & $28.0 \pm 2.8 \#$ & $9.8 \pm 1.1 \#$ & $6.5 \pm 1.1$ \\
\hline brain & Control & $3.8 \pm 0.6$ & $3.7 \pm 0.3$ & $14.7 \pm 3.3 \#$ & $10.1 \pm 2.6 \#$ & $4.9 \pm 0.9$ \\
& L-Name & $2.7 \pm 0.3$ & $3.7 \pm 0.6$ & $12.2 \pm 2.3 \#$ & $12.8 \pm 3.4 \#$ & $5.8 \pm 2.0$ \\
\hline cerebrum & Control & $2.1 \pm 0.5$ & $2.2 \pm 0.3$ & $6.6 \pm 1.9 \#$ & $5.9 \pm 1.8 \#$ & $2.5 \pm 0.7$ \\
& L-Name & $0.6 \pm 0.1$ & $0.6 \pm 0.1$ & $1.8 \pm 0.5 *$ & $2.0 \pm 0.6 *$ & $1.2 \pm 0.4$ \\
\hline brainstem & Control & $1.6 \pm 0.6$ & $1.0 \pm 0.1$ & $5.2 \pm 1.0 \#$ & $2.9 \pm 0.5$ & $1.2 \pm 0.4$ \\
& L-Name & $1.4 \pm 0.2$ & $1.7 \pm 0.3$ & $7.5 \pm 1.4 \#$ & $7.1 \pm 1.7 *$ \# & $3.5 \pm 1.2$ \\
\hline adrenal & Control & $0.2 \pm 0.0$ & $0.2 \pm 0.1$ & $0.8 \pm 0.2 \#$ & $0.5 \pm 0.2$ & $0.2 \pm 0.1$ \\
& L-Name & $0.1 \pm 0.0$ & $0.2 \pm 0.0$ & $0.5 \pm 0.1$ & $0.4 \pm 0.1$ & $0.5 \pm 0.1$ \\
\hline carcass & Control & $37.5 \pm 3.3$ & $31.8 \pm 4.3$ & $16.7 \pm 2.4 \#$ & $16.9 \pm 3.1 \#$ & $29.9 \pm 3.4$ \\
& L-Name & $46.2 \pm 2.1$ & $45.6 \pm 2.8 *$ & $17.0 \pm 4.3 \#$ & $32.7 \pm 4.0 *$ *\# & $39.5 \pm 2.3$ \\
\hline
\end{tabular}

Values are given as means \pm standard error.

$\# P<0.05$, significant versus control at timepoint $t-75$ within group

$P<0.05$, significant between groups at the same timepoint.

\section{Adrenal}

Blood flow to the adrenals decreased by $57 \%$ immediately after L-NAME injection and remained low compared to the control group where there was an increase in blood flow during and after aorta occlusion (+2 and $+4 \mathrm{~min})$ (Table 3$)$.

\section{Carcass}

During hypoxia, changes in blood flow to the carcass were very similar in the two groups. In the L-NAME group the increase in percentage cardiac output during the recovery period was less than that measured in the control group. 


\section{Comments}

$\mathrm{NO}$ is known to be a potent mediator in the regulation of resting tone in cerebral, renal, mesenteric and hindquarter vascular beds and hence in blood pressure homeostasis in adults $(19,20)$. There is also some suggestion that NO contributes to cardiovascular control during hypoxia in adults and 0.75 gestation sheep $(19,14,20)$. NO might mediate the fetal circulatory centralization that occurs during partial cord occlusion (21). There is also evidence that NO regulates the rise in fetal cerebral blood flow and fall in carotid vascular resistance seen during hypoxia (14). Nevertheless, the impact of NO on fetal cardiovascular control is only partially understood and especially in 0.75 gestation fetuses, there is significant lack of data on NOmediated blood flow regulation. There are no data concerning the impact of NO on the regional blood flow distribution using radioactive microspheres. Also, blood flow changes in a chronic sheep model using acute hypoxia, are not yet studied. We therefore examined the distribution of cardiac output in 0.75 gestation sheep during normoxia and acute hypoxia studying a large amount of organs. NOS was inhibited using nitro-L-arginine methyl ester (L-NAME).

The amount of hypoxia was quite severe since oxygen content fell almost to zero at the bottom of hypoxia but also recovered quickly during recovery period. Since none of the control animals became acidemic the hypoxic period was not too extreme. Intravenous application of L-NAME to 0.75 gestation fetal sheep resulted in bradycardia, hypertension and a significant fall in combined cardiac output. Blood flow to the fetal body and placenta decreased by more than 60 $\%$. During acute hypoxia, L-NAME did not change the redistribution of cardiac output towards the central organs. However, the control of fetal heart rate and blood pressure was altered in the L-NAME group. After hypoxia L-NAME delayed the recovery of cardiac output and blunted the increase in blood flow to the brain and heart. NO, therefore, seems to play a role in fetal cardiovascular control during normoxia and acute hypoxia. An alternative explanation for part of the observed changes might be a direct action of NO on the heart itself. 
The rise in MAP after L-NAME injection was most likely caused by systemic and umbilicoplacental vasoconstriction due to inhibition of NOS. The simultaneous fall in fetal heart rate that seems to result from baroreflex activation associated with an increased vagotonus exerting a direct effect on the sino-atrial node (22). In addition, inhibition of NOS was also accompanied by a transient rise in hemoglobin concentration. Since no significant release of erythrocytes occurs from storage sites such as the spleen in chronically instrumented fetal sheep (23), the most plausible explanation for this finding is a reduction in plasma volume associated with a fluid shift from intravascular to extravascular compartments. One factor that presumably contributed to such a fluid shift is the high permeability of fetal capillaries, which predisposes to transudation of fluid across the capillary membrane with increases in hydrostatic pressure (24). In line with this proposal, increases in hemoglobin concentration accompanied by falls in fetal blood volume have been reported after elevation of fetal blood pressure following infusion of vasoconstrictor compounds such as norepinephrine, epinephrine and angiotensin II $(25,26)$.

The observed changes in MAP, FHR, and hemoglobin concentration that were found to accompany inhibition of NOS are particularly relevant, since increases in MAP $(27,28)$, reductions in FHR (29), hemoconcentration (30), and fall in circulating blood volume (31) all reduce fetal cardiac output. It is therefore likely that these alterations contribute to the fall in combined ventricular output evident with inhibition of NOS (15). The fall in fetal cardiac output in 0.75 gestation sheep after blockade of NOS seems to be much more pronounced than in term fetal sheep.

During acute hypoxia redistribution of cardiac output towards the central organs was not influenced by L-NAME suggesting that chemoreflex mechanisms remained intact. The observation that MAP rose significantly in the L-NAME group suggests that the activity of vasoconstrictive mechanisms during acute hypoxia in 0.75 gestation sheep is counteracted by 
NO under normal circumstances. This is also true for the immediate recovery period.

Furthermore, L-NAME seems to inhibit baroreflex activation during acute hypoxia, since the rise in MAP was not accompanied by a fall in FHR in the L-NAME group. This observation concurs with a previous report showing that the sensitivity of the baroreflex is reduced by NOS inhibition (28) in the rat.

During the immediate recovery period, the increase in blood flow to the heart and brain was blunted in the L-NAME group suggesting that in the vascular bed of these organs hypoxiainduced hyperperfusion is mediated via activation of NOS. This observation ties in with previous studies showing that NOS inhibition attenuated the delayed rise in brain blood volume after cerebral ischemia (31). Van Bel and co-workers (32) described that NO mediates resting tone in the fetal cerebral vascular bed and is required for hypoxia-induced vasodilation. Recent work by Blood et al show that adenosine can account for virtually all of cerebral blood flow increases during acute hypoxia in near-term fetal sheep (33).

Faraci and colleagues (34) reported how NO influences the resting tone of vessels but that the effect was greater in larger vessels. In the present study regional differences in vascular control within the brain could not be detected after L-NAME application. The hypoxia-induced activation of NOS seems therefore to be quite uniform throughout the cerebral circulation.

L-NAME attenuated the postasphyxic rebound tachycardia observed in the control group. The absence of rebound tachycardia has been described earlier (14). This effect might be attributed to a possible reduction in catecholamine release from adrenals during acute hypoxia in connection with the abolished increase in adrenal blood flow after L-NAME. In addition, application of L-NAME could have inhibited NO mediated heart rate responses to adrenaline (19). 
102 Chapter 4

The recovery of cardiac output after hypoxia was considerably delayed in the L-NAME group. Placental hypoperfusion was followed by progressive fetal deterioration resulting in hypoxemia and acidemia.

The decrease in cardiac output in the control group before hypoxia is significant, and this decrease in cardiac output during control measurements is then reflected in nearly all other organ blood flow measurements. A number of shortcomings, which are difficult to control for in such a complicated model, may be responsible for this effect. Firstly, fetal stress may occur from handling during repeated flushing of vascular catheters, sampling and blood withdrawal and infusion. Secondly, the three-day post surgical period may have been too short for the fetuses to recover and be stable. Thirdly, the impact of extensive fetal instrumentation with arterial and venous catheters in fore and hindlimbs, a prerequisite for complete fetal organ blood flow measurements, may have caused perturbation of the physiological status, as damage in downstream tissues will occur and release of cytokines and vasoactive substances ensues (35), especially as catheterisation in smaller peripheral vessels is limited with younger gestational age and smaller fetuses. Furthermore, one cannot rule out chance happenings as may occur with the microsphere technique. This potential bias appears to be unavoidable in this model as we have observed this untoward effect also in earlier studies with the same experimental setup (36). The results are therefore to be interpreted in view of these premises.

Despite these limitations the current study documents the essential role of NO in the fetal circulation both during normoxia and acute hypoxia in the preterm sheep.

In conclusion, inhibition of NOS causes fetal bradycardia and transient hypertension. This is accompanied by a severe fall in combined cardiac output without any considerable redistribution of blood flow. During acute hypoxia application of L-NAME does not alter fetal circulatory centralisation, but it prevents baroreflex-induced bradycardia. Activation of NOS seems to mediate the hypoxia-induced rise in blood flow to the heart and brain. The recovery of cardiac output after acute hypoxia is considerably delayed by application of L-NAME and associated 
with progressive fetal deterioration. These results indicate that NO plays a role in maintaining organ and placental perfusion and regulating vascular tone during both normoxia and hypoxia in preterm sheep.

\section{Acknowledgements:}

We would like to thank May Bost, Joyce Suyk and Jan Geilen for the excellent technical assistance and Frans Slangen and Monique de Jong for animal care. 


\section{References:}

1. Levene MI, Kornberg J, Williams THC. The incidence and severity of post asphyxial encephalopathy in fullterm infants. Early Hum Dev 1985;11:21-28.

2. Giussani DA, Spencer JAD, Hanson MA. Fetal cardiovascular reflex responses to hypoxaemia. Fet Matern Med Rev 1994;6:17-37.

3. Sheldon RE, Peeters LL, Jones MD Jr, Makowski EL, Meschia G. Redistribution of cardiac output and oxygen delivery in the hypoxemic fetal lamb. Am J Obstet Gynecol 1979:15;135(8):1071-1078.

4. Peeters LLH, Sheldon RE, Jones Jr MD, Makowski EL, Meschia G. Blood flow to fetal organs as a function of arterial oxygen content. Am J Obstet and Gynecol 1979;135: 637646.

5. Jensen A, Berger R. Fetal circulatory responses to oxygen lack. J Dev Physiol 1991:16:181207.

6. Ovadia B, Bekker JM, Fitzgerald RK, et al. Nitric oxide-endothelin-1 interactions after acute ductal constriction in fetal lambs. Am J Physiol Heart Circ Physiol 2002;282(3):H862-71.

7. Nathan C. Nitric oxide as a secretory product of mammalian cells. FASEB J 1992;6:30513064.

8. Bolaños JP, Almeida A, Medina JM. Nitric oxide mediates brain mitochondrial damage during perinatal anoxia. Brain Res 1998;787:117-122.

9. Bredt DS, Hwang PM, Snyder SH. Localisation of nitric oxide synthase indicating a neural role for nitric oxide. Nature 1990;347:768-770.

10. Marletta MA, Yoon PS, Iyengar R, Leaf CD, Wishnok JS. Macrophage oxidation of Larginine to nitrite and nitrate: nitric oxide is an intermediate. Biochem 1988;27:8706-8711.

11. Beasley D. Interleukin 1 and endotoxin activate soluble guanylate cyclase in vascular smooth muscle. Am J Physiol 1990;259: R38-R44.

12. Nozaki K, Moskowitz MA, Maynard KI, et al. Possible origins and distribution of immunoreactive nitric oxide synthase-containing nerve fibers in cerebral arteries. J Cerebr Blood Flow Metab 1993;13: 70-79.

13. Wood KS, Buga GM, Byrns RE, Ignarro LJ. Vascular smooth muscle-derived relaxing factor (MDRF) and its close similarity to nitric oxide. Biochem Biophys Res Comm 1990;170: 80-88.

14. Green LR, Bennet L, Hanson MA. The role of nitric oxide synthesis in cardiovascular responses to acute hypoxia in the late gestation sheep fetus. J Physiol 1996;497(1):271-277. 
15. Smolich JJ. 1998 NO modulates fetoplacental blood flow distribution and whole body oxygen extraction in fetal sheep. Am J Physiol 1998;274: R1331-R1337.

16. Chlorakos A, Langille BL, Adamson SL. Cardiovascular responses attenuate with repeated NO synthesis inhibition in conscious fetal sheep. Am J Physiol 1998; 274: H1472-H1480.

17. Heymann MA, Payne BD, Hoffman JIE, Rudolph AM. Blood flow measurements with radionuclide-labeled particles. Progr Cardiovasc Dis 1977;20;55-79.

18. Rudolph AM, Heymann MA. Circulation of the fetus in utero: Methods for studying distribution of blood flow, cardiac output and organ blood flow. Circ Res 1967;21;163-184.

19. Gardiner SM, Compton AM, Bennet T, Palmer RMJ, Moncada S. Control of regional blood flow by endothelium derived nitric oxide. Hypertension 1990;15:486-492.

20. Iadecola C, Pelligrino DA, Moscowitz MA, Lassen NA. Nitric oxide synthase inhibition and cerebrovascular regulation. J Cereb Blood Flow Metab 1994;14:175-192.

21. Santos AC, Yun EM, Bobby PD, Noble G, Arthur GR, Finster M. The effects of bupivacaine, L-nitro-L-arginine-methyl ester, and phenylephrine on cardiovascular adaptations to asphyxia in the preterm fetal lamb. Anesth Analg 1997;85:1299-1306.

22. Fernandez N, Garcia JL, Garcia Villalon AL, Monge L Gomez B, Dieguez G. Cerebral blood flow and cerebral vascular reactivity after inhibition of nitric oxide synthesis in conscious goats. Br J Pharmacol 1993;110:428-434.

23. Brace RA. Blood volume and its measurement in the chronically catheterized sheep fetus. Am J Physiol 1983;244(4):H487-94.

24. Brace RA, Gold PS. Fetal whole-body interstitial compliance, vascular compliance, and capillary filtration coefficient. Am J Physiol 1984;247(5 Pt 2):R800-5.

25. Cheung CY, Brace RA. Norepinephrine effects on fetal cardiovascular and endocrine systems. Am J Physiol 1988;254(4 Pt 2):H734-41.

26. Paulick RP, Meyers RL, Rudolph CD, Rudolph AM. Umbilical and hepatic venous responses to circulating vasoconstrictive hormones in fetal lamb. Am J Physiol 1991;260:H1205-H1213.

27. Gilbert RD. Control of fetal cardiac output during changes in blood volume. Am J Physiol 1980;238:H80-H86.

28. Scrogin KE, Veelken R, Luft FC. Sympathetic baroreceptor responses after chronic $\mathrm{N}^{\mathrm{G}}$ nitro-L-arginine methyl esther treatment in conscious rats. Hypertension 1994;23:982-986.

29. Rudolph AM. Distribution and regulation of blood flow in the fetal and neonatal lamb. Circ Res 1985;57:811-821. 
30. Fumia, FD, Edelstone DI, Holzman IR. Blood flow and oxygen delivery to fetal organs as a function of hematocrit. Am J Obstet Gynecol 1984; 150:274-282.

31. Marks KA, Mallard CE, Roberts I, Williams CE, Gluckman PD, Edwards AD. Nitric Oxide synthase inhibition attenuates delayed vasodilation and increases injury after cerebral ischemia in fetal sheep. Ped Res 1996;40(2):185-191.

32. Van Bel F, Sola A, Roman C, Rudolph AM. Role of nitric oxide in the regulation af the cerebral circulation in the lamb fetus during normoxemia and hypoxemia. Biol Neonate 1995;68:200-210.

33. Blood AB, Hunter CJ, Power GG. The role of adenosine in regulation of cerebral blood flow during hypoxia in the near-term fetal sheep. J Physiol 2002;15:543:1015-23.

34. Faraci FM. Role of endothelium-derived relaxing factor in cerebral circulation. Am J Physiol 1991;261:H1038-H1042.

35. Foex BA. Systemic responses to trauma. Br Med Bull 1999;55(4):726-743.

36. Garnier Y, Coumans A, Berger R, Jensen A, Hasaart THM. Endotoxemia severely affects circulation during normoxia and asphyxia in immature fetal sheep. J Soc Gynecol Investig 2001;8:134-142 


\section{Chapter 5}

The role of nitric oxide in fetal organ blood flow distribution during normoxia and acute hypoxia in endotoxin treated preterm sheep. A.B.C. Coumans, Y. Garnier, S.Supçun, A. Jensen, R. Berger, T.H.M. Hasaart 


\section{Introduction}

Newborn encephalopathy was previously thought to be caused by birth asphyxia in the majority of cases, but studies of antenatal and intrapartum factors involved in the development of cerebral palsy have identified other etiologies such as intra uterine growth retardation, metabolic diseases, clotting disorders and infection. The causes of newborn encephalopathy are thus heterogenous and many relate to the antepartum period (1). Birth asphyxia is often preceded by antenatal infections and therefore often linked to the occurrence of brain damage (2). Combined exposure to perinatal infection and birth asphyxia dramatically increases the risk of spastic cerebral palsy (3). On the long term, other studies have shown that antenatal exposure to intraamniotic inflammation and evidence of a systemic fetal inflammatory response such as funisitis are strong and independent risk factors for the subsequent development of cerebral palsy at the age of 3 years (4).

The exact mechanism by which asphyxia and infection are linked in the development of brain damage is not yet understood. In this process, several products like LPS (lipopolysaccharides, pyrogens that are derived from cell walls of gram-negative bacteria during infection) may play a role. LPS stimulates astrocytes and microglia to produce various cytokines such as TNF- $\alpha$, IL$1 \beta$ and IL-6. Recent clinical studies have demonstrated that expression of TNF- $\alpha$, IL-1 $\beta$, and IL-6 is much higher in brains with periventricular lesions (PVL) than in those without PVL (5). The mothers of newborns with brain white matter lesions had higher concentrations of these cytokines in their amniotic fluid than did mothers delivered of newborns without white matter lesions (6).

Hypoxia/ischemia also induces an inflammatory response in the immature rodent central nervous system, characterized by the very early expression of IL-1 $\beta$ and TNF- $\alpha$ (7). The latter induces nitric oxide (NO) production in astrocytes (8).

NO, a vascular and neuronal messenger and a cytotoxic and cytostatic agent, is synthesized from L-arginine by the enzyme nitric oxide synthase (NOS) (9). In a study on the effects of LPS on 
the fetal circulation during normoxia and hypoxia, we found that endotoxemia resulted in prolonged placental hypoperfusion and reduction in oxygen delivery to the brain, which may contribute to perinatal brain damage in preterm fetal sheep. Furthermore, LPS blunted circulatory centralisation, resulting in decreased blood flow to the placenta and brain, while that to the carcass, heart, lungs and adrenals increased (10).

Our hypothesis was that LPS-induced peripheral vasodilation and the circulatory decentralisation during acute hypoxia might be NO-mediated.

Therefore, we studied the effects of LPS after blocking the NOS system using nitro-L-arginine methyl ester (L-NAME) in 0.75 gestation fetal sheep.

\section{Methods}

\section{$\underline{\text { Animal preparation }}$}

Fifteen preterm sheep were chronically instrumented at a mean gestational age of $107 \pm 1$ days (term is 147 days). All ewes underwent surgery with use of sterile techniques while they were under general anesthesia (thiopental sodium $1 \mathrm{gm} / 70 \mathrm{~kg}$ intravenously for induction, $0.5-1.0 \%$ halothane in a 1:1 nitrous oxide and oxygen mixture for maintenance). The ewes received $1 \mathrm{gm}$ ampicilline (Pentrexyl®; Bristol-Myers, Woerden, The Netherlands) s.c. and $10 \mu \mathrm{g}$ buprenorphin (Temgesic ${ }^{\circledR}$; Schering, The Netherlands) per kg body weight twice a day for three consecutive postoperative days. A midline abdominal incision was performed. A snare was placed around the maternal distal aorta below the renal artery to arrest uterine and ovarian blood flow and to induce fetal asphyxia. The fetal limbs were identified and through an incision in the uterus exteriorised. Polyvinyl catheters (Maxxim Medical BV, Den Bosch, The Netherlands) with $0.75 \mathrm{~mm}$ inner diameter and $1.25 \mathrm{~mm}$ outer diameter were inserted via a tibial fetal vein and artery of each hindleg and advanced into the caudal vena cava and abdominal aorta, respectively. Catheters were also placed into both brachial arteries. The fetal skin was closed with cyanoacrylate glue (Cyanolit, Japan). An intrauterine pressure catheter was placed, and the 
uterus was sutured after replacing the amniotic fluid with a saline solution at $39^{\circ} \mathrm{C}$. Catheters were filled with heparin (100 IU/ml; Heparin-Natrium®, Braun, Melsungen, Germany) and exteriorised through a small incision in the flank of the ewe. Catheters were protected by a pouch sewn to the skin of the ewe. A recovery period of 72 hours followed the operation before experiments were started. Ewes were housed in individual cages and had free access to food and water.

Guidelines for care and use of animals met the guidelines of the responsible governmental agencies and were approved by the Animal Medical Ethics Committee of Maastricht University.

\section{Experimental protocol}

The experiments were performed 3 days after the surgical procedure at $110 \pm 1$ days. After control measurements of blood flow and physiological variables, eight random selected fetuses were injected with a $30 \mathrm{mg}$ intravenous bolus L-NAME (t -75) (Sigma Aldrich, Zwijndrecht, The Netherlands) followed by a continuous L-NAME infusion of $6 \mathrm{mg} / \mathrm{min}$. Adequate blockade of NOS was proven by injection of $2 \mu \mathrm{g}$ acethylcholine (ACH) intravenously. Before NOS inhibition, ACH induced a decrease in MAP of $\pm 15 \mathrm{~mm} \mathrm{Hg}$ which was completely abolished with NOS inhibition. All fifteen fetuses received LPS $(51 \pm 7 \mu \mathrm{g} / \mathrm{kg})(\mathrm{t}=-60)($ E.Coli; 0127:B8, Sigma Aldrich, Zwijndrecht, The Netherlands) in the same dose as in our previous study namely $50 \mu \mathrm{g} / \mathrm{kg}$ estimated fetal weight (13). To determine the effects of L-NAME and endotoxemia on the time course of circulatory centralization before, during and after hypoxia, blood flow to fetal organs and the distribution of combined ventricular output were measured by injecting five batches of differently labeled isotope microspheres $\left({ }^{141} \mathrm{Ce},{ }^{114} \mathrm{In},{ }^{113} \mathrm{Sn},{ }^{103} \mathrm{Ru}\right.$ and ${ }^{46} \mathrm{Sc}, 16 \mu \mathrm{m}$ diameter, New England Nuclear, Boston, MA, USA) suspended in 10\% dextran containing $0.01 \%$ Tween 80 , sonicated and checked for size, shape and aggregation. Depending on the specific activity 0.7-1.8 million microspheres per batch were injected over a period of 20 
seconds before infusion of L-NAME (control, at -75), before the onset of maternal aortic occlusion (-1), at the bottom of asphyxia (+2), and after the release of the snare (recovery, at +4 and +30$)$ into the inferior vena cava $(12 ; 13)$ with $t 0$ being the start of the occlusion. In fetal lambs, 6 different injections of 0.5-2.0 × 10 $0^{6}$ microspheres of $15 \mu \mathrm{m}$ diameter, can be made without significant acute or choronic hemodynamic changes (14). Reference blood samples were withdrawn from both a carotid and a femoral artery at a rate of $1.75 \mathrm{ml} / \mathrm{min}$. Sampling was continuous for $390 \mathrm{~s}$ from -1 to +5.5 minutes. Separate samples were taken for $90 \mathrm{sec}$ at control (-75 min) and during recovery (+30 $\mathrm{min})$. The volume of blood withdrawn was replaced by maternal blood maintained at $39^{\circ} \mathrm{C}$ in a waterbath.

The experimental protocol was approved by the Animal Medical Ethics Committee of Maastricht University and met the guidelines of the responsible governmental agency.

\section{$\underline{\text { Measurements }}$}

Fetal heart rate (FHR) and mean blood pressure (MAP) were continuously recorded during the experiment on a personal computer, using a customized hemodynamic data acquisition system. Before each blood flow measurement, and additionally at -30 min, blood samples were taken from the fetal descending aorta and analysed for blood gases, acid base balance (AVL 993, Radiometer, Copenhagen, Denmark), hemoglobin concentration and arterial oxygen saturation of hemoglobin (OSM 2 Hemoximeter, Radiometer, Copenhagen, Denmark). At the same time points, glucose and lactate were measured (YSI, 2300 Statplus Analyzer/2, Yellow Springs Instruments, Ohio, United States).

After the experiment a lethal dose of sodium pentobarbitone (Euthesate $\AA$; Apharmo, Duiven, The Netherlands) was given to the ewe and the fetuses were perfused with $200 \mathrm{ml}$ formalin (10\% in saline). Fetal organs were weighed and placed in vials, which were filled to the same height to reduce variations in geometry. The intestines were separated from the mesentery, opened and cleared from contents. Paired organs (lungs, kidneys, and adrenals) were counted 
separately, as were the right and left sides of the cerebrum. Significant preferential streaming of microspheres could not be detected. Specimens of skin and muscle were taken from the hips and shoulders. Cotyledons, upper and lower carcass were homogenized by a meat chopper and the samples filled into vials.

The applied solid-state semi-conductor gamma counter (thallium activated, sodium iodine crystal) had a high energy resolution of about $2 \mathrm{keV}$ and was connected to a mulitchannel (1024) pulse height analyzer (LKB 1282, Compugamma, Wallac, Turku, Finland). The results were normalized with respect to time and sample weight.

\section{Calculations}

Fetal combined ventricular output (CVO) and blood flow to the various organs were calculated from counts of the injected nuclide recovered in fetal organs or placenta, from counts in the appropriate reference samples, and from the withdrawal rate of the reference samples $(11 ; 12)$. The percentage of combined ventricular output distributed to a given organ was calculated from the absolute blood flow to that organ and the combined ventricular output. Oxygen delivery to the various organs ([DO2];:ml O2/min/100g) was calculated according to the following formula: organ blood flow $(\mathrm{ml} / \mathrm{min} / 100 \mathrm{~g})$ x SO 2 x hemoglobin $(\mathrm{g} / \mathrm{ml})$ x $1.34(\mathrm{ml} \mathrm{O} 2 / \mathrm{g} \mathrm{Hb})$.

\section{$\underline{\text { Statistics }}$}

Results are given as means \pm SEM. The data were analysed for intra- and intergroup differences by two-way multivariate analysis of variance for repeated measures. Games-Howell-test was used as post-hoc testing procedure. Statistical analysis was performed by Super Anova Statistical Package (Abacus, Inc. Ca. USA). 


\section{Results}

Control measurements of cardiac output, organ blood flow distribution, blood gases, $\mathrm{pH}$, glucose and lactate were in the normal range for chronically prepared immature fetal sheep $(10 ; 15)$ with the same experimental set-up and showed no significant differences between the LPS group and the LPS + L-NAME group (tables 1-4).

\section{$\underline{\text { LPS Group }}$}

\section{Normoxia}

During normoxia, LPS injection severely affected fetal cardiovascular control leading to a significant decrease in oxygen saturation, arterial $\mathrm{pH}$, base excess and an increase in partial bicarbonate pressure and lactate levels (Table 1). MAP tended to decrease after LPS injection although this was not significant while FHR increased between t-30 and t-1 $(\mathrm{p}<0.001)$ (Figures 1 and 2). Administration of LPS caused a significant fall in cardiac output (-35\%). The percentage of cardiac output directed to the placenta decreased with $70 \%$ after LPS $(p<0.001)$ and in contrast the percentage cardiac output to the fetal body increased with $62 \%$ after LPS $(\mathrm{p}<0.01$ at $\mathrm{t}-1)$. After LPS administration, blood flow to the heart increased with $69 \%(\mathrm{p}<0.05$ at $\mathrm{t}-1)$ and to the adrenals with $107 \%(\mathrm{p}<0.001$ at $\mathrm{t}-1)$. The percentage cardiac output to the liver was 6 times higher $(\mathrm{p}<0.001$ at $\mathrm{t}-1)$ and to the carcass increased with $44 \%(\mathrm{p}<0.01$ at $\mathrm{t}-1)$. In various regions of the brain, such as the cerebrum, cerebellum and colliculi, blood flow did not change significantly after LPS (Table 3,4). Although blood flow to the brain was unchanged there was a significantly decreased oxygen delivery to the cerebrum after LPS $(p<0.001)$.

\section{Acute hypoxia}

Arrest of uterine blood flow for 2 minutes resulted in severe acidosis and metabolic changes (Table 1). Also a significant decrease in FHR (-38\%) and MAP (-30\%) to significant lower levels at the end of occlusion was observed. (Figures 1 and 2).

Arrest of uterine blood flow also lead to a further decrease in cardiac output $(-70 \%, \mathrm{p}<0.001)$. Placental blood flow also decreased further $(\mathrm{p}<0.001)$ during occlusion. In contrast, the 
percentage cardiac output to the fetal body increased with $76 \%$ compared to control value $(\mathrm{p}<0.001)$. The percentage of cardiac output to the heart was 5 times higher at the bottom of asphyxia compared to control values $(\mathrm{p}<0.001)$. The portion of cardiac output to the adrenals was 4.5 times higher at the bottom of the occlusion compared to control value $(\mathrm{p}<0.001$ at $\mathrm{t} 2)$. Also the percentage cardiac output to the liver increased further to 6.8 times control value during occlusion $(\mathrm{p}<0.001)$. Percentage blood flow to the carcass increased after LPS $(\mathrm{p}<0.01$ at t2). In the cerebrum, cerebellum and colliculi, flow did not change during occlusion. (Table 3,4$)$ Oxygen delivery to the cerebrum decreased further to nearly zero at the bottom of occlusion $(\mathrm{p}<0.001)$

\section{Post occlusion phase}

During the immediate recovery phase (t4) there was no improvement in the metabolic status of the LPS treated animals and mixed acidosis persisted. Cardiac output did not recover and placental blood flow remained low. Cerebral oxygen delivery remained low during the recovery phase $(\mathrm{p}<0.001)$. The prolonged hypotension in combination with bradycardia led to the death of five of seven LPS animals after timepoint t 4 unlike in the L-NAME + LPS group in which six of eight animals survived up to the end of the experiment when animals were sacrificed at $t$ 30. 


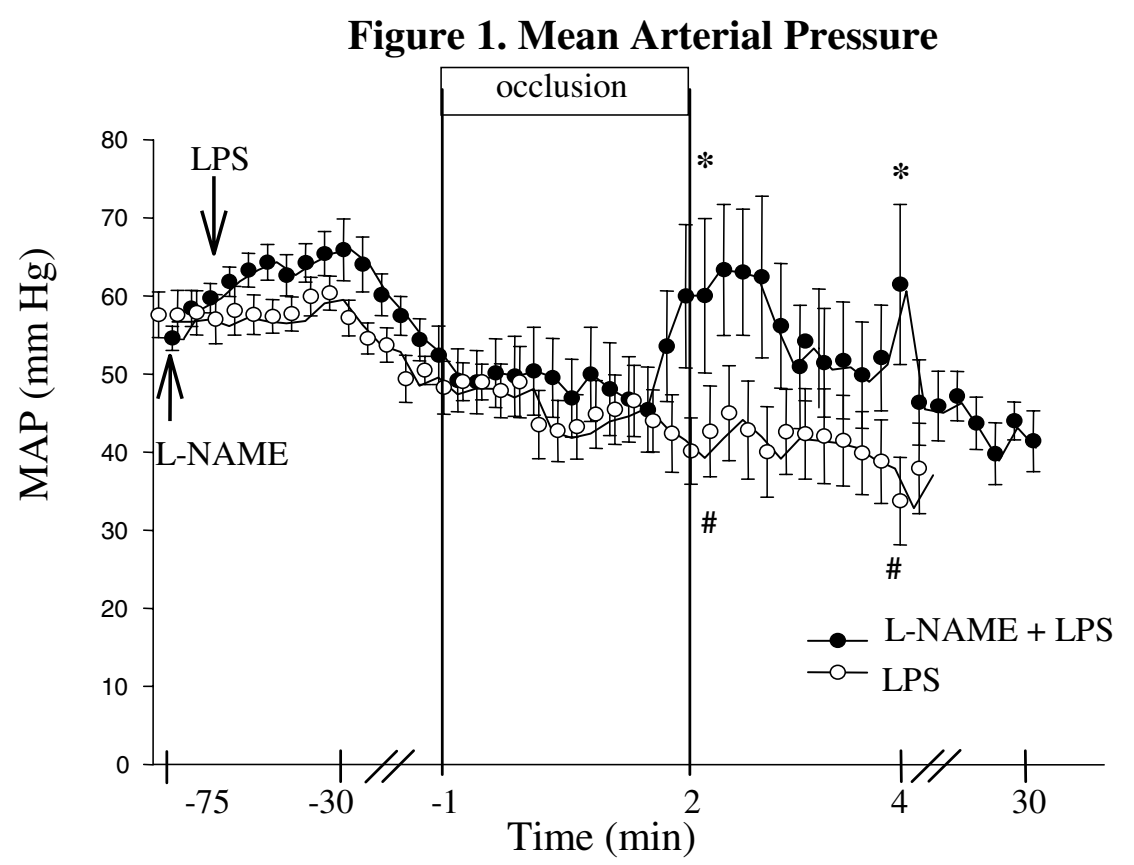

Figure 1.

Mean Arterial Pressure in LPS $(n=7)$ and L-NAME + LPS $(n=8)$ treated fetuses before, during and after hypoxia.

$* p<0.05 \quad * * p<0.001$ significance between the groups

\# $p<0.05 \quad \#$ \# $p<0.001$ significance versus control within the LPS group 
Figure 2. Fetal Heart Rate

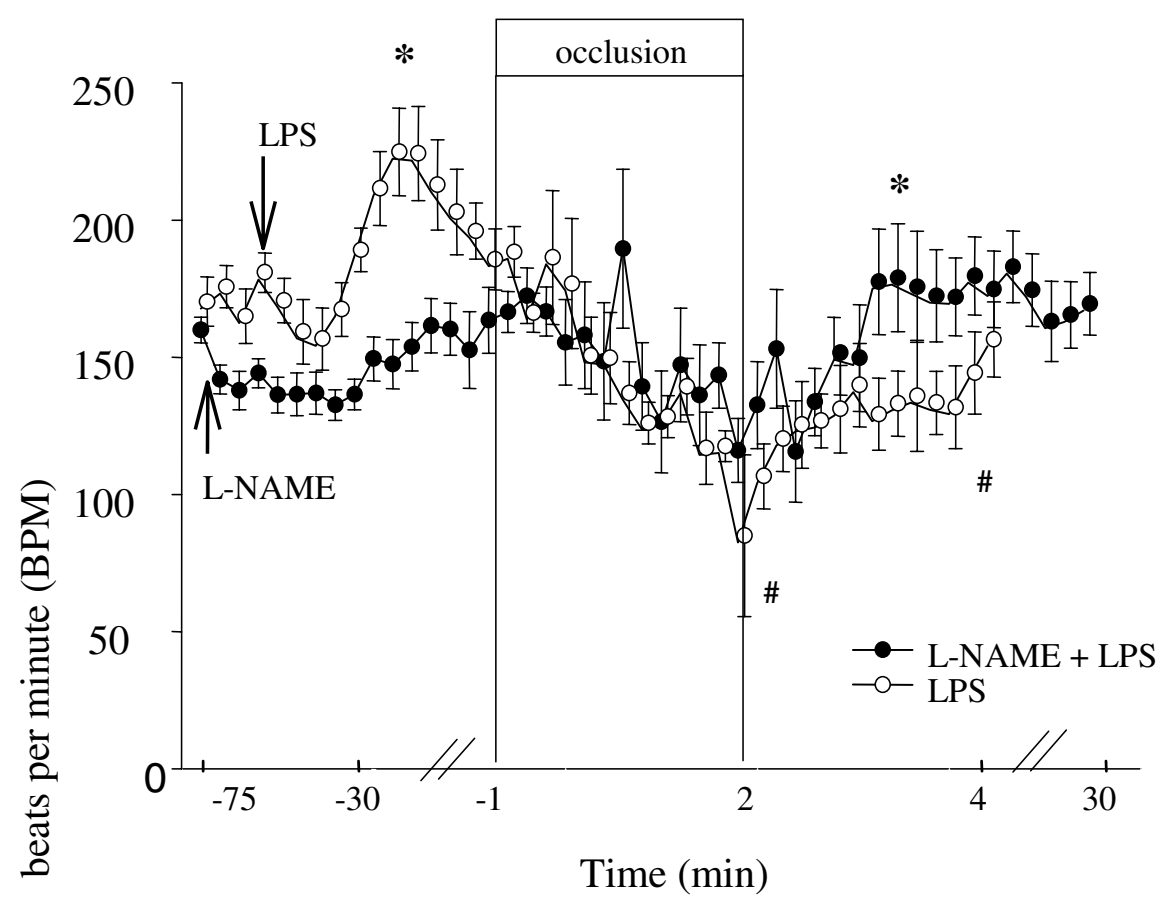

Figure 2.

Fetal heart rate in LPS $(n=7)$ and L-NAME + LPS $(n=8)$ treated fetuses before, during and after hypoxia.

$\# p<0.05 \quad \# p<0.001$ significance versus control within the LPS group

$* p<0.05 \quad * * p<0.001$ significance between the groups 


\section{$\underline{L-N A M E+L P S \text { group }}$}

\section{Normoxia}

Control values of blood gases were not different from the LPS group.

During normoxia, L-NAME injection resulted in a lower arterial $\mathrm{pH}(\mathrm{p}<0.01$ at $\mathrm{t}-1)$ and $\mathrm{BE}$ $(\mathrm{p}<0.001$ at $\mathrm{t}-1)$ in the L-NAME + LPS group than in the LPS group. Glucose concentration was higher in the L-NAME + LPS group $(\mathrm{p}<0.05$ at $\mathrm{t}-1)$. Partial bicarbonate pressure, oxygen saturation and lactate concentrations were not statistically different between the two groups (Table 1). MAP tended to increase after L-NAME whereas after LPS the hypotensive effect overruled and MAP was not different anymore between the two groups. Fetal heart rate in the LNAME + LPS group tended to decrease in the normoxic period unlike the LPS group where FHR increased ( $<<0.001$ between the groups). (Figures 1 and 2). During normoxia, cardiac output decreased after L-NAME administration and was 39\% of the value in the LPS group $(\mathrm{p}<0.01$ at $\mathrm{t}-1)$. Placental blood flow decreased to about the same level in both groups. Fetal body flow decreased after L-NAME and was significantly lower in this group $(\mathrm{p}<0.001$ at $\mathrm{t}-1)$. The percentage cardiac output distributed to the heart was twice as high in the L-NAME + LPS group during normoxia $(\mathrm{p}<0.01$ at $\mathrm{t}-1)$. Adrenal blood flow showed a lesser increase in the LNAME + LPS group during normoxia compared to the LPS group ( $<<0.05$ at $\mathrm{t}-1)$. In contrast to the LPS group there was no change in percentage cardiac output to the liver in the L-NAME + LPS group which was lower than the flow in the LPS group $(\mathrm{p}<0.001$ at $\mathrm{t}-1)$. Cerebral blood flow was not different between the two groups although the percentage cardiac output to the brain was lower in the L-NAME + LPS group, especially in the recovery phase $(\mathrm{p}<0.01)$. Cerebral oxygen delivery showed the same pattern in both groups decreasing with about $50 \%$ during normoxia (Tables 3, 4). 


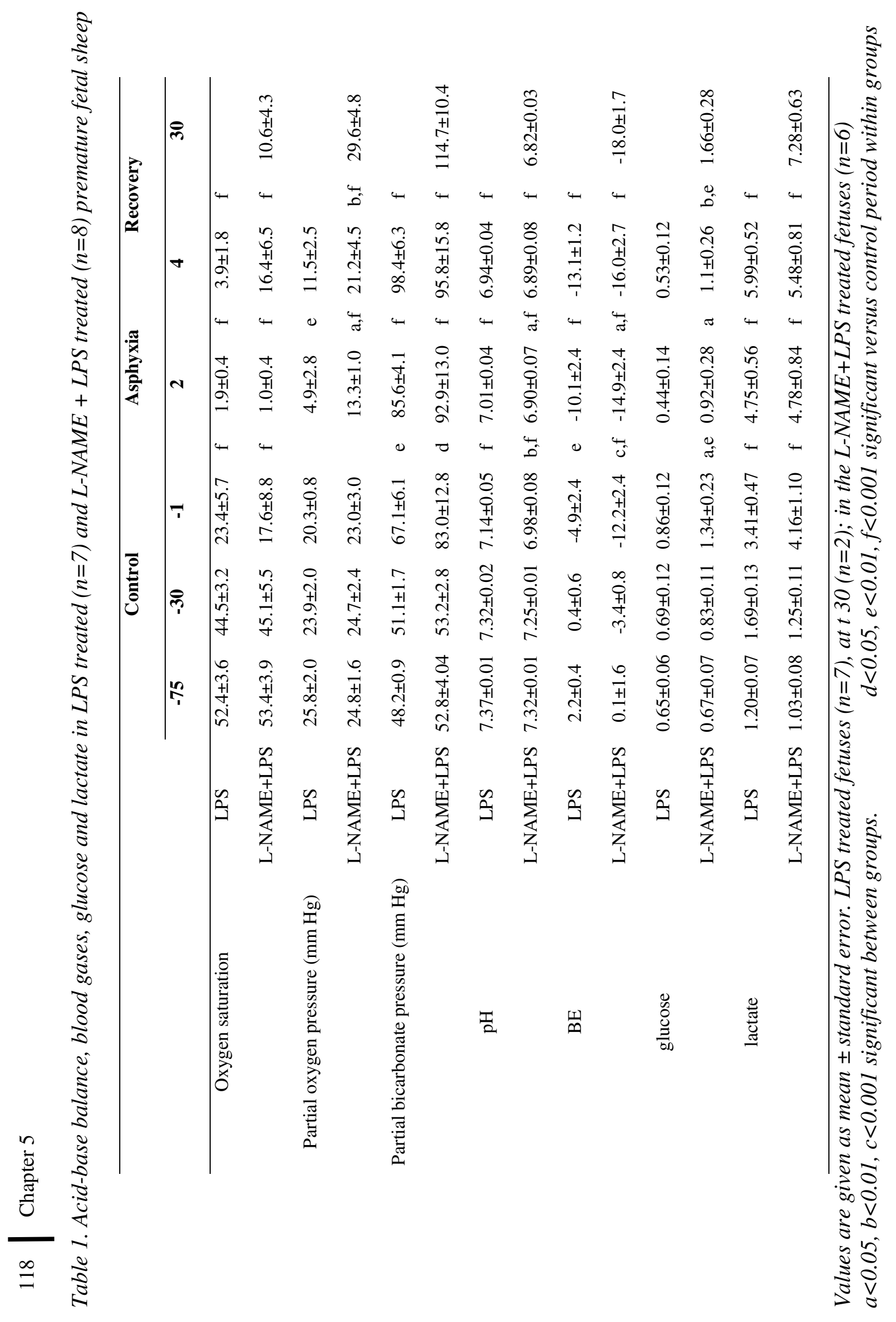




\section{Acute hypoxia}

Oxygen saturation declined to the same extent in both groups during hypoxia. Partial oxygen pressure and glucose concentration were higher in the L-NAME + LPS group $(\mathrm{p}<0.05)$. Arterial $\mathrm{pH}$ and $\mathrm{BE}$ were lower in the L-NAME + LPS group $(\mathrm{p}<0.05)$. MAP showed an increase in the L-NAME + LPS group at the end of occlusion whereas in the LPS group MAP decreased further $(\mathrm{p}<0.01$ at $\mathrm{t} 2$ ) while FHR was not different between the groups (Figures 1 and 2 ). In both groups cardiac output decreased during occlusion $(\mathrm{p}<0.001)$ and thus showed no difference between the two groups. Although absolute flow in the placenta was not different between the two groups, the percentage cardiac output to the placenta was three times higher in the L-NAME group during hypoxia $(\mathrm{p}<0.05)$. Fetal body flow decreased with $83 \%$ after L-NAME and was significantly lower in this group ( $34 \%$ of flow in the LPS group, $\mathrm{p}<0.05$ at $\mathrm{t} 2)$. The increase in percentage cardiac output to the fetal body was less in the L-NAME + LPS group than in the LPS group and this difference became significant at the end of the occlusion $(\mathrm{p}<0.05$ at $\mathrm{t} 2)$. Cardiac blood flow was not different between the two groups in the hypoxia period. During occlusion blood flow to the adrenals increased in the LPS group but decreased in the L-NAME + LPS group ( $\mathrm{p}<0.05$ between the groups). The percentage cardiac output to the liver was also lower in the L-NAME + LPS group $(\mathrm{p}<0.001)$. The percentage cardiac output to the cerebrum was 3.4 times lower in the L-NAME group during hypoxia $(\mathrm{p}<0.01$ at $\mathrm{t} 2)$. Cerebral oxygen delivery decreased to the same extent in both groups to levels almost zero at the bottom of asphyxia (Tables 3,4).

\section{Post occlusion phase}

Oxygen saturation was reduced to significant lower levels in both groups $(\mathrm{p}<0.001)$ and was not different between both groups. Arterial $\mathrm{pH}$ and $\mathrm{BE}$ were not significantly different between the two groups. Partial oxygen pressure and glucose concentration remained higher in the L-NAME + LPS group $(\mathrm{p}<0.05)$. During the recovery phase MAP showed an increase in the L-NAME + LPS group in the recovery period whereas in the LPS group MAP decreased $(p<0.01$ at $t 4)$. FHR 
increased in the L-NAME + LPS group and exceeded values of those in the LPS group $(\mathrm{p}<0.05$ at t4). (Table 1, Figure 1 and 2).

Cardiac output remained significantly lower throughout the experiment in the L-NAME + LPS group compared to the LPS group ( $\mathrm{p}<0.05$ at $\mathrm{t} 4)$. The percentage cardiac output to the placenta was higher during recovery after L-NAME + LPS ( $\mathrm{p}<0.05$ at $\mathrm{t} 4)$. Fetal body blood flow remained significantly lower in this group during the immediate recovery period $(\mathrm{p}<0.001$ at $\mathrm{t} 4)$ and also the increase in percentage cardiac output to the fetal body was lower in the L-NAME + LPS group during recovery ( $\mathrm{p}<0.05$ at $\mathrm{t} 4)$. Adrenal blood flow and percentage cardiac output to the liver remained lower in the L-NAME + LPS group ( $\mathrm{p}<0.05$ at $\mathrm{t} 4)$ as well as blood flow to the carcass $(\mathrm{p}<0.01$ at $\mathrm{t} 4)$. The lower percentage cardiac output to the cerebrum persisted in the L-NAME + LPS group during recovery $(\mathrm{p}<0.01$ at $\mathrm{t} 4$. The expected post-hypoxia rise in cerebral blood flow was absent in both groups (Tables 3,4). 


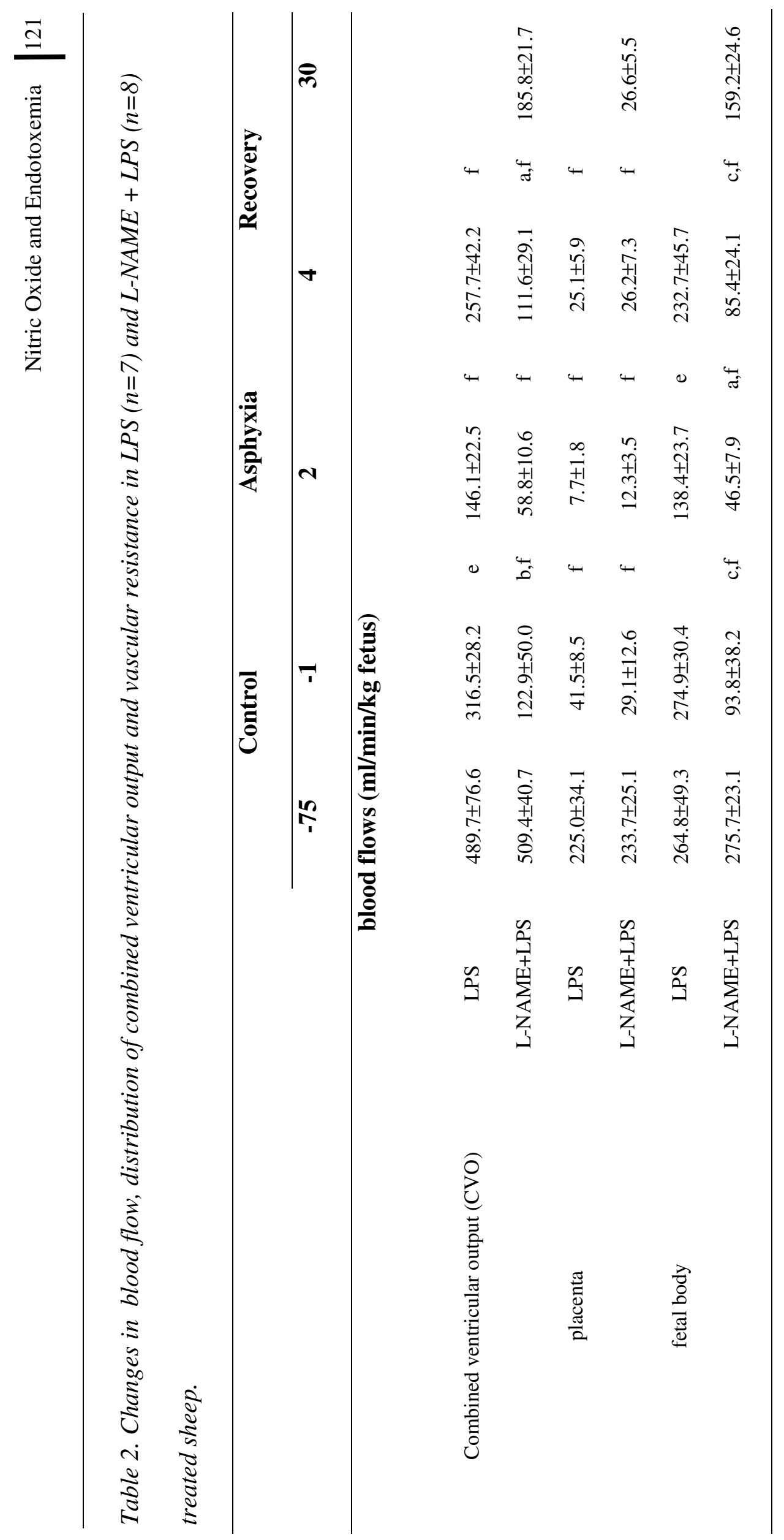




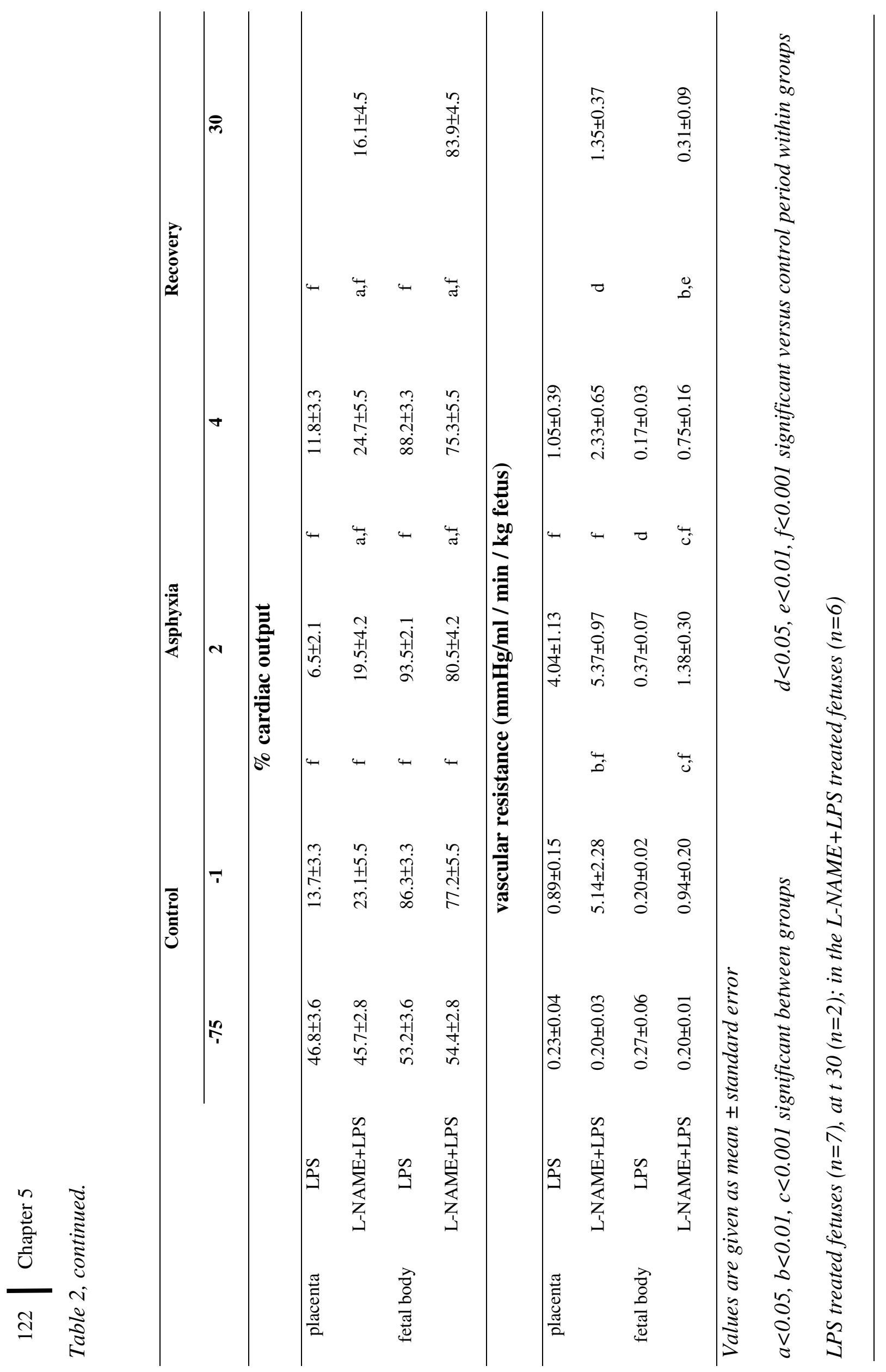




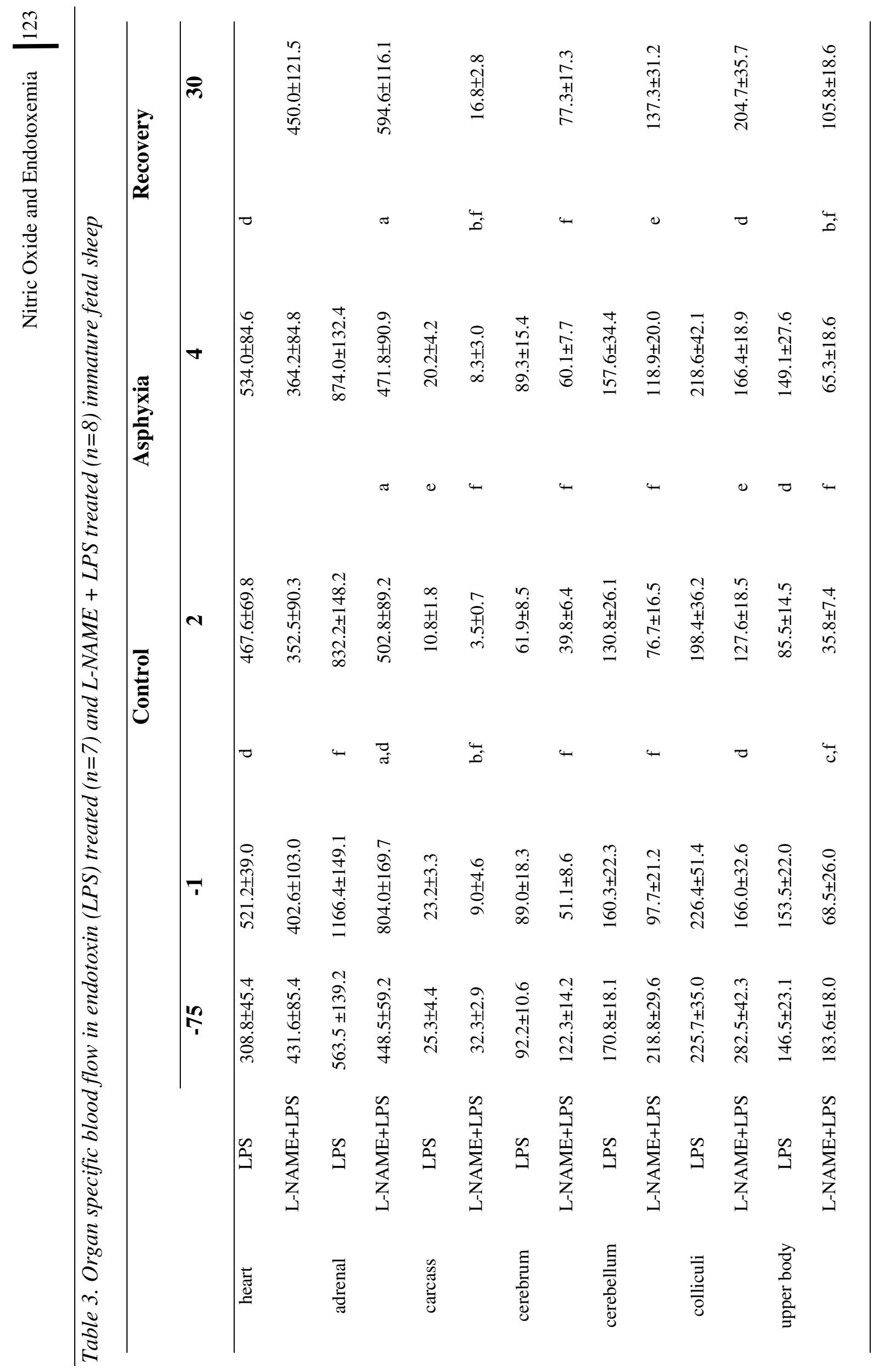




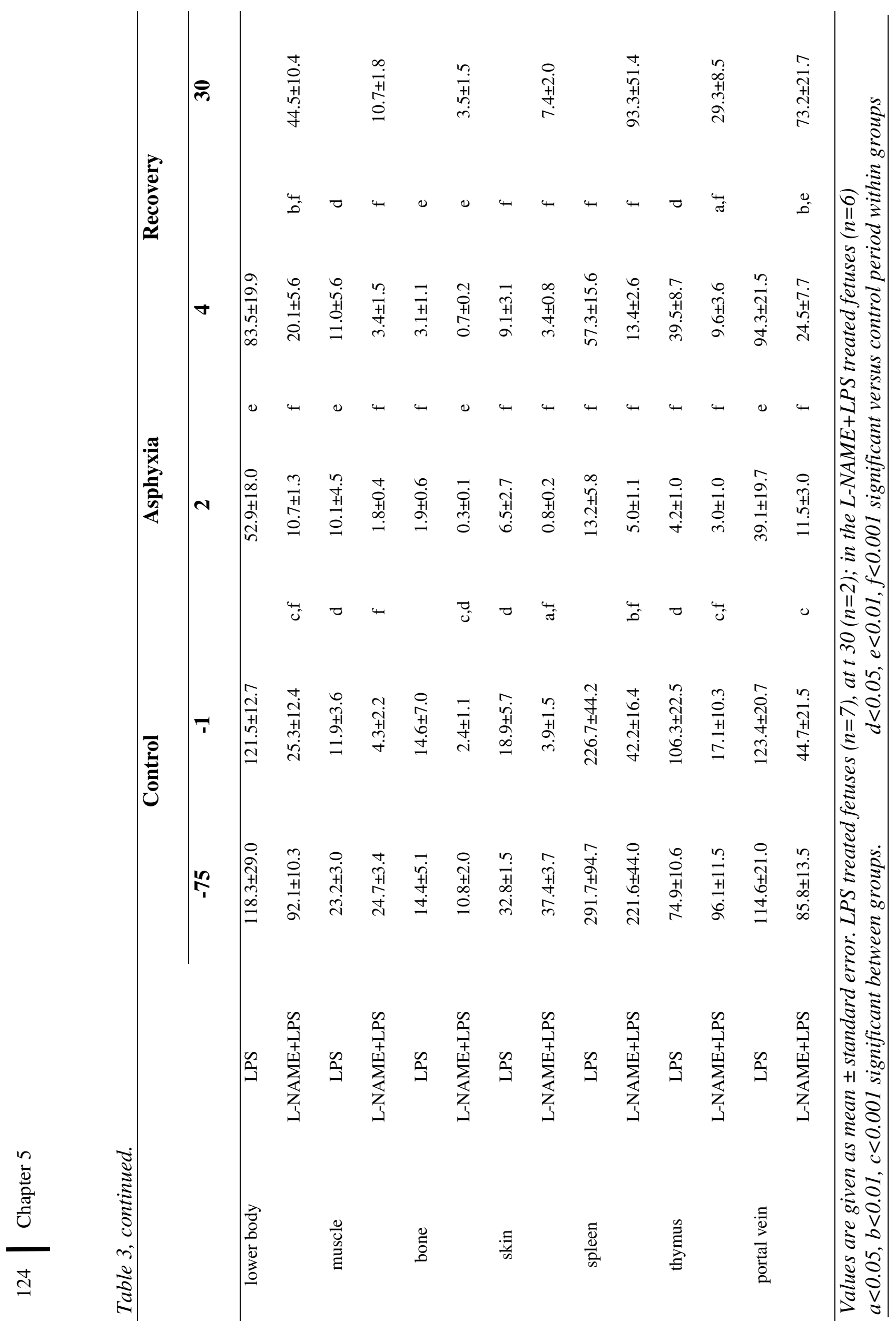




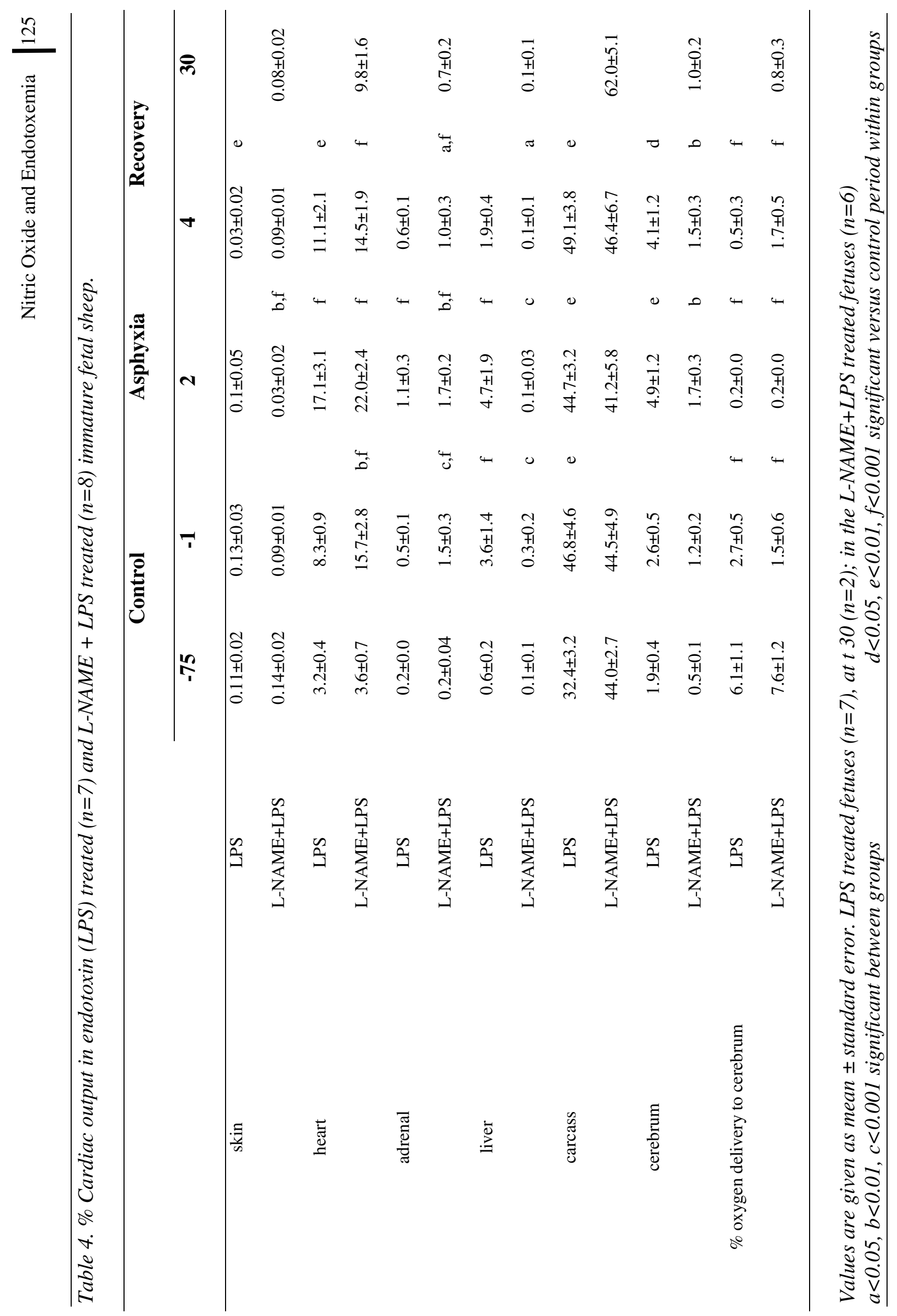




\section{Comments:}

LPS-induced endotoxemia severely impairs fetal cardiovascular control during normoxia and acute asphyxia resulting in circulatory decentralisation with a decrease in placental blood flow and an increase in flow to the fetal body, adrenals, carcass and heart. This decentralisation leads to a severe decrease in oxygen delivery to the brain (10).

NO is produced in large quantities after LPS administration and hence might be involved in the pathway that connects endotoxemia to circulatory failure (8). Several studies have investigated the effect of $\mathrm{NO}$ on circulation, but the role of $\mathrm{NO}$ in the process of circulatory decentralisation caused by endotoxins was not established. We therefore studied the effects of NOS inhibition on fetal circulation and blood flow distribution during endotoxemia.

\section{Circulation}

After application of LPS fetal cardiovascular control was severely affected with the development of tachycardia and hypotension which became more severe during and after occlusion. These changes were of the same order and magnitude as we have described before (10).

In the L-NAME + LPS group, NOS inhibition induced a rise in fetal blood pressure and a decrease in fetal heart rate immediately after L-NAME but as soon as the effect of LPS on the circulation was established (t-30) fetal heart rate increased again and blood pressure started to fall during the control period. The fetal hypertension and bradycardia immediately after LNAME has been described in fetal sheep studies (16). The initial transient rise in MAP in the LNAME + LPS group, although not significant, is most likely caused by systemic and umbilicoplacental vasoconstriction due to NOS inhibition (17).

In the LPS group hypotension was more pronounced during occlusion and after occlusion 5 out of 7 fetuses died while in the L-NAME group 6 out of the 8 fetuses survived.

These findings might indicate that the LPS induced fetal heart changes are mediated by NO. 
The steep decrease in cardiac output in the L-NAME + LPS group did not recover after hypoxia. Cardiac output in the L-NAME + LPS group was approximately $40 \%$ of cardiac output in the LPS group at the bottom of asphyxia, which can be ascribed to an increase in MAP leading to an increase in afterload and a decrease in FHR which reduce fetal cardiac output (18). These alterations contribute to the fall in combined ventricular output evident with inhibition of NOS (19).

\section{Fetal body}

LPS induced peripheral vasodilation with an increase in blood flow to the fetal body that was partly blocked by pretreating the animals with L-NAME. In the L-NAME + LPS group blood flow to the fetal body was lower than in the LPS group. Studies of adults have shown evidence of a role for NO in the regulation of resting tone in renal, mesenteric, hindquarter, carotid and cerebral vascular beds and thus in blood pressure homeostasis $(20 ; 21)$. Our results suggest that the vascular bed of the preterm fetal body is also mediated via NO and that the vascular beds remain NO dependent during hypoxia and even under endotoxemic conditions.

\section{Placenta}

Absolute placental blood flow was not different in both groups, since flow was diminished to almost zero at the bottom of asphyxia and did not recover. The normal umbilico-placental circulation of sheep receives $40 \%$ of the fetal combined ventricular output at term (22). In our study this percentage was about $45 \%$ during normoxia which decreased during occlusion with a slight recovery in the L-NAME treated fetuses. Absolute placental flow also decreased in both groups and there was no significant difference between the two groups. The regulation of umbilical and placental blood flow must depend on circulating or locally released vasoactive substances $(23 ; 24)$ since these vessels lack autonomic innervation $(25)$. In the fetal sheep, the microcirculation of the placenta is remarkably inert to many vasoconstrictors whereas the umbilical artery and vein are more vasoactive $(26 ; 27)$. NOS inhibition seems to merely partially influence the changes in placental blood flow in endotoxin treated fetal sheep. Therefore this 
decrease could also result from endothelin (ET) mediated vasoconstriction of the umbilical arteries. ET-1 is a strong endothelium-derived vasoconstrictor peptide, which constricts fetoplacental microcirculation and decreases fetal oxygen consumption in sheep. The vasoconstrictive effects of ET-1 are brought about by $\mathrm{ET}_{\mathrm{A}}$ receptors and a small subpopulation of $\mathrm{ET}_{\mathrm{B}} . \mathrm{ET}_{\mathrm{A}}$ receptors predominate on vascular smooth muscle, are highly specific for ET-1 and are the primary effectors of its vasoconstrictor activity. ET $_{\mathrm{B}}$ receptors are located primarily on endothelial cells and respond to all three isoforms of endothelin. Activation of the $\mathrm{ET}_{\mathrm{B} 1}$ receptor, located on vascular endothelium, causes the release of vasoactive substances such as NO leading to vasodilation $(28 ; 29)$. Activation of the $\mathrm{ET}_{\mathrm{B} 2}$ receptor located on vascular smooth muscle leads to vasoconstriction. The placental blood flow changes might be attributed to a combination of $\mathrm{ET}_{\mathrm{B} 2}$ and $\mathrm{ET}_{\mathrm{B} 1}$ effects.

\section{Brain}

Cerebral blood flow and percentage cardiac output to the brain decreased in the L-NAME + LPS group. At mean arterial pressures below $25-30 \mathrm{mmHg}$ there is increased loss of autoregulation and thus reduced cerebral blood flow. In the L-NAME + LPS group, MAP was higher than 25$30 \mathrm{mmHg}$, therefore we assume cerebral autoregulation still to be present in the L-NAME group. Thus reduced cerebral blood flow seems to be caused by increased resistance in the brain. In both groups there was an absent post-hypoxia rise in the cerebrum as seen in control animals undergoing hypoxia (11). In the LPS group this is probably due to hypotension after occlusion whereas in the L-NAME + LPS group the lack of NO is involved. NO mediates resting tone in the fetal cerebral vascular bed and is required for hypoxia-induced cerebral vasodilation (30). At 0.6 and 0.9 gestation the post-hypoxia rise in cerebral blood flow was not diminished after LNAME compared to the control group (33). Also, NOS inhibition attenuated the delayed rise in cerebral blood volume and increased the extent of cerebral injury (16;32). In our study, endotoxemia resulted in a constant cerebral blood flow but a severe fall in oxygen saturation coincided. Previous studies have shown a positive correlation between cerebral blood flow and 
oxygen saturation (33). The normally occurring response of cerebral blood flow to hypoxia might be altered by endotoxemia. In the L-NAME + LPS group there was a reduction of cerebral flow by half although saturation was the same in both groups. This may be caused by a normalizing effect of NOS inhibition on the altered response during endotoxemia thus leading to a higher vascular resistance in the cerebrum. In the literature there is evidence that severe hypoxia in the newborn lamb induces impairment of the autoregulatory ability of the cerebral vascular bed and that even low-dose NOS inhibition started upon reperfusion, restored autoregulation suggesting a role for NO induced vasodilation in the impairment of autoregulation of the cerebral blood flow after birth asphyxia (34).

We conclude from our data that NOS inhibition causes a collapse in combined ventricular output and a general vasoconstriction in practically all organs.

The changes in blood flow distribution in endotoxin treated fetal sheep seem in part to be mediated by NO. Certain changes in organ blood flow seem less affected by NOS inhibition such as the placenta where other mediators might be more important.

Furthermore, we conclude from these results that NOS inhibition partially overrules the LPSinduced peripheral vasodilation and that NOS inhibition leads to a reduction in the decentralisation caused by LPS.

\section{Acknowledgements:}

We thank May Bost, Joyce Suyk and Jan Geilen for the excellent technical assistance and Frans Slangen and Monique de Jong for animal care. 


\section{References:}

1. Badawi N, Watson L, Petterson B et al. What constitutes cerebral palsy? Dev Med Child Neurol 1998;40:520-527.

2. Grether JK, Nelson KB. Maternal infection and cerebral palsy in infants of normal birth weight. JAMA 1997;278:207-211.

3. Nelson KB, Grether JK. Potentially asphyxiating conditions and spastic cerebral palsy in infants of normal birth weight. Am J Obstet Gynecol 1998;179:507-513.

4. Yoon BH, Romero R, Park JS et al. Fetal exposure to an intra-amniotic inflammation and the development of cerebral palsy at the age of three years. Am J Obstet Gynecol 2000;182:675-681.

5. Yoon BH, Romero R, Kim CJ et al. High expression of tumor necrosis factor- $\alpha$ and interleukin-6 in periventricular leukomalacia. Am J Obstet Gynecol 1997;177:406-11.

6. Yoon BH, Jun JK, Romero R et al. Amniotic fluid inflammatory cytokines (interleukin-6. interleukin- $1 \beta$ and tumor necrosis factor- $\alpha$ ), neonatal brain white matter lesions and cerebral palsy. Am J Obstet Gynecol 1997;177:19-26.

7. Szaflarski J. Burtrum D. Silverstein FS. Cerebral hypoxia-ischemia stimulates cytokine gene expression in perinatal rats. Stroke 1995;26:1093-100.

8. Cerami A. Inflammatory cytokines. Clin Immunol Immunopathol 1992;62:3-10.

9. Nathan C. Nitric oxide as a secretory product of mammalian cells. FASEB J 1992;6:30513064.

10. Garnier Y, Coumans ABC, Berger R, Jensen A, Hasaart THM. Endotoxemia severely affects circulation during normoxia and asphyxia in immature fetal sheep. J Soc Gynecol Investig 2001;8:134-142.

11. Heymann MA, Payne BD, Hoffman JIE, Rudolph AM. Blood flow measurements with radionuclide-labeled particles. Prog Cardiovasc Dis 1977;20:55-79.

12. Rudolph AM, Heymann MA. Circulation of the fetus in utero: Methods for studying distribution of blood flow, cardiac output and organ blood flow. Circ Res 1967;21:163-84.

13. Jensen A, Roman C, Rudolph AM. Effects of reducing uterine blood flow on fetal blood flow distribution and oxygen delivery. J Dev Physiol 1991;15:309-323.

14. Rudolph AM, Heymann MA. The circulation of the fetus in utero: methods for studying distribution of blood flow, cardiac output and organ blood flow. Circ Res. 1967;21:163-184.

15. Jensen A, Berger R. Fetal circulatory responses to oxygen lack. J Dev Physiol 1991;16:181207. 
16. Green LR. Bennet L. Hanson MA. The role of nitric oxide synthesis in cardiovascular responses to acute hypoxia in the late gestation sheep fetus. J Physiol 1996;497:271-277.

17. Chlorakos A, Langille BL, Adamson SL. Cardiovascular responses attenuate with repeated NO synthesis inhibition in conscious fetal sheep. Am J Physiol 1998;274: H1472-H1480.

18. Hawkins J, Van Hare GF, Schmidt KG, Rudolph AM. Effects of increasing afterload on left ventricular output in fetal lambs. Circ Res 1989;65:127-134.

19. Smolich JJ. NO modulates fetoplacental blood flow distribution and whole body oxygen extraction in fetal sheep. Am J Physiol 1998;274: R1331-R1337.

20. Gardiner SM, Compton AM, Bennet T, Palmer RMJ, Moncada S. Control of regional blood flow by endothelium-derived nitric oxide. Hypertension 1990;15:486-492.

21. Iadecola C, Pellegrino DA, Moscowitz MA, Lassen NA. Nitric oxide synthase inhibition and cerebrovascular regulation. J Cereb Blood Flow Metab 1994;14:175-192.

22. Rudolph AM. Distribution and regulation of blood flow in the fetal and neonatal lamb. Circ Res 1985;57:811-821.

23. Hemsen A. Biochemical functional characterization of endothelin peptides with special reference to vascular resistance. Acta Physiol Scand Suppl 1991;602:1-61.

24. Hemsen A, Gillis C, Larsson O, Haegerstrand A, Lundberg JM. Characterization, localisation and actions of endothelins in umbilical vessels and placenta of man. Acta Physiol Scand 199;143:395-404.

25. Reilly FD, Russel PT. Neurohistochemical evidence supporting an absence of adrenergic and cholinergic innervation in the human placenta and umbilical cord. Anat Rec 1977;188:277-286.

26. Huisseling van H, Muijsers GJJM, de Haan J, Hasaart THM. Fetal hypertension induced by norepinephrine infusion and umbilical artery flowvelocity waveforms in fetal sheep. Am J Obstet Gynecol 1991;165:450-455.

27. Paulick RP, Meyers RL, Rudolph CD, Rudolph AM. Umbilical and hepatic venous responses to circulating vasoconstrictive hormones in fetal lamb. Am J Physiol 1991;260:H1205-H1213.

28. Madsen KM, Neerhof MG, Wessale JL, Thaete LG. Influence of $\mathrm{ET}_{\mathrm{B}}$ receptor antagonism on pregnancy outcome in rats. J Soc Gynecol Investig; 2001;8:239-244.

29. Luscher TF, Yang Z, Tschudi M et al. Interaction between endothelin-1 and endothelium derived relaxing factor in human arteries and veins. Circ Res 1990;660:1088-1094. 
30. Van Bel F, Sola A, Roman C, Rudolph AM. Role of nitric oxide in the regulation af the cerebral circulation in the lamb fetus during normoxemia and hypoxemia. Biol Neonate 1995;68:200-210.

31. Harris AP, Helou S, Gleason CA, Traystman RJ, Kochler RC. Fetal cerebral and peripheral circulatory responses to hypoxia after nitric oxide synthase inhibition. Am J Physiol Regul Integr Comp Physiol 2001;281:R381-390.

32. Marks KA, Mallard CE, Roberts I, Williams CE, Gluckman PD, Edwards AD. Nitric Oxide synthase inhibition attenuates delayed vasodilation and increases injury after cerebral ischemia in fetal sheep. Pediatr Res 1996;40:185-191.

33. Ashwal S, Dale PS, Longo LD. Regional cerebral blood flow: Studies in the fetal lamb during hypoxia, hypercapnia, acidosis and hypertension. Pediatr Res 1984;18:1309-16.

34. Dorrepaal CA, Steendijk P, Baan J, van Bel F. Inhibition of nitric oxide synthesis following severe hypoxia-ischemia restores autoregulation of cerebral blood flow in newborn lambs. Early Human Development 2001;60:159-170. 


\section{Chapter 6}

Endotoxin mediated changes in cardiac output distribution to the fetal sheep lung.

A.B.C. Coumans, Y. Garnier, R. Berger, T.H.M. Hasaart 


\section{Introduction}

Despite widespread adoption of preventive strategies, Respiratory Distress Syndrome (RDS) is still a major health concern in low birth weight infants leading to chronic lung disease or bronchopulmonary dysplasia (BPD) (5;11). Apart from other factors such as preeclampsia, intra uterine growth retardation and cervical incompetence, infection is the most important causative factor in preterm delivery.

BPD has been attributed to the effects of oxidant toxicity and barometric or volumetric trauma resulting from mechanical ventilation necessary for treatment. Recent evidence, however, suggests that pulmonary inflammation plays a role in predisposing preterm infants to the development of BPD $(5 ; 6 ; 11 ; 12 ; 18)$. Pulmonary inflammation might be caused by chorioamnionitis and intrauterine infection. Chorioamnionitis enhances the risk of BPD but decreases the risk of RDS $(7 ; 23)$. These findings led to the hypothesis that intrauterine infection causes lung inflammation with subsequent acceleration of lung maturation, but also fosters the development of lung damage, manifested as BPD.

Endotoxins, (Lipopolysaccharides, LPS) are frequently used in animal models as a paradigm for fetal infections. Endotoxin, injected intra-amniotically 6 days before delivery, increased lung compliance by $59 \%$, increased lung gas volume 2.3 fold, raised concentrations of surfactant lipids, increased surfactant A and B protein levels and increased messenger ribonucleic acid expressions for surfactant proteins while betamethasone exposure resulted in less consistent effects (12). The mechanisms behind these changes however are not yet clear although an acceleration of maturation leading to increased production of surfactant protein due to inflammation is often mentioned (9). However recent work by Moss and co-workers on lung maturation following intra-amniotic endotoxin administration showed that pulmonary inflammation was only present if there was a communication between the respiratory tract and the amniotic sac which was then associated with lung function improvement and increased surfactant production by a direct effect on the developing respiratory system (16). 
In an experimental model of endotoxaemic shock in preterm sheep induced by LPS, we observed pulmonary hyperperfusion during normoxia and asphyxia (4). We hypothesized that these changes in lung perfusion are mediated by endothelin and nitric oxide. In the present study the effects of LPS on pulmonary perfusion were analyzed after pre-treatment with the selective endothelin-A antagonist BQ123 and the nitric oxide synthase inhibitor nitro-L-arginine methyl ester (L-NAME) during normoxia and acute asphyxia.

\section{Material and methods}

\section{$\underline{\text { Animal preparation }}$}

All 25 preterm sheep were chronically instrumented at a mean gestational age of $107 \pm 1$ days (term is 147 days). All ewes underwent surgery with use of sterile techniques while under general anesthesia (thiopental sodium $1 \mathrm{gm} / 70 \mathrm{~kg}$ intravenously for induction, $0.5-1.0 \%$ halothane in a 1:1 nitrous oxide and oxygen mixture for maintenance). Ewes received $1 \mathrm{gm}$ ampicilline (Pentrexyl®; Bristol-Myers, Woerden, The Netherlands) s.c. and $10 \mu \mathrm{g}$ buprenorphin (Temgesic $₫$; Schering, The Netherlands) per kg body weight twice a day for three consecutive postoperative days. A midline abdominal incision was performed. A snare was placed around the maternal descending distal aorta below the renal artery to arrest uterine and ovarian blood flow and to induce fetal asphyxia. The fetal limbs were identified and exteriorised through an incision in the uterus. Polyvinyl catheters (Maxxim Medical BV, Den Bosch, The Netherlands) with $0.75 \mathrm{~mm}$ inner diameter and $1.25 \mathrm{~mm}$ outer diameter were inserted via a tibial fetal vein and artery of each hindleg and advanced into the caudal vena cava and abdominal aorta, respectively. Catheters were also placed into both brachial arteries. Fetal skin was closed with cyanoacrylate glue (Cyanolit, Japan). An intrauterine pressure catheter was placed, and the uterus was sutured after replacing the amniotic fluid with a saline solution at $39^{\circ} \mathrm{C}$. Catheters were filled with heparin (100 IU/ml; Heparin-Natrium® ${ }^{\circledR}$, Braun, Melsungen, Germany) and exteriorised through a small incision in the flank of the ewe. Catheters were protected by a 
pouch sewn to the skin of the ewe. A recovery period of 72 hours followed the operation before experiments were started. Ewes were housed in individual cages and had free access to food and water.

Guidelines for care and use of animals met the guidelines of the responsible governmental agencies and were approved by the Animal Medical Ethics Committee of Maastricht University.

\section{$\underline{\text { Experimental protocol }}$}

The experiments were performed 3 days after the surgical procedure at $110 \pm 1$ days. Fetuses were randomized into 4 different groups:

Group 1. Control group $(\mathrm{n}=6)$,

Group 2. LPS group (n=7) with LPS injection at t-60 (52 $\pm 6 \mu \mathrm{g} / \mathrm{kg})$ (LPS from E.Coli;

0127:B8, Sigma Aldrich, Zwijndrecht, The Netherlands),

Group 3. L-NAME + LPS group ( $\mathrm{n}=8$ ) with L-NAME pre-treatment at $\mathrm{t}-75$ with a $30 \mathrm{mg}$ intravenous bolus followed by a continuous L-NAME infusion of $6 \mathrm{mg} / \mathrm{min}$ and LPS administration at t-60 as described above (L-NAME from Sigma Aldrich, Zwijndrecht, The Netherlands),

Group 4. BQ123 + LPS group (n=4) with BQ 123 pre-treatment at $\mathrm{t}-75$ minutes with a $50 \mu \mathrm{g}$ bolus iv, followed by $3.3 \mu \mathrm{g} / \mathrm{min}$ for $2 \mathrm{~h}$ and LPS injection at $\mathrm{t}-60$ as described above (BQ 123 from Sigma Aldrich, Zwijndrecht, The Netherlands).

Adequate blockade of eNOS was proven by intravenous injection of $2 \mu \mathrm{g}$ acethylcholine (ACH). Before eNOS inhibition, $\mathrm{ACH}$ induced a decrease in MAP of $\pm 15 \mathrm{~mm} \mathrm{Hg}$ which was completely abolished with NOS inhibition.

To determine the effects on the time course of circulatory centralization before, during and after asphyxia, blood flow to fetal organs and the distribution of combined ventricular output were measured by injecting six batches of differently labeled isotope microspheres $\left({ }^{141} \mathrm{Ce},{ }^{114} \mathrm{In},{ }^{113} \mathrm{Sn}\right.$, 
${ }^{103} \mathrm{Ru},{ }^{95} \mathrm{Nb}$, and ${ }^{46} \mathrm{Sc}, 16 \mu \mathrm{m}$ diameter, New England Nuclear, Boston, MA, USA) suspended in $10 \%$ dextran containing $0.01 \%$ Tween 80 , sonicated and checked for size, shape and aggregation. Depending on the specific activity 0.7-1.8 million microspheres per batch were injected over a period of 20 seconds before infusion of either vehicle or L-NAME or BQ123 (control, at -75), before the injection of vehicle or LPS (t-60), shortly before maternal occlusion $(-1)$, at the bottom of asphyxia ( +2$)$, and after the release of the snare (recovery, at +4 and +30 ) into the inferior vena cava (19) with t 0 being the start of the occlusion. Reference blood samples were withdrawn from both a carotid and a femoral artery at a rate of $1.75 \mathrm{ml} / \mathrm{min}$. Sampling was continuous for $390 \mathrm{~s}$ from -1 to +5.5 minutes. Separate samples were taken for 90 $\mathrm{sec}$ at control (-75 $\mathrm{min})$ and during recovery (+30 min). The volume of blood withdrawn was replaced by maternal blood maintained at $39^{\circ} \mathrm{C}$ in a waterbath.

The experimental protocol was approved by the Animal Medical Ethics Committee of Maastricht University and met the guidelines of the responsible governmental agency.

\section{Measurements}

Fetal heart rate (FHR) and mean blood pressure (MAP) were continuously recorded during the experiment on a personal computer, using a customized hemodynamic data acquisition system. Before each blood flow measurement, and additionally at $-30 \mathrm{~min}$, blood samples were taken from the fetal descending aorta and analysed for blood gases, acid base balance (AVL 993, Radiometer, Copenhagen, Denmark), hemoglobin concentration and arterial oxygen saturation of hemoglobin (OSM 2 Hemoximeter, Radiometer, Copenhagen, Denmark). After the experiment a lethal dose of sodium pentobarbitone (Euthesate $\AA$; Apharmo, Duiven, The Netherlands) was given to the ewe and the fetuses were perfused with $200 \mathrm{ml}$ formalin (10\% in saline). The lungs were weighed and placed in vials, which were filled to the same height to reduce variations in geometry. Both lungs were counted separately. Significant preferential streaming of microspheres could not be detected. The applied solid-state semi-conductor gamma 
counter (thallium activated, sodium iodine crystal) had a high energy resolution of about $2 \mathrm{keV}$ and was connected to a multichannel (1024) pulse height analyzer (LKB 1282, Compugamma, Wallac, Turku, Finland). The results were normalized with respect to time and sample weight.

\section{$\underline{\text { Calculations }}$}

Fetal combined ventricular output (CVO) and blood flow to the various organs were calculated from counts of the injected nuclide recovered in fetal organs, from counts in the appropriate reference samples, and from the withdrawal rate of the reference samples (19). The percentage of combined ventricular output distributed to a given organ was calculated from the absolute blood flow to that organ and the combined ventricular output. Measurement of absolute blood flow to the lungs requires a catheter in the pulmonary artery, which was not inserted. Relative changes in lung blood flow are therefore expressed as percentage change in the number of radioactive microspheres trapped in the capillary beds of the lungs.

\section{$\underline{\text { Statistics }}$}

Results are given as means \pm SEM. The data were analysed for intra- and intergroup differences by two-way multivariate analysis of variance for repeated measures. Differences between control group and LPS group and between L-NAME + LPS group versus LPS group and BQ 123 + LPS group versus LPS group are compared since we were interested in the role of NO and endothelin in the LPS induced changes in lung perfusion. Games-Howell-test was used as posthoc testing procedure. Statistical analysis was performed by Super Anova Statistical Package (Abacus, Inc. Ca. USA). 


\section{Results}

Control measurements for MAP, FHR, blood gases and blood flows were all in the normal range for fetal sheep in this experimental set-up (4).

Results from the control group, LPS group and L-NAME + LPS group are from previously completed experiments, all with the same experimental set-up.

\section{Control group}

In the control group no significant changes in MAP, FHR or acid-base balance in the normoxic period were observed. At the end of occlusion, MAP was lower although this change was not significant and FHR decreased by 40\% (Figure 1 and 2). Cardiac output was $610 \pm 85$ $\mathrm{ml} / \mathrm{min} / \mathrm{kg}$ fetus during the normoxic period which was in the same range as the other groups (Figure 3). Cardiac output decreased with $72 \%$ (from 610 to $170 \mathrm{ml} / \mathrm{min}$ ) at the end of occlusion. During the recovery phase cardiac output returned to baseline values. Although $\mathrm{pH}$ did not change significantly during the experiment, the other parameters decreased significantly as shown in Table 1.

The percentage microspheres to the lungs did not change during the course of the experiment in the control group (Figure 4). 
Table 1. Blood gases in control $(n=6), L P S(n=7), L-N A M E+L P S(n=8), B Q 123+L P S(n=4)$ group.

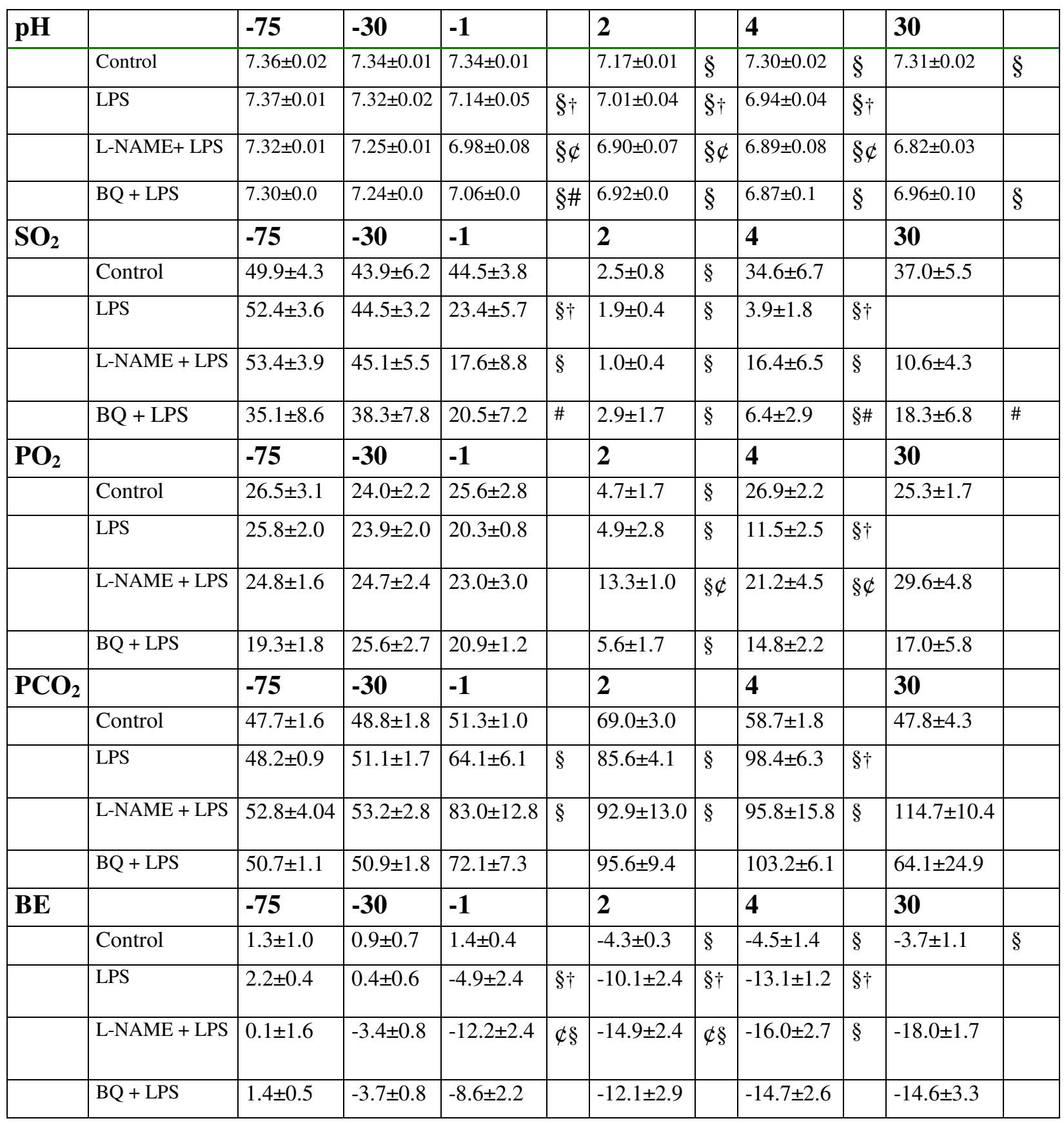

$\S p<0.05$ between control period in the same group $\dagger p<0.05$ between control group and LPS group $\phi p<0.05$ between LPS and L-NAME + LPS $\# p<0.05$ between LPS and BQ123 + LPS group 
LPS group

Compared with the control group the following differences were observed in the LPS group. In the LPS group, mean arterial blood pressure tended to increase and FHR tended to decrease immediately after LPS with a reversed response later on but these changes were not significant. MAP decreased significantly during occlusion and remained low during the recovery phase in the LPS group $(\mathrm{p}<0.01)$ while FHR was in the same range in both groups (Figures 1 and 2). Base excess, $\mathrm{SO}_{2}$ and $\mathrm{pH}$ significantly decreased. Acidosis occurred in the LPS group before occlusion deepened during occlusion and did not recover afterwards. $\mathrm{PO}_{2}$ was lower and $\mathrm{PCO}_{2}$ higher in the LPS group during the recovery phase (Table 1). Cardiac output during normoxia decreased to significantly lower levels in the LPS group $(\mathrm{p}<0.05)$ and did not return to control levels during the recovery period as occurred in the control group. (Figure 3). The percentage microspheres to the lungs significantly increased after LPS and increased even further during the occlusion period. During the recovery period the percentage microspheres to the lungs slowly decreased (Figure 4). At the end of the experiment sustained hypotension lead to the death of five of seven fetuses in the LPS group whereas all fetuses in the control group recovered completely.

\section{$L-N A M E+$ LPS group}

Compared to the LPS group the following changes occurred. MAP increased after L-NAME but 45 minutes after LPS injection, there was a decrease in MAP in both groups. MAP showed an increase in the L-NAME + LPS group at the end of occlusion whereas in the LPS group MAP decreased further ( $\mathrm{p}<0.01$ at $\mathrm{t} 2$ and $\mathrm{t} 4$ ) (Figure 1). Fetal heart rate in the L-NAME + LPS decreased in the normoxic period unlike the LPS group where FHR did not attenuate $(p<0.001$ from LPS group). During occlusion FHR was not different between the groups but at the end of the occlusion FHR increased in the L-NAME + LPS group and exceeded values of those in the LPS group $(\mathrm{p}<0.05)$ (Figure 2). L-NAME injection resulted in a lower arterial $\mathrm{pH}(\mathrm{p}<0.05)$ in the L-NAME + LPS group than in the LPS group during the experiment $(\mathrm{p}<0.05)($ Table 1$)$. 
Cardiac output was lower in the L-NAME + LPS group compared to the LPS group before the start of the occlusion and during the immediate recovery period (Figure 3 ). Six out of eight fetuses survived the experiment up to the end of the experiment.

The increase in percentage microspheres to the lungs caused by LPS was completely absent after pre-treatment with L-NAME (Figure 4).

$B Q 123+$ LPS group

The course of FHR and MAP showed the same pattern in the BQ123 + LPS group as well as in the LPS group (Figures 1 and 2). Blood gases in both BQ123 group and LPS group were in the same range during the entire course of the experiment (Table 1).

Cardiac output was not different between BQ123 + LPS and LPS group (Figure 3). The increase in percentage microspheres directed to the lungs after LPS injection was partially blocked by pre-treatment with BQ123 before LPS ( $<<0.05$ at t2) (Figure 4). In this group all fetuses survived until the end of the experiment.

Figure 1a. Mean Arterial Pressure in Control and LPS group

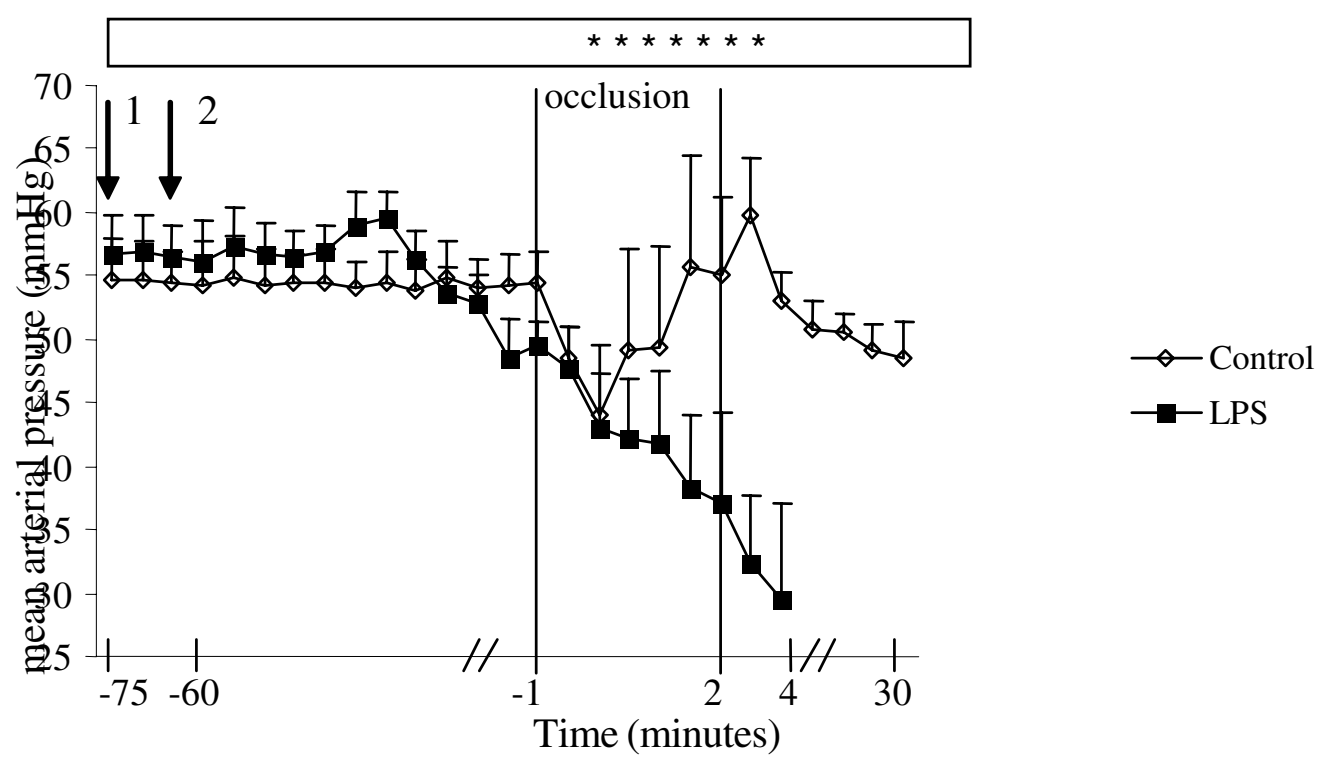

Figure 1a.First arrow indicating injection of vehicle, second arrow indicating injection of LPS

* indicating $p<0.05$ between control group and LPS group at this timepoint 
Figure 1b. Mean Arterial Pressure in LPS and L-NAME + LPS group

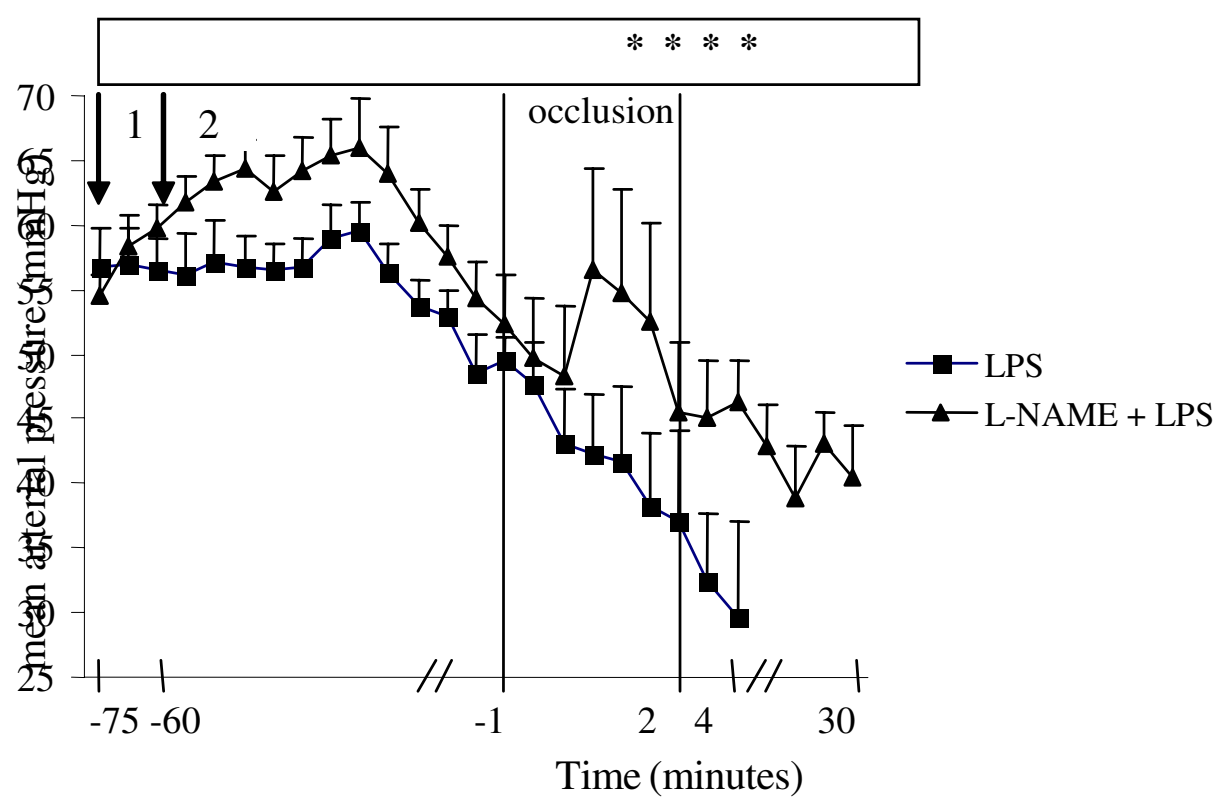

Figure 4lb. First arrow indicating injection of L-NAME, second arrow indicating injection of LPS

* indicating $p<0.05$ between L-NAME + LPS group and LPS group at this timepoint

Figure 1c. M e an Arterial Pressure in LPS group and B Q123+

LPS group

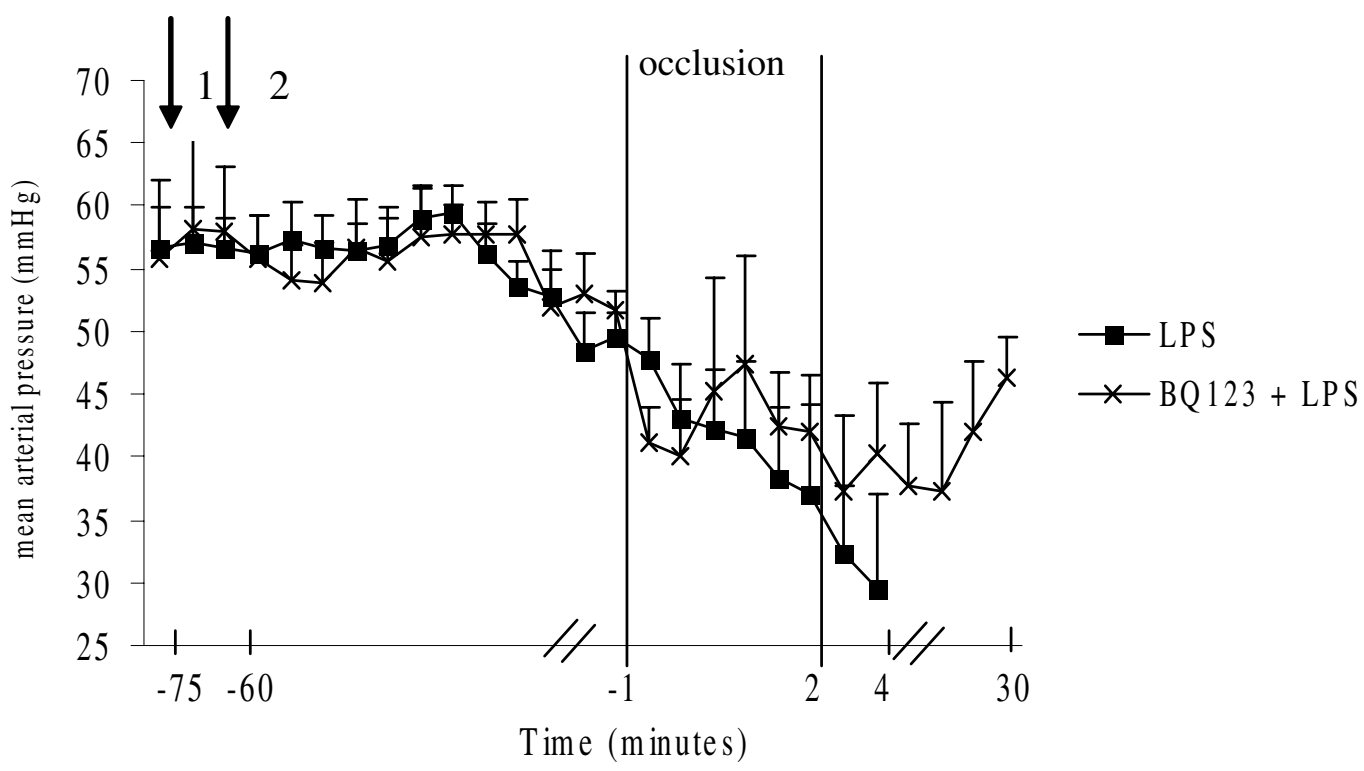

Figure 1c. First arrow indicating injection of $B Q 123$, second arrow indicating injection of $L P S$ 
Figure 2a. Fetal Heart Rate in Control group and LPS group

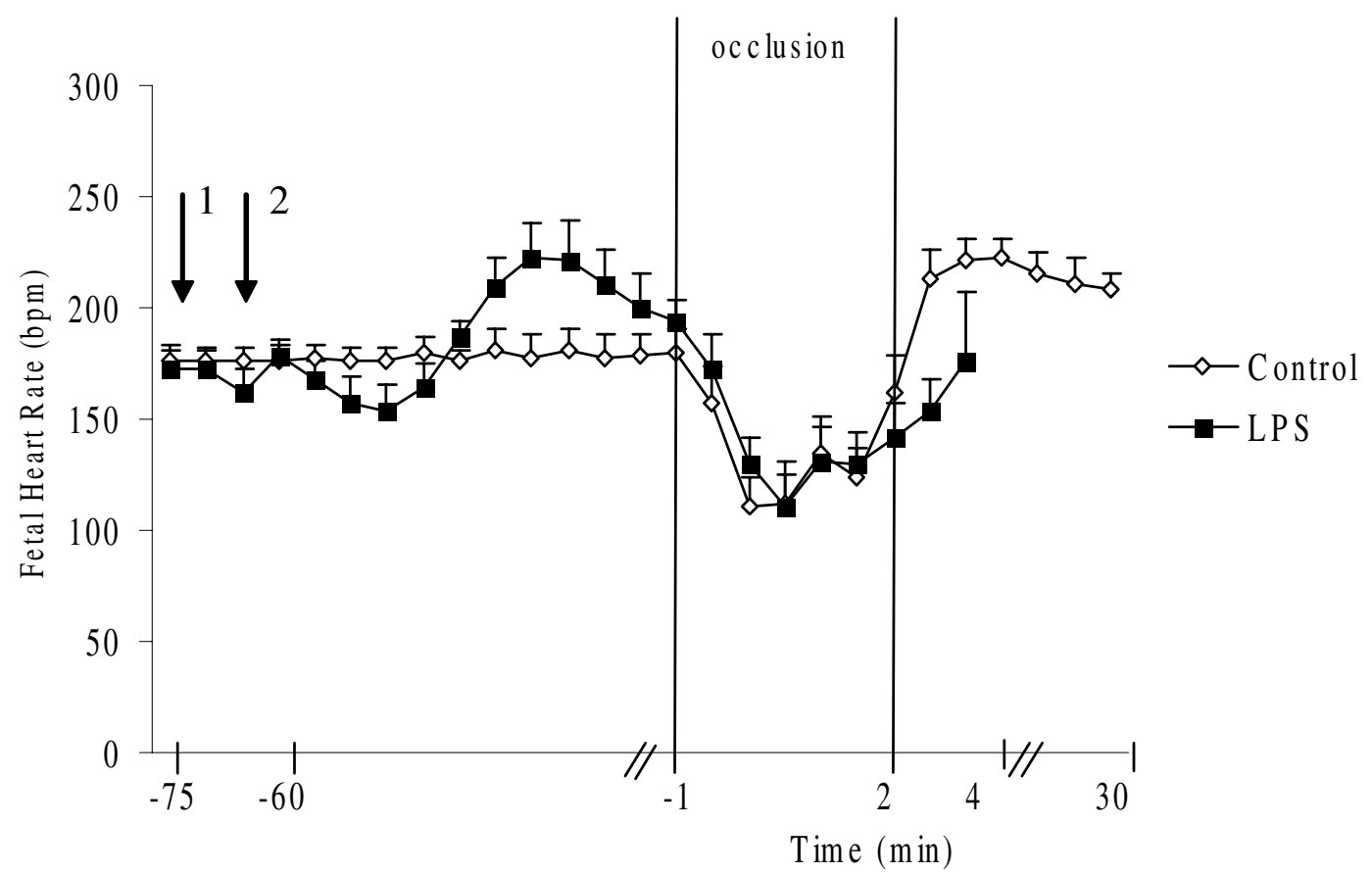

Figure 2b. Fetal Heart Rate in L-NAME + LPS group and LPS group

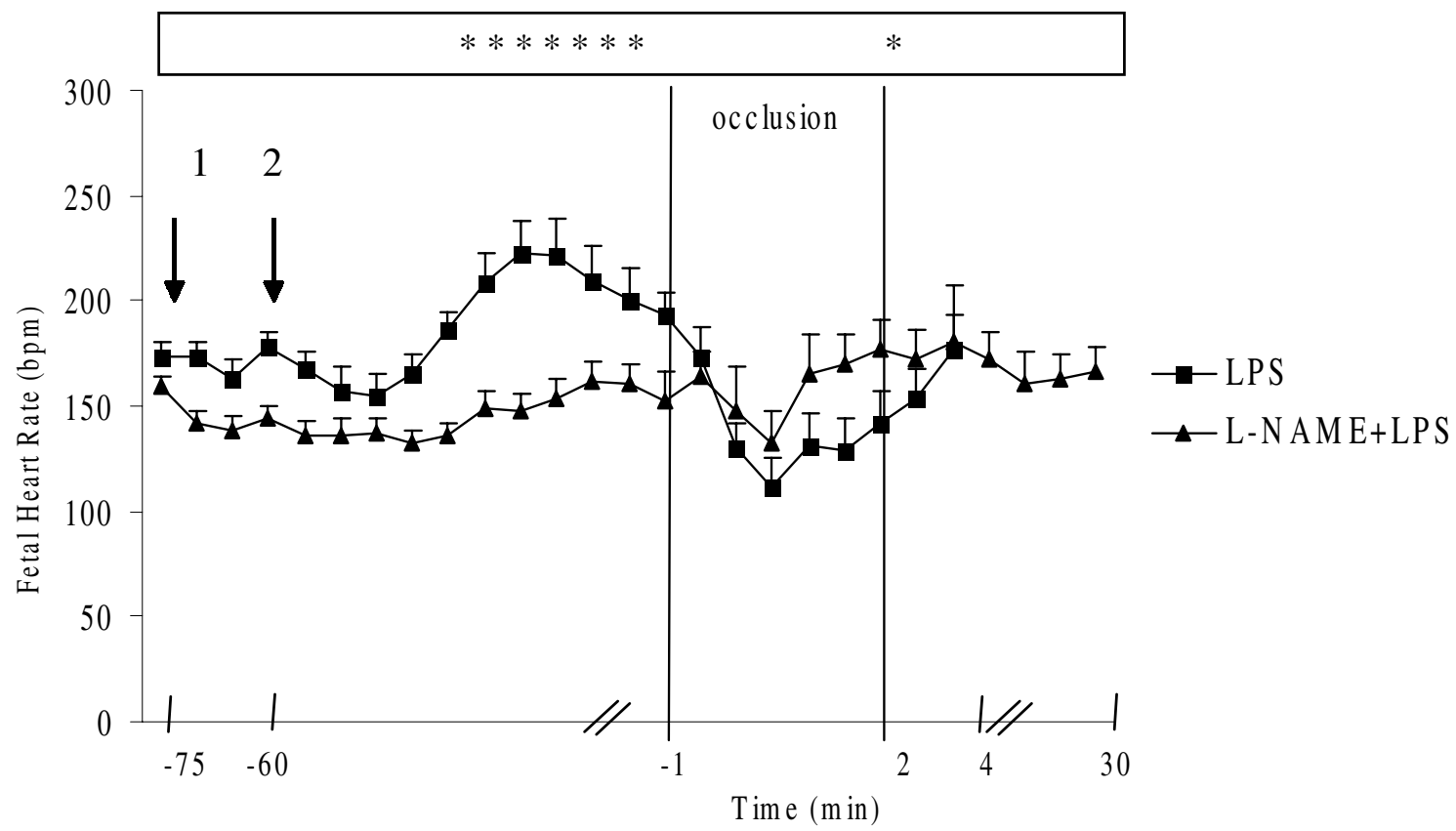

Figure $2 a$ and $2 b$. First arrow indicating injection of L-NAME, second arrow indicating injection of LPS

* indicating $p<0.05$ between L-NAME + LPS group and LPS group at this timepoint 
Figure 2c. Fetal Heart Rate in B Q123 + LPS group and LPS group

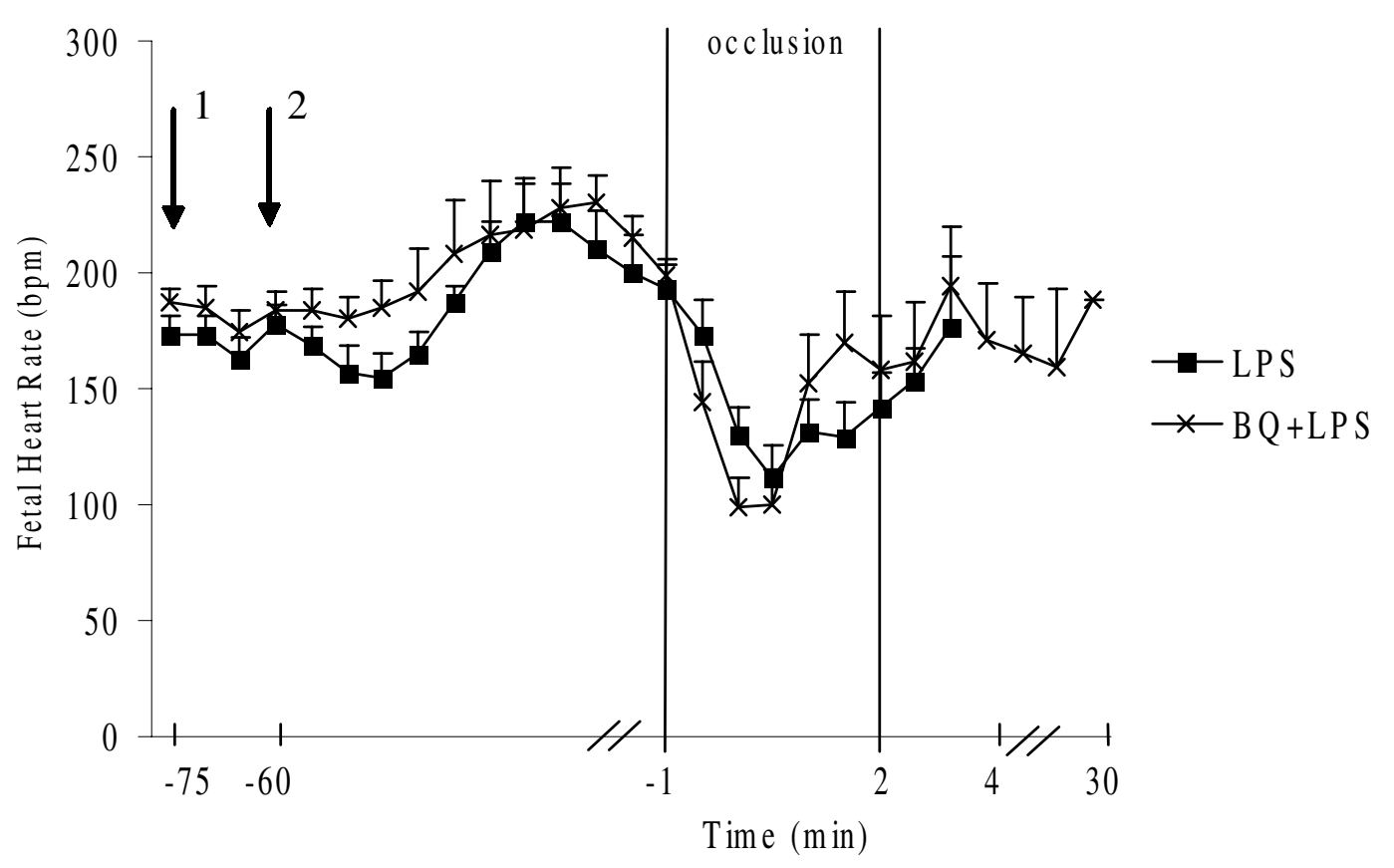

Figure 2c. First arrow indicating injection of BQ123, second arrow indicating injection of LPS 
Figure 3. Cardiac output

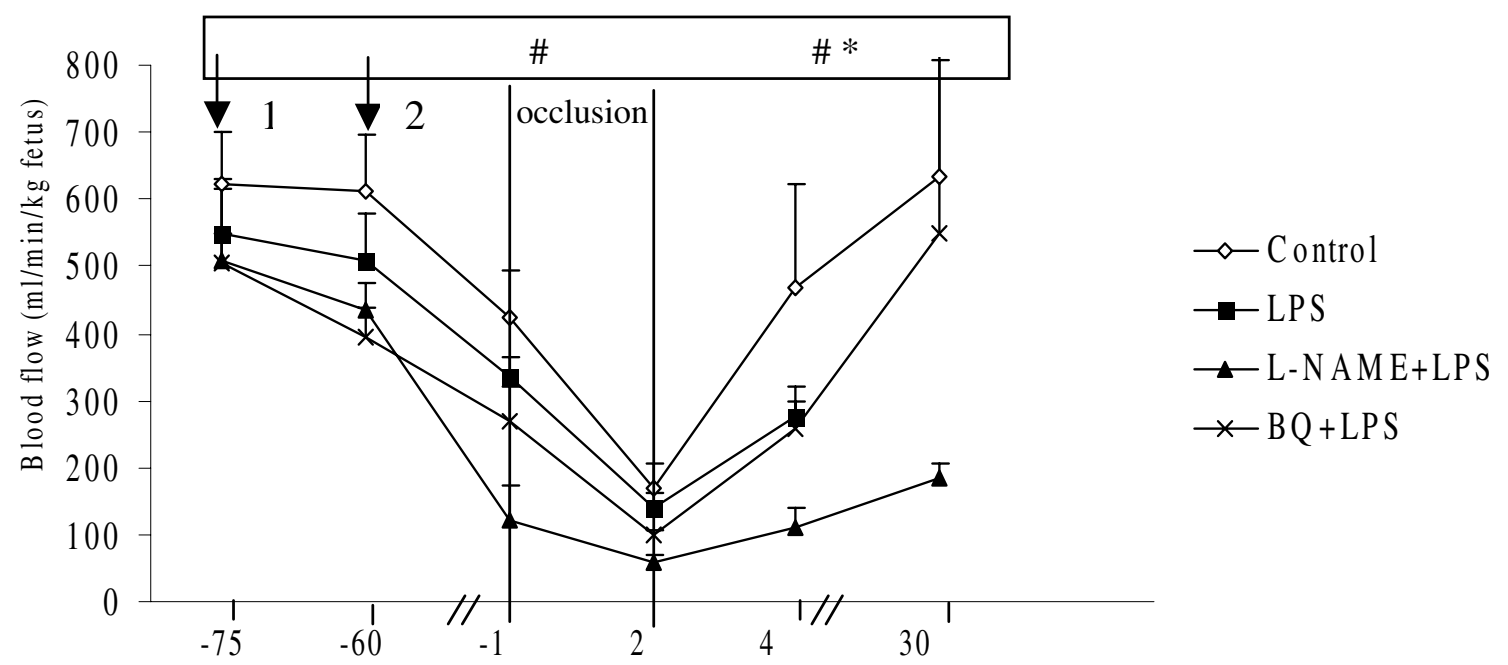

Figure 3.

First arrow ( $t$-75) indicating the pre-treatment with either vehicle, L-NAME or BQ123.

Second arrow (t-60) indicating the injection of either vehicle or LPS.

$* p<0.001$ between Control group and LPS group

\# $p<0.001$ between L-NAME + LPS group and LPS group 
Figure 4. Percentage microspheres in the lung

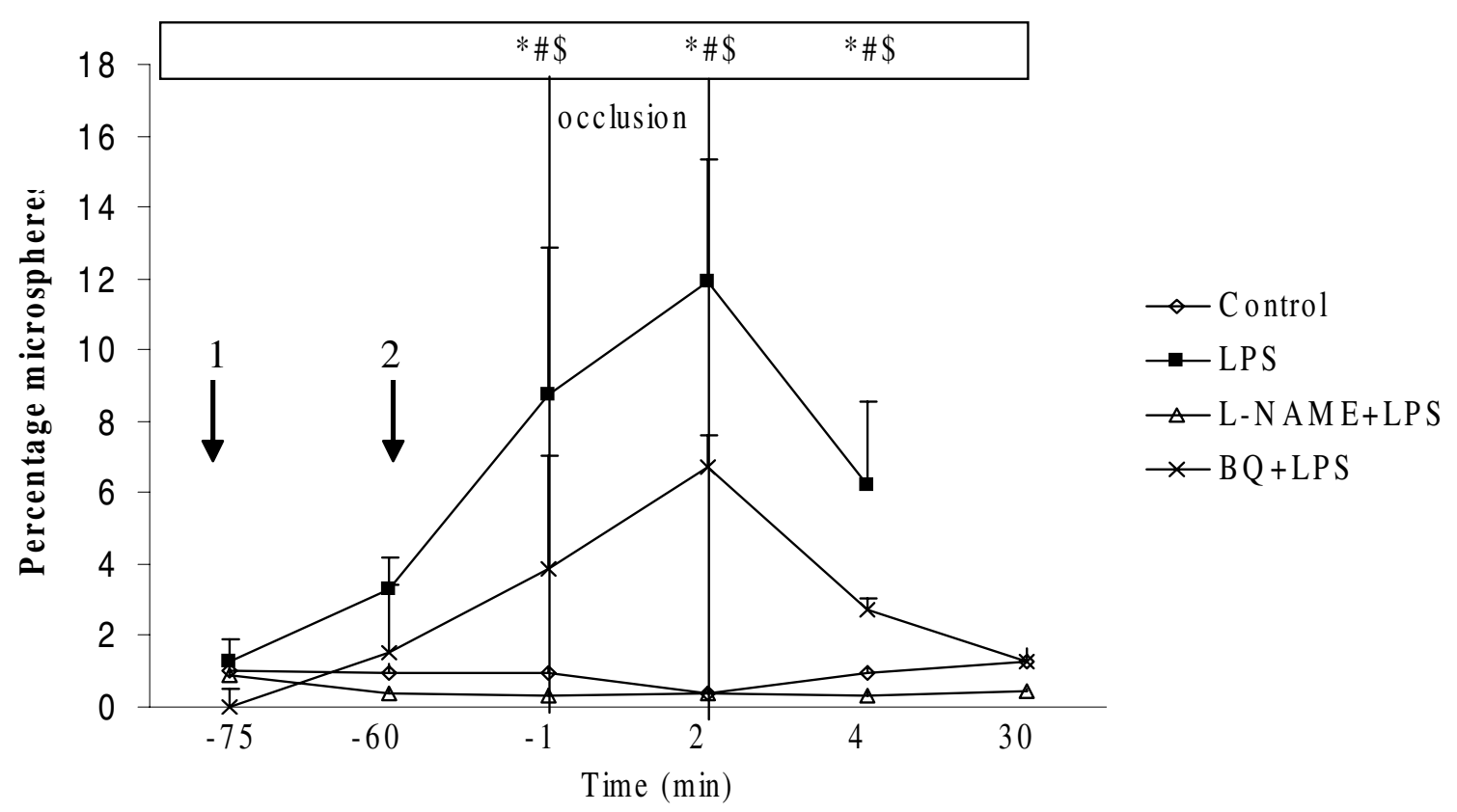

Figure 4.

First arrow (t-75) indicating the pre-treatment with either vehicle, L-NAME or BQ123.

Second arrow (t-60) indicating the injection of either vehicle or LPS.

$* p<0.05$ between Control group and LPS group

\# $p<0.05$ between L-NAME + LPS group and LPS group

$\$ p<0.05$ between BQ123+ LPS group and LPS group 


\section{Discussion}

After LPS application, the percentage cardiac output to the fetal lung, was markedly enhanced and even further increased when a short period of asphyxia was superimposed. This increase might be explained by the following hypothesis. Endotoxemia causes an increase in cytokines which can lead to an increased production of endothelin and NO. The hyperperfusion during superimposed asphyxia might be caused by the higher circulating cytokine levels after hypoxiaischema leading to even higher NO production (22). NO relaxes vascular smooth muscle and leads to vasodilatation, thus increasing blood flow. After pre-treatment with L-NAME, a nonselective NO synthase inhibitor, a complete abolishment of the increased cardiac output to the lung, during normoxia as well as during acute asphyxia occurred. Whizemann and co-workers concluded that intravenous injection of rats with LPS caused a time-dependent increase in inducible nitric oxide synthase (iNOS) mRNA expression in the lung, which reached a maximum after $24 \mathrm{~h}(24)$. From our results we conclude that the pulmonary hyperperfusion following LPS injection seems to be, at least in part, NO mediated.

On the other hand, endothelin (ET) also appears to play a significant role in the mechanism of pulmonary perfusion following LPS (15). In this study we observed a partial inhibition of endotoxin mediated pulmonary hyperperfusion after BQ123 was administered. MAP and FHR did not change after BQ123 pretreatment. Endothelin 1 is a potent vasoconstrictor which is induced by endothelial cells (27). Endothelin has two forms of receptors. ETA receptors are the primary effectors of its vasocontrictor activity. ETB receptors have two subtypes, ETB $_{1}$ activation causes the release of vasoactive substances such as nitric oxide leading to vasodilation. Activation of the $\mathrm{ETB}_{2}$ receptor located on vascular smooth muscle leads to vasoconstriction $(2 ; 21)$. Although the ETA receptor predominates, ETB receptors have been shown in pulmonary resistance arteries.

Wong and co-workers investigated the role of ET-1 and its receptors in the regulation of fetal pulmonary vascular tone using BQ 123 and 4 Ala ET-1 (an ETB receptor agonist). In six fetal 
sheep, BQ 123 increased pulmonary blood flow and decreased pulmonary vascular resistance but 4 Ala ET-1 lead to a higher increase in pulmonary blood flow and decreased pulmonary vascular resistance. This study demonstrates that ETA receptor activation has a role in maintaining basal fetal pulmonary vascular tone, but specific ETB receptor activation produces a more distinctive pulmonary vasodilation (25).

Recently, a clinical study showed that postoperative elevation of pulmonary vascular resistance in children after surgical intervention for congenital heart disease is responsive to endothelin A blockade with BQ123 (20).

In order to find a concise answer to why merely the lungs show such explicit changes in our study, several mechanisms are possible. Bound BQ123 dissociates easier than bound endothelin. BQ123 inhibited $0.1 \mathrm{nM}$ ET-1 binding by more than $80 \%$ after $15 \mathrm{~min}$ of incubation, and the inhibition decreased to less than $20 \%$ after 24 hours of incubation. This suggests that the ability of antagonists to inhibit ET-1 binding to the receptor is critically dependent on the incubation time (26). For this reason we decided to give a BQ123 perfusion during the entire experiment. The dose BQ123 used in this study is in accordance with previous established doses in the literature (10).

Since BQ123 only partially, and L-NAME completely abolishes pulmonary hyperperfusion, it seems that, besides the NO production following endothelin, a different route of NO production exists.

In the preterm infant, the lungs are susceptible to injury leading to RDS and BPD. BPD develops in $20 \%$ of neonates who require mechanical ventilation and in $15 \%$ to $47 \%$ of those with birthweights lower than 1500 gram $(1 ; 3)$. Infants with BPD are at risk for death, cerebral palsy, recurrent respiratory infection, cardiovascular disease and delayed growth. Although immaturity, barotraumas and oxygen toxicity are important contributors, Rojas and co-workers observed a role for infection in the etiology of BPD (18). There is clinical evidence that histologic chorioamnionitis can enhance maturation of fetal lungs but this inflamed pulmonary 
tissue may be vulnerable to injury, thus predisposing the infant to BPD and long-term disease (23;28). Several studies showed improvement in lung compliance, lung volumes and an increase in surfactant levels after a single injection into the amniotic fluid of E.Coli endotoxin across a wide range of doses $(13 ; 14)$. Endotoxin infusion into the trachea, stomach and amniotic cavity each resulted in inflammatory responses in lung fluid and improved postnatal lung function. These effects occurred with minimal features of systemic inflammation although intraperitoneal infusion resulted in severe fetal acidosis or death (17).

In this study we show that LPS induces pulmonary hyperperfusion during normoxia and acute asphyxia, that can be partly counteracted by BQ 123, a selective endothelin A antagonist, and it can be completely abolished by pretreating the animals with L-NAME, a NO synthase inhibitor.

We conclude that endotoxin-induced pulmonary hyperperfusion is partly mediated by endothelin and nitric oxide. 


\section{References}

1. Abman SH, Groothuis JR. Pathophysiology and treatment of bronchopulmonary dysplasia: current issues. Pediatr Clin North Am 1994;41:277-315.

2. Douglas SA, Beck GR, Elliott JD, Ohlstein EH. Pharmacological evidence for the presence of three functional endothelin receptor subtypes in rabbit saphenous vein. J Cardiovasc Pharmacol 1995;26:S163-168.

3. Dusick AM. Medical outcomes in preterm infants. Semin Perinatol 1997;21:164-77.

4. Garnier Y, Coumans ABC, Berger R, Jensen A, Hasaart THM. Endotoxemia severely affects circulation during normoxia and asphyxia in immature fetal sheep. J Soc Gynecol Investig 2001;8:134-142.

5. Ghezzi F, Gomez R, Romero R, Yoon BH, Edwin SS, David C, Janisse J, Mazor M. Elevated interleukin- 8 concentrations in amniotic fluid of mothers whose neonates subsequently develop bronchopulmonary dysplasia. Eur J Obstet Gynecol 1998;78:5-10.

6. Greenough A. Measuring respitatory outcome. Semin Neonatol 2000;5:119-126.

7. Hannaford K, Todd DA, Jeffery H, John E, Byth K, Gilbert GL. Role of ureaplasma urealyticum in lung disease of prematurity. Arch Dis Child Fetal Neonatal Educ 1999;81:F162-167.

8. Heymann MA, Payne BD, Hoffman JIE, Rudolph AM. Blood flow measurements with radionuclide-labeled particles. Progr Cardiovasc Dis 1977;20;55-79.

9. Ikegami T, Tsuda A, Karube A, Kodama H, Hirano H, Tanaka T. Effects of intra uterine IL-6 and IL-8 on the expression of surfactant apoprotein mRNA's in the fetal rat lung. Eur J Obstet Gynecol 2000;93:97-103.

10. Ivy DD, Parker TA, Ziegler JW, Galan HL, Kinsella JP, Tuder RM, Abman SH. Prolonged endothelin A receptor blockade attenuates chronic pulmonary hypertension in the ovine fetus. $\mathbf{J}$ Clin Invest 1997;15:1179-86.

11. Jobe AH, Ikegami M. Mechanisms initiating lung injury in the preterm. Early Hum Dev 1998;53:81-94.

12. Jobe AH. The new BPD: An arrest of lung development. Pediatr Res 1999;46:641-643.

13. Jobe AH, Newnham JP, Willet KE, Sly P, Ervin MG, Bachurski C, Possmayer F, Hallman M, Ikegami M. Effects of antenatal endotoxin and glucocorticoids on the lungs of preterm lambs. Am J Obstet Gynecol 2000;182:401-8.

14. Jobe AH, Newnham JP, Willet KE, Moss TJ, Gore Ervin M, Padbury JF, Sly P, Ikegami M. Endotoxin-induced lung maturation in preterm lambs is not mediated by cortisol. Am J Respir Crit Care Med 2000;162:1656-61.

15. Morel DR, Lacrouix JS, Hemsen A, Steinig DA, Pittet JF, Lundberg JM. Increased plasma and pulmonary lymph levels of endothelin during endotoxin shock. Eur J Pharmacol 1989;167:427428. 
16. Moss TJM, Nitsos I, Kramer BW, Ikegami M, Newnham JP, Jobe AH. Intra-amniotic endotoxin induces lung maturation by direct effects on the developing respiratory tract in preterm sheep. Am J Obstet Gyencol 2002;187:1059-1065.

17. Newnham JP, Moss TJM, Kramer BW, Nitsos I, Ikegami M, Jobe AH. The fetal maturational and inflammatory responses to different routes of endotoxin infusion in sheep. Am J Obstet Gynecol 2002;186:1062-8.

18. Rojas M.A., Gonzalez A, Bancalari E, Claure N, Poole C, Silva-Neto G. Changing trends in the epidemiology and pathogenesis of neonatal chronic lung disease. J Pediatr 1995;126:605-610.

19. Rudolph AM, Heymann MA. Circulation of the fetus in utero: Methods for studying distribution of blood flow, cardiac output and organ blood flow. Circ Res 1967;21;163-184.

20. Schulze-Neick I, Li J, Reader JA, Shekerdemian L, Redington AN, Penny DJ. The endothelin antagonist BQ 123 reduces pulmonary vascular resistance after surgical interventrion for congenital heart disease. J Thorac Cardiovasc Surg 2002;124:435-441.

21. Sokolovsky M, Ambar I, Galron R. A novel subtype of endothelin receptors. J Biol Chem $1992 ; 267: 20551-20554$

22. Szaflarski J, Burtrum D, Silverstein FS. Cerebral hypoxia-ischemia stimulates cytokine gene expression in perinatal rats. Stroke 1995;26:1093-100.

23. Watterberg K.L., Demers L.M., Scott S.M., Murphy S. Chorioamnionitis and early lung inflammation in infants in whom bronchopulmonary dysplasia develops. Pediatrics 1996;97:210215.

24. Wizemann TM, Gardner CR, Laskin JD, Quinones S, Durham SK, Goller NL, Ohnishi ST, Laskin DL. Production of nitric oxide and peroxynitrite in the lung during acute endotoxemia. J Leukoc Biol 1994;56:759-68.

25. Wong J, Fineman JR, Heymann MA. The role of endothelin and endothelin receptor subtypes in regulation of fetal pulmonary vascular tone. Pediatr Res 1994;35:664-70.

26. Wu-Wong JR, Chiou WJ, Dixon DB, Opgenorth TJ. Dissociation characteristics of endothelin ETA receptor agonists and antagonists. J Cardiovasc Pharmacol 1995;26:S380-4.

27. Yanagisawa M, Kurihara H, Kimura S et al.. A novel potent vasoconstrictor peptide produced by vascular endothelial cells. Nature 1988;332:411-415.

28. Yoon BH, Romero R, Kim KS, Park JS, Ki SH, Kim BI et al. A systemic fetal inflammatory response and the development of bronchopulmonary dysplasia. Am J Obstet Gynecol 1999;181:773-9. 


\section{Chapter 7}

Intracisternal application of endotoxin enhances the susceptibility to subsequent hypoxic-ischemic brain damage in neonatal rats A.B.C. Coumans, J. Middelanis, Y. Garnier, H.M.Vaihinger, S.L. Leib, M. von Duering, T.H.M. Hasaart, A. Jensen, R. Berger

Pediatr Res 2003;53(5):1-6 
154 Chapter 7

\section{Introduction.}

Hypoxic-ischemic cerebral damage is an important contributor to perinatal mortality and morbidity, including long-term neurologic sequelae in term and preterm fetuses $(1,2)$. However, as shown in recent studies, perinatal brain injury may be associated not only with hypoxic-ischemic insults but also with an ascending intrauterine inflammation before or during birth (3). It is widely known that gram-negative anaerobic bacteria are involved in colonization and infection of the genitourinary tract in pregnant women, which could affect labor and preterm birth. Because pregnant women with fever and bacteriuria give birth to infants with a higher incidence of neurologic defects at 1 year of age than do mothers free of urinary tract infection (4), it seems that human maternal endotoxemia is associated with fetal central nervous system damage. Furthermore, there is a growing body of evidence from epidemiologic studies that exposure to placental inflammation before or during birth is accompanied by cerebral white matter damage, especially in the very preterm fetuses, i.e. those born before $32 \mathrm{wk}$ of gestation (3). In addition, the incidence of peri/intraventricular hemorrhage is significantly increased in premature infants who are exposed to intrauterine inflammation $(5,6)$.

An increasing number of experimental studies showing various effects of endotoxins on cerebral tissue are being published. Thus, administration of endotoxin has been reported to induce an increased cytokine expression in adult rat brains (7-9). In particular, a rise in the release of TNF- $\alpha$ has been thought to be associated with neuronal cell damage (10). In addition, an increased expression of IL-1 $\beta$ and TNF- $\alpha$ mRNA has been observed in the brain of fetal rats after intraperitoneal application of LPS to the dam. This was followed by minimal cerebral injury (11). Similar observations have been described in immature rabbits after uterine infection with bacteria (12) and in newborn kittens after intraperitoneal injection of LPS (13). Only recently, it was reported that intraperitoneal injection of LPS in neonatal rats aggravates hypoxic-ischemic damage in the immature brain (14). To elucidate the effects of endotoxins on 
fetal cardiovascular control we applied i.v. LPS to preterm fetal lambs (15). During a short period of superimposed asphyxia, these fetuses were not able to maintain circulatory centralisation, i.e. to increase blood flow to the central organs at the expense of the peripheral perfusion. In the immediate recovery period, oxygen delivery to the fetal brain was nearly arrested. It is quite conceivable that under such conditions, fetal brain injury is brought about by hypoxic-ischemic insults.

Under clinical conditions, intrauterine inflammation is often accompanied by fetal asphyxia. The combination of exposure to inflammation and aspyhxia during birth has been linked to a dramatic increase in the risk of spastic cerebral palsy (16), suggesting that there may be an interaction between the pathophysiological mechanisms induced by inflammation and perinatal hypoxia. Up to now, few data have been presented on the effect of an early administration of endotoxins before a hypoxic-ischemic insult in the immature brain. In the present study, we therefore investigated whether intracisternal (i.c.) application of LPS enhances the susceptibility to subsequent hypoxic-ischemic brain damage in neonatal rats. 


\section{Material and Methods.}

\section{$\underline{\text { Animals }}$}

Experiments were performed on 7-day-old neonatal Wistar rats $(n=61)$ of both sexes. Until the day of the surgery, the pups stayed under controlled conditions in cages with their dams. A constant temperature of $20^{\circ} \mathrm{C}$, a 12 hour day / night rhythm, food and drink at libitum were maintained. Mean body weight on the surgery day was $14.9 \pm 0.7 \mathrm{~g}$.

\section{$\underline{\text { Surgical procedure }}$}

The pups were held and fixated by hand. After the skin was disinfected with $70 \%$ alcohol, $\mathrm{NaCl}$ or LPS (5 $\mu \mathrm{g}$ / pup; Escherichia coli; O127:B8, Sigma Chemical Co. Aldrich) was manually injected into the cisterna magna as described previously (17). Briefly, a syringe connected to a 32-gauge needle was used to inject $10 \mu \mathrm{l}$ of fluid intracisternally. The landmarks for the injection were the opistion and the crista occipitalis externa on the superior side and the basion on the inferior side. The needle was inserted within the quadrangle bounded by these points about one third of the way between the opistion and the basion. To check that the LPS was indeed being injected into the cisterna magna, we performed a pilot study on fifty 7-day-old rat pups. In these animals, Chinese ink was co-injected with $\mathrm{NaCl}$ or LPS and the correct administration was verified macroscopically. After the first ten animals, this pilot study had a success rate of $96 \%$.

One hour after i.c. application of LPS, the rat pups were anesthetized deeply by halothane inhalation. The left common carotid artery was exposed through a midline neck incision and ligated with 6-0 surgical silk. The duration of anesthesia and surgery never exceeded 15 min. After surgery, the pups were allowed to recover with their dams for another hour. The pups were placed in an incubator (Intensive Care Incubator 7510, Fa. Dräger, Lübeck, Germany) and were exposed to a hypoxic gas mixture ( $8 \%$ oxygen / $92 \%$ nitrogen). The ambient temperature was 
strictly maintained at $36^{\circ} \mathrm{C}$. After 60 min of hypoxia, the incubator was opened to room air and the pups returned to their dams (18). In the present study, we did not measure body temperature in the rat pups, since this is extremely difficult to do in such small animals. However, in experiments on adult animals, fever has not been reported after intracerebroventricular administration of LPS $(19,20)$. The experimental protocols were approved by the appropriate institutional review committee and met the guidelines of the governmental agency responsible.

\section{$\underline{\text { Experimental groups }}$}

The pups were randomized to four experimental groups.

Sham control group (1): Animals of this group underwent the surgical procedure described above except for the ligation of the carotid artery $(n=5)$.

LPS group (2): These animals were subjected only to i.c. application of LPS ( $\mathrm{n}=7)$.

Hypoxic-ischemic study group (3): Animals received an i.c. injection of $\mathrm{NaCl}$ and were exposed to hypoxia for $60 \mathrm{~min}$ after ligation of the left carotid artery $(\mathrm{n}=17)$.

Hypoxic-ischemic / LPS study group (4): Animals received an i.c. injection of LPS and were exposed to hypoxia for $60 \mathrm{~min}$ after ligation of the left carotid artery $(\mathrm{n}=19)$.

\section{$\underline{\text { Histology }}$}

Seven days after the insult, the rat pups were anesthetized with i.p. thiopental (12 mg / animal), a butterfly needle (21 gauge) was inserted into the left ventricle, and the right atrium was incised. Each animal was perfusion-fixed with $4 \%$ formaldehyde. After perfusion, the brains were removed and stored in the same fixative for at least 3 days. Coronal blocks of the brains were processed in graded ethanols and rotihistol. After embedding in paraffin wax, $5 \mu \mathrm{m}$-thick coronal slices were sectioned every $500 \mu \mathrm{m}$ and stained with cresyl-violet / fuchsin. 
158 Chapter 7

Hypoxic-ischemic brain injury was assessed directly after the brains were removed from the cranial cavity using a macroscopic 4-point scale (modified after (21)): $0=$ no macroscopically detectable damage; 1 = discrete, delineated, superficial pigmentation of the ipsilateral hemisphere; $2=$ moderate cystic infarction of the ipsilateral hemisphere $(\leq 4 \mathrm{~mm}) ; 3=$ severe cystic infarction of the ipsilateral hemisphere (>4 mm).

Hypoxic-ischemic neuronal cell damage within the cerebral cortex was also assessed microscopically. The cortex ipsilateral to the ligated carotid artery was evaluated at 6 coronal levels (longitudinal coordinates relative to Bregma: A $1.0 \mathrm{~mm}$, A $2.0 \mathrm{~mm}$, A $3.0 \mathrm{~mm}$, A $4.0 \mathrm{~mm}$, A $5.0 \mathrm{~mm}$, A $6.0 \mathrm{~mm}$ ). Coronal level A $2.0 \mathrm{~mm}$ showing the middle of the dorsal hippocampus was taken as the reference plane according to a stereotaxic atlas of 14-day-old rat brains (22). The longitudinal coordinates of the other coronal levels were determined by counting the number of the 5- $\mu \mathrm{m}$-thick histologic slices in posterior and anterior direction. The ipsilateral cortex was analysed by visual field at a magnification of 250x. Neurons with ischemic cell damage were identified according to the criteria of Brown and Brierley (23). Neuronal cell damage in each microscopical visual field was quantified by the following score: 0-5\% damage (score 1), 5-50\% damage (score 2), 50-95\% damage (score 3), 95-99\% damage (score 4), and $100 \%$ damage (score 5) (24). The histologic score of each coronal level was calculated by averaging the scores of all visual fields analyzed in that level. In the same way, neuronal cell damage of four hippocampal structures (dentate gyrus, CA 4, CA 3, CA 1 and CA 2) was evaluated at the coronal plane A $2.0 \mathrm{~mm}$ and that of the striatum at the coronal planes A $3.0 \mathrm{~mm}$ and A $4.0 \mathrm{~mm}$. The scoring system used in the present study has been previously established and evaluated by our group. The intraobserver and interobserver reliabilities were assessed by coefficients of variation and amounted to 3 and $10 \%$, respectively. This system has been used by our group and others successfully in a large number of studies (24-26).

In addition, coronal sections were scanned at 2700 x 2700 dpi with a film scanner (SprintScan 35 Plus, Polaroid Europe Ltd., Uxbridge, Middlesex, UK) and the digitized images were 
analyzed using the public domain NIH Image program (Version 1.61, U.S. National Institute of Health, Bethesda, MD, USA). Neuronal injury to the cortex was defined as areas of decreased neuronal density, confirmed by simultaneous bright field microscopy, and the area of cortical brain damage was expressed as percentage of the total cortex in each section. The mean value per brain was calculated and used for statistical evaluation (27). All observers involved in the histologic evaluations were blind to the treatment procedures.

\section{$\underline{\text { Immunohistochemistry }}$}

To clarify whether the injected LPS is really active in the immature brain, we studied the expression of TNF- $\alpha$. For this purpose, another group of rat pups $(n=9)$ were treated with LPS as described above. At 4, 10 and $24 \mathrm{~h}$ after the application, these animals as well as $\mathrm{NaCl}$ treated control pups $(n=4)$ were killed and perfusion-fixed with $4 \%$ formaldehyde. After incubation for $48 \mathrm{~h}$ in formaldehyde, the brains were transferred into $18 \%$ sucrose. Twenty $\mu \mathrm{m}$-thick coronal frozen sections of the brains were processed on a cryostat. For detection of TNF- $\alpha$, antirat TNF- $\alpha$ was used as primary antibody (Endogen, Woburn, MA, USA) at a working dilution of $1: 1000$. After incubation with primary antibody at room temperature for $2 \mathrm{~h}$, the avidinbiotin-horseradish peroxidase system (ABC kit from Vector Laboratories, Burlingame, CA, USA) was used for detection of immunopositive cells following the manufacturer's instructions. Negative controls were performed by omitting the primary antibody and by preadsorbtion of the TNF- $\alpha$ antibody with the homologous antigen (PeproTech EC Ltd, London, UK).

\section{$\underline{\text { Statistics }}$}

All data are given as means \pm SD. Statistical differences between groups were evaluated by the $\mathrm{X}^{2}$ test, Mann-Whitney $\mathrm{U}$ test or unpaired t-test where appropriate. $\mathrm{P}<0.05$ was considered significant. 


\section{Results}

Neuronal cell damage could not be observed in sham control animals or in rat pups that were subjected solely to LPS injection into the cisterna magna. In the cerebral cortex of the animals allotted to macroscopic score 1 and 2, only selective neuronal necrosis could be detected without any evidence of infarction. In the neonates that underwent hypoxia-ischemia plus LPS injection, the macroscopically assessed brain injury was significantly higher than that observed in pups subjected to hypoxia-ischemia and administration of $\mathrm{NaCl}$ (Table 1).

\begin{tabular}{lcc}
\hline Table 1: Macroscopically evaluated hypoxic-ischemic brain injury in neonatal rats. \\
$\begin{array}{lcc}\text { Score } & \text { NaCl/HI } & \text { LPS/HI } \\
0 & 8 & 4 \\
1 & 6 & 8 \\
2 & 3 & 0 \\
3 & 0 & 7 *\end{array}$
\end{tabular}

Rat pups were subjected to either i.c. application of NaCl $(n=17)$ or LPS $(n=19)$. One hour later, the animals underwent unilateral carotid artery occlusion followed by 60 min of hypoxia (HI). $0=$ no macroscopically detectable damage; $1=$ discrete, delineated, superficial pigmentation of the ipsilateral hemisphere $; 2=$ moderate cystic infarction of the ipsilateral hemisphere $(\leq 4 \mathrm{~mm}) ; 3=$ severe cystic infarction of the ipsilateral hemisphere $(>4 \mathrm{~mm})$. Statistically significant differences between control and study group were evaluated by $X^{2}$ test $(* p<0.01)$

Whereas 7 animals of the LPS group (group 4) developed severe cystic cerebral infarction, only mild to moderate damage could be observed in the rat pups of the $\mathrm{NaCl}$ group (group 3). 
The extent of microscopically determined neuronal cell damage in these two groups is illustrated in Table 2 and Figure 1.

Table 2: Microscopically evaluated hypoxic-ischemic brain injury in neonatal rats.

\section{$\mathbf{N a C l} / \mathrm{HI} \quad$ LPS/HI}

\section{Cortex}

Level 1 (A 1.0)

$1.31 \pm 0.21$

$1.95 \pm 1.25$

Level 2 (A 2.0)

$1.29 \pm 0.23$

$2.13 \pm 1.20 \quad *$

Level 3 (A 3.0)

$1.24 \pm 0.15$

$1.88 \pm 1.12$

Level 4 (A 4.0)

$1.08 \pm 0.11$

$1.60 \pm 0.98 \quad * *$

Level 5 (A 5.0)

$1.03 \pm 0.10$

$1.37 \pm 0.90 \quad * *$

Level 6 (A 6.0)

$1.03 \pm 0.13$

$1.39 \pm 1.06$

total

$1.18 \pm 0.12$

$1.81 \pm 1.05$

\section{Hippocampus}

DG

$1.59 \pm 1.33$

$1.26 \pm 0.73$

CA $1 / 2$

$1.59 \pm 1.37$

$1.11 \pm 0.32$

CA 3

$1.82 \pm 1.55$

$1.54 \pm 1.01$

CA 4

$1.65 \pm 1.32$

$1.54 \pm 1.20$

\section{$\underline{\text { Striatum }}$}

$$
1.27 \pm 0.70 \quad 1.65 \pm 1.16
$$

Rat pups were subjected to either i.c. application of NaCl $(n=17)$ or LPS $(n=19)$. One hour later, the animals underwent unilateral carotid artery occlusion followed by 60 min of hypoxia (HI). Score 1:0-5\% damage; score 2: 5-50\% damage; score 3:50-95\% damage; score 4: 9599\% damage; score 5: 100\% damage. Values are given as means \pm SD. Statistically significant differences between control and study group were evaluated by Mann-Whitney U test $(*: p<$ $0.05, * *: p<0.01, * * *: p<0.001)$ 

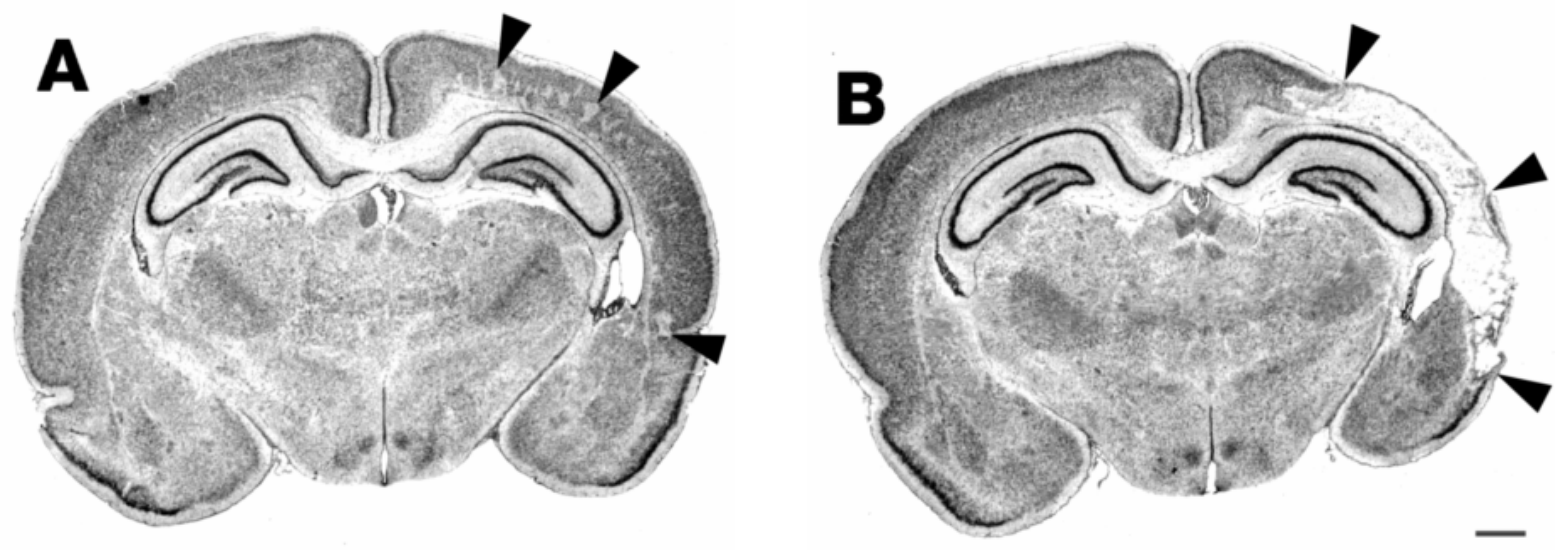

Figure 1. Photomicrographs showing coronal sections (A $2.0 \mathrm{~mm}$ ) of $\mathrm{NaCl}$ - (A) and LPS-

treated $(B)$ rat pups subjected to 60 min of hypoxia-ischemia. Sections were stained with cresylviolet/fuchsin. Whereas only selective neuronal necrosis (arrow heads) could be observed in the animals that received $\mathrm{NaCl}$, the i.c. application of LPS sensitized the immature brain to a subsequent hypoxic-ischemic insult and resulted in cerebral infarction (arrow heads).

Neuronal cell damage was most pronounced in the posterior levels of the cerebral cortex. Except at the levels A 1.0 and A 3.0 neuronal cell injury was significantly higher in the cortex of the animals subjected to hypoxia-ischemia and LPS injection. No differences between groups could be detected in the hippocampus and striatum. Cellular damage in the white matter could not be observed in any of the brains evaluated.

The mean neuronal injury in the cerebral cortex of the animals of experimental group 4 analyzed by the above described CCD-based image analysis system was significantly higher than that in the rat pups of group $3(8.9 \pm 3.2 \%$ versus $1.2 \pm 0.2 \%, \mathrm{p}<0.001)$ (Figure 2). In group 4 animals, neuronal cell damage or white matter injury could not be detected in the contralateral hemisphere. We therefore did not randomize rat pups to sham surgery and LPS application. 


\section{Figure 2.}

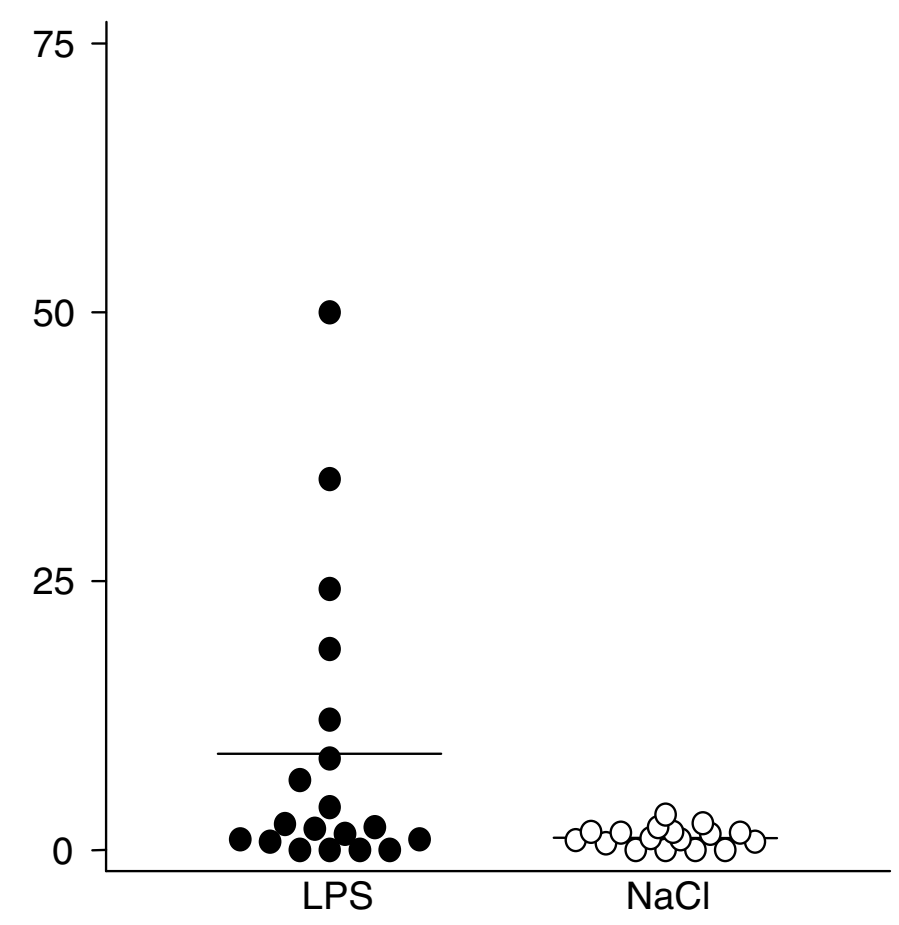

Groups

Figure 2. Effect of LPS (5 $\mu$ g/animal i.c.) on subsequent hypoxic-ischemic brain damage in neonatal rats. Neuronal injury to the cortex was defined as areas of decreased neuronal density, confirmed by simultaneous bright field microscopy, and the area of cortical brain damage was expressed as \% of the total cortex in each section. Statistically significant differences between control and study group were evaluated by unpaired t test $(p<0.03)$. 
Ten hours after injection of LPS into the cisterna magna, a weak expression of TNF- $\alpha$ could be observed in the leptomeninges $(n=3)$. After $24 \mathrm{~h}$, this expression was considerably stronger $(n=3$; Figure 3). Most of the cells that were positive for TNF- $\alpha$ staining seemed to be macrophages. No staining for TNF- $\alpha$ could be detected in the cerebral parenchyme at any time after LPS injection. Animals that received an injection with $\mathrm{NaCl}$ also gave no positive staining for TNF- $\alpha(\mathrm{n}=4$; Figure 3).
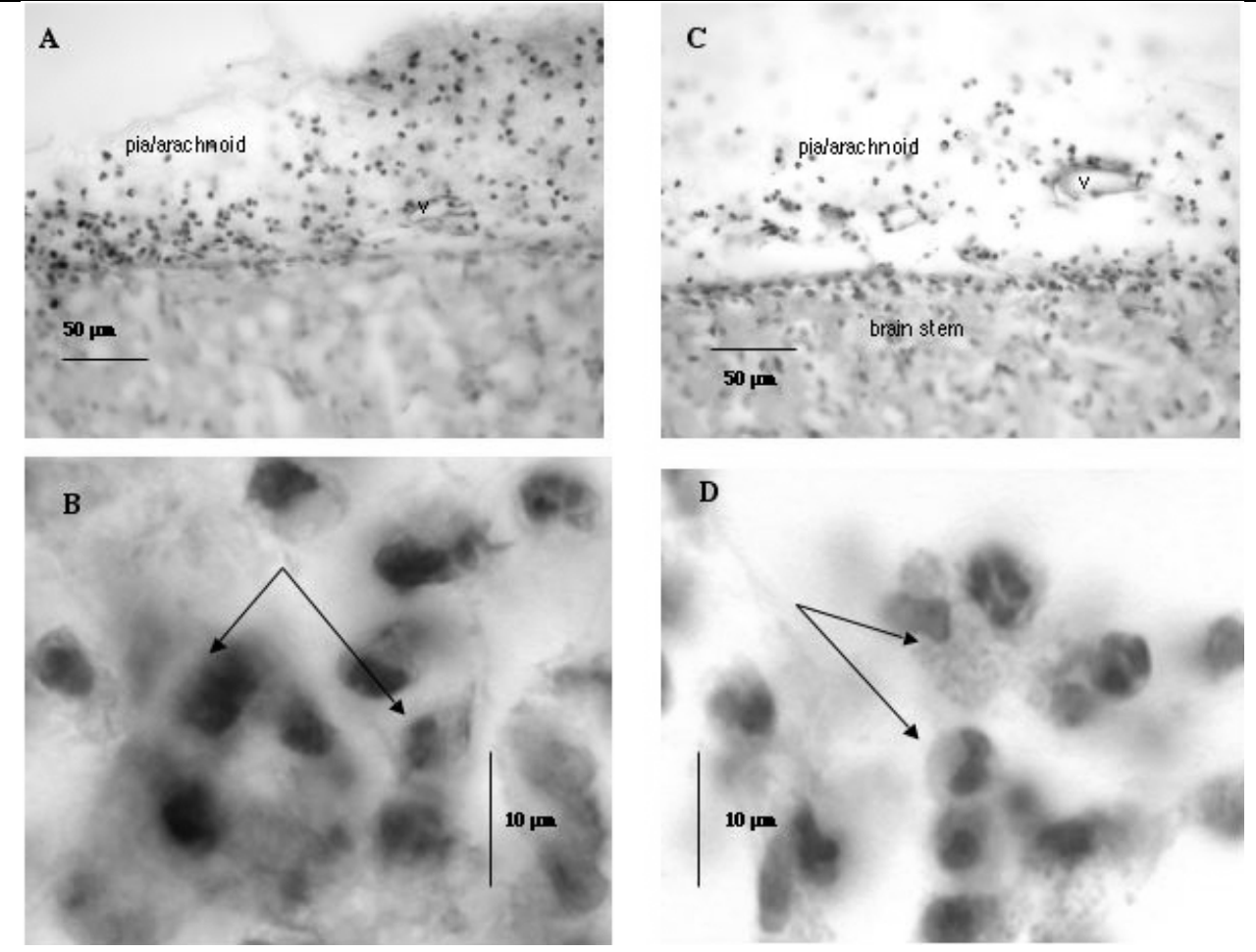

Figure 3. Representative photomicrographs of immunostaining for TNF- $\alpha$ in neonatal rat brain-stem sections. Anti-rat TNF- $\alpha$ against TNF- $\alpha$ was used as primary antibody at a working dilution of $1: 1000$. After incubation with primary antibody at room temperature for $2 \mathrm{~h}$, the avitin-biotin-horseradish peroxidase system was used for detection of immunopositive cells. Rat pups were subjected to either i.c. application of $\mathrm{NaCl}(\mathrm{C})$ or LPS (A). The immunoreactive product could be detected only in the leptomeninges of the animals of the study group. Bar $=50$ $\mu m$. B, The cytoplasmic TNF-a staining is indicated by arrows. Preadsorption of the TNF- $\alpha$ antibody with the homologous antigen is shown in D. Bar $=10 \mu \mathrm{m} . v$, venous vessel. 


\section{Discussion.}

The central finding of the present study was that endotoxin enhances the susceptibility to subsequent hypoxic-ischemic brain damage in neonatal rats. In most studies on LPS and ischemic neuronal injury, preconditioning effects were described with reduced brain injury when LPS was applied several days before middle cerebral artery occlusion in adult rats (28). However, the time interval between the primary and secondary insults seem to be the most important variable determining whether an alleviation or an aggravation of the final outcome is observed. Thus, sensitization of the immature brain to injury has been demonstrated after repeated brief episodes of cerebral hypoxia-ischemia (26). A similar relationship may exist between LPS and hypoxia-ischemia.

The mechanisms that mediate the sensitizing effects of LPS to hypoxic-ischemic insults are little understood. In a recent study on neonatal rats, altered expression of CD14 mRNA and toll-like receptor-4 mRNA (TLR) were detected in the brain after i.p. injection of LPS and a subsequent hypoxic-ischemic insult (14). After binding LPS, the membrane-bound and soluble forms of CD14 promote the activation of myeloid (monocyte / macrophage / polymorphonuclear leukocyte) and non-myeloid (endothelial / epithelial) cells, respectively (29). The elusive signaling unit of the LPS receptor includes members of the human TLR family. The cytoplasmic tail of TLR has a similar sequence homology to the IL-1 receptor I and TLR stimulation induces synthesis of pro-inflammatory cytokines, such as IL-1 and TNF- $\alpha$ (30; for review 31). IL-1 mediates ischemic, excitotxic and traumatic brain injury, probably through multiple actions on glia, neurons and the vasculature. TNF- $\alpha$ has also been reported to contribute to neuronal injury (32). Altered expression of CD14 and TLR-4 may therefore be one of the underlying mechanism through which LPS sensitizes the immature brain to a subsequent hypoxic-ischemic insult (14). 
It is interesting to note that in the present study, neuronal cell damage was only aggravated in the cortex, but not in deeper brain structures such as the striatum and the hippocampus. We speculate that the TNF- $\alpha$ released in the leptomeninges penetrated the underlying cerebral cortex and accelerated cyclooxygenase 2 and the inducible form of nitric oxide synthase in the microglia (33). Radicals produced through these pathways are widely known to injure the neuronal network. In addition, TNF- $\alpha$ has been reported to activate the Fas-receptor system and to cause subsequent apoptotic cell death (for review 31). Another mechanism by which TNF- $\alpha$ could injure the immature brain is its stimulatory effects on metalloproteinases. These enzymes are known to degrade virtually all components of the extracellular matrix. They also lyse the subendothelial basement membrane, which forms the blood-brain barrier around cerebral capillaries and mediates the extravasation of leukocytes $(27,34)$. However, additional experiments will have to be performed to clarify whether these mechanisms are involved in the LPS-induced sensitization of the immature brain to ischemia.

Recently, Eklind et al (14) also described a sensitization of the immature rat brain to hypoxicischemic insults by i.p. injection of LPS $(0.3 \mathrm{mg} / \mathrm{kg}$ body $\mathrm{wt})$. The aggravation of the hypoxicischemic insult that they observed was more pronounced than that found in the present study. There could be various reasons for this: the LPS have been taken from different strains of bacteria and have been applied via differing routes in the two studies. Furthermore, the studies vary with regard to endpoints investigated. Whereas the rat pups were killed $3 \mathrm{~d}$ after the insult in the former report, in the present investigation animals were not perfusion-fixed until the seventh day after hypoxia. Eklind et al (14) also measured cerebral blood flow immediately after the insult using the antipyrine technique and did not detect any differences between their study and control groups. From these results, they concluded that the effects of LPS on the immature brain were not mediated by an alteration of cerebral vasculature. However, as shown in a recent study on fetal sheep, i.v. application of LPS at a much lower concentration (50 $\mu \mathrm{g} / \mathrm{kg}$ body wt) 
severely compromised fetal cardiovascular control and nearly arrested cerebral oxygen delivery shortly after superimposed hypoxia (15). LPS-induced effects on cerebral blood flow therefore cannot be excluded by a single measurement at the end of a hypoxic-ischemic insult. In the present study, LPS was injected directly into the cerebrospinal fluid. Severe disturbances of the cardiovascular system are unlikely under such conditions but cannot be excluded, because blood flow measurements were not performed. Some reports describe an increase in cerebral blood flow within the first hours after intracerebroventricular injection of LPS $(19,20)$. Although such changes in cerebral perfusion are very unlikely to exacerbate hypoxic ischemic brain injury, LPS-induced alterations of cerebral blood flow that enhances the susceptibility of the immature brain to subsequent insults can not be excluded in the present study.

Despite extensive histologic examination, we did not detect any white-matter injury in the brains investigated. This seems to contradict epidemiological data reporting an association between inflammation and white matter damage in immature fetuses $(35,36)$. However, one should take into consideration that the endotoxins were applied intracisternally in the present study and that the expression of TNF- $\alpha$ could only be observed in the leptomeninges. It is therefore conceivable that the concentration of the administered LPS did not reach concentrations in the cerebral white matter high enough to activate the pathophysiological cascade leading to cellular damage. The same may be true for the striatum and the hippocampus. Since we did not perform immunohistochemistry to characterize the various cellular subtypes of the brain parenchyma, subtle injury to smaller groups of cells such as oligodendrocytes and their precursors cannot be fully excluded.

Expression of TNF- $\alpha$ could not be observed in the present study until $10 \mathrm{~h}$ after the application of LPS, which is somewhat later than in previous studies performed in adult mice (37). As already mentioned, differences in the bacterial strain from which the LPS was derived as well as 
168 Chapter 7

differences in the maturity of the immunologic system of the studied animals may be responsible for this finding.

From the results of the present study, we conclude that i.c. application of LPS enhances the susceptibility to subsequent hypoxic-ischemic brain damage in neonatal rats. The underlying mechanisms are not yet fully understood. 


\section{References}

1. Berger R, Garnier Y 1999 Pathophysiology of perinatal brain damage. Brain Res Brain Res Rev 30:107-134.

2. Volpe JJ 1995 Neurology of the newborn, Saunders, Philadelphia.

3. Damman O, Leviton A 1997 Maternal intrauterine infection, cytokines, and brain damage in the preterm infant. Pediatr Res 42:1-8.

4. Nisswander KR, Gordon M 1972 The women and their pregnancies. The collaborative Perinatal Study of the National Institute of Neurological Diseases and Stroke. Philadelphia: WB Saunders, pp 252-256.

5. Berger R, Bender S, Sefkow S, Klingmüller V, Künzel W, Jensen A 1997 Peri/intraventricular haemorrhage : A cranial ultrasound study on 5286 neonates. Eur J Obstet Genecol Reprod Biol 75:191-203.

6. Paneth N, Pinto-Martin J, Gardiner J, Wallenstein S, Katsikiotis V, Hegyi T, Hiatt IM, Susser M 1993 Incidence and timing of germinal matrix/ventricular hemorrhage in low birth weight infants. Am J Epidemiol 137:1167-1176.

7. Gatti S, Bartfai T 1993 Induction of tumor necrosis factor-alpha mRNA in the brain after peripheral endotoxin treatment: comparison with interleukin-1 family and interleukin-6. Brain Res 624:291-4.

8. Hillhouse EW, Mosley K 1993 Peripheral endotoxin induces hypothalamic immunoreactive interleukin-1 beta in the rat. Br J Pharmacol 109:289-290.

9. Van Dam AM, Bauer J, Tilders FJ, Berkenbosch F 1995 Endotoxin-induced appearance of immunoreactive interleukin-1 beta in ramified microglia in rat brain: a light and electron microscopic study. Neuroscience 65:815-826.

10. Barone FC, Arvin B, White RF, Miller A, Webb CL, Willette RN, Lysko PG, Feuerstein GZ 1997 Tumor necrosis factor-alpha. A mediator of focal ischemic brain injury. Stroke 28:12331244.

11. Cai Z, Pan Z, Pang Y, Evans OB, Rhodes PG 2000 Cytokine induction in fetal rat brains and brain injury in neonata rats after maternal lipopolysaccharide administration. Pediatr Res 47: 6472.

12. Yoon BH, Kom CJ, Romero R, Jun JK, Park KH, Choi ST, Chi JG 1997 Experimentally induced intrauterine infection causes fetal brain white matter lesions in rabbits. Am J Obstet Gynecol 177:797-802.

13. Gilles FH, Averill DR Jr, Kerr CS 1977 Neonatal endotoxin encephalopathy. Ann Neurol 2:4956. 
14. Eklind S, Mallard C, Leverin A, Gilland E, Blomgren K, Mattsby-Baltzer I and Hagberg H 2001 Bacterial endotoxin sensitizes the immature brain to hypoxic-ischaemic injury. Eur J Neuroscience 13:1101-1106.

15. Garnier Y, Coumans ABC, Berger R, Jensen A, Hasaart THM 2001 Endotoxemia severely affects circulation during normoxia and asphyxia in immature fetal sheep. J Soc Gynecol Investig 8:134-142.

16. Nelson KB, Grether JK 1998 Potentially asphyxiating conditions and spastic cerebral palsy in infants of normal birth weight. Am J Obstet Gynecol 179:507-513.

17. Leib SL, Clements JM, Lindberg RL, Heimgartner C, Loeffler JM, Pfister LA, Tauber MG, Leppert D 2001 Inhibition of matrix metalloproteinases and tumour necrosis factor alpha converting enzyme as adjuvant therapy in pneumococcal meningitis. Brain 124:1734-1742.

18. Rice JED, Vannucci RC and Brierley JB 1981 The influence of immaturity on hypoxic-ischemic brain damage in the rat. Ann Neurol 9:131-141.

19. Okamoto H, Ito O, Roman RJ, Hudetz AG 1998 Role of inducible nitric oxide synthase and cyclooxygenase-2 in endotoxin-induced cerebral hyperemia. Stroke 29:1209-1218.

20. Brian JE, Heistad DD, Faraci FM 1995 Dilatation of cerebral arterioles in response to lipopolysaccharide in vivo. Stroke 26:277-281.

21. Bona E, Johansson BB, Hagberg H 1997 Sensorimotor function and neuropathology five to six weeks after hypoxia-ischemia in seven-day-old rats. Pediatr Res 42:678-683.

22. Sherwood NM, Timiras PS 1970 A Stereotaxic Atlas of the Developing Rat Brain. University of California Press, Berkeley, pp 15-75.

23. Brown AW, Brierley JB 1972 Anoxic-ischaemic cell change in rat brain light microscopic and fine structural observations. J Neurol Sci 16:59-84.

24. Berger R, Lehmann T, Karcher J, Garnier Y, Jensen A 1998 Low dose flunarizine protects the fetal brain from ischemic injury in sheep. Pediatr Res 44:277-282.

25. Berger R, Lehmann T, Karcher J, Schachenmayr W, Jensen A 1996 Relation between cerebral oxygen delivery and neuronal cell damage in fetal sheep near term. Reprod Fertil Dev 8:317321.

26. Mallard EC, Williams CE, Gunn AJ, Gunning MI, Gluckman PD 1993 Frequent episodes of brief ischemia sensitize the fetal sheep brain to neuronal loss and induce striatal injury. Pediatr Res 33:61-65.

27. Leib SL, Leppert D, Clements J, Täuber MG 2000 Matrix metalloproteinases contribute to brain damage in experimental pneumococcal meningitis. Infect Immun 68:615-620.

28. Dawson DA, Furuya K, Gotoh J, Nakao Y, Hallenbeck JM 1999 Cerebrovascular hemodynamics and ischemic tolerance: lipopolysaccharide-induced resistance to focal cerebral 
ischemia is not due to changes in severity of the initial ischemic insult, but is associated with preservation of microvascular perfusion. J Cereb Blood Flow Metab 19:616-623.

29. Ulevitch RJ, Tobias PS 1995 Receptor-dependent mechanisms of cell stimulation by bacterial endotoxin. Annu Rev Immunol 13:437-457.

30. Kopp EB, Medzhitov R 1999 The Toll-receptor family and control of innate immunity. Curr Opin Immunol 11:13-18.

31. Ulevitch RJ, Tobias PS 1999 Recognition of gram-negative bacteria and endotoxin by the innate immune system. Curr Opin Immunol 11:19-22.

32. Allan SM, Rothwell NJ 2001 Cytokines and acute neurodegeneration. Nat Rev Neurosci 2:734744.

33. Serou MJ, DeCoster MA, Bazan NG 1999 Interleukin-1 beta activates expression of cyclooxygenase- 2 and inducible nitric oxide synthase in primary hippocampal neuronal culture: platelet-activating factor as a preferential mediator of cyclooxygenase-2 expression. J Neurosci Res 58:593-598.

34. Rosenberg GA, Estrada EY, Dencoff JE, Stetler-Stevenson WG 1995 Tumor necrosis factoralpha-induced gelatinase B causes delayed opening of the blood-brain barrier: an expanded therapeutic window. Brain Res 703:151-155.

35. Leviton A, Paneth N, Reuss ML, Susser M, Allred EN, Dammann O, Kuban K, Van Marter LJ, Pagano M, Hegyi T, Hiatt M, Sanocka U, Shahrivar F, Abiri M, Disalvo D, Doubilet P, Kairam R, Kazam E, Kirpekar M, Rosenfeld D, Schonfeld S, Share J, Collins M, Genest D, ShenSchwarz S 1999 Maternal infection, fetal inflammatory response, and brain damage in very low birth weight infants. Developmental Epidemiology Network Investigators. Pediatr Res 46:566575.

36. Wu YW, Colford JM Jr 2000 Chorioamnionitis as a risk factor for cerebral palsy: A metaanalysis. JAMA 284:1417-1424.

37. Faggioni R, Fantuzzi G, Villa P, Buurman W, van Tits LJ, Ghezzi P 1995 Independent downregulation of central and peripheral tumor necrosis factor production as a result of lipopolysaccharide tolerance in mice. Infect Immun 63:1473-147. 



\section{Chapter 8}

The effects of low dose endotoxin (LPS) on the umbilicoplacental circulation in preterm sheep

A.B.C. Coumans, Y. Garnier, S. Supçun, A. Jensen, R. Berger, T.H.M. Hasaart 


\section{Introduction}

Hypoxic-ischemic brain damage was previously thought to be the leading cause of perinatal brain damage, but during the last years other aetiologies have been acknowledged as causes for such injury $(1,2)$. Perinatal brain damage is often preceded by antenatal infections and antenatal infection is inherently associated with the development of cerebral palsy $(3,4,5)$. Recently, a meta-analysis evaluated the potential association between chorioamnionitis and cerebral palsy, in both full term and preterm infants (6). The authors reported an association between clinical chorioamnionitis and both cerebral palsy (RR 1.9; 95\% CI 1.-2.5) and cystic periventricular leukomalacia (RR 2.6; 95\% CI 1.7-3.9). However, the pathogenesis of infection/inflammationinduced neuronal and oligodendroglial cell damage remains unclear.

Yoon and co-workers have shown that antenatal exposure to intra-amniotic inflammation and evidence of a systemic fetal inflammatory response such as funisitis are strong and independent risk factors for the subsequent development of cerebral palsy at the age of 3 years (7). Furthermore, endotoxins may be involved in provoking preterm birth as they increase the expression of prostaglandins (8). There is evidence from epidemiologic studies that exposure to placental infection before or during birth is associated with cerebral white matter damage especially in very preterm fetuses (before 32 weeks gestation) and those with very low birth weight $(<1500 \mathrm{~g})(9)$. Endotoxin might cause an increased production of cytokines which may have a direct neurotoxic effect. Also, endotoxin might lead to perinatal brain damage by causing endotoxemic shock and hypoperfusion of the brain and placenta (10). A study we performed last year in neonatal rats showed that bacterial endotoxin sensitizes the brain to hypoxic-ischemic injury and induces cerebral infarction in response to short periods of hypoxia-ischemia that individually caused no injury (11). These results were also found after intraperitoneal injections of LPS (12).

Results from an earlier study performed in our laboratory clearly show that systemic application of a large dose endotoxin in premature fetal sheep severely impairs fetal cardiovascular control 
during normoxia and hypoxia. Thus, application of LPS resulted in placental hypoperfusion and alteration of circulatory centralization during hypoxia, leading to early fetal death in nearly all LPS treated animals (10). In the present study we examined the effects of a non-lethal dose LPS on the umbilicoplacental circulation.

\section{Material and Methods}

\section{$\underline{\text { Animal preparation }}$}

Twenty fetal sheep were chronically instrumented at a mean gestational age of $107 \pm 1$ days (term is 147 days). All ewes underwent surgery with use of sterile techniques while they were under general anesthesia (thiopental sodium $(1 \mathrm{gm} / 70 \mathrm{~kg})$ intravenously for induction, $0.5-1.0 \%$ halothane in a 1:1 nitrous oxide and oxygen mixture for maintenance). The ewes received $1 \mathrm{gm}$ ampicilline (Pentrexyl®; Bristol-Myers, Woerden, The Netherlands) s.c. and $10 \mu \mathrm{g}$ buprenorphin (Temgesic ${ }^{\circ}$; Schering, The Netherlands) per kg body weight twice a day for three consecutive postoperative days. A midline abdominal incision was performed. The fetal limbs were identified and exteriorised through an incision in the uterus. Polyvinyl catheters (Maxxim Medical BV, Den Bosch, The Netherlands) with $0.75 \mathrm{~mm}$ inner diameter and $1.25 \mathrm{~mm}$ outer diameter were inserted via a tibial fetal vein and artery of each hindleg and advanced into the caudal vena cava and abdominal aorta, respectively. A transonic flow probe (Transonics Systems Inc., Ithaca, NY, USA) was placed around the common umbilical artery through a retroperitoneal approach. In eight fetuses, anatomical variation with a too short common umbilical artery precluded placement around the common umbilical artery and therefore the flow probe had to be placed around one of the two single umbilical arteries. The fetal skin was closed with cyanoacrylate glue (Cyanolit, Japan). An intrauterine pressure catheter was placed, and the uterus was sutured after replacing the lost amniotic fluid with a $0.9 \%$ saline solution at $39^{\circ} \mathrm{C}$. Catheters were filled with heparin $\left(500 \mathrm{IU} / \mathrm{ml}\right.$; Heparin-Natrium ${ }^{\circledR}$, Braun, Melsungen, Germany) and exteriorised through a small incision in the flank of the ewe. Catheters were 
protected by a pouch sewn to the skin of the ewe. A recovery period of 72 hours followed the operation before experiments were started. After the experiment the animals were anesthetized with thiopental (thiopental sodium $1 \mathrm{gm} / 70 \mathrm{~kg}$ intravenously for induction, $0.5-1.0 \%$ halothane in a 1:1 nitrous oxide and oxygen mixture for maintenance). The right atrium and both jugular veins were incised. After intracardiac injection with $10.000 \mathrm{IU}$ heparin, each animal was perfusion-fixed through a needle placed in the left ventricle with $500 \mathrm{ml} 10 \%$ formaldehyde until the fluid efflux from the jugular veins was clear.

Ewes were housed in individual cages and had free access to food and water.

Guidelines for care and use of animals, as approved by the local Animal Medical Ethics Committee at Maastricht University, were followed.

\section{Experimental protocol}

The experiments were performed 3 days after the surgical procedure at $110 \pm 1$ days. The study group was treated by either $100(n=9)$ or 500 nanogram $(n=5)$ LPS i.v. from one batch (derived from E. coli; O127:B8, Sigma-Aldrich) while the control group $(\mathrm{n}=6)$ received $2 \mathrm{~mL}$ 0,9\% saline i.v. The total number of animals included in the experiment was 20. Six fetuses from the LPS group died during the experiment and were thus excluded from statistical analysis.

Fetal heart rate (FHR), mean arterial pressure (MAP) and umbilical blood flow (Qumb) were monitored for three consecutive days. At timepoints -1 hour (control value) +1 hour, +6 hours, +12 hours, +18 hours, +24 hours, +48 hours and +72 hours with 0 corresponding to saline or LPS injection, blood gas analysis was performed. After 72 hours animals were perfusion fixed with formaldehyde as described above.

The experimental protocols were approved by the Animal Medical Ethics Committee of Maastricht University and met the guidelines of the responsible governmental agencies. 


\section{$\underline{\text { Measurements }}$}

Placental blood flow, fetal heart rate and mean blood pressure were continuously recorded during the experiment on a personal computer, using a customized hemodynamic data acquisition system (University of Maastricht, The Netherlands).

Blood samples were taken at various timepoints from the fetal descending aorta and analysed for blood gases, acid base balance (AVL 993, Radiometer, Copenhagen, Denmark), hemoglobin concentration and arterial oxygen saturation of hemoglobin (OSM 2 Hemoximeter, Radiometer, Copenhagen, Denmark).

Placental vascular resistance $(\mathrm{mmHg} / \mathrm{mL}$ per minute per kilogram fetal weight) was calculated by dividing the perfusion pressure of the umbilical circulation by umbilical blood flow. Perfusion pressure was defined as mean arterial blood pressure minus caval vein pressure.

\section{$\underline{\text { Statistics }}$}

The data were analysed for intra- and intergroup differences by two-way multivariate analysis of variance for repeated measures. Games-Howell-test was used as post-hoc testing procedure. Statistical analysis was performed by Super Anova Statistical Package (Abacus Inc., Ca., USA). Results are given as means \pm SEM. 


\section{Results}

All measurements of MAP, FHR, blood gases and umbilical blood flow in the control period were in the normal range for chronically prepared fetal sheep of this gestational age (13). There were no significant differences between the control and LPS group at this time point (Table I). Mean Arterial Pressure (MAP) in the control group was $42 \pm 2.2 \mathrm{mmHg}$ during normoxia, and did not change during the course of the experiment. MAP increased significantly in the LPS group 1 hour after LPS injection and returned to control levels 4-5 hours after LPS administration (from $39 \pm 2.38 \mathrm{mmHg}$ to $46 \pm 2.53 \mathrm{mmHg},+17.8 \%, \mathrm{p}<0.001$ ) (Figure 1 ).

Fetal Heart Rate (FHR) increased five hours after LPS injection from $180 \pm 7$ to $221 \pm 9 \mathrm{bpm}$ $(+22.4 \%)$, and was significantly higher than fetal heart rate in the control group which did not change significantly from control values $(181 \pm 6 \mathrm{bpm}, \mathrm{p}<0.01)$. FHR normalized 15 hours after LPS injection (Figure 2).

Table I. Blood gases in endotoxin treated $(n=8)$ and control animals $(n=6)$

\begin{tabular}{|c|c|c|c|c|c|c|c|c|c|c|}
\hline & & -1 & 1 & 3 & 6 & 12 & 24 & 48 & 72 & \\
\hline \multirow[t]{2}{*}{$\mathrm{sO}_{2}$} & Control & $46.2 \pm 4.4$ & $50.9 \pm 2.0$ & $51.6 \pm 4.0$ & $52.7 \pm 2.6$ & $45.5 \pm 4.5$ & $51.2 \pm 3.3$ & $51.2 \pm 8.9$ & $54.8 \pm 10.7$ & \\
\hline & LPS & $50.9 \pm 6.9$ & $51.3 \pm 5.0$ & $38.8 \pm 6.0$ & $32.2 \pm 4.2 \quad \mathrm{a}, \mathrm{d}$ & $40.9 \pm 5.1$ & $49.5 \pm 3.2$ & $51.7 \pm 4.6$ & $35.5 \pm 6.6$ & $\mathrm{a}, \mathrm{d}$ \\
\hline \multirow[t]{2}{*}{$\mathrm{pH}$} & Control & $7.31 \pm 0.01$ & $7.33 \pm 0.01$ & $7.33 \pm 0.02$ & $7.33 \pm 0.01$ & $7.32 \pm 0.02$ & $7.32 \pm 0.01$ & $7.34 \pm 0.02$ & $7.31 \pm 0.01$ & \\
\hline & LPS & $7.36 \pm 0.01$ & $7.33 \pm 0.02$ & $7.31 \pm 0.02$ & $7.31 \pm 0.01$ & $7.36 \pm 0.02$ & $7.34 \pm 0.01$ & $7.32 \pm 0.02$ & $7.27 \pm 0.05$ & $\mathrm{e}$ \\
\hline \multirow{2}{*}{$\underset{(\mathrm{mmHg})}{\mathrm{pO}_{2}}$} & Control & $19.5 \pm 2.4$ & \pm 1.9 & .9 & .8 & .6 & 1.2 & $22.5 \pm 2.5$ & $19.5 \pm 1.4$ & \\
\hline & LPS & $21.5 \pm 1.6$ & $22.1 \pm 1.2$ & $19.8 \pm 0.9$ & $17.6 \pm 1.3$ & $19.5 \pm 1.9$ & $22.3 \pm 1.8$ & $23.2 \pm 2.3$ & $22.8 \pm 3.4$ & \\
\hline \multirow{2}{*}{$\begin{array}{c}\mathrm{pCO}_{2} \\
(\mathrm{mmHg})\end{array}$} & Control & $55.3 \pm 2.0$ & $56.3 \pm 3.0$ & $56.6 \pm 3.1$ & $57.5 \pm 3.1$ & $44.7 \pm 9.6$ & $50.4 \pm 7.8$ & $57.2 \pm 4.6$ & $77.0 \pm 14.2$ & \\
\hline & LPS & $54.4 \pm 2.0$ & $54.6 \pm 2.2$ & $58.2 \pm 1.9$ & $58.6 \pm 1.7$ & $55.4 \pm 1.4$ & $53.1 \pm 1.9$ & $60.6 \pm 8.3$ & $48.5 \pm 10.5$ & \\
\hline \multirow[t]{2}{*}{$\mathrm{Hb}$} & Control & $6.1 \pm 0.2$ & $6.1 \pm 0.2$ & $6.8 \pm 0.3$ & $5.7 \pm 0.1$ & $5.9 \pm 0.3$ & $5.9 \pm 0.4$ & $5.8 \pm 0.9$ & $5.3 \pm 0.5$ & \\
\hline & LPS & $6.5 \pm 0.4$ & $6.8 \pm 0.4$ & $7.0 \pm 0.4$ & a $\quad 6.6 \pm 0.4$ & $6.3 \pm 0.4$ & $6.2 \pm 0.3$ & $6.0 \pm 0.2$ & $6.0 \pm 0.3$ & \\
\hline
\end{tabular}

Values are given as means \pm standard error, for statistical analyses a ANOVA and Games-

Howell post hoc test was used.

a $p<0.05$, significant between groups

$d p<0.05$, significant versus control within group

b $p<0.01$, significant between groups e $p<0.01$, significant versus control within group

$c p<0.001$, significant between groups f $p<0.001$, significant versus control within group 
Figure 1. Mean arterial pressure in control and endotoxin treated

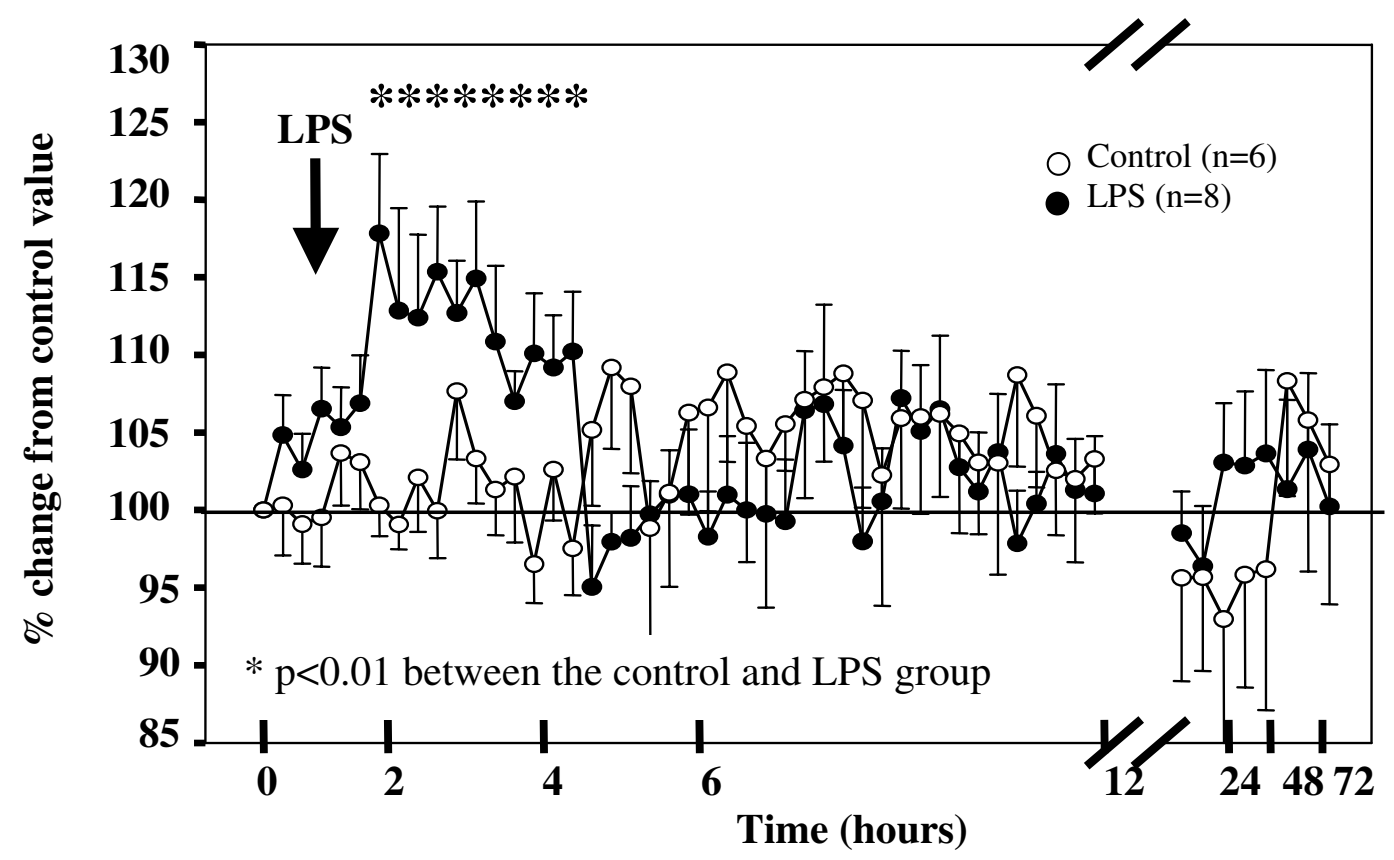


Figure 2. Fetal heart rate in control and endotoxin treated animals.

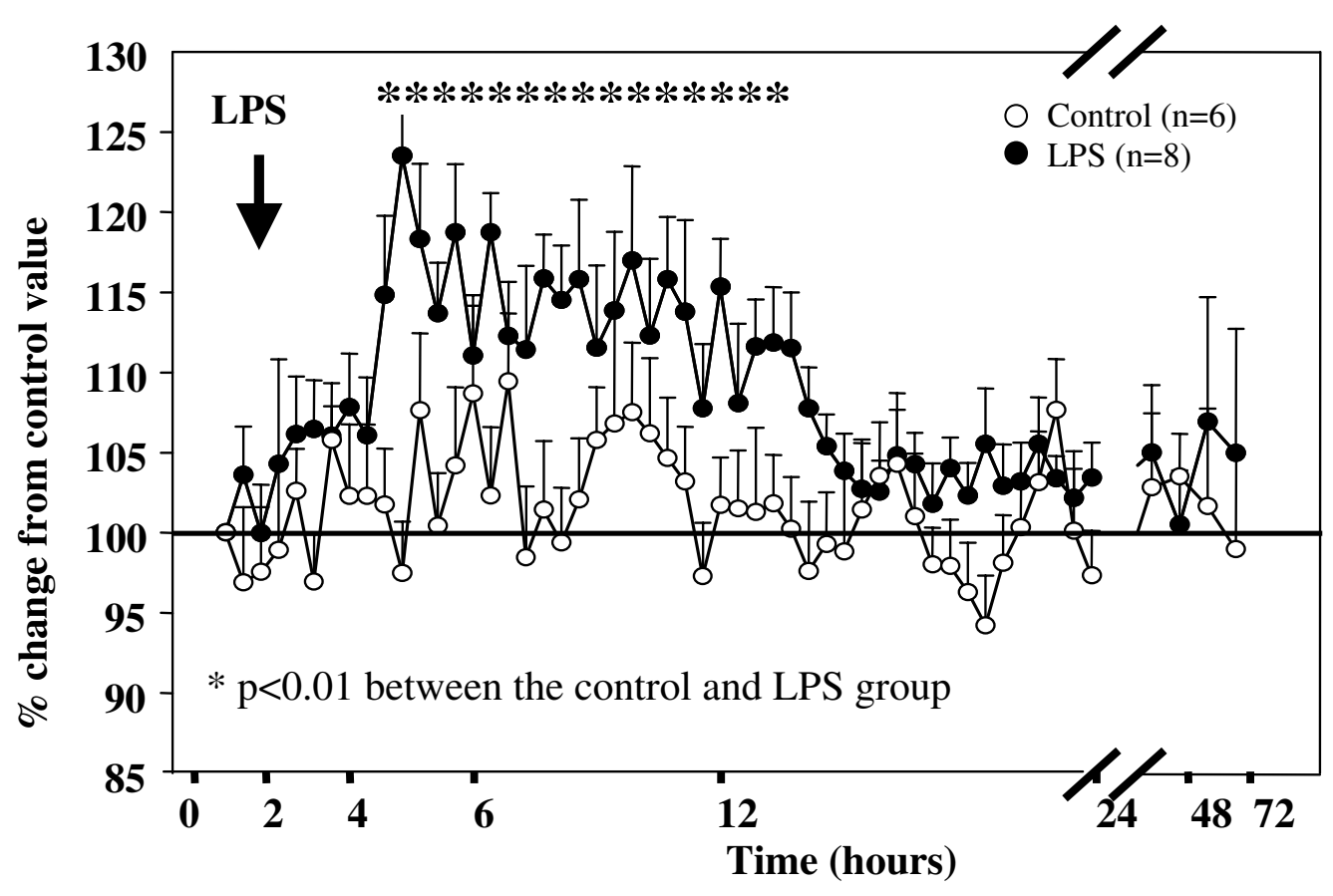

Oxygen saturation was significantly lower in the LPS group at 6 hours $(\mathrm{P}<0.05)$ and slowly recovered during the following 24 hours although not completely ( $<<0.05$ at 72 hours). There was no significant difference in arterial blood $\mathrm{pH}$ between the two groups (Table I). There were no significant differences in the blood gas parameters detected between treated and untreated fetuses (Table I).

Since in eight cases the flow probe was placed around one single umbilical artery, due to anatomical variations, we give the results as percentage change from control value. Absolute umbilical blood flow in the fetuses, with a flow probe around the common umbilical artery, was $257 \pm 31 \mathrm{ml} / \mathrm{min} / \mathrm{kg}$ fetal weight. Statistical analysis revealed no significant intergroup differences in umbilical blood flow in response to 100 or 500 nanogram LPS treatment protocol 
and these data were thus combined. In the control group, umbilical blood flow did not change significantly during the experiment. In contrast, in the LPS group (100 and 500 nanogram), umbilical blood flow decreased 1 hour after LPS to significant lower levels (-30\% at timepoint $+5, \mathrm{p}<0.01)$ and remained low during 12 hours after LPS. Although placental blood flow recovered after LPS, attenuation of blood flow compared to the control group persisted for the remainder of the experiment $(\mathrm{p}<0.05)$ (Figure 3$)$.

Figure 3. Umbilical blood flow in control and endotoxin treated animals.

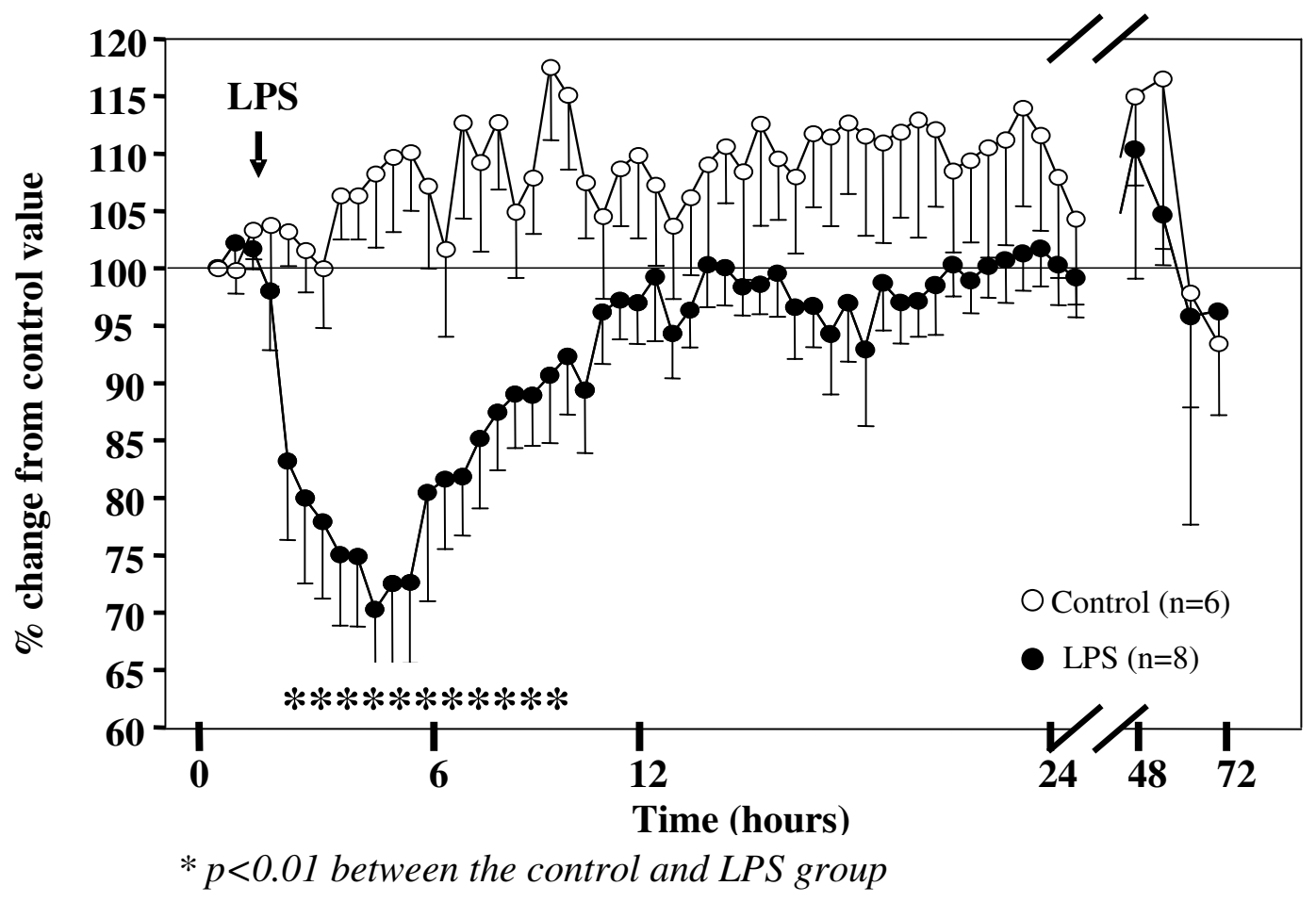


In line with the decrease in placental blood flow vascular resistance increased one hour after LPS and returned to control values 12 hours after LPS injection $(\mathrm{p}<0.01)$. In the control group vascular resistance did not change significantly during the experiment (Figure 4).

Figure 4. Placental vascular resistance in control and endotoxin treated animals.

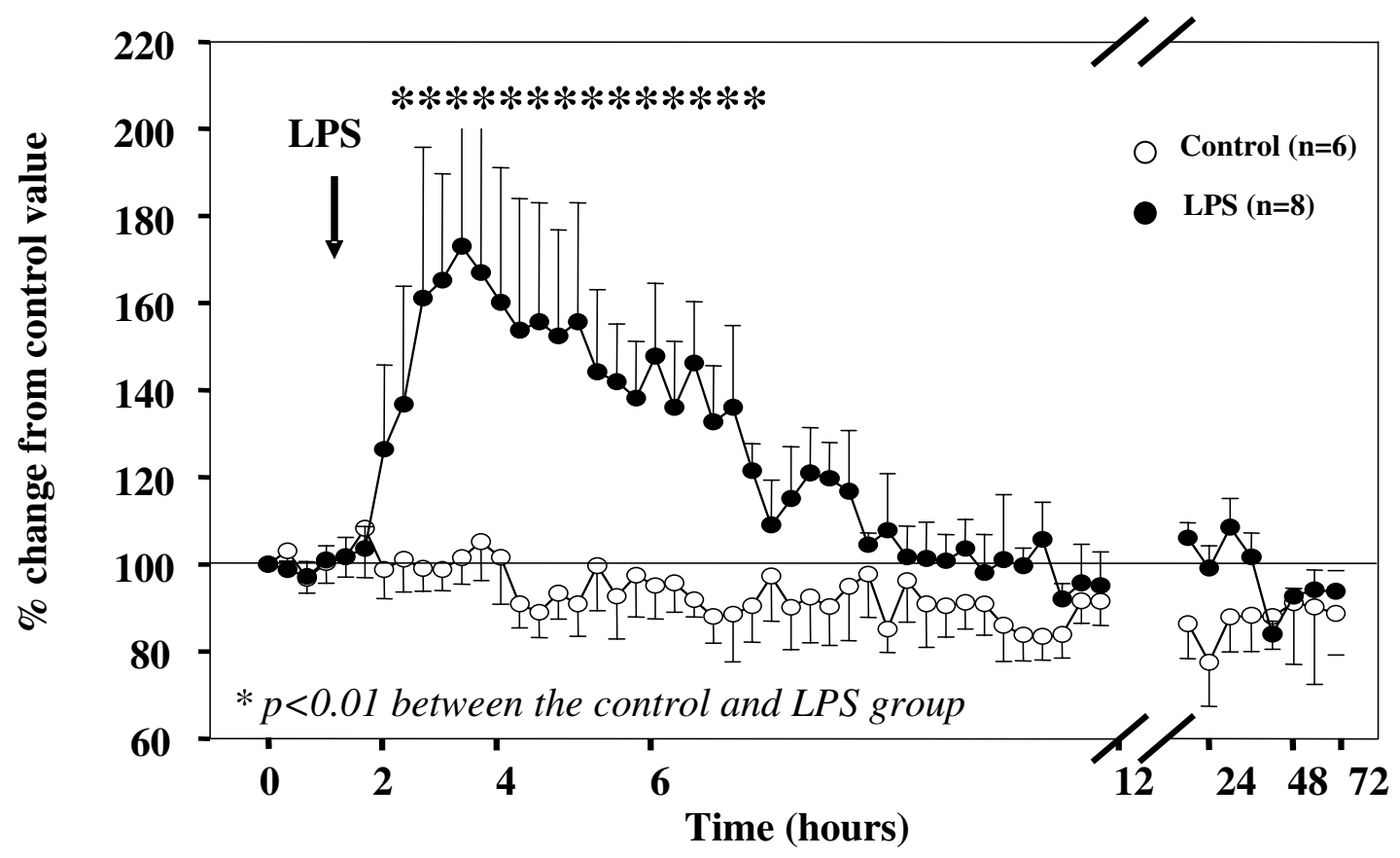


Six out of the 14 LPS fetuses died within 2-12 hours because of impairment of umbilicoplacental perfusion and development of severe fetal acidosis. The non-survivors showed a more severe drop in umbilical blood flow which did not recover during the experiment. An example of the steep decrease in umbilical flow leading to fetal death within six hours after LPS is presented in Figure 5.

Figure 5. Three examples of the course of umbilical blood flow in endotoxin

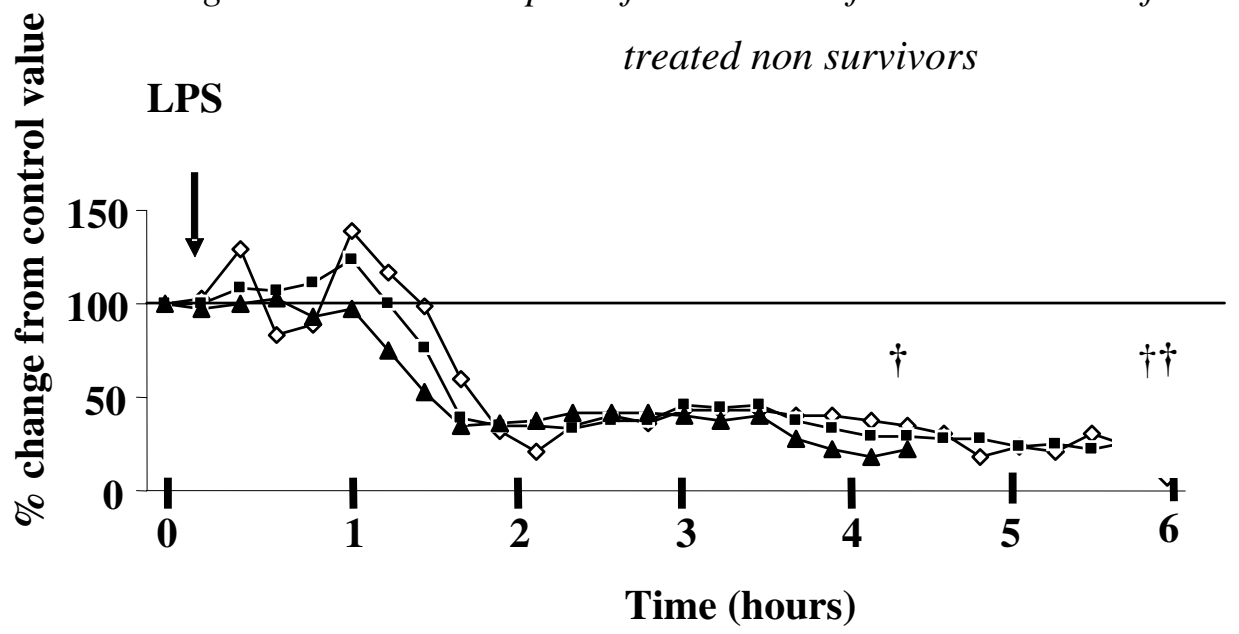

\section{Discussion}

Clinical and epidemiological studies have shown that exposure to intrauterine infection increases the risk of perinatal brain damage $(3,4,5,6)$. In a previous study from our group we showed that a large dose of endotoxin during normoxia and hypoxia results in circulatory decentralization and hypoperfusion of the placenta leading to a decrease in cerebral oxygen delivery and subsequent fetal demise (10). 
In the present study we show that exposure to a non-lethal dose endotoxin causes a substantial and long-lasting decrease in placental blood flow resulting in hypoxemia without appreciable changes in $\mathrm{pH}$ in preterm sheep at 110 days gestation.

After LPS injection there was an increase in MAP. In an earlier study in preterm sheep (10) we showed that adrenal blood flow increased with $100 \%$ after endotoxin administration. This increase in flow leads to a surge of catecholamines, which have a vasoconstrictive effect on the circulation (14). This surge of catecholamines might thus, apart from the release of other vasoconstrictors such as endothelin, explain the increase in MAP after endotoxin administration although it does not clarify the decrease in placental blood flow since the placental microcirculation is relatively inert to various vasoconstrictors including norepinephrine. A study by van Huisseling et al (15) showed that fetal arterial hypertension provoked by norepinephrine had no effect on placental vascular resistance, umbilical blood flow, and umbilical artery pulsatility index.

Fetal heart rate was significantly increased after LPS and remained high during 12 hours after LPS, then slowly returned to control values (Figure 1). Other routes of administration cause different responses in FHR; when LPS is injected in the amniotic fluid of fetal sheep, there is no significant change in fetal heart rate (16), nor is there a reaction on FHR following the injection of a low-dose LPS in neonatal rats (12).

Maternal administration of LPS induces maternal fever and an increase of fetal body temperature (17). The increase in FHR might thus be explained by a higher fetal body temperature, although we did not measure temperature.

Several mechanisms are potentially involved in the fall in placental blood flow, which are discussed below. 
Firstly, endotoxin is known to induce production of endothelin-1, which is a potent vasoconstrictive peptide that is able to constrict fetoplacental microcirculation and decrease fetal oxygen consumption in sheep (18) and is active in pigs and humans (19). ET-1 is released in response to several stimuli, including hypoxia $(20,21)$, endotoxemia $(22,23)$, increased pressure (24), and shear stress (25). In response to these stimuli, ET-1 causes both acute responses, such as vasodilation and vasoconstriction, as well as chronic changes, such as smooth muscle proliferation. ET-1 is the most active pressor substance yet discovered, with a potency some ten times that of angiotensin II (26). Endothelin-1 is mainly produced by vascular endothelium and is secreted constitutively thereby participating in the regulation of vascular tone (27).

Endothelin-2 may be found in the intestine and endothelin-3 in the lung, central nervous system and intestine $(28,29)$.

Among the pathophysiological conditions known to activate the endothelin system, sepsis presents with the highest plasma levels of endothelin (30). The possible involvement of the endothelin system in human septic shock is further supported by a clear correlation between endothelin plasma levels and morbidity and mortality in septic patients (31). Bacterial endotoxin or sepsis was shown to increase ET-1 concentrations in fetal umbilical arterial plasma more than fivefold in both pigs and humans reaching levels close to threshold vasoconstriction (32). Other pro-inflammatory agents such as IL-1, TNF- $\alpha$, and TGF- $\beta$, also increase the production of ET-1 from endothelial cells (33).

Secondly, the fall in placental blood flow might be related to the formation of placental edema, caused by increases in vascular permeability during endotoxemia. The concurrent restriction of placental gas exchange contributes then to prolonged fetal hypoxemia. Cotyledons of fetuses that died after LPS appeared on gross examination edematous. Cock and co-workers also 
observed changes in placental weight, placental edema and hemoconcentration at 4 hours after LPS administration (34).

Thirdly, endotoxemia with high doses of LPS severely impairs fetal cardiovascular control both during normoxia and hypoxia. Under non-endotoxic circumstances the fetus protects itself against hypoxemia by redistribution of blood flow with increases in blood flow to central organs such as brain, heart and adrenals and reductions in blood flow to peripheral organs such as lungs, skin, muscle, gastro-intestinal tract, and fetal body. During endotoxemia however this protective mechanism is blunted by a lack of control of vascular resistance (10). Endotoxemia then leads to an increase in flow to the fetal body and adrenals at the expense of placental blood flow. This "steal" effect may add to the fall in umbilical blood flow.

In summary, we found, that a non-lethal dose of endotoxin resulted in surviving fetuses $(n=8)$ in transient tachycardia $(+25 \%)$ and hypertension $(+18 \%)$. There was also a long-lasting decrease in umbilical blood flow (-30\%) with an increase in umbilico-placental resistance $(+73 \%)$ and a sustained hypoxemia (-40\%) without acidosis. We speculate, that the observed changes in placental blood flow might be attributed to an elevated production of endothelin-1, possibly in combination with increased capillary leakage and formation of placental edema.

We conclude from these results that sublethal exposure to a single low dose endotoxin causes a substantial and longlasting decrease in umbilico-placental perfusion, resulting in sustained fetal hypoxemia without appreciable acidemia. Fetuses for which endotoxin was lethal within 12 hours showed a more impaired umbilical perfusion upon endotoxin administration and subsequent development of severe hypoxia and acidosis with fetal demise. Further studies need to clarify the involvement of placental edema formation and release of vasoconstrictors in this process of impaired placental perfusion. Apart from the potential direct deleterious effect of 
endotoxin on the brain by increases in e.g. cytokines, the concurrent fall in umbilical blood flow might contribute to the development of fetal brain damage associated with intrauterine infection.

\section{Acknowledgments}

We thank May Bost, Joyce Suyk and Jan Geilen for the excellent technical assistance and Frans Slangen and Monique de Jong for animal care. 


\section{References}

1. Davis DW. Review of cerebral palsy, Part I: Description, incidence, and etiology. Neonatal Netw 1997;16:7-12.

2. Paneth N. The causes of cerebral palsy. Recent evidence. Clin Invest Med 1993; 16:95-102.

3. Nelson KB, Ellenberg JH. Obstetric complications as risk factors for cerebral palsy or seizure disorders. JAMA 1984;251:1843-1848.

4. Nelson KB, Grether JK. Maternal infection and cerebral palsy in infants of normal birthweight. JAMA 1997;278:201-211.

5. Nelson KB, Grether JK. Potentially asphyxiating conditions and spastic cerebral palsy in infants of normal birth weight. Am J Obstet Gynecol 1998;179:507-513.

6. Wu YW, Colford JM. Chorioamnionitis as a risk factor for cerebral palsy: a meta-analysis. JAMA 2002;284:1417-1424.

7. Yoon BH, Romero R, Park JS, Kim CJ, Kim SH, Choi JH, Han TR. Fetal exposure to an intraamniotic inflammation and the development of cerebral palsy at the age of three years. Am J Obstet Gynecol 2000;182:675-681.

8. Grossman EM, Longo WE, Mazuski JE, Panesar N, Kaminski DL. Role of cytoplasmic and secretory phospholipase A2 in intestinal epithelial cell prostaglandin E2 formation. Int J Surg Investig 2000;1:467-76.

9. Dammann O, Leviton A. Maternal intrauterine infection, cytokines, and brain damage in the preterm newborn. A Review. Pedriatr Res 1997;42:1-8.

10. Garnier Y, Coumans ABC, Berger R, Jensen A, Hasaart THM. Endotoxemia severely affects circulation during normoxia and asphyxia in immature fetal sheep. J Soc Gynecol Investig 2001;8:134-142.

11. Coumans ABC, Middelanis J, Garnier Y, Vaihinger HM, Leib SL, von Duering M, Hasaart THM, Jensen A, Berger R. Intracisternal application of endotoxin aggravates hypoxic-ischemic brain damage in neonatal rats. 2002. Ped Res In press.

12. Eklind S, Mallard C, Leverin AL, Gilland E, Blomgren K, Mattsby-Baltzer I, Hagberg H. Bacterial endotoxin sensitizes the immature brain to hypoxic--ischaemic injury. Eur J Neurosci 2001;13:1101-6.

13. Jensen A, Berger R. Fetal circulatory responses to oxygen lack. J Dev Physiol 1991;16:181-207.

14. Giussani DA, Spencer JAD, Hanson MA. Fetal cardiovascular reflex responses to hypoxaemia. Fet and Mat Med Rev 1994;6:17-37.

15. van Huisseling H, Muijsers GJ, de Haan J, Hasaart TH. Fetal hypertension induced by norepinephrine infusion and umbilical artery flow velocity waveforms in fetal sheep. Am $\mathbf{J}$ Obstet Gynecol 1991;165:450-5. 
16. Nitsos I, Moss TJM, Cock ML, Harding R, Newnham JP. Fetal responses to intra-amniotic endotoxin in sheep. J Soc Gynecol Investig 2002;9:80-85.

17. Laburn HP, Mitchell D, Goelst K. Fetal and maternal body temperatures measured by radiotelemetry in near-term sheep during thermal stress. J Appl Physiol 1992;72:894-900.

18. Adamson SL, Whiteley KJ, Langille BL. Endothelin-1 constricts fetoplacental microcirculation and decreases fetal O2 consumption in sheep. Am J Physiol 1996;270:H16-23

19. Lundberg JM, Ahlborg G, Hemsen A et al. Evidence for release of endothelin-1 in pigs and humans. J Cardiovasc Pharmacol 1991;17:350-3.

20. Elton TS, Oparil S, Taylor GR, Hicks PH, Yang RH, Jin H, Chen YF. Normobaric hypoxia stimulates endothelin-1 gene expression in the rat. Am J Physiol 1992;263:R1260-4.

21. Li H, Chen SJ, Chen YF, Meng QC, Durand J, Oparil S, Elton TS. Enhanced endothelin-1 and endothelin receptor gene expression in chronic hypoxia. J Appl Physiol 1994;77:1451-9.

22. Morel DR, Pittet JF, Gunning K, Hemsen A, Lacroix JS, Lundberg JM. Time course of plasma and pulmonary lymph endothelin-like immunoreactivity during sustained endotoxaemia in chronically instrumented sheep. Clin Sci (Lond) 1991;81:357-65.

23. Nakamura T, Kasai K, Sekiguchi Y, Banba N, Takahashi K, Emoto T, Hattori Y, Shimoda S. Elevation of plasma endothelin concentrations during endotoxin shock in dogs. Eur J Pharmacol 1991;205:277-82.

24. Hishikawa K, Nakaki T, Marumo T, Suzuki H, Kato R, Saruta T. Pressure enhances endothelin1 release from cultured human endothelial cells. Hypertension 1995;25:449-52.

25. Kuchan MJ, Frangos JA. Shear stress regulates endothelin-1 release via protein kinase $C$ and cGMP in cultured endothelial cells. Am J Physiol 1993;264:H150-6.

26. Yanagisawa M, Kurihara H, Kimura S, Tomobe Y, Kobayashi M, Mitsui Y, Yazaki Y, Goto K, Masaki T. A novel potent vasoconstrictor peptide produced by vascular endothelial cells. Nature 1988;31:411-5.

27. Haynes WG, Webb DJ. Contribution of endogenous generation of endothelin-1 to basal vascular tone. Lancet 1994;344:852-854.

28. Rubanyi G, Polokoff M. Endothelins: molecular biology, biochemistry, pharmacology, physiology and pathophysiology. Pharmacol Rev 1994;46:325-415.

29. Wanecek M, Weitzberg E, Rudehill A, Oldner A. The endothelin system in septic and endotoxin shock. Eur J Pharmacol 2000;407:1-15.

30. Battistini B, Forget MA, Laight D. Potential roles for endothelins in systemic inflammatory response syndrome with a particular relationship to cytokines. Shock 1996 5:167-83.

31. Pittet JF, Morel DR, Hemsen A, Gunning K, Lacroix JS, Suter PM, Lundberg JM. Elevated plasma endothelin-1 concentrations are associated with the severity of illness in patients with sepsis. Ann Surg 1991;213:261-4. 
32. Cai Z, Pan Z, Pang Y, Evans O and Rhodes P. Cytokine induction in fetal rat brains and brain injury in neonatal rats after maternal lipopolysaccharide administration. Ped Res 2000;47:1;6472.

33. Ishimaru S, Shichiri M, Mineshita S, Hirata Y. Role of endothelin-1/endothelin receptor system in endotoxic shock rats. Hypertens Res 2001;24:119-26.

34. Cock ML, Dalitz PA, Harding R. Placental blood flow following endotoxin administration in the preterm ovine fetus. J Soc Gyn Investig 2002;9:191. 


\title{
Appendix to Chapter 8
}

\author{
Brain histology
}


192 Chapter 8, appemdix

\section{Introduction}

As shown in Chapter 8, sublethal exposure to a single low dose endotoxin causes a substantial and longlasting decrease in umbilico-placental perfusion, resulting in sustained fetal hypoxemia without appreciable acidemia. In this appendix to the former study, some observations on brain histology are presented.

\section{Material and Methods}

\section{Experimental protocol}

The brains were collected from the fetal sheep which were used in the study described in chapter 8. At the end of the experiment, animals were perfusion-fixed with formaldehyde, the brains were removed and postfixed. Brains were divided in half, one part was used for frozen sections and the other half was paraffin embedded. Ten coronal subserial sections of $10 \mu \mathrm{m}$ were obtained from selected areas such as lateral from the cornu frontale, pars centralis, cornu temporale and cornu occipitale, and were then treated with Klüver-Barrera staining. Neuronal cell damage was assessed at a magnification of 250x. Neurons with ischemic cell damage were identified according to the criteria of Brown and Brierley (Brown and Brierley, 1972).

As there was no neuronal cell damage in the cerebrum, evenly spaced subserial coronal sections of $10 \mu \mathrm{m}$ were obtained from the periventricular region close to the interventricular foramen. With the use of Klüver-Barrera staining, the severity of the white matter lesions was assessed using scores such as normal, disarrangement of the nerve fibers, formation of marked vacuoles, and disappearance of myelinated fibers.

\section{Calculations}

Brain sections were analyzed by two independent observers, unaware of experimental group allocation. Periventricular white matter cell count was also assessed. 


\section{Results}

An increase in periventricular white cell count was observed in the LPS group $(+110 \%, \mathrm{p}<0.05)$ as depicted in figures 1, 2 and 3. Histopathological changes showed signs of programmed cell death in the periventricular white matter, with intense and uniform nuclear staining, chromatin condensation with karyorrhexis, and formation of apoptotic bodies (plasma membrane enclosing cytoplasm, which frequently obtained dense basophilic chromatin) (Figures 1,2 and 3). To obtain further evidence of programmed cell death, electron micrographs of selected areas were taken at a magnification of 16,000. Electron micrographs revealed characteristic chromatin condensation and segregation, extracellular apoptotic bodies, and cell fragments phagocytosed in macrophages in the periventricular white matter. The LPS animals showed an increased amount of apoptosis and mitosis in the periventricular region (Figure 4). Unlike in control animals, in all LPS treated animals, groups of inflammatory cell infiltrations were observed in both the periventricular white matter and thalamus, corresponding to groups of macrophages and polymorphonuclear cells (Figure 5). 
Figure 1. Brain histology in the periventricular cell layer, around the lateral ventricle in a control animal using Klüver-Barrera staining. Magnified 15 times and 100 times, respectively.
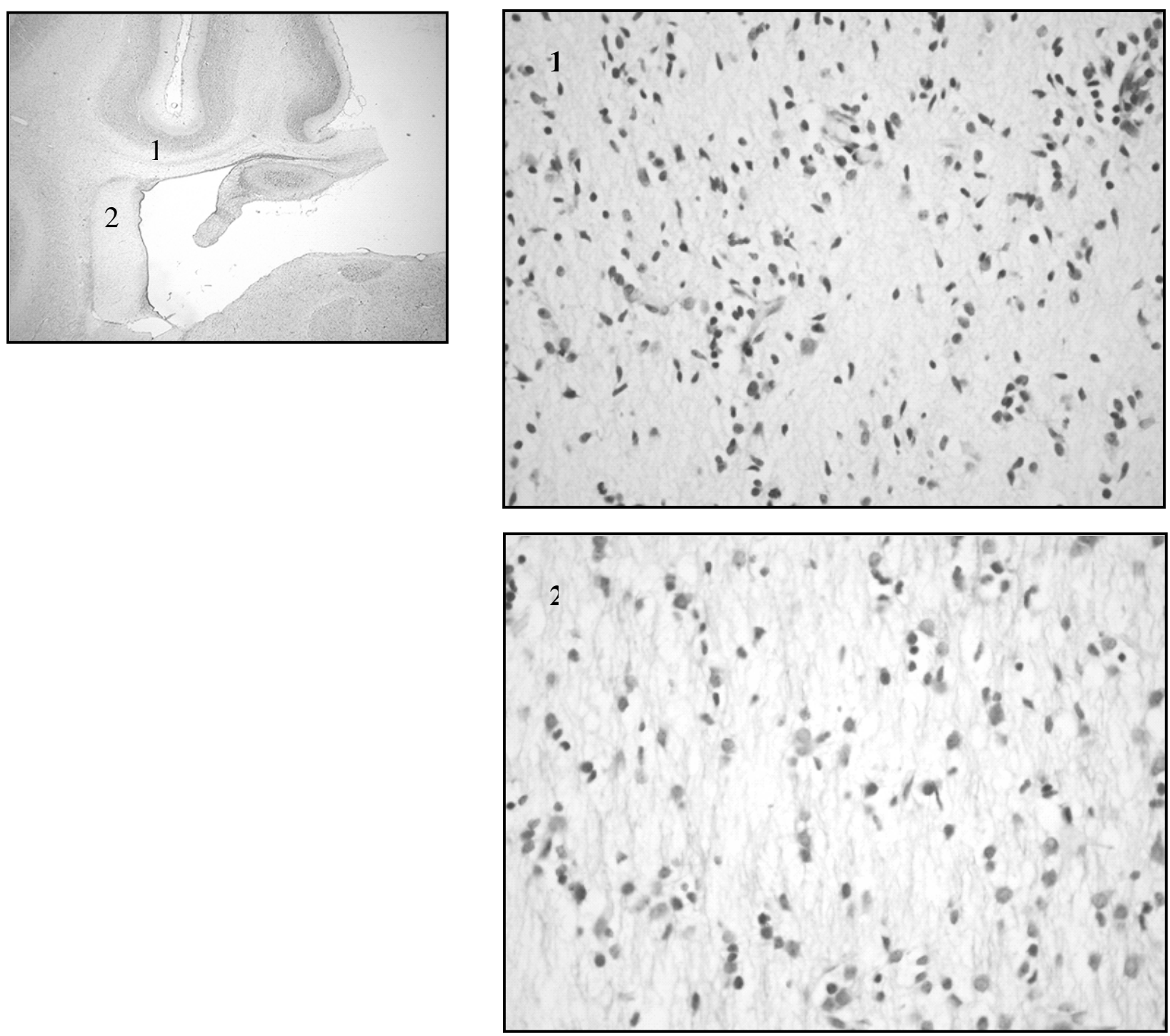
Figure 2. Brain histology in the periventricular cell layer, around the lateral ventricle in an LPS animal using Klüver-Barrera staining. Magnified 15 times and 100 times, respectively.
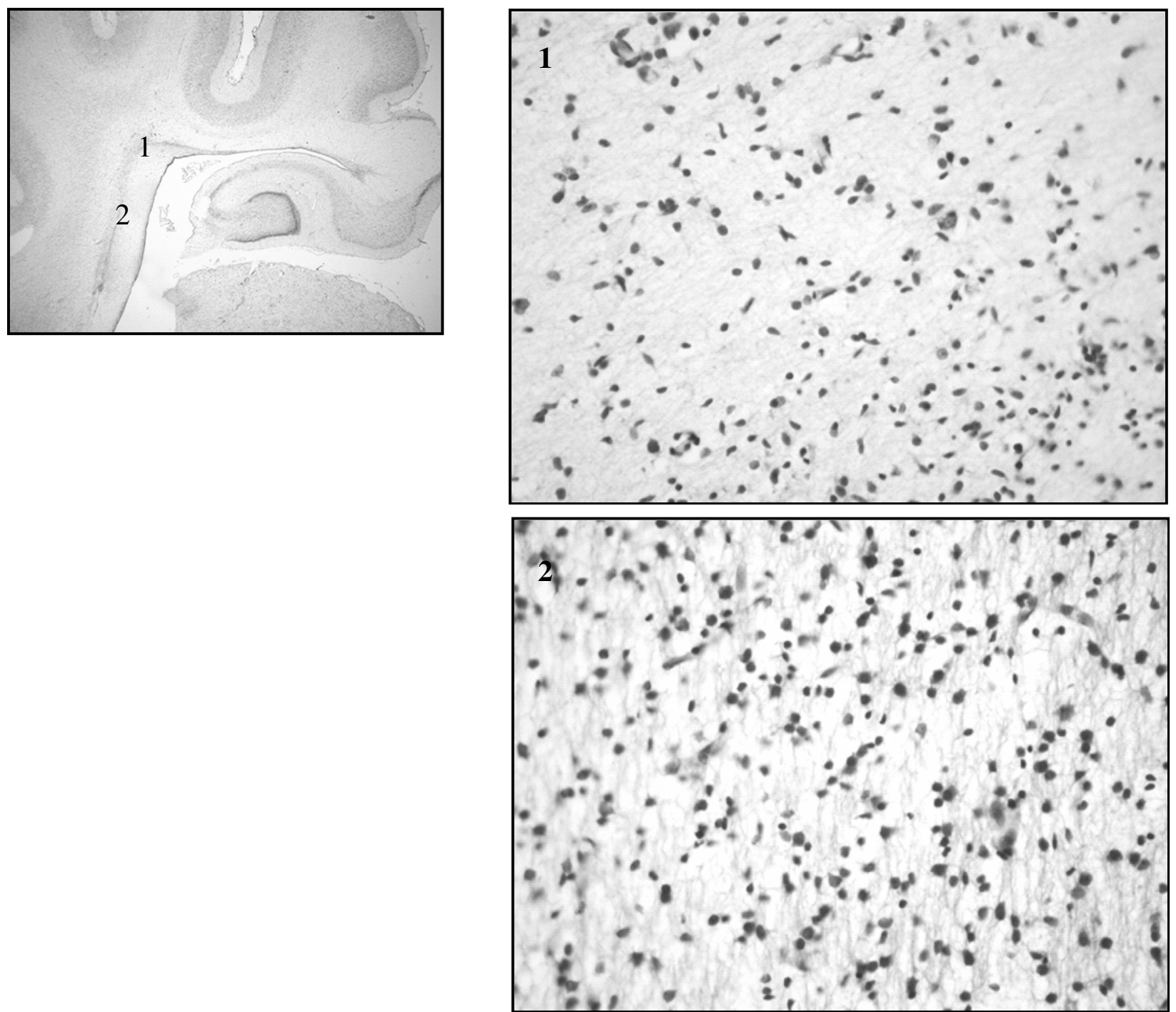
Figure 3. Periventricular white matter cell count

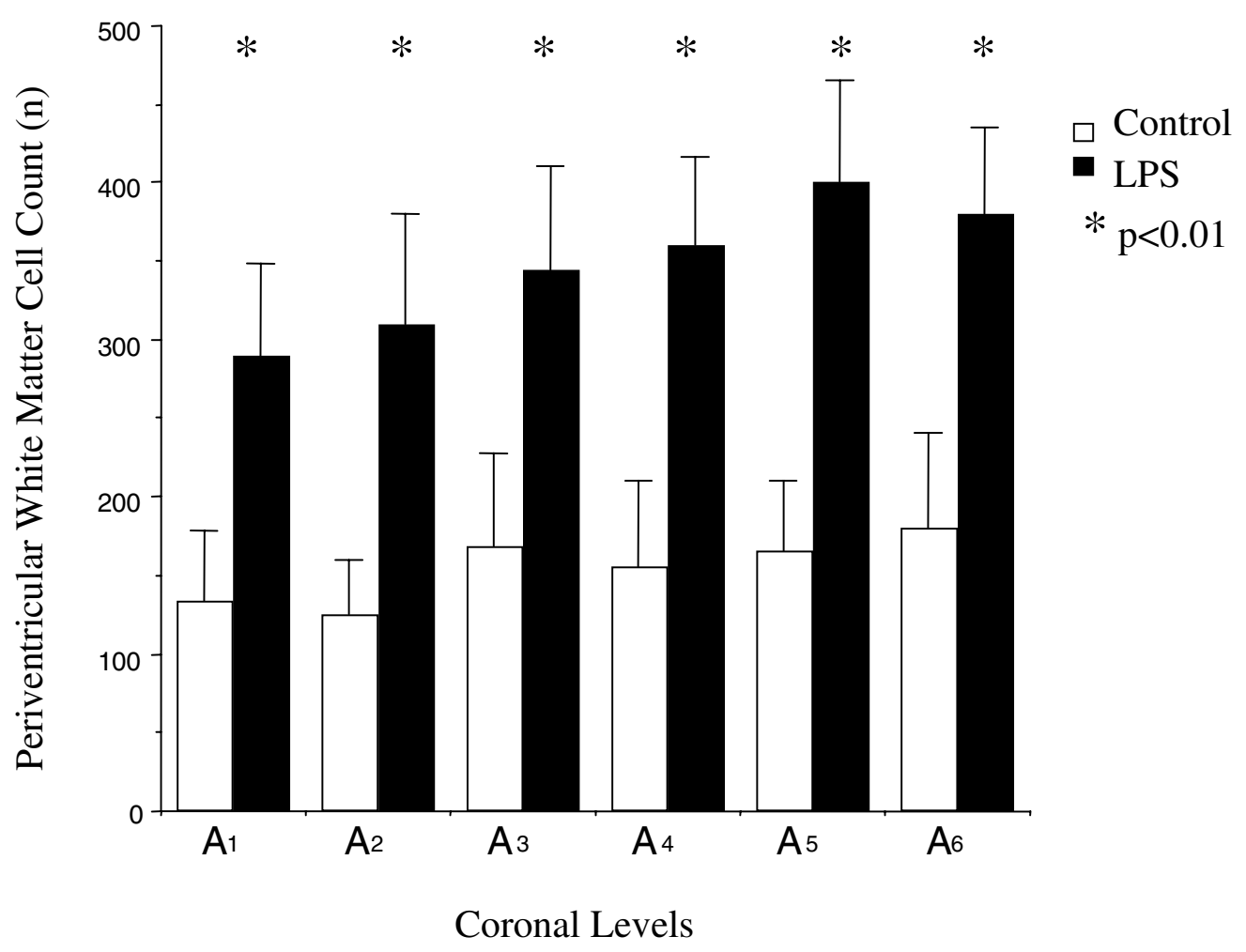

Figure 4. Increased apoptosis and mitosis in the LPS animals. Electronmicroscopic picture taken in the periventricular region. Magnified 16,000 times.
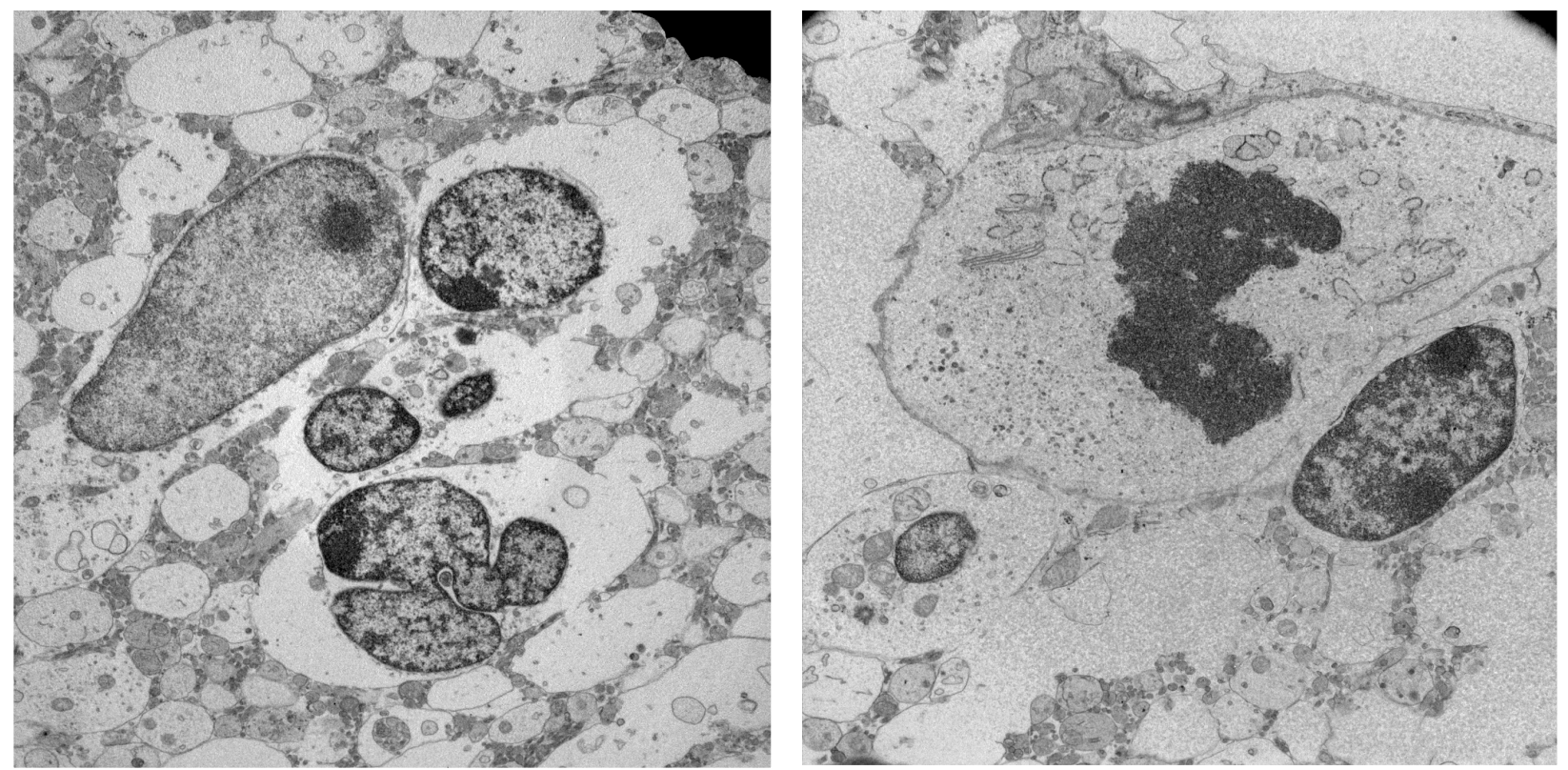
Figure 5. Infiltration in the thalamus in an LPS animal, 20 times enlarged.

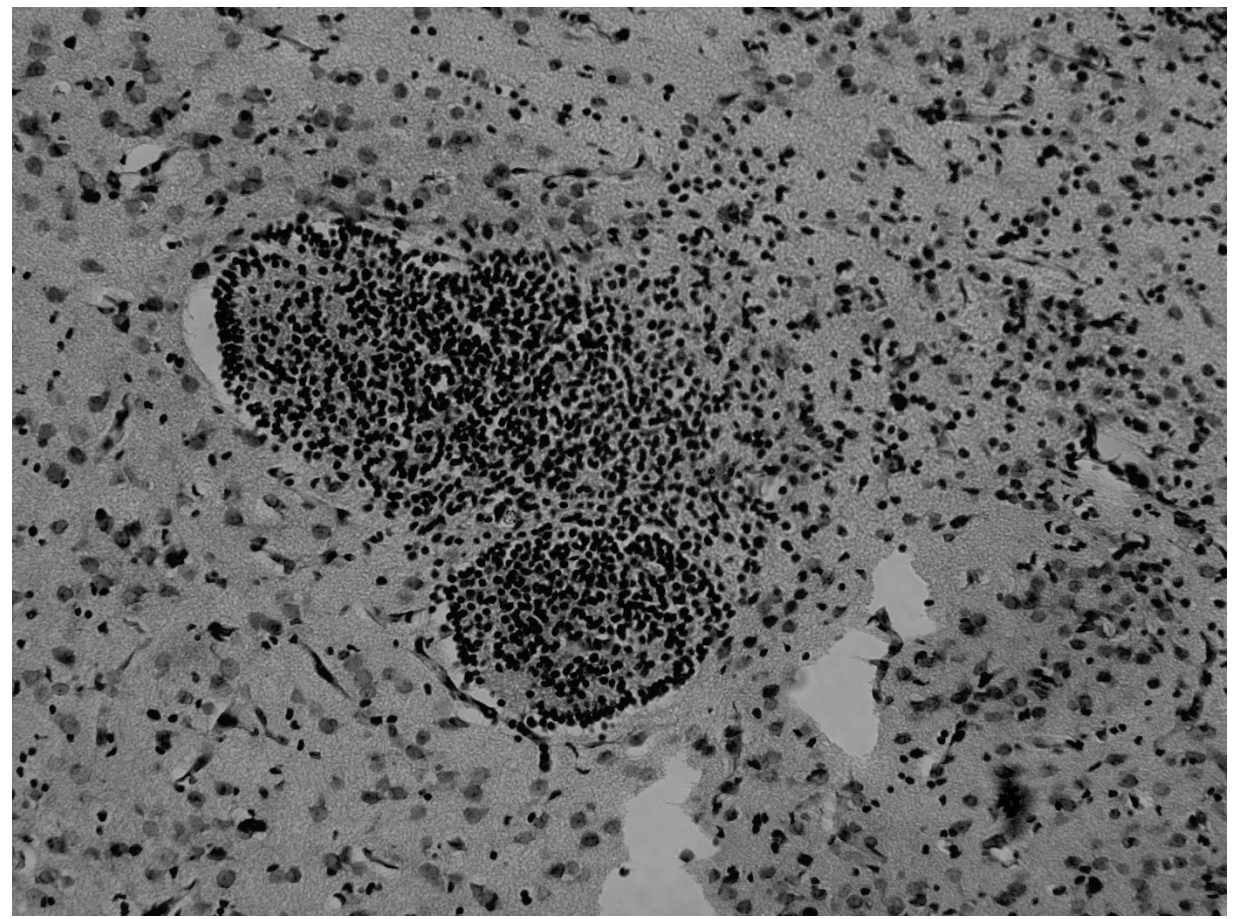

\section{Discussion}

The last few years there has been a change in the course of thinking about the cause of perinatal brain damage. Not only asphyxia but also endotoxemia increases the risk of brain damage in neonates. Therefore, we studied the hemodynamic effects of a low dose LPS, and investigated whether or not this endotoxemia could subsequently alter brain histology.

We found an increase in periventricular white matter cell count, with intense and uniform nuclear staining and chromatin condensation with karyorrhexis. The increased periventricular white cell count appears to be activated microglia under electronmicroscopic investigation. The important question is, whether the observed histological changes in the fetal ovine brain are due to the mild hypoxia caused by endotoxemia-induced placental hypoperfusion, or because of an inflammatory response in the brain.

Studies investigating hypoxic-ischemic brain injury have been inconsistent in producing specific neuropathological results. Differences in gestational age are likely to explain these apparent 
discrepancies. Several studies reveal periventricular and subcortical white matter damage with involvement of the striatum and thalamus (Reddy et al, 1998; Mallard et al, unpublished). Areas of coagulation necrosis and accumulation of activated microglia were observed after hemorrhagic hypotension in fetal sheep (Matsuda, 1999). Gunn and co-workers reported neocortical, hippocampal and striatal neuronal injury after occlusion of the common uterine artery, either alone, or in combination with superimposed maternal hypoxia at 119 to 128 days' gestation (Gunn et al, 1992). White matter damage was not observed in this study. Sustained hypoxia caused periventricular white matter injury with cortical necrosis, but no selective neuronal injury in the near-term and midgestation ovine fetus (Penning et al, 1994). An episode of hypoxemia near mid-gestation in fetal sheep reduced neuronal numbers in the hippocampus and cerebellum (Rees et al, 1999).

The effects of endotoxin on the perinatal brain have been investigated in several studies. In response to repeated dosages LPS in fetal sheep at 0.7 of gestation, less and less pronounced hemodynamic effects were observed, while white matter injury was present (Duncan et al, 2002). Peebles and co-workers (unpublished) observed widespread injury in the periventricular and subcortical white matter, with regional infiltrates of inflammatory cells, after the injection of 100 nanogram LPS in 93 day old fetal sheep.

In our study, there is a distinct response, which shows groups of inflammatory cell infiltrations probably corresponding to clustered macrophages and activated microglia. A study by Young and co-workers also reported this finding on dogs (Young et al, 1983). In pregnant rabbits, injection of LPS in the cervix induced white matter injury with increased karyorrhexis and TUNEL positive cells in the fetuses (Yoon et al, 1997).

Since the degree of hypoxia present in our study is moderate, it is not likely that it can lead to histological brain injury. However, after LPS injection brain blood flow was attenuated in the 
ovine fetus during both hypoxia and the recovery phase, while cerebral blood flow in control animals immediately recovered after acute asphyxia (Garnier et al, 2001) and was increased in comparison to control levels. Thus it seems that LPS attenuates the post-hypoxia rise in cerebral blood flow, which might indicate an increased susceptibility to moderate hypoxia.

In conclusion, LPS injection in our study lead to changes in MAP $(+20 \%)$ in combination with a reduction in umbilical blood flow (-30\%). Histological investigation of the brain showed an inflammatory response with an increased periventricular cell count, clustered microglia and macrophages in this region, as well as an increase in apoptosis and mitosis.

Since the introduction of LPS as a paradigm to induce brain damage, several studies have observed brain damage after LPS, while others have not. From our results, it is not conclusive whether endotoxin leads to changes in brain histology due to mild hypoperfusion, or due to an inflammatory response in the brain after LPS.

It seems likely that brain damage induced by LPS is a combination of a direct inflammatory reaction in the brain, and also an inflammatory response in the fetal circulation leading to a redistribution in organ blood flow with placental hypoperfusion and decreased oxygen delivery. 


\section{Literature}

1. Brown AW, Brierley JB. Anoxic-ischaemic cell change in rat brain light microscopic and fine structural observations. J Neurol Sci 1971;16:59-84.

2. Duncan JR, Cock ML, Scheerlinck JP, Westcott KT, McLean C, Harding R, Rees SM. Cerebral and physiological effects of repeated endotoxin exposure in the preterm ovine fetus. Pediatr Res 2002;52(6):941-9.

3. Garnier Y, Coumans ABC, Berger R, Jensen A, Hasaart THM. Endotoxemia severely affects circulation during normoxia and asphyxia in immature fetal sheep. J Soc Gynecol Investig 2001;8(3):134-143.

4. Gunn AJ, Parer JT, Mallard EC, Williams CE, Gluckman PD. Cerebral histologic and electrocorticographic changes after asphyxia in fetal sheep. Pediatr Res 1992;31:486-491.

5. Hagberg H, Peebles D, Mallard C. Models of white matter injury: comparison of infectious, hypoxic-ischemic, and excitotoxic insults. Ment Retard Dev Disabil Res Rev. 2002;8:30-38.

6. Matsuda T, Okuyama K, Cho K, Hoshi N, Matsumoto Y, Kobayashi Y, Fujimoto S. Induction of antenatal periventicular leukomalacia by hemorrhagic hypotension in the chronically instrumented fetal sheep. Am J Obstet Gynecol 1999;181:725-730.

7. Penning DH, Grafe MR, Hammond R, Matsuda Y, Patrick J, Richardson B. Neuropathology of the near-term and midgestation ovine fetal brain after sustained in utero hypoxemia. Am J Obstet Gynecol 1994;170:1425-32.

8. Reddy K, Mallard C, Guan J, Marks K, Bennet L, Gunning M, Gunn A, Gluckman P, Williams C. Maturational change in the cortical response to hypoperfusion injury in the fetal sheep. Pediatr Res. 1998;43:674-682.

9. Rees S, Breen S, Loeliger M, McCrabb G, Harding R. Hypoxemia near mid-gestation has longterm effects on fetal brain development. J Neuropathol Exp Neurol 1999;58(9):932-45.

10. Yoon BH, Kim CJ, Romero R, Jun JK, Park KH, Choi ST, Chi JG. Experimentally induced intrauterine infection causes fetal brain white matter lesions in rabbits. Am J Obstet Gyencol 1997; 177:797-802.

11. Young RS, Yagel SK, Towfighi J. Systemic and neuropathologic effects of E. coli endotoxin in neonatal dogs. Pediatr Res 1983;17: 349-353. 


\section{Chapter 9}

Summary and discussion 
202 Chapter 9

Despite the improvements in obstetric care, the number of children suffering from perinatal brain damage has not been decreased over the past two decades. On the contrary, epidemiological data show an increase in the number of children affected by cerebral palsy. The assumption that asphyxia is the major cause of perinatal brain damage has recently been questioned since several studies showed that other factors are as significant in solving the puzzle of perinatal brain damage, one of the most prominent being intrauterine infection.

The objective of this thesis is to investigate the role of endotoxins (LipoPolySaccharides, LPS) as a paradigm for fetoplacental infection on the fetal circulation and the brain, as well as to elucidate some of the underlying mechanisms.

In Chapter 1, perinatal brain damage is linked to asphyxia, preterm birth and intrauterine infection. It has been assumed that asphyxia is the major cause of perinatal brain damage. However, pregnant women with fever and bacteriuria have a higher incidence of giving birth to infants with neurological defects at 1 year of age, than do mothers free of urinary tract infection. Recent studies have investigated the role of intrauterine infection in causing cerebral palsy and concluded that fetuses with a prenatal exposure to infection have an increased risk of developing brain damage. Thus it appears that maternal endotoxemia is associated with fetal central nervous system damage.

Clinical chorioamnionitis is defined as an infection of the uterus and its contents during pregnancy. Its diagnosis is based on the presence of fever $\left(\mathrm{T}>38^{\circ} \mathrm{C}\right)$ plus two or more of the following conditions: maternal tachycardia, fetal tachycardia, uterine tenderness, foul smelling of the amniotic fluid, or maternal leukocytosis. Its incidence varies between $10 \%$ and $20 \%$. Antenatal exposure to intra-amniotic inflammation and evidence of a systemic fetal inflammatory response are strong and independent risk factors for the subsequent development of cerebral palsy at the age of three years. 
Documented intrauterine infection, with associated maternal and fetal inflammatory responses, may account for up to $30 \%$ of preterm birth. Intrauterine infection is associated with increased interleukin levels, which lead to higher prostaglandin concentrations and thus may cause preterm birth.

In Chapter 2, the objectives of this study are summarized and placed in a clinical context. Since endotoxin can mimic a clinical infection we decided to use LPS in our experimental setting. The relation between intrauterine infection and fetal brain damage is incompletely understood. Two pathways seem to be likely. First, brain injury might result from a direct neurotoxic effect of increased cytokine production during chorioamnionitis. Second, cerebral damage might be caused by endotoxemic alterations of the fetal cardiovascular system resulting in placental and cerebral hypoperfusion.

Based on these facts, we hypothesized that endotoxemia can affect fetal circulatory centralization, a vital mechanism that enables the fetus to maintain cerebral blood flow during asphyxia and thus protect its brain from hypoxic-ischemic injury. Therefore, we combined LPS and acute hypoxia in the first four experiments.

In Chapter 3, we wanted to determine whether endotoxins affect the fetal cardiovascular system in a way likely to cause brain damage. Thirteen fetal sheep were chronically instrumented at a mean gestational age of $107 \pm 1$ days. The ewe's abdominal wall was opened in the midline, and a snare was placed around the descending aorta below the renal artery, which was then used to arrest uterine and ovarian blood flow during the experiment for 2 minutes. Polyvinyl catheters were inserted into a tibial fetal vein and artery of each hindleg and were advanced into the caudal vena cava and abdominal aorta respectively. Furthermore, catheters were placed into both brachial arteries. A recovery period of 72 hours followed the operation before experiments started. After control measurements of organ blood flow (microsphere method), blood gases, 
and acid base balance were obtained, 7 out of 13 fetuses received LPS $(53 \pm 3 \mu \mathrm{g} / \mathrm{kg}$ fetal weight) intravenously. Sixty minutes later, asphyxia was induced by occlusion of the maternal aorta for 2 minutes. Measurements of organ blood flows were made at $-60,-1,+2,+4,+30$, and +60 minutes, with timepoint zero being the start of asphyxia.

In the LPS group, there was a significant decrease in arterial oxygen saturation $(-46 \% ; \mathrm{P}<$ $0.001)$ and in $\mathrm{pH}(\mathrm{P}<0.001)$, unlike in the control group. In LPS-treated fetuses the portion of combined ventricular output directed to the placenta decreased significantly $(76 \% ; \mathrm{P}<0.001)$, whereas output to the fetal body $(+60 \%$; $\mathrm{P}<0.001)$, heart $(+167 \% ; \mathrm{P}<0.05)$, and adrenals $(+229 \% ; \mathrm{P}<0.01)$ increased. Furthermore during asphyxia, circulatory centralization was considerably impaired in LPS-treated fetuses, and there was clear evidence of circulatory decentralization. This decentralization caused a severe decrease in cerebral oxygen delivery of 70\%. Within 30 minutes after induction of asphyxia five out of seven LPS-treated fetuses died, whereas all control fetuses recovered completely.

From this study we conclude that endotoxemia severely impairs fetal cardiovascular control during normoxia and asphyxia, resulting in a considerable decrease in cerebral oxygen delivery. Our findings also indicate that this impaired fetal cardiovascular control and organ blood flow is caused by the interference of LPS with the centralisation mechanism during hypoxia-ischemia.

Since LPS leads to an increased production of NO, this vasodilator might mediate the mechanism of decentralization after LPS. The role of nitric oxide in the control of fetal cardiovascular functions and of cerebral blood flow during normoxia and acute hypoxia is only partially known. In Chapter 4, the results of a study regarding the effects of nitric oxide synthase inhibition on the distribution of cardiac output in preterm sheep, during normoxia and acute hypoxia using L-NAME (a NOS inhibitor), are presented.

We used the same experimental set-up as described before. Three days later, fetuses received LNAME $(n=7)$ or vehicle infusion $(n=6)$. At timepoint zero, acute hypoxia was induced by 
occlusion of the maternal aorta for 2 min. Organ blood flows (microsphere method) and physiological variables (fetal heart rate, mean arterial pressure, oxygen saturation, $\mathrm{pH}$ ) were measured at $-75,-1,+2,+4$ and +30 minutes.

L-NAME caused bradycardia and a rise in MAP. Combined fetal cardiac output declined by $64 \%$. Blood flow to the fetal body, placenta and cerebrum decreased by $62 \%, 66 \%$, and 55\%, respectively. During acute hypoxia, L-NAME did not change the redistribution of cardiac output towards the central organs. In the L-NAME group, MAP rose and FHR was maintained in contrast to controls where MAP initially decreased and then returned to control value while FHR decreased. After hypoxia, L-NAME delayed the recovery of cardiac output and blunted the increase in blood flow to the brain and heart.

From this study we concluded that NO plays a role in fetal cardiovascular control during normoxia and acute hypoxia. It also mediates the increase in blood flow to the brain and heart immediately after hypoxia.

Recently, Morrison and co-workers have described a technique called the NO clamp to test the hypothesis that enhanced NO opposes fetal peripheral vasoconstrictor responses to acute hypoxemia via actions involving carotid chemoreflex and adrenal medulla. This technique combines treatment of the animal with L-NAME and the NO-donor, sodium nitroprusside (NP). In contrast to treatment with L-NAME alone, combined treatment with L-NAME and NP prevents generalized vasoconstriction and pronounced hypertension, not only maintaining basal cardiovascular function, but also permitting blockade of the de novo synthesis of NO during acute hypoxaemia while compensating for the tonic production of the gas (Morrison et al, $\mathbf{J}$ Physiol 2003;547:283-291). In the future, this technique could aid to investigations describing the effects of $\mathrm{NO}$ on the fetal circulation. 
Since we established that circulatory centralization during hypoxia is blunted by LPS, we wanted to further investigate the mediators in this process in Chapter 5. As stated before, endotoxin leads to an increased production of NO, which might influence the effects of LPS on the fetal circulation. Fifteen fetal sheep were instrumented as previously described. After three days, eight fetuses received $30 \mathrm{mg}$ L-NAME (t-75) followed by a continuous infusion. All fetuses received LPS at-60. At timepoint zero, hypoxia was induced by occlusion of the maternal aorta for 2 minutes. Organ blood flows (microsphere method) and physiological variables were measured at $\mathrm{t}-75,-1,+2,+4$ and +30 minutes.

After LPS administration there was a significant decrease in the percentage cardiac output to the placenta and cerebral oxygen delivery and an increase to the fetal body, heart, and adrenals. These changes were further enhanced during hypoxia. In the L-NAME + LPS group, fetal body and adrenal blood flow were lower than in the LPS group, while cerebral and placental blood flows were in the same range in both groups. These changes occurred during normoxia and continued during hypoxia and recovery phase.

In conclusion, endotoxemia severely impaired fetal cardiovascular control, leading to peripheral vasodilation. NOS inhibition partially overruled the LPS-induced peripheral vasodilation.

In the study presented in Chapter 6, we investigated the changes in cardiac output distribution to the fetal lung, following a fetal intravenous LPS injection, during normoxia and asphyxia. We also aimed at analysing the role of NO and endothelin in this process, pretreating one group of animals with L-NAME, and another group of animals with BQ 123, an endothelin A selective antagonist, before the injection of LPS.

Experiments were performed 3 days after the surgical procedure at $110 \pm 1$ days. Fetuses were randomized into 4 groups: group1, the control group (n=6), group 2 the LPS group $(n=7)$ with LPS injection at t-60 $(52 \pm 6 \mu \mathrm{g} / \mathrm{kg})$, group 3, the L-NAME+LPS group ( $\mathrm{n}=8)$ with L-NAME pre-treatment at $\mathrm{t}-75$ and LPS administration at $\mathrm{t}-60$ as described above and group 4 , the 
BQ123+LPS group (n=4) with BQ123 pre-treatment at $\mathrm{t}-75$ minutes and LPS injection at $\mathrm{t}-60$ as described above. All groups started with 75 minutes normoxia, then received a 2 minute period of acute asphyxia at timepoint zero, with 30 minutes recovery thereafter.

Under normal conditions, the amount of blood flow through the lungs is only approximately $4 \%$ of cardiac output. In the control group there was a low percentage cardiac output directed to the lungs which was not altered during fetal asphyxia. However, a marked elevation in the percentage microspheres after LPS was observed during normoxia, which was even further increased during asphyxia. This increase was partially blocked by BQ 123, an endothelin antagonist and completely abolished by pretreatment with L-NAME, an eNOS inhibitor. Therefore we conclude that during endotoxemia, cardiac output to the fetal lung is increased by LPS and this seems to be in part NO and in part endothelin dependent.

Two pathways seem likely to explain the relation between infection and perinatal brain damage. First, brain injury might be caused by the substantial changes in fetal organ blood flow distiribution and the concomitant considerable decrease in oxygen delivery to the brain, caused by decentralization as we observed in Chapter 3, Chapter 5 and Chapter 6 . On the other hand, LPS induces cytokine production in the brain and may thus lead to cytotoxic brain damage.

Therefore, we used a different route of LPS administration, the intracisternal application, which has only minimal side-effects on the cardiovascular system, in order to bypass hemodynamic changes. We wanted to assess whether intracisternal LPS injection could cause brain damage, in combination with and without a subsequent hypoxic-ischemic insult.

In chapter 7, we studied seven-day-old Wistar rats, which were subjected to intracisternal application of $\mathrm{NaCl}$ or LPS ( $5 \mu \mathrm{g} / \mathrm{pup})$. One hour later the left common carotid artery was exposed through a midline neck incision and ligated. After another hour of recovery the pups were subjected to a hypoxic gas mixture for $60 \mathrm{~min}$. The animals were randomized to four 
experimental groups. Sham control group (1): left common carotid artery exposed, but not ligated. LPS group (2): subjected to intracisternal application of LPS. Hypoxic-ischemic study group (3): intracisternally injected with $\mathrm{NaCl}$ and exposed to hypoxia after ligation of the left carotid artery. Hypoxic-ischemic / LPS study group (4): intracisternally injected with LPS and exposed to hypoxia after ligation of the left carotid artery. Seven days later the neonatal brains were assessed for neuronal cell damage. In a second set of experiments, rat pups were injected with LPS and evaluated for TNF- $\alpha$ expression by immunohistochemistry.

Neuronal cell damage could not be observed in the sham control or in the LPS group. In the hypoxic-ischemic/LPS group, neuronal injury in the cerebral cortex was significantly higher than in animals subjected to hypoxia/ischemia after application of $\mathrm{NaCl}$. Injecting LPS intrathecally caused a marked expression of TNF- $\alpha$ in the leptomeninges.

Thus, applying LPS intrathecally sensitizes the immature rat brain to a subsequent hypoxicischemic insult.

In order to study the long-term effects of LPS on umbilico-placental blood flow and to assess whether a relationship exists between fetal endotoxemia and histological brain injury, we administered a low dose LPS to fetal sheep intravenously.

In chapter 8 we present the data on continuously recorded umbilical blood flow after LPS administration. Fetal sheep were catheterized at a gestational age of $107 \pm 1$ days. A flow probe was placed around either the common umbilical artery or one single umbilical artery. Three days later fetuses received either 100 or 500 nanogram LPS or saline i.v.. Six fetuses died within 12 hours after LPS. FHR, MAP, and umbilical blood flow were monitored for three consecutive days.

FHR increased by $25 \%$ at approximately 4-5 hours after LPS and remained high for 15 hrs after LPS. MAP increased by $18 \%$ one hour after LPS and returned to control value 4-5 hrs after LPS. Umbilical blood flow began to fall one hour after LPS, it was minimal (-30\%) at 4-5 hours after 
LPS injection, but slowly returned to control values 12 hours after LPS. Placental vascular resistance rose by $73 \%(\mathrm{p}<0.01)$, while $\mathrm{pH}$ did not appreciably change.

Thus, intravenous application of endotoxin caused a substantial and longlasting decrease in umbilical blood flow, resulting in sustained fetal hypoxemia without acidemia.

In the appendix of Chapter 8 we present the data on brain histology of fetal sheep after LPS injection. We wanted to address the question if, and to what degree endotoxemia could cause histological brain injury. Histological investigation of the brain showed an inflammatory response with an increased periventricular cell count, with clustered microglia and macrophages in this region, as well as an increase in apoptosis and mitosis.

Thus, LPS leads to a distinct inflammatory reaction in the brain with an increased periventricular white cell count, which seem to be activated microglia. These findings indicate that LPS contributes to the development of histological brain damage.

Several conclusions can be drawn as to the harmful effects of endotoxemia on the fetal circulation and the brain.

Endotoxemia severely impaired fetal cardiovascular control during normoxia and asphyxia, resulting in a considerable decrease in cerebral oxygen delivery. This is caused by the interference with the centralisation mechanism during hypoxia-ischemia. The impaired fetal cardiovascular control leads to peripheral vasodilation which can be partially overruled by NOS inhibition.

Due to this decentralisation, endotoxemia also leads to increased cardiac output to the fetal lung which seems to be in part NO- and in part endothelin- dependent.

The long-term effects of intravenous application of endotoxin are a substantial and longlasting decrease in umbilical blood flow, resulting in sustained fetal hypoxemia without acidemia. These hemodynamic changes are followed by a distinct inflammatory reaction in the brain with 
an increased periventricular white cell count, caused by an increase of macrophages and microglia. Furthermore, the intracisternal injection of LPS sensitizes the immature rat brain to a subsequent hypoxic-ischemic insult, while endotoxin injection alone does not result in histological brain damage.

These findings indicate that LPS contributes to the development of histological brain damage.

The effort to understand the effects of endotoxin on the fetal circulation and brain is by no means complete.

Several topics for future research are obvious.

1. Possible sensitization of the brain by repeated doses of endotoxin with and without the effect of additional hypoxic events e.g. induced by repeated brief umbilical cord occlusions is a subject for fetal sheep studies.

2. The mechanisms by which the decrease in umbilico-placental blood flow after LPS is established is a challenging research topic.

3. The relationship between infection and preterm birth and the role of the hypothalamicpituitary-adrenal axis in the initiation of labour can be addressed in the fetal sheep model.

4. The chicken embryo is an established model in perinatal research and is suitable for study of the long-term effects of LPS on brain histology after application of LPS on the chorioallantoic membrane.

5. Intervention strategies with drugs in order to prevent or ameliorate the deleterious effects of perinatal infection can be tested in various animal models.

6. Doppler blood flow velocity waveform analysis in the fetal pulmonary artery and the umbilical artery as a potential tool for detection of intrauterine infection is a subject for studies in the human fetus.

7. Endotoxemia and effects on brain function by means of behavioural studies in a rat model. 
Research usually generates more questions than answers and this is also the case for this thesis. For the future, we should bear in mind the mythological Hydra. On many an occasion, the route to finding a solution gives birth to more problems, which nevertheless need to be afforded copious amounts of research. 

Hoofdstuk 10

Samenvatting en discussie 
214 Hoofdstuk 10

Perinatale hersenschade heeft, ondanks alle technologische vooruitgang, nog steeds een zeer hoge incidentie en leidt tot een aanzienlijke mortaliteit en morbiditeit.

Tijdens de laatste jaren is er een omslag gekomen in de zoektocht naar oorzaken van hersenschade. Het werd langzaamaan duidelijk dat meerdere problemen, niet alleen perinatale asfyxie, kunnen leiden tot perinatale hersenschade en spasticiteit. Van deze oorzaken wordt intra-uteriene infectie als een van de belangrijkste factoren genoemd.

Het doel van dit proefschrift is het onderzoeken van de effecten van endotoxines (lipopolysaccharides, LPS) die afkomstig zijn van gram negatieve bacteriën, op de foetale cardiovasculaire functie en het foetale brein, alsmede enkele onderliggende mechanismen te bestuderen.

In Hoofdstuk 1 wordt er een relatie gelegd tussen asfyxie, vroeggeboorte en intra-uteriene infectie. Er werd vroeger gedacht dat asfyxie tijdens de perinatale periode de belangrijkste oorzaak was van perinatale hersenschade. Toch is gebleken dat zwangere vrouwen met koorts en een urineweginfectie, een hogere incidentie van kinderen met neurologische afwijkingen op een leeftijd van een jaar hebben dan vrouwen zonder urineweginfectie. Recent werden in verschillende studies de rol van een intra-uteriene infectie in het ontstaan van spasticiteit aangetoond en werd geconcludeerd dat een foetus met prenatale blootstelling aan infectie een verhoogd risico heeft op het krijgen van hersenschade. Dus lijkt er een associatie tussen maternale endotoxemie en foetale hersenschade te bestaan.

Klinische chorioamnionitis is gedefinieerd als een infectie van de uterus en uterusinhoud tijdens zwangerschap. De diagnose wordt gebaseerd op de aanwezigheid van koorts (temperatuur boven de $38^{\circ} \mathrm{C}$ ) in combinatie met twee of meer van de volgende symptomen: maternale tachycardie, fetal tachycardie, gevoeligheid van de uterus en riekend vruchtwater, of maternale leukocytose. De incidentie van chorioamnionitis varieert van $10 \%$ tot $20 \%$. Antenatale blootstelling aan intra 
amniotische infectie en bewijs van een systemische foetale inflammatoire respons, zijn duidelijke risicofactoren voor het ontstaan van spasticiteit op drie-jarige leeftijd.

Gedocumenteerde intra-uteriene infecties, met een maternale of foetale inflammatoire respons, kunnen leiden tot $30 \%$ van vroeggeboorten. Een intra-uteriene infectie kan leiden tot vroeggeboorte door verhoogde interleukine spiegels, welke een hogere prostaglandine concentratie, en dus vroeggeboorte tot gevolg kunnen hebben.

In Hoofdstuk 2 worden de doelstellingen van dit proefschrift samengevat en in een klinische context geplaatst. Daar endotoxines een klinische infectie kunnen nabootsen, werd LPS gebruikt in onze experimentele opstelling.

Er zijn klinische aanwijzingen dat neonaten die geboren worden na blootstelling aan een intra uteriene infectie, een hoger risico hebben op hersenschade. Hoe een intra-uteriene infectie leidt tot perinatale hersenschade is niet bekend, wel zijn er twee plausibele mogelijkheden. Enerzijds kan een infectie leiden tot direct cytotoxische hersenschade door de aanwezigheid van cytokines, die in grote hoeveelheden in de hersenen worden geproduceerd tijdens een infectie. Anderzijds kan een intra-uteriene infectie leiden tot een verstoord afweermechanisme, centralisatie, dat de foetus gebruikt als bescherming tegen zuurstofgebrek. Als dit mechanisme verstoord wordt, treedt er hypoperfusie van de placentaire circulatie op met cerebraal zuurstofgebrek dat tot hersenschade kan leiden.

Naar aanleiding van deze mogelijkheden was onze hypothese dat endotoxemie de foetale circulatoire centralisatie, een vitaal beschermingsmechanisme dat de foetus in staat stelt de cerebrale doorbloeding te handhaven tijdens asfyxie en dus bescherming geeft tegen hypoxische-ischemische schade, kan beïnvloeden. Derhalve gebruikten we LPS in combinatie met acute hypoxie in de eerste vier experimenten.

In Hoofdstuk 3 hebben we onderzocht of endotoxine de foetale circulatie beïnvloedt op een manier die kan leiden tot hersenschade. Dertien foetale schapen werden geïnstrumenteerd bij 
216 Hoofdstuk 10

een zwangerschapsduur van $107 \pm 1$ dagen. Het abdomen van de ooi werd geopend en een draad werd om de aorta descendens, onder het niveau van de arteria renalis, geplaatst. Deze draad werd vervolgens gebruikt om uteriene en ovariële bloeddoorstroming gedurende 2 minuten te onderbreken. Polyvinyl catheters werden ingebracht in de arteria en vene tibialis van iedere achterpoot en werden opgeschoven in de vena cava and abdominale aorta, respectievelijk. Ook werden catheters geplaatst in beide arteriae brachiales. Na een herstelperiode van 72 uur werd gestart met de experimenten. Na controle meting van orgaandoorbloeding (microsfeer methode), bloed gassen en zuur-base evenwicht, kregen 7 van de 13 foetus intraveneus LPS $(53 \pm 3 \mu \mathrm{g} / \mathrm{kg}$ foetaal gewicht) toegediend. Na 60 minuten werd asfyxie geïnduceerd door occlusie van de maternale aorta gedurende 2 minuten. Metingen van de orgaandoorbloeding werden verricht op t $-60,-1,+2,+4,+30$ en +60 minuten met tijdpunt 0 de start van de asfyxie.

$\mathrm{Na}$ LPS werd er een significante daling gezien in de zuurstofsaturatie $(-46 \% ; \mathrm{P}<0.001)$ en $\mathrm{pH}$ $(\mathrm{P}<0$.001), welke niet in de controle groep optrad. In de LPS groep daalde de hoeveelheid cardiac output naar de placenta significant $(-76 \%$; $\mathrm{P}<0.001)$, terwijl de cardiac output naar het karkas (+60\%; $\mathrm{P}<0.001)$, hart $(+167 \%$; $\mathrm{P}<0.05)$, en bijnieren $(+229 \% ; \mathrm{P}<0.01)$ steeg. Ook was de centralisatie tijdens asfyxie duidelijk aangetast in de LPS groep en waren er zelfs aanwijzingen voor circulatoire decentralisatie. Deze decentralisatie leidde tot een daling van $70 \%$ van het cerebraal zuurstofaanbod. Binnen 30 minuten na asfyxie waren vijf van de zeven foetus in de LPS groep overleden terwijl in de controle groep alle dieren overleefden.

Uit deze studie concluderen we dat endotoxemie de foetale cardiovasculaire funktie tijdens normoxie en asfyxie aantast en dat dit een aanzienlijke daling in cerebraal zuurstofaanbod veroorzaakt. Verder duiden deze resultaten aan dat het verlies van cardiovasculaire functie en veranderingen in orgaandoorbloeding veroorzaakt worden door verstoring van het centralisatie mechanisme tijdens normoxie en hypoxie-ischemie. 
Daar LPS leidt tot een verhoogde productie van Nitric Oxide (NO), kan deze vasodilatator de verstoring van de centralisatie beïnvloeden. De rol van NO in het handhaven van de foetale circulatie en cerebrale bloeddoorstroming tijdens normoxie en acute hypoxie is slechts gedeeltelijk bekend. In hoofdstuk 4 worden de resultaten van het onderzoek naar de rol van NO in het onderhoud van cardiovasculaire functie in foetale schapen tijdens normoxische en hypoxische omstandigheden gepresenteerd. Dezelfde experimentele opstelling zoals eerder beschreven, werd gebruikt. Na drie dagen herstelperiode, kregen de foetus L-NAME (een NOS inhibitor) $(\mathrm{n}=7)$ of $\mathrm{NaCl}(\mathrm{n}=6)$ toegediend. Op $\mathrm{t}=0$, werd acute hypoxie geïnduceerd.

Orgaandoorbloeding (d.m.v. microsfeer methode) en fysiologische parameters (gemiddelde arteriele druk (MAP), foetale hartslag (FHR) en bloedgasanalyse) werden gemeten op -75, $1,+2,+4$ and +30 minuten. Na L-NAME trad er bradycardie en hypertensie op. De cardiac output daalde met $64 \%$. De doorbloeding van het karkas, de placenta en cerebrum na L-NAME injectie waren verminderd met $62 \%, 66 \%$, and 55\%, respectievelijk. Na L-NAME toediening veranderde de redistributie van cardiac output naar de centrale organen tijdens acute hypoxie niet. In de L-NAME groep steeg MAP en bleef de FHR gelijk, in tegenstelling tot de controle groep waar de MAP aanvankelijk daalde en vervolgens terugkeerde naar de uitgangswaarde terwijl de FHR daalde. Na hypoxie vertraagde L-NAME het herstel van cardiac output en verminderde de toename van doorbloeding naar de hersenen en het hart.

Uit deze resultaten concluderen we dat NO een rol speelt in het handhaven van de cardiovasculaire functie tijdens normoxie en acute hypoxie. NO speelt ook een rol in de stijging van hersen- en hart-doorbloeding na hypoxie.

Nadat was gebleken dat de circulatoire centralisatie tijdens hypoxie wordt aangetast door LPS, was de volgende stap het onderzoeken van de rol van NO in dit proces. Zoals eerder gezegd leidt LPS tot een verhoogde productie van NO, dat derhalve de effecten van LPS op de foetale circulatie kan beïnvloeden. In het vijfde hoofdstuk gebruikten we dezelfde experimentele 
218 Hoofdstuk 10

opstelling. Vijftien foetale schapen werden chronisch geïnstrumenteerd zoals voorheen beschreven. Na drie dagen kregen 8 foetus een bolus van 30 mg L-NAME (t-75) gevolgd door een continu infuus. Alle foetus kregen op -60 LPS toegediend. Op t 0 werd acute hypoxie geïnduceerd door occlusie van de maternale aorta gedurende 2 minuten. De orgaandoorbloeding (microsfeer methode) en fysiologische parameters (FHR, MAP en bloedgasanalyse) werden gemeten op t-75, $-1,+2,+4$ and +30 minuten.

Na LPS was er een significante daling in het percentage cardiac output naar de placenta en zuurstof aanbod aan de hersenen, en een stijging naar het karkas, hart en bijnieren. Deze veranderingen werden versterkt tijdens hypoxie. In de L-NAME + LPS groep waren de doorbloeding naar het karkas en bijnieren lager dan in de LPS groep terwijl de doorbloeding naar de hersenen en placenta in beide groepen gelijk was. Deze veranderingen traden reeds op tijdens de normoxische periode en bleven voortduren tijdens hypoxie- en herstel-fase.

Concluderend leidt endotoxemie tot een ernstige aantasting van de cardiovasculaire functie en perifere vasodilatatie. NOS inhibitie vermindert de LPS-geïnduceerde vasodilatatie.

In de studie beschreven in hoofdstuk 6 hebben we de veranderingen in cardiac output naar de foetale longen onderzocht na toediening van LPS, tijdens normoxie en asphyxie. Ook werd de rol van NO en endotheline in dit proces onderzocht, door een groep schapen met L-NAME, en een andere groep schapen met BQ-123, een endotheline A selectieve antagonist, te injecteren, alvorens LPS toe te dienen.

De experimenten werden 3 dagen na de operatie uitgevoerd bij een zwangerschapsduur van 110 \pm 1 dagen. De foetus werden in 4 groepen gerandomiseerd: groep 1, de controle groep $(n=6)$, groep 2, de LPS groep ( $\mathrm{n}=7)$ met LPS injectie op t-60 (52 $\pm 6 \mu \mathrm{g} / \mathrm{kg})$, groep 3, de L-NAME + LPS groep $(n=8)$ met L-NAME injectie op $\mathrm{t}-75$ en LPS toediening op $\mathrm{t}-60$ zoals eerder beschreven, en groep 4, de BQ123 + LPS groep $(n=4)$ met BQ 123 injectie op t-75 minutes en 
LPS toediening op t-60. Alle groepen startten met 75 minuten normoxie waarna een periode van 2 minuten hypoxie volgde met een 30 minuten durende herstelperiode.

Onder normale omstandigheden is de hoeveelheid cardiac output naar de longen slechts $4 \%$ van de totale cardiac output. In de controle groep was er in de longen een laag percentage cardiac output. Dit veranderde niet tijdens de periode van foetale asfyxie in de controle groep.

Daarentegen was er een duidelijke toename in het percentage cardiac output in de LPS groep reeds tijdens normoxie, welke nog verder toenam tijdens hypoxie. Deze toename werd gedeeltelijk geblokkeerd door BQ 123, een endotheline antagonist en werd geheel tegengegaan door injectie met L-NAME, een NOS inhibitor.

Concluderend leidt endotoxemie tot een stijging in het percentage cardiac output naar de foetale long, welke gedeeltelijk NO- en endotheline- afhankelijk lijkt.

Twee mechanismen lijken de relatie tussen infectie en perinatale hersenschade te kunnen verklaren. Allereerst kan hersenschade veroorzaakt worden door de aanzienlijke veranderingen in foetale orgaandoorbloeding en de begeleidende aanzienlijke daling in zuurstof aanbod aan de hersenen, veroorzaakt door decentralisatie zoals beschreven in Hoofdstuk 3, 5 en 6. Aan de andere kant kan LPS cytokine productie stimuleren en aldus tot cytotoxische hersenschade leiden. Daarom kozen we voor een andere toegangsroute om LPS toe te dienen, de intracisternale methode, welke minimale bijwerkingen heeft op het cardiovasculaire systeem, zodat de hemodynamische veranderingen konden worden omzeild.

In hoofdstuk 7 werden 7-dagen oude Wistar ratten intracisternaal geïnjecteerd met of $\mathrm{NaCl}$ of LPS (5 $\mu \mathrm{g} / \mathrm{pup})$. Na een uur werd de linker A. Carotis Communis vrijgeprepareerd en geligeerd door een incisie in het midden van de hals. Na opnieuw een uur herstelperiode werden de pups hypoxisch door inademing van een gasmengsel gedurende 60 minuten. De dieren werden gerandomiseerd in 4 groepen. Sham controle groep (1): linker arteria carotis communis werd 
220 Hoofdstuk 10

vrijgeprepareerd maar niet geligeerd. LPS groep (2): intracisternale LPS toediening. Hypoxieischemie studie groep (3): intracisternale injectie met $\mathrm{NaCl}$ en later hypoxie na ligatie.

Hypoxie-ischemie / LPS studie groep (4): intracisternale injectie met LPS en hypoxie-ischemie na ligatie. Zeven dagen later werden de neonatale hersenen onderzocht op neuronale celschade. In een tweede set experimenten werden ratten pups geïnjecteerd met LPS en onderzocht op TNF- $\alpha$ expressie door middel van immunohistochemie.

Er was geen neuronale celschade in de sham of LPS groep zichtbaar. In de hypoxie-ischemie/ LPS groep was er significant meer neuronale schade in de cerebrale cortex in vergelijking met de dieren in de $\mathrm{NaCl}$ met hypoxie groep. Intracisternale LPS toediening leidde tot een verhoogde TNF- $\alpha$ expressie in de leptomeningen, maar niet tot hersenschade.

Concluderend sensibiliseert intracisternale LPS toediening de immature ratten hersenen voor een later hypoxisch-ischemisch insult.

Om de langetermijn effecten van LPS op de placentaire doorbloeding te meten en te onderzoeken of er een relatie bestaat tussen foetale endotoxemie en histologische veranderingen in de hersenen, werd een lage dosis LPS intraveneus toegediend in foetale lammeren.

In hoofdstuk 8 werden de effecten van LPS op de umbilicoplacentaire doorbloeding en de cardiovasculaire functie onderzocht. De umbilicale doorbloeding werd continu gemeten gedurende 3 dagen. Foetale lammeren werden geïnstrumenteerd bij een zwangerschapsduur van $107 \pm 1$ dagen. Een flow probe werd ofwel om de Arteria Umbilicalis Communis, danwel om een enkele Arteria Umbilicalis geplaatst. Na een drie dagen durende herstelperiode kregen de fetus of 100 of 500 nanogram LPS of $\mathrm{NaCl}$ toegediend. Zes foetus stierven binnen 12 uur na LPS toediening. Foetale hartslag, gemiddelde arteriële druk en umbilicale doorbloeding werden gedurende 3 dagen gemeten. 
De foetale hartslag steeg met $25 \%$ ongeveer $4-5$ uur na LPS toediening en bleef verhoogd gedurende 15 uur na LPS. De arteriële bloeddruk steeg met $18 \%$ een uur na LPS toediening en keerde langzaam terug naar controle waarden 4-5 uur na LPS. De placentaire doorbloeding verminderde een uur na LPS en verminderde tot $70 \%$ van de controle waarde ongeveer 4-5 uur na LPS maar herstelde langzaam naar de uitgangswaarde 12 uur na LPS. De weerstand in de placenta steeg met $73 \%$ terwijl de $\mathrm{pH}$ niet veranderde. Concluderend leidt intraveneuze injectie van endotoxine tot een langdurige en significante daling in placentaire doorbloeding, resulterend in een ononderbroken hypoxemie zonder acidemie.

In de appendix van Hoofdstuk 8 worden de data van de histologie van de hersenen na LPS injectie gepresenteerd. Met deze studie wilden we de vraag beantwoorden of endotoxemie in het foetale lam kan leiden tot histologische afwijkingen in de hersenen. Histologisch onderzoek liet een inflammatoire respons zien in de hersenen met een stijging in het aantal periventriculair gelokaliseerde cellen, welke geactiveerde microglia leken te zijn. Deze bevindingen duiden aan dat LPS bijdraagt tot het ontstaan van histologische hersenschade.

Verschillende conclusies kunnen gemaakt worden ten aanzien van de effecten van LPS op de foetale circulatie en de hersenen.

Endotoxemie tast de foetale cardiovasculaire functie aan tijdens normoxie en hypoxie, leidend tot een daling in zuurstof aanbod aan de hersenen. Deze aantasting van foetale cardiovasculaire functie en verdeling in orgaandoorbloeding wordt veroorzaakt door de verstoring van het centralisatie mechanisme tijdens hypoxie-ischemie. De verstoorde cardiovasculaire functie leidt tot een perifere vasodilatatie welke gedeeltelijk kan worden tegengegaan door NOS inhibitie. Door bovengenoemde decentralisatie na LPS injectie onstaat er een stijging in het percentage cardiac output naar de foetale longen welke gedeeltelijk NO- en endotheline-afhankelijk lijkt. De langetermijn effecten van intraveneuze toediening zijn een aanzienlijke en aanhoudende daling in placentaire doorbloeding resulterend in foetale hypoxemie zonder acidose. Deze 
222 Hoofdstuk 10

hemodynamische veranderingen worden gevolgd door een inflammatoire reactie in de hersenen met een verhoging van de periventriculaire witte cellen, welke blijkt te berusten op een toename van geactiveerde microglia.

Intracisternale toediening van LPS leidt tot een verhoogde gevoeligheid van immature rattenhersenen voor een later hypoxisch-ischemisch insult.

Deze bevindingen duiden aan dat LPS bijdraagt aan de ontwikkeling van histologische hersenschade.

Het beschreven onderzoek heeft verschillende vragen opgeworpen; de krachtsinspanning om de effecten van endotoxine op de foetale circulatie en de hersenen te onderzoeken is dan ook niet voorbij.

Verschillende onderwerpen zijn een logische stap voor verder onderzoek.

1. De mogelijkheid van sensibilisering van de hersenen door herhaaldelijke toediening van LPS met en zonder het effect van gesuperponeerde hypoxie zoals bijvoorbeeld door korte herhaalde navelstrengocclusies is een onderwerp voor onderzoek in foetale schapen.

2. De mechanismen waardoor de daling in placentaire doorbloeding na LPS onstaat is een interessant onderwerp.

3. De relatie tussen infectie en vroeggeboorte en de rol van de hypofyse-hypothalamus-bijnier as in het begin van de baring kan worden onderzocht in het foetale schapen model.

4. Het kippenembryo is een goed onderzocht model in perinataal onderzoek en is geschikt om, na LPS toediening op de chorion-allantois membraan, de lange-termijn effecten van LPS op histologie van hersenweefsel te onderzoeken.

5. Interventie strategieën met medicatie om de schadelijke effecten van LPS te voorkomen of op te heffen. 
6. Doppler flow analyse in de foetale arteria pulmonalis en de arteria umbilicalis als een mogelijk hulpmiddel om intrauteriene infectie op te sporen is een onderwerp voor onderzoek in de menselijke foetus.

7. Endotoxemie kan ook een effect hebben op hersenfunctie; dit kan onderzocht worden door gedragsstudies in het rattenmodel.

Onderzoek leidt meestal tot meer vragen dan antwoorden en dat is ook het geval voor dit proefschrift.

Voor de toekomst is het belangrijk om aan de mythologische Hydra te denken.

Meermaals creëert de weg naar het vinden van een oplossing aanleiding tot vragen, waar desondanks uitvoerig onderzoek naar moet worden verricht. 

Dankwoord 225

Dankwoord 
Vele mensen hebben hun steentje dan wel steen bijgedragen aan dit proefschrift. Enkele van hen wil ik persoonlijk bedanken.

Dr T.H.M. Hasaart, co-promotor, beste Tom. Nog altijd is het lastig om je baas bij de voornaam te noemen, maar het gaat me steeds beter af. Bedankt voor je vertrouwen; nog voor ik mijn artsexamen had gehaald mocht ik bij je beginnen. Een vrouwelijke promovendus die met schapen gaat slepen zal niet makkelijk voor je zijn geweest, toch stond je deur altijd open. Bedankt.

Prof. Dr. J. de Haan, promotor. Dankzij U is het contact met de Duitse collega's gelegd, zonder dat was het "boekje" niet gelukt. Dank voor uw interesse gedurende de jaren.

Prof. Dr. Berger, dear Richard, your patience is admirable. You were there from the beginning, guiding me through this scientific adventure, thank you.

Dr. Y. Garnier, dear Yves. Thanks for your cooperation the past years. The first time I saw the meat-grinder I wasn't so happy to be your colleague, but it turned out very well after all.

Dr. J. Middelanis, dear Johannes. We had a lot of fun during the experiments in Bochum, even when we were breathing in a bit too much halothane. Thanks for your dedication.

De mensen van de centrale proefdieren voorziening, Joyce Suyk en May Bost, bedankt voor jullie expertise, gezelligheid en hulp. Frans Slangen en Monique de Jong, jullie leefden mee als het weer eens mis ging en hielpen mee waar nodig.

Jan Geilen zorgde altijd weer dat het HDAS optimaal functioneerde nadat ik weer eens met de verkeerde knopjes had gespeeld.

Rob van Sebille. Bedankt voor je flexibele hulp toen mijn computer crashte, er zijn momenten die ik niet wil overdoen, dat was er een van. 
De onderzoekers van PERIM: Olivier, onderzoeker vanaf het eerste uur, nu dan ook in de kliniek, succes met je opleiding. Robert, jouw speciale humor maakt het onderzoek iedere dag weer een uitdaging, sterkte met je boekje. De rest van de PERIM- club: Marc, Hugo, Timo en Inez, bedankt en succes voor de toekomst.

Dorette, samen hebben we heel wat geklaagd, gerookt (in de goeie ouwe tijd) en vooral gelachen. Bedankt dat je op deze dag mijn paranimf wil zijn.

De gynaecologen, en verpleegkundigen en medewerkers van het secretariaat uit het Maaslandziekenhuis Sittard, jullie hebben me opgevangen en wegwijs gemaakt in de wondere wereld van de gynaecologie. Het was een leuke tijd die ik niet zal vergeten.

Alle collega-assistenten, gynaecologen en medewerkers van de afdeling Obstetrie en Gynaecologie uit het Academisch Ziekenhuis Maastricht, bedankt voor de fijne samenwerking sinds de start van mijn opleiding.

Dhr A.P.C. Smit, bedankt voor het maken en vermaken van het ontwerp.

Mijn oom, Willem K. Coumans, voor het corrigeren van de nederlandse vertaling.

Tenslotte mijn ouders, pap en mam, wat zullen jullie wel gedacht hebben toen ik kwam vertellen dat ik onderzoek met schapen ging doen. Na 2 jaar vonden jullie dat "het nu wel eens klaar mocht zijn dat boekje”. Bedankt voor jullie steun, ook toen het wat langer duurde...

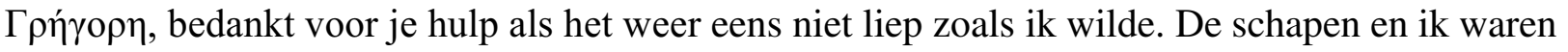
blij als jij er bij was 's nachts in het lab. De afgelopen jaren maak jij iedere dag tot vakantie. Je bent de rustgevende factor in mijn leven, hopelijk nog heel lang. 



\section{Curriculum Vitae}

Audrey Barbara Catharina Coumans werd op 24 juni 1972 te Heerlen geboren. Na het afronden van de Humaniora te Hasselt in België, ging zij geneeskunde studeren in Diepenbeek. Na het behalen van de eerste en tweede kandidatuur, zette zij haar studie voort aan de Vrije Universiteit te Amsterdam. Tijdens haar studie heeft zij geparticipeerd in wetenschappelijk onderzoek en in Bolivia een Obstetrie-stage gedaan. Na het artsexamen dat zij in 1999 behaalde heeft zij 2 jaar als arts-onderzoeker gewerkt aan het onderzoek dat wordt beschreven in dit proefschrift. In 2001 heeft zij een jaar als Assistent Geneeskundige Niet in Opleiding (AGNIO) gewerkt in het Maaslandziekenhuis te Sittard.

Sinds 1 april 2002 is zij in opleiding tot gynaecoloog in het Academisch Ziekenhuis Maastricht (opleider Prof. Dr J.L.H. Evers). 